\title{
DESIGN AND EXPERIMENTAL STUDIES OF FLEXIBLE TRAILING EDGE FOR VARIABLE CAMBER MORPHING WING
}

by

\author{
Ahmad T. Kalaji \\ Bachelor of Engineering, Ryerson University (2015)
}

\author{
A thesis \\ presented to Ryerson University \\ in partial fulfillment of the \\ requirements for the degree of \\ Master of Applied Science \\ in the program of \\ Aerospace Engineering
}

Toronto, Ontario, Canada, 2017

(C)Ahmad T. Kalaji, 2017 


\section{AUTHOR'S DECLARATION}

I hereby declare that I am the sole author of this thesis. This is a true copy of the thesis, including any required final revisions, as accepted by my examiners.

I authorize Ryerson University to lend this thesis to other institutions or individuals for the purpose of scholarly research.

I further authorize Ryerson University to reproduce this thesis by photocopying or by other means, in total or in part, at the request of other institutions or individuals for the purpose of scholarly research. I understand that my thesis may be made electronically available to the public. 


\title{
DESIGN AND EXPERIMENTAL STUDIES OF FLEXIBLE TRAILING EDGE FOR VARIABLE CAMBER MORPHING WING
}

\author{
Ahmad T. Kalaji. \\ Master of Applied Science, Aerospace Engineering, Ryerson University, Toronto (2017)
}

\begin{abstract}
This thesis presents a flexible trailing edge mechanism capable of undergoing a change in camber for a wing section. The mechanism takes advantage of a rigid constraint between the ends of two flexible carbon fiber panels, which produces a deflection when there is a difference in length between the two panels.
\end{abstract}

A prototype was designed and built and experimental data was collected for the deformation of the panels for different values of lengths and analyzed to find a function to describe the coefficients which form the polynomials describing the shape for each of the panels, based on the difference in length value. Deflection and deflection angle results were used to develop a controller which will calculate the required change in length based on a deflection or angle and a bottom panel length input. 


\section{ACKNOWLEDGMENTS}

I would like extend my sincere gratitude to my supervisor Dr. Jeff $\mathrm{Xi}$ for giving me the opportunity to be part of the morphing wing research team and for his continued help and guidance, without which I would have never been able to reach this point. I would also like to thank Dr. Alighanbari for helping me get this opportunity and for his continued support, without whom it wouldn't have been possible. I would like to thank all my colleagues in the Intelligent Systems and Robotics Laboratory for creating a fun and productive work environment. I would also like to thank Dr. Wenbin Wang for all of his help and efforts into this project. I would also like to thank all of my friends for their continued support and last but not least I would like to extend my thanks to my family, who sacrificed a lot for me to have such an opportunity, for always being there for me, for supporting me and being with me every step of the way. 


\section{DEDICATION}

To my parents, grandparents, and sisters. For your support and sacrifices. 


\section{TABLE OF CONTENTS}

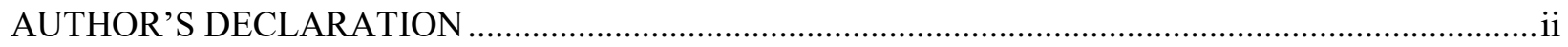

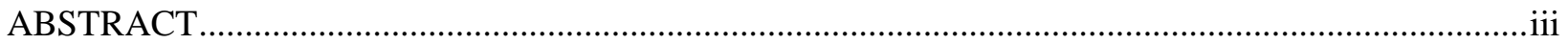

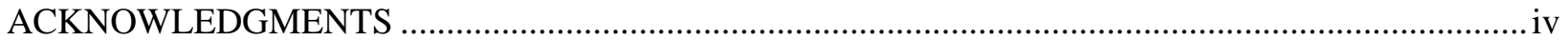

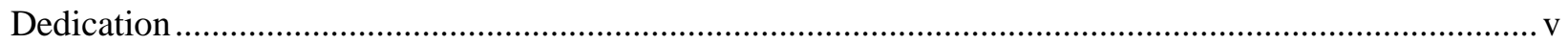

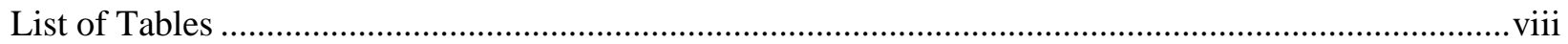

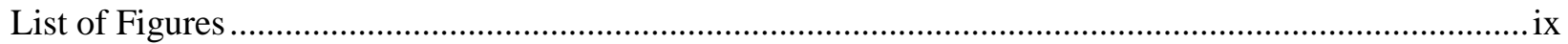

Nomenclature ..............................................................................................................................

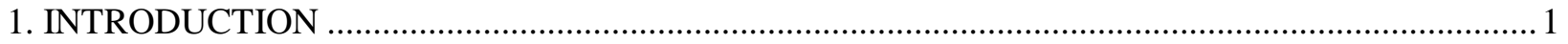

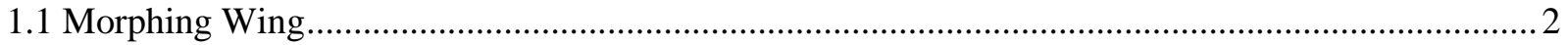

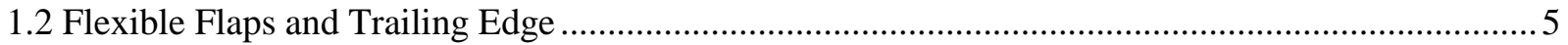

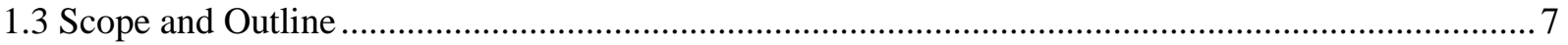

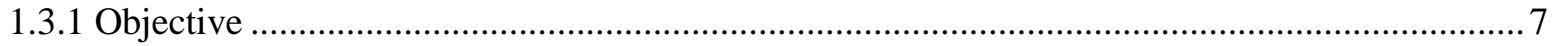

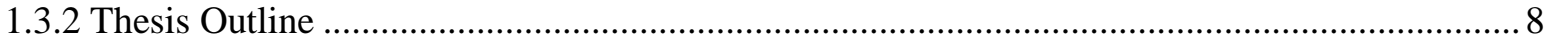

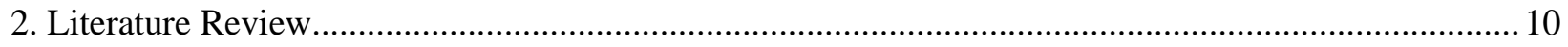

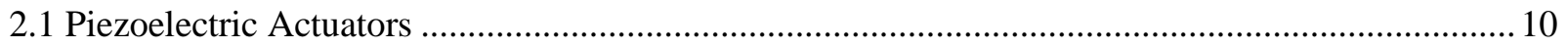

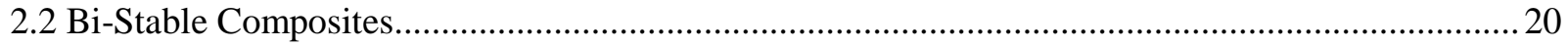

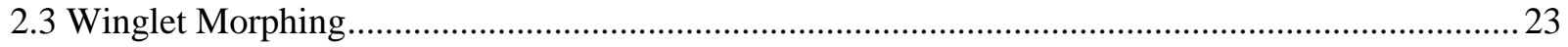

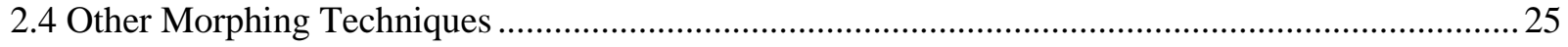

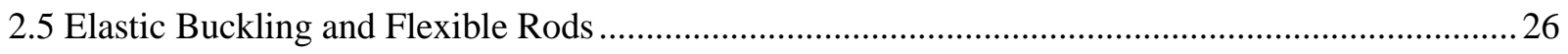

3. Design of A Flexible Panel Trailing Edge .................................................................................. 30

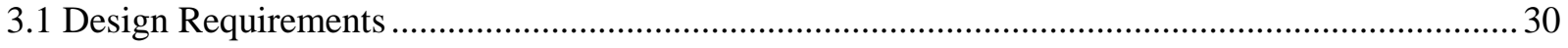

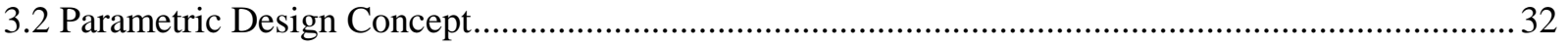

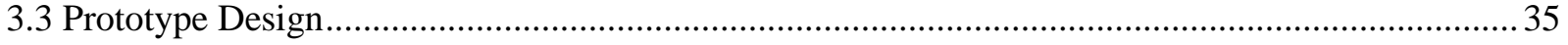

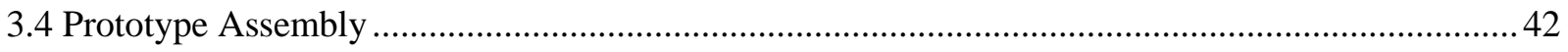

3.4.1 Component Selection ................................................................................................... 42

3.4.2 Flexible Panel Fabrication................................................................................................ 46

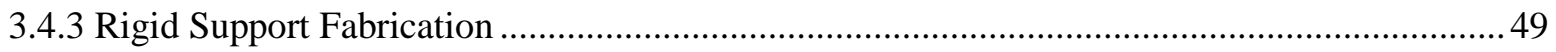

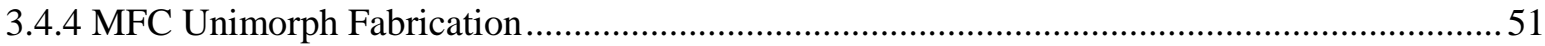

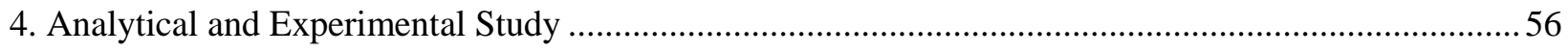

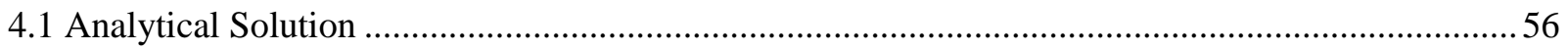

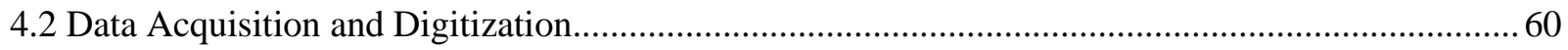

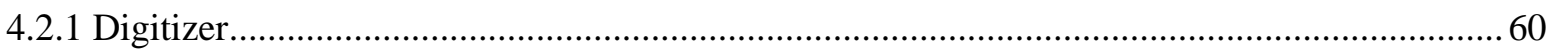

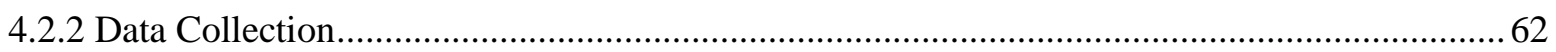




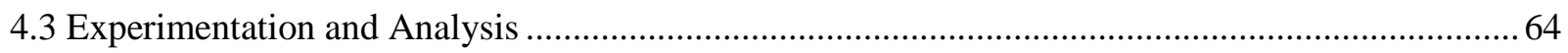

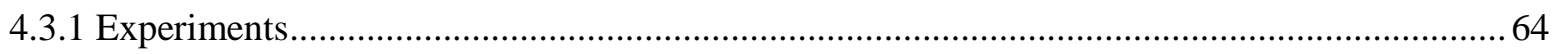

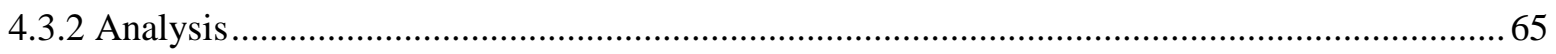

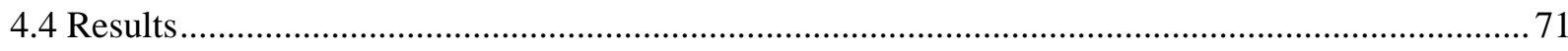

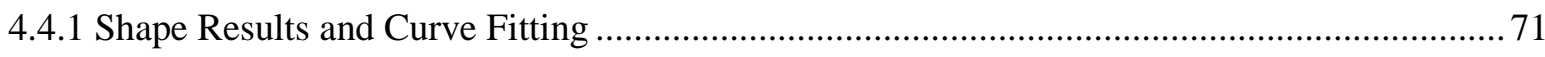

4.4.2 Deflection and Deflection Angle.................................................................................. 78

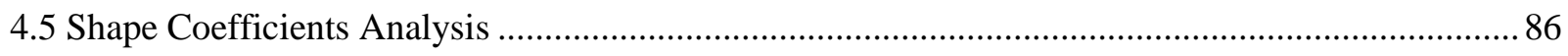

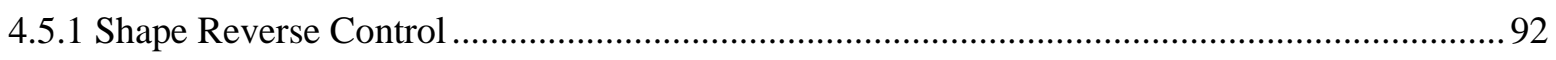

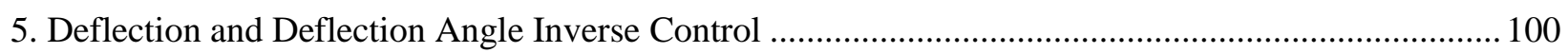

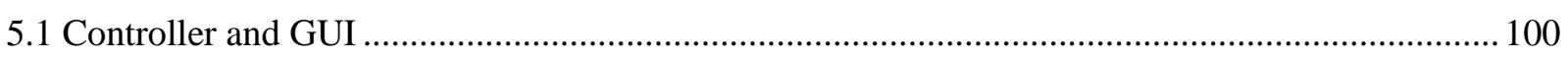

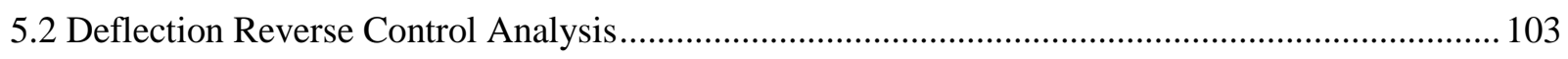

5.3 Deflection Reverse Controller Performance .............................................................................. 105

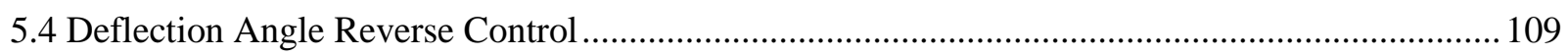

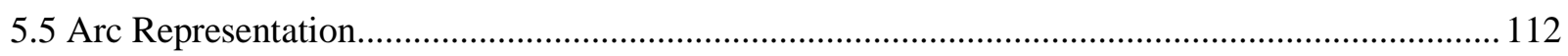

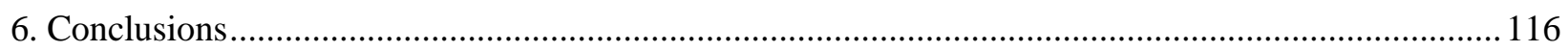

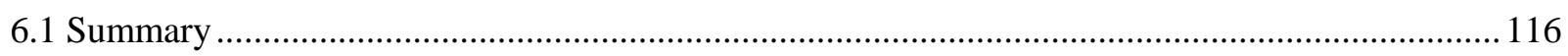

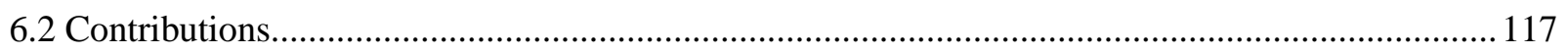

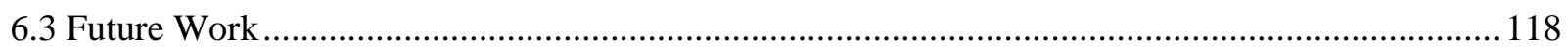

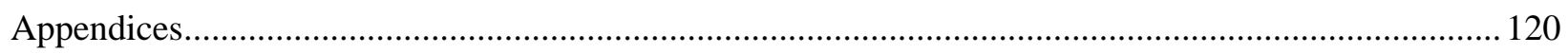

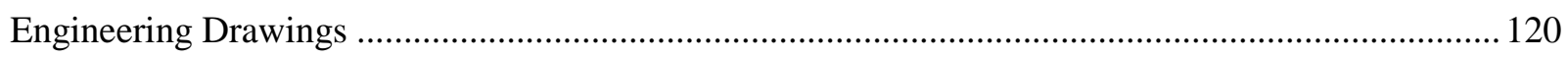

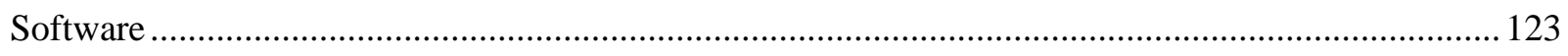

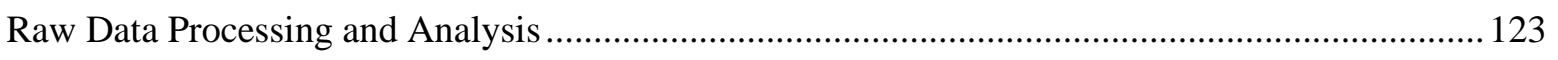

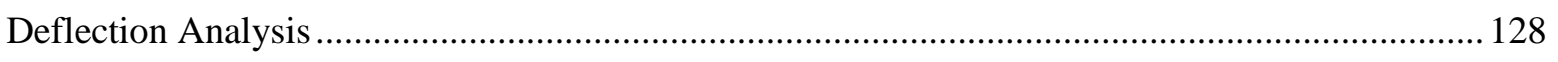

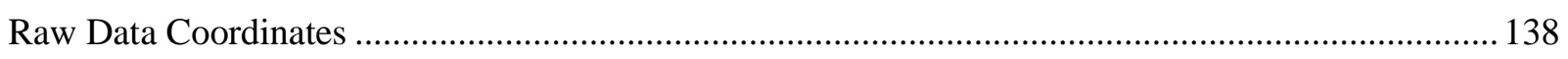

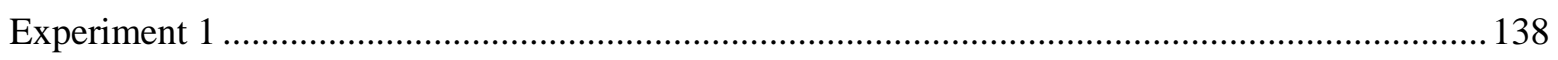

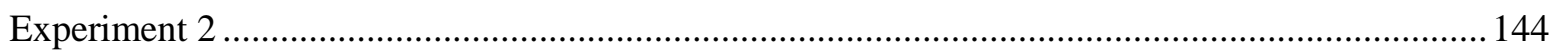

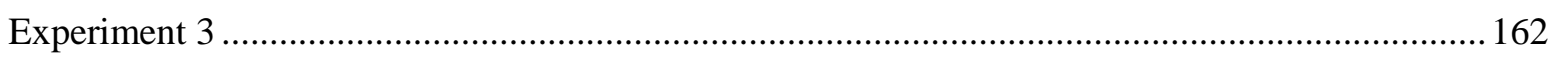

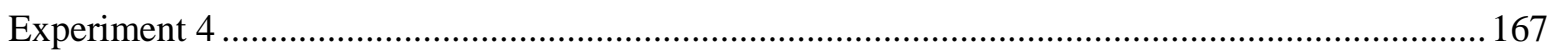

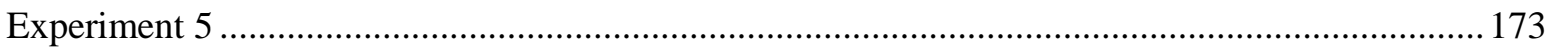

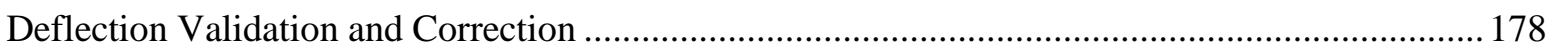

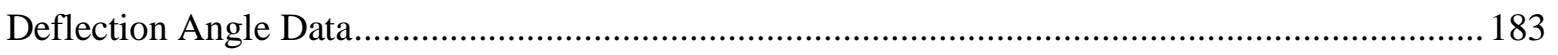

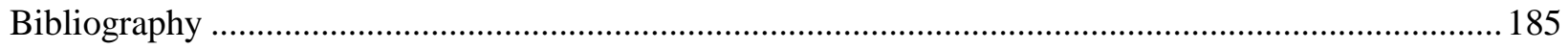




\section{LIST OF TABLES}

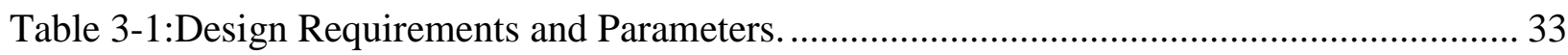

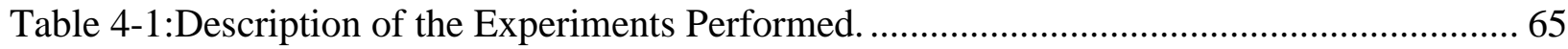

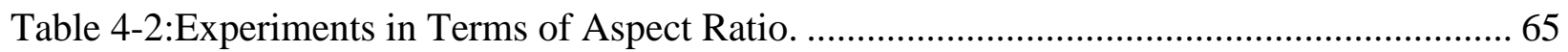

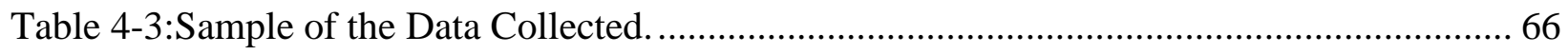

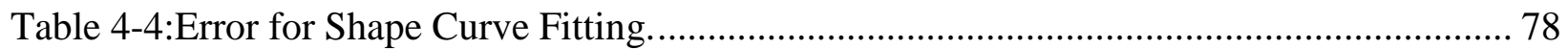

Table 4-5:Max Error for Deflection and Deflection Angle Results. ............................................. 80

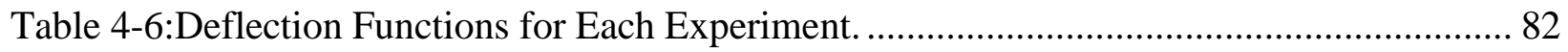

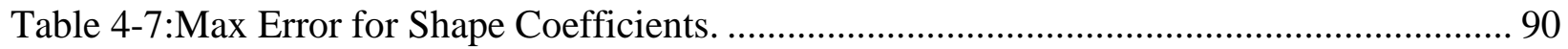

Table 4-8:Coefficient Results for Experiment 1...................................................................... 90

Table 4-9:Coefficient Results for Experiment 2 ……….................................................... 90

Table 4-10:Coefficient Results for Experiment 3 .................................................................... 91

Table 4-11:Coefficient Results for Experiment 4.................................................................... 91

Table 4-12:Coefficient Results for Experiment 5.................................................................... 91

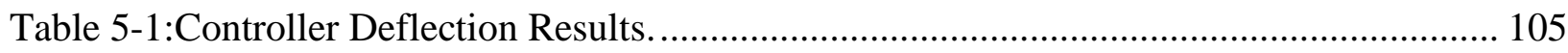

Table 5-2:Functions of Correction Plot for Different Lengths. ..................................................... 107

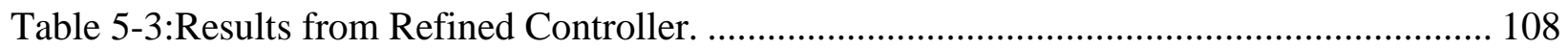

Table 5-4:Percent Error for Obtained Deflection. .................................................................. 108

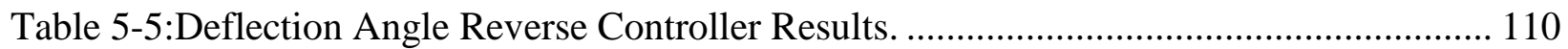

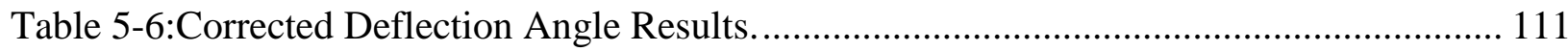

Table 5-7:Percent Error for Angle Deflection Experiment......................................................... 111

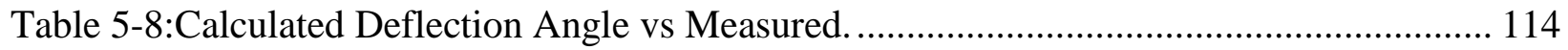

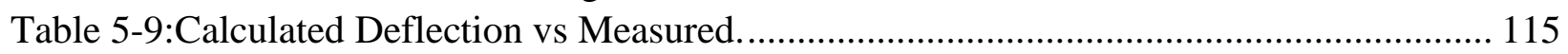

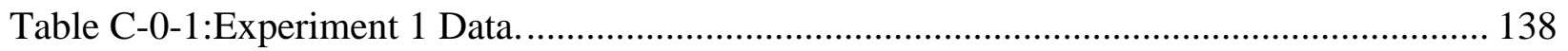

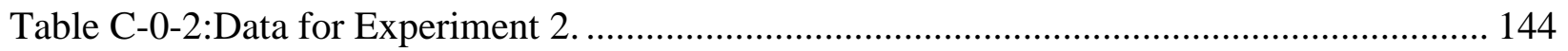

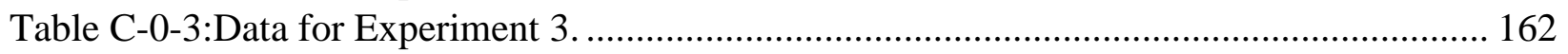

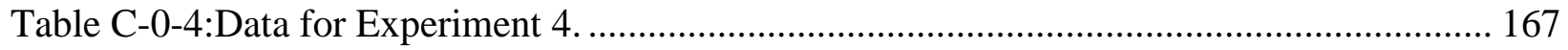

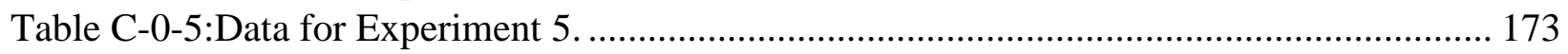

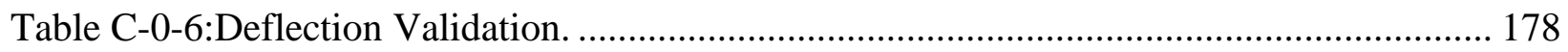

Table C-0-7:Deflection Correction........................................................................................... 181

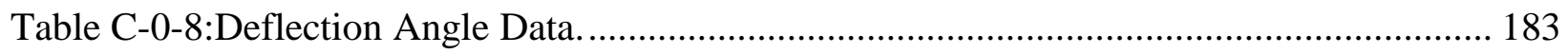




\section{LIST OF FIGURES}

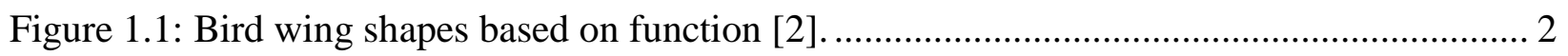

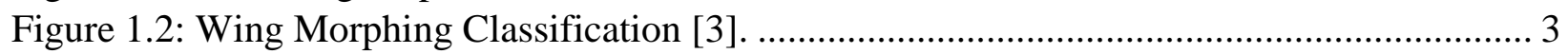

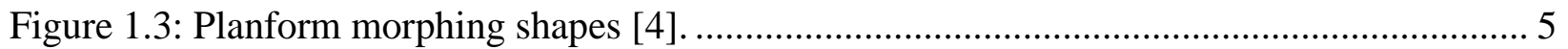

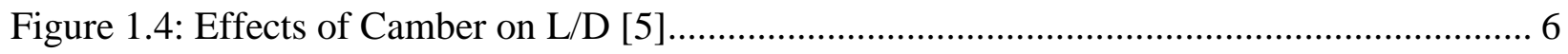

Figure 2.1: MFC Actuator [www.smart-material.com] ........................................................ 11

Figure 2.2: Schematic of MFC [www.smart-material.com] .................................................. 11

Figure 2.3: Unimorph Actuator (Prazenica, Kim, Moncayo, Azizi, \&Chan, 2014)..................... 13

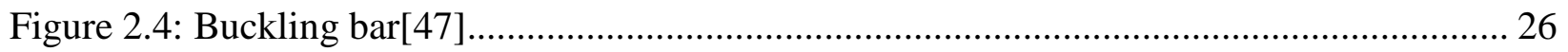

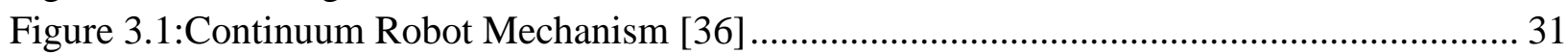

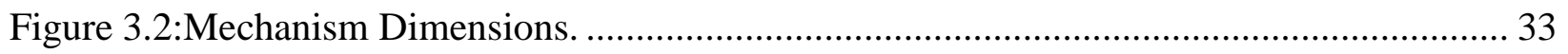

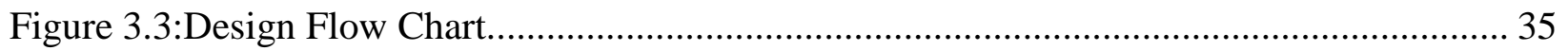

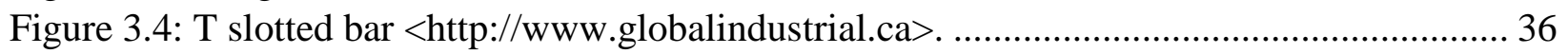

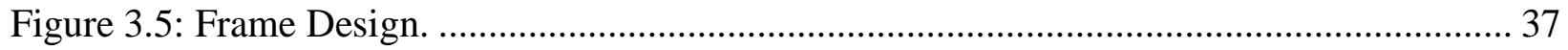

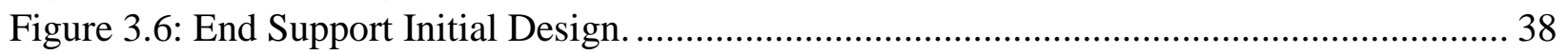

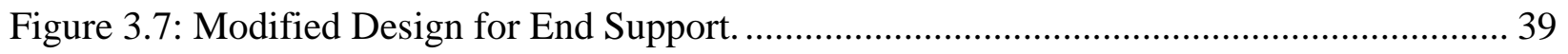

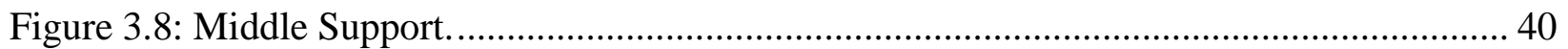

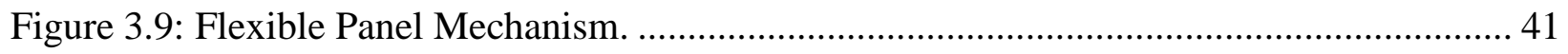

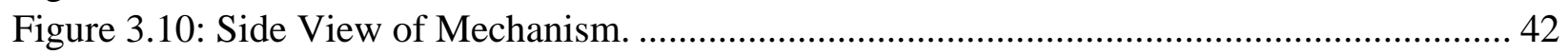

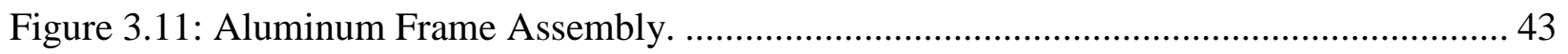

Figure 3.12: Linear Axis Motion System …………............................................................... 44

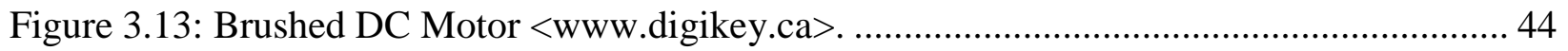

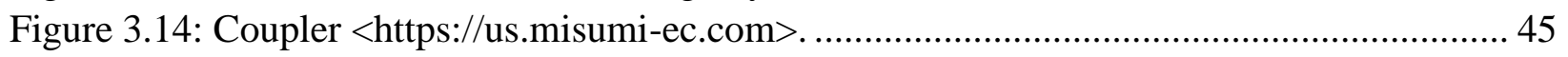

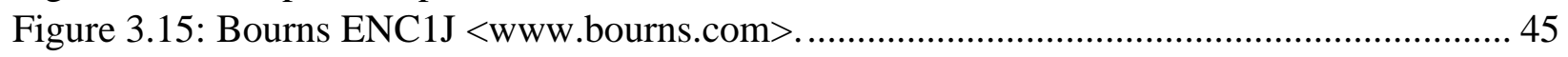

Figure 3.16: Misumi Roller with internal bearing and Shaft <https://us.misumi-ec.com> .......... 46

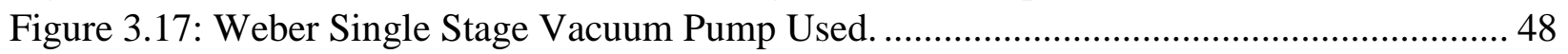

Figure 3.18: The Flexible Panel Assembly During Curing. ........................................................... 48

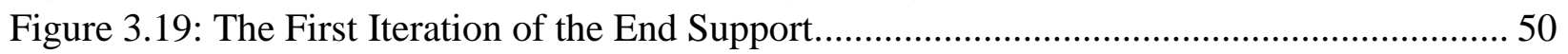

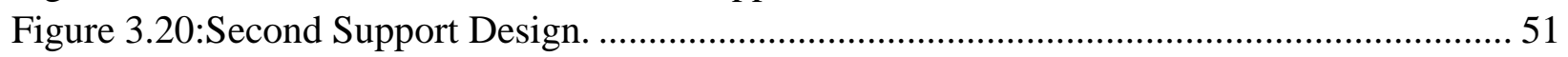

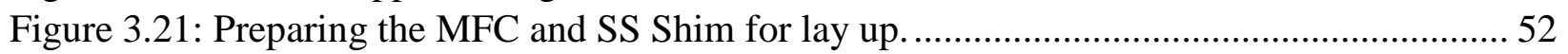

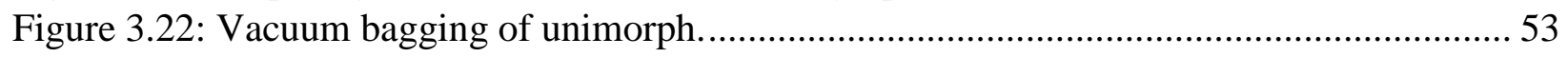

Figure 3.23: AMD2012-CE HV Amplifier <www.smart-material.com>.................................... 54

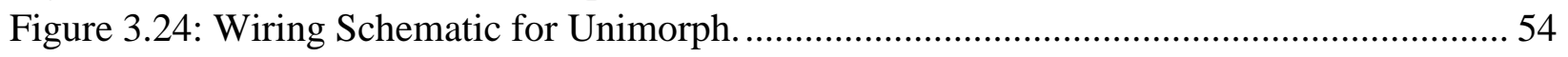

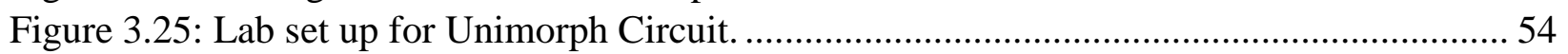

Figure 3.26: Unimorph with -500V supplied (left) and 1500V (right) ....................................... 55

Figure 4.1:Diagram of Mechanism for Analytical Solution. ....................................................... 57

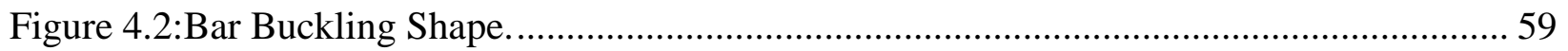

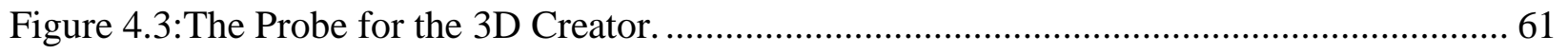

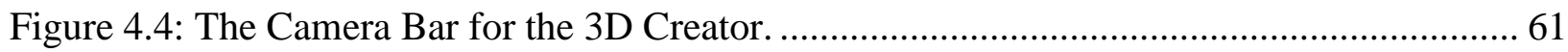

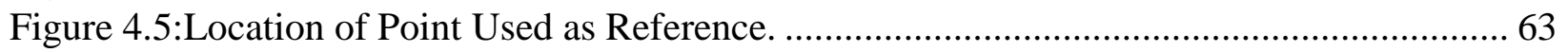

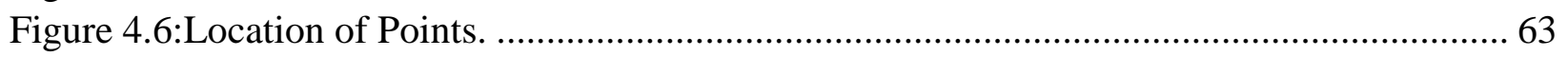

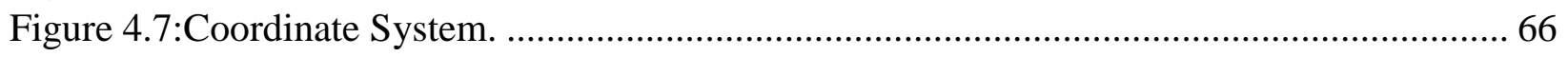

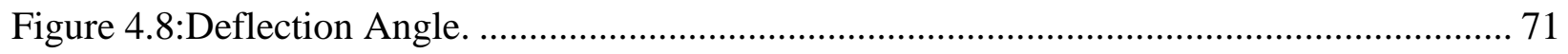




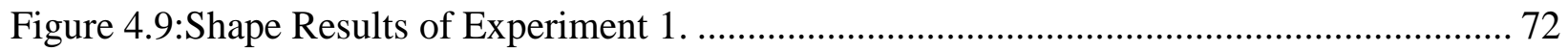

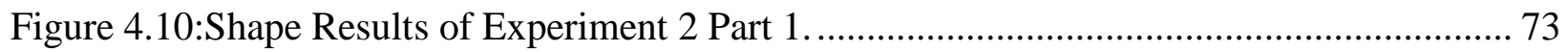

Figure 4.11:Shape Results of Experiment 2 Part 2 ................................................................. 74

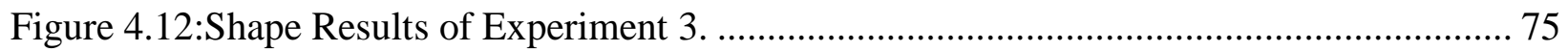

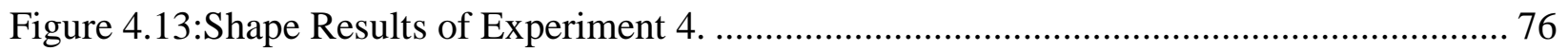

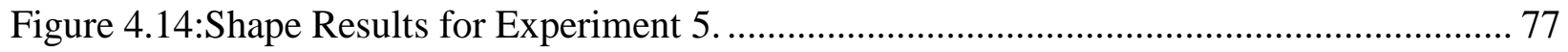

Figure 4.15:Deflection Results for Various Experiments......................................................... 79

Figure 4.16:Deflection Angle Results for Various Experiments............................................... 80

Figure 4.17:Slope of Deflection Functions Vs. The Bottom Panel Lengths. ............................... 83

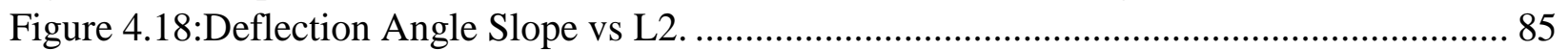

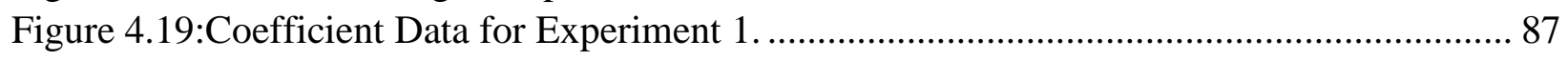

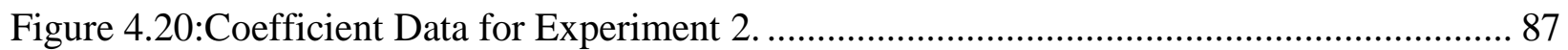

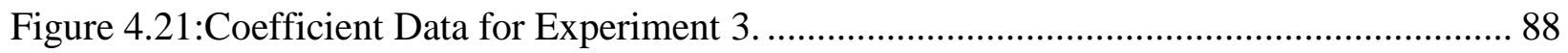

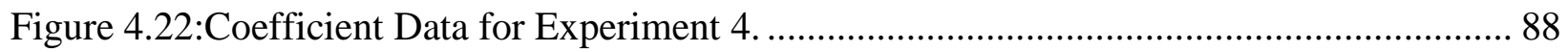

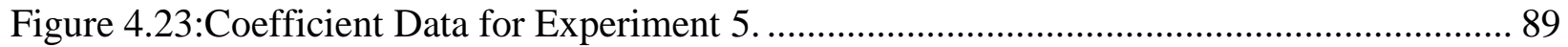

Figure 4.24:Coefficient Validation for Experiment 1.............................................................. 93

Figure 4.25:Coefficient Validation for Experiment 2 Part 1................................................. 94

Figure 4.26:Coefficient Validation for Experiment 2 Part 2 ................................................... 95

Figure 4.27:Coefficient Validation for Experiment 3............................................................... 96

Figure 4.28:Coefficient Validation for Experiment 4............................................................... 97

Figure 4.29:Coefficient Validation for Experiment 5 ......................................................... 98

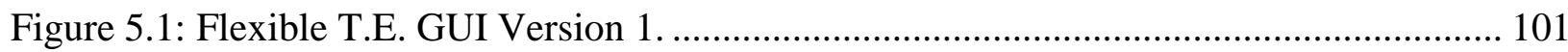

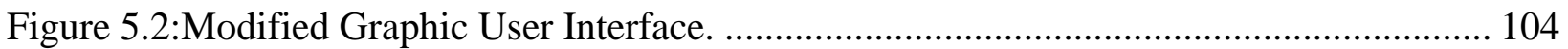

Figure 5.3:Desired Deflection Vs Measured Deflection........................................................... 106

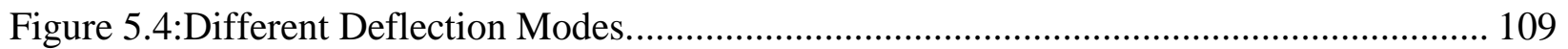

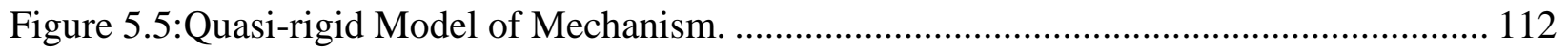

Figure 5.6:Circular Arc Motion of the Panel.......................................................................... 113

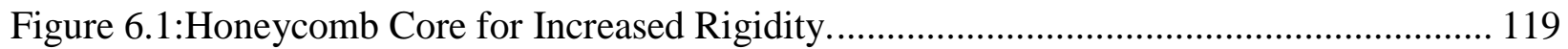

Figure A.0.1:Engineering Drawings for First Support Part 1................................................. 120

Figure A.0.2:Engineering Drawings for First Support Part 2 ……………………………...... 121

Figure A.0.3:Engineering Drawings for Second Support...................................................... 122 


\section{NOMENCLATURE}

\begin{tabular}{ll}
$\mathbf{A}_{\text {bot }}$ & A polynomial coefficient for bottom panel \\
$\mathbf{A}_{\text {top }}$ & A polynomial coefficient for top panel \\
$\mathbf{A R}$ & Aspect Ratio \\
$\mathbf{B}_{\text {bot }}$ & B polynomial coefficient for bottom panel \\
$\mathbf{B}_{\text {top }}$ & B polynomial coefficient for top panel \\
$\mathbf{C}_{\mathbf{b o t}}$ & C polynomial coefficient for bottom panel \\
$\mathbf{C}_{\mathbf{D}}$ & Coefficient of drag \\
$\mathbf{C}_{\mathbf{L}}$ & Coefficient of lift \\
$\mathbf{C}_{\text {top }}$ & C polynomial coefficient for top panel \\
$\mathbf{E}_{\mathbf{B X}}$ & End support X-coordinates of bottom panel \\
$\mathbf{E}_{\mathbf{B Y}}$ & End support Y-coordinates of bottom panel \\
$\mathbf{E}_{\mathbf{T X}}$ & End support X-coordinates of top panel \\
$\mathbf{E}_{\mathbf{T Y}}$ & End support Y-coordinates of top panel \\
$\mathbf{h}_{\mathbf{1}}$ & Distance between the top and bottom panel at the root \\
$\mathbf{h}_{\mathbf{2}}$ & Distance between the top and bottom panel at the tip \\
$\mathbf{K}$ & Encoder count value \\
$\mathbf{L}_{\mathbf{1}}$ & Length of top flexible panel \\
$\mathbf{L}_{\mathbf{2}}$ & Length of bottom flexible panel \\
$\mathbf{L} / \mathbf{D}$ & Lift over drag ratio \\
$\mathbf{P}_{\mathbf{c r}}$ & Critical load \\
$\mathbf{R}$ & Count to length ratio \\
$\mathbf{R}_{\mathbf{a v g X}}$ & X-coordinate of reference point \\
$\mathbf{R}_{\mathbf{a v g Y}}$ & Y-coordinate of reference point \\
$\mathbf{S}$ & Deflection line slope \\
$\mathbf{t}_{\mathbf{M F C}}$ & MFC thickness \\
$\mathbf{t}_{\mathbf{S}}$ & Substrate thickness \\
$\mathbf{V}_{\text {app }}$ & Applied voltage \\
$\mathbf{X}_{\mathbf{B}}$ & Bottom panel X-coordinates \\
$\mathbf{X}_{\mathbf{T}}$ & Top panel X-Coordinates \\
$\mathbf{Y}_{\mathbf{B}}$ & Bottom panel Y-coordinates \\
$\mathbf{Y}_{\mathbf{T}}$ & Top panel Y-Coordinates \\
$\mathbf{A L}_{\mathbf{L}}$ & Difference in length between top and bottom panels \\
& Mid-point deflection \\
\hline
\end{tabular}




\section{INTRODUCTION}

The journey of achieving flight started with a dream, turned to ideas, and then finally became a reality. This process took a lot of years to get to that stage, however, it was clear on that morning in 1903 when the Wright brothers made the first powered flight in history [1]. It was evident that it was only the beginning of a new era. The next step was to improve and optimize the design of aircrafts, which had us reach the traditional configuration found today. A fixed wing, optimized for a range of flight conditions, with control surfaces to improve the performance for specific conditions. This typical design can be improved greatly if the wing is able to change its shape depending on the flight condition so that an optimum performance can be obtained throughout the flight mission. Most scientific discovery is made by reverse engineering nature, since nature does it best. If we look at birds for example, they don't possess fixed wings, instead their wings change their shape depending on the task they want to carry out. The same concept applied to aircrafts is known as morphing, where morphing can mean a different range of changes to the wing shape based on the different conditions. 


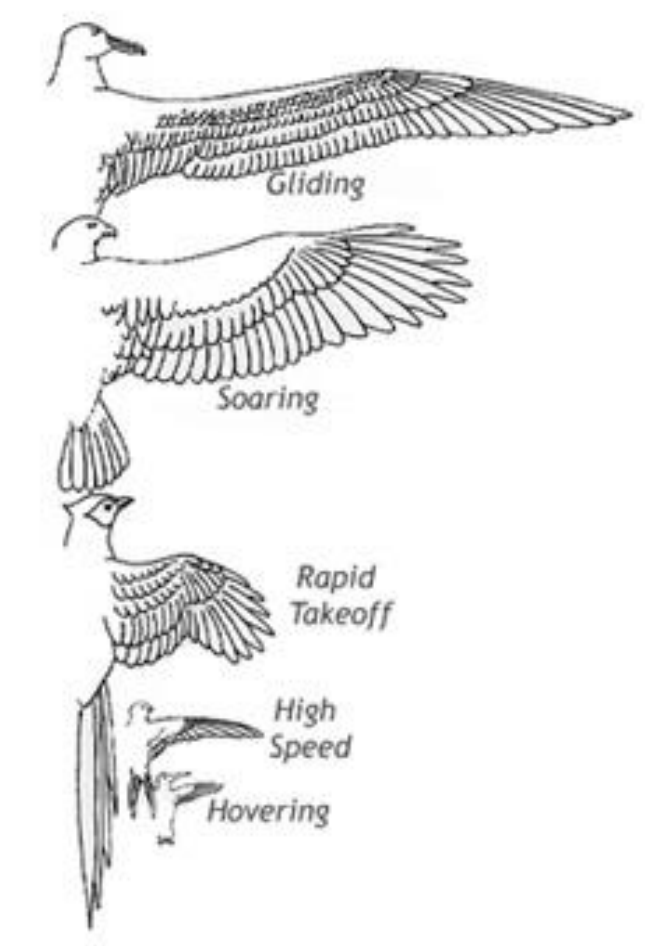

Figure 1.1: Bird wing shapes based on function [2].

\subsection{Morphing Wing}

The idea of morphing, which is the ability to change the shape of the wing during flight, is not a new concept. In fact, the first airplane created by the Wright brothers used a variable twist mechanism to control the roll. However, as aircraft design progressed, a stronger and more rigid structure was required to the increased demand for a higher speed, which meant a mechanism such as the one used by the Wright brothers would not work. Wings are usually designed and optimized for the cruise segment of a flight, however, since they are fixed, they can't provide the optimum performance for varying flight conditions. Morphing is studied as a question of benefit vs. weight, meaning how much improvement can be obtained and what are the weight penalties associated with it, since morphing usually comes with an expensive weight penalty [3]. However, recently the idea is becoming a popular topic again due to new technologies and new materials developed, such as smart materials. 
Barabarino et al. performed an in-depth analysis of the overall concept of morphing and all of the different application of the concept over the years [3]. Wing morphing is usually split into three categories: planform morphing; out of plane morphing; and airfoil morphing:

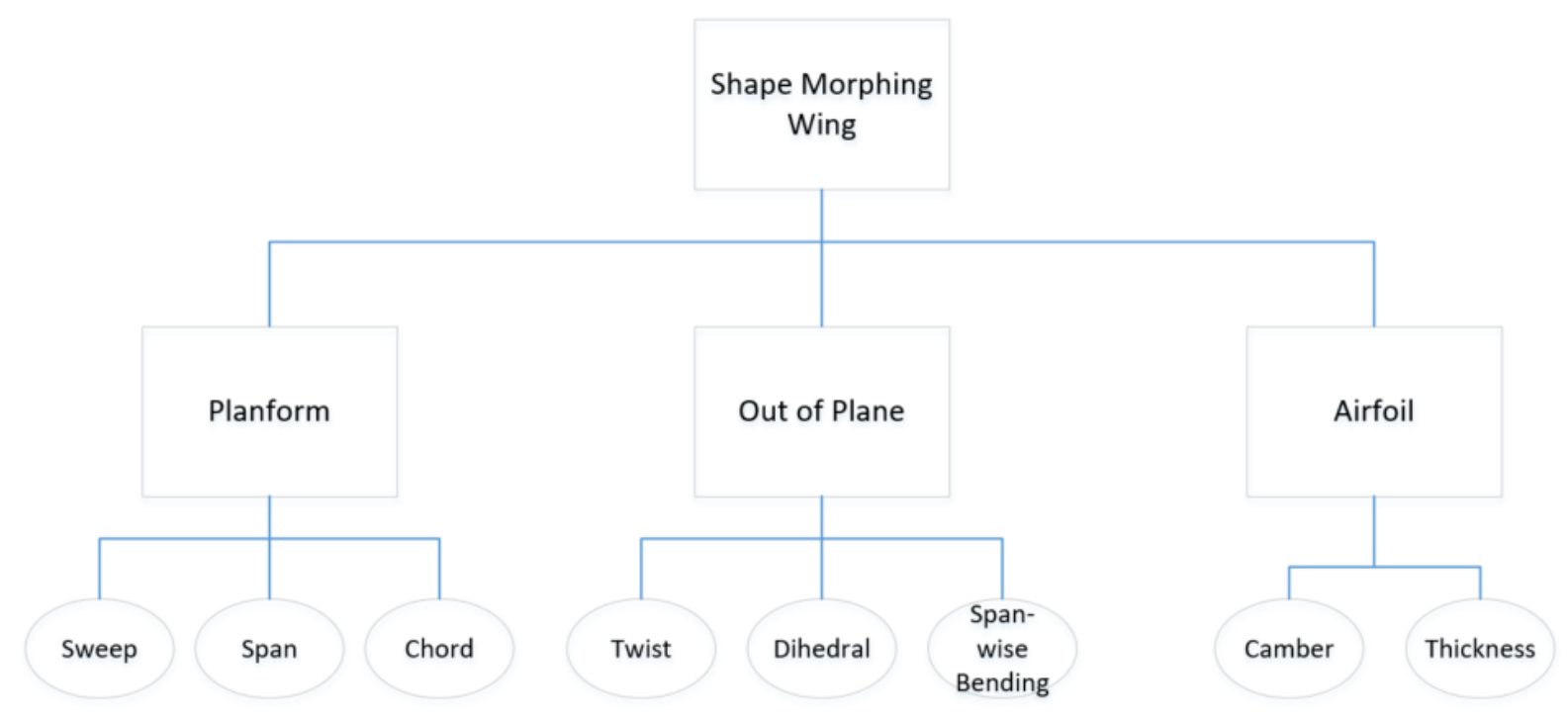

Figure 1.2: Wing Morphing Classification [3].

In the study, the typical challenges with wing morphing are discussed. The first challenge usually encountered with wing morphing is the heavy weight penalty associated with all the mechanisms and linkages required for morphing, and any reinforcements required to make up for any gaps in the structure. This is usually the main challenge; however, if a design addresses this challenge, the next main obstacle is the skin. Skin design is viewed as a challenge since from a structural point of view it has to be strong enough to withstand the aerodynamic loads, while from a morphing point of view it has to be compliant enough to move with the morphing mechanism [3]. This is essentially one of the biggest challenges found in the morphing field, as the requirements contradict one another. However, with advances in technology, smart materials, and composite materials, a lot of new approaches to solving this problem exists. When 
comparing the benefits of using a morphing configuration in lieu of a traditional fixed wing and control surfaces, the advantages become evident. The discrete nature of control surfaces introduces a lot of disruptions to the flow over the wing; thus, increasing the drag and limiting the range to improve aerodynamic qualities. If morphing is properly achieved and controlled, it can refine the shape based on the varying conditions, making sure the optimum lift of drag ratio (L/D) is always achieved; thus, ensuring maximum range and lowering the fuel required.

Over the years, many morphing concepts have been applied for the different types. Platform morphing is concerned with changing the wing platform area, with the three categories being variable sweep, variable span, and variable chord. Each one of those can be extremely complicated to implement; however, it would provide a drastic change. Variable sweep is a concept implemented before, especially in fighter jets, where the main idea is having the wing pivot at the root to change the sweep angle depending on the flight requirements. Variable span has been performed using a telescopic spar arrangement, where the spar goes into itself essentially increasing or decreasing the span. Another method is using a foldable wing concept, which usually raises aeroelastic concerns. Variable camber can be achieved by rotating the rib, in a similar manner to how an aileron works. If it is implemented along the span, the twist of the wing can be controlled. The internal mechanism, however, requires to be coupled with a flexible skin to allow for the change in shape [4]. 


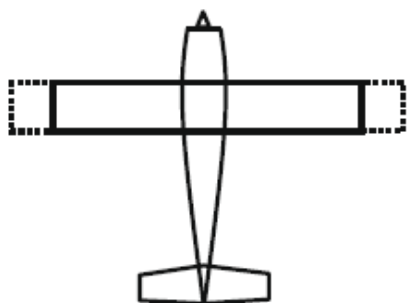

Span Change

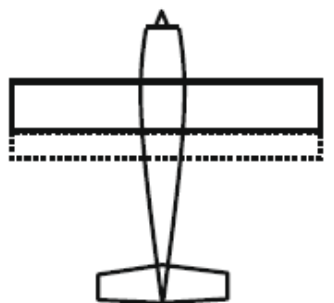

Chord Length Change

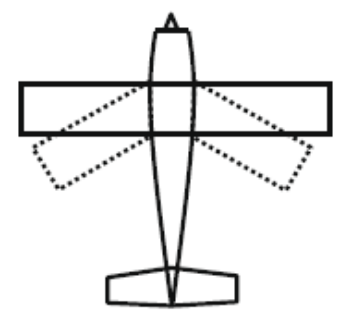

Sweep Change

Figure 1.3: Planform morphing shapes [4].

\subsection{Flexible Flaps and Trailing Edge}

The trailing edge is an area of focus when it comes to wing morphing. Since camber is essential for obtaining and modifying lift, the trailing edge is looked at due to the many improvement areas available, especially when it comes to improving and replacing traditional discrete lifting surfaces with a much smoother and continuously contoured structure [5]. Trailing edge morphing would allow for camber readjustment which is essential in L/D improvement. The higher the lift of drag ratio the higher the reduction in fuel consumption, especially with the aircraft weight decreasing as fuel is burnt. Span-wise morphing would also allow for redistributing the lift distribution to allow favourable loading at all times and under all conditions. 


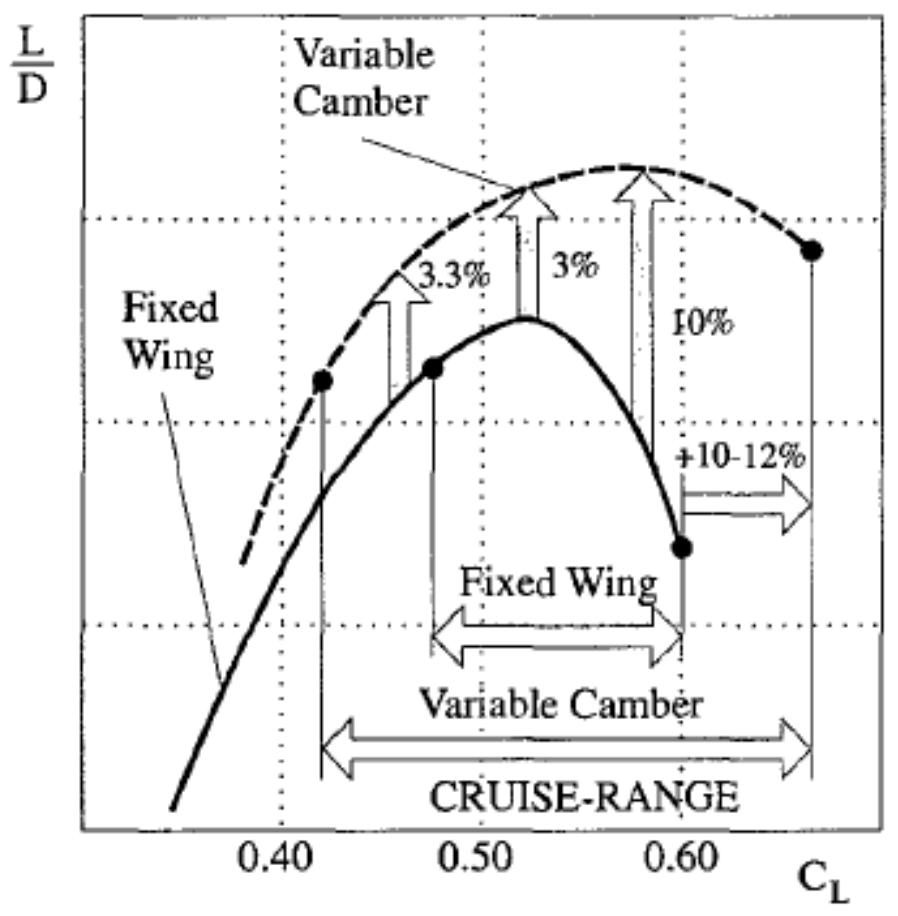

Figure 1.4: Effects of Camber on L/D [5].

Monner, et al. [5] developed a design for an elastic trailing edge utilizing flexible ribs. The ribs are composed of separate plate like elements attached via revolute joints with actuation applied at a single point of each rib, which is then transferred gradually from one element to the next, resulting in the required contour. The rib elements are attached to the upper and lower skin by linear slide bearing to allow the skin to morph along the mechanism. The resultant motion provided a variation in camber of $\pm 15^{\circ}$, which translates to a trailing edge tip deflection of \pm 185 mm. At transonic speeds, which are the speeds at which most civilian airplanes cruise at, a slight change in camber can have a tremendous effect on the aerodynamic performance of the aircraft[6]. This is also clearly evident from the mathematical equation for lift, which relates lift to the square of the speed, which means the effects speed has on the lift are magnified.

Many other concepts have been explored and tested for trailing edge morphing. One research focused on using smart materials as the actuation method to develop a hingeless, gapless control 
surface [7]. The proposed design was placed in a wind tunnel for testing and comparison with a traditional hinged control surface to study the improvement it provides. The deformable wing was modeled as a clamped beam with a distributed load applied to it, which is split into actuator loads and aerodynamic loads, the different loading will have an effect on the shape, which is why it was important to perform wind tunnel testing to look at the deformation. The three key issues faced were for the development of a flexible structure, having a high-rate and a large stroke, and having easily integrable power electronics. It can be realized that those three key issues are not specific to this study, but overall pose as the universal issues faced in the field of morphing, especially when focusing on changing the camber. The design employed a flexible honeycomb core with an eccentuator which is essentially a bent beam that transforms a rotary motion into a translation. Other studies have performed flight tests on the concept of recontouring the upper and lower surfaces of the airfoil [8]. The goal is to eliminate any discontinuities in the flap, lowering the drag and increasing the control authority of the control surface. A wing fitted with the technology was mounted to a white knight aircraft. The AoA was held constant while the compliant flap was deployed, the results showed an increase in lift while maintaining a laminar boundary layer, thus providing a favourable pressure gradient over the upper surface of the wing.

\subsection{Scope and Outline}

\subsubsection{Objective}

The objective of this thesis is to design a flexible trailing edge mechanism for an aircraft winglet, which will be capable of undergoing a camber change for a winglet cross section. The deflection will be achieved utilizing flexible material with a set of predefined boundary conditions. By utilizing these boundary conditions, the panels will deflect. The scope of this thesis is to go over the design and concept of the morphing mechanism and the production of a prototype to provide 
a proof of concept. After a functioning prototype is achieved, the thesis will cover a number of experimental studies to study the behavior of the flexible material with relation to the deflection. After the experimental study is performed, a controller will be developed to relate the input parameter to the deflection, using the results from the experimental study. Improvements and limitations of the current design will be identified so that the next iteration of the concept would address areas of concern.

\subsubsection{Thesis Outline}

The thesis is broken down into the following sections:

- Literature review

- Design of the flexible trailing edge

- Experimental study

- Controller development

Chapter 2 of the thesis was the first step conducted in this study, which is a literature review of the current technologies used in morphing. The review focuses on technologies utilizing smart materials, since in the beginning of the design process smart materials were considered as the material of choice, since they would serve as both the actuation method and the material. The study explores different technologies, other than smart material and moves toward some of the fundamental concepts which were used in the design.

In Chapter 3, the design process is discussed in details, with the steps of how the mechanism was designed, materials selected and the set up. The chapter will discuss the functionality of the mechanism and the supports used to achieve the required behavior. It will also demonstrate the parametric nature of the design to allow for variations in the different design parameters, so that many experimental studies can be performed using the same set up.

The proceeding chapter, Chapter 4, discusses the experimental study performed on the design. The experimental study is performed to study the overall behavior of the flexible panel and the 
relationship between the input parameters and the deflection achieved. Other aspects are also studied to see how the shape of the flexible panels can be modeled so that the shape of the top and bottom skin would be predictable.

Chapter 5 discusses the utilization of the data gathered in chapter 4 in order to come up with a reverse control method for the mechanism. The controller development is based on the relation between the input and the output parameters of the design and using experimental data to develop reverse control.

The thesis concludes with Chapter 6, which offers concluding remarks and areas of future focus to improve the overall design and address any areas of concern. 


\section{LITERATURE REVIEW}

A literature review on various morphing technologies is conducted to explore the different methods used, with a focus on technologies utilized for camber change. The study explores a number of different key topics starting with a focus on smart materials, moving to bi-stable composites and corrugated composites, flexible rods, and sliding skin concepts. The study also explores the effects of winglet morphing. The study is organized into different sections based on each topic studied. The topics were selected on the basis of utilizing an appropriate method for achieving trailing edge deflection.

\subsection{Piezoelectric Actuators}

Piezoelectric actuators are studied since they offer attractive qualities, such as the fact that a piezoelectric patch would be both the skin material and the actuator embedded within, providing actuation within the patch itself or can be attached to a bigger skin material, such as a composite or metallic plate, and provide actuation while taking minimal space. The term piezoelectric refers to materials which generate an electrical charge when they have a pressure applied to them. These materials have been studied since 1880, when Pierre and Jacques Curie discovered this phenomenon in substances such as quartz, a naturally occurring piezoelectric substance. If an electrical charge is applied to piezoelectric substances, their shape will change, thus, these substances provide a link between mechanical and electrical systems. These effects, however, have a wide range of magnitudes, depending on a lot of factors such as the size and the structure of the material[9]. A lot of research went into utilizing piezoceramic fibers and trying to obtain a functional actuator, which is easy to use and manufacture. One of these methods uses interdigitated electrodes (IDE) on piezoelectric wafers to produce in-plane electric fields, utilizing the $d_{33}$, which will cause the fibers to elongate with applied voltage. The Active Fiber 
Composite (AFC) actuator was developed, however, it had limited applications and was very inefficient to produce. This led to the development of the Macro Fiber Composite (MFC)[10]. The MFC was invented at the NASA Langley Research Centre in 1996.Figure 2.1shows the largest actuator supplied by Smart Material Corp. It consists of rectangular piezoceramic rods which are sandwiched in layers of adhesive. IDE's are attached to the film allowing for the transfer of the voltage to the fibers. Figure 2.2 provides a schematic of the MFC. This set up allows for the in-plane polling, essentially providing a piezoelectric assembly in a sealed flexible patch and allowing for it to be embedded in a composite structure. MFC's can be used as an actuator or as a sensor. The downside to using MFC's is that they require high voltages to operate and the fibers are very brittle [11].

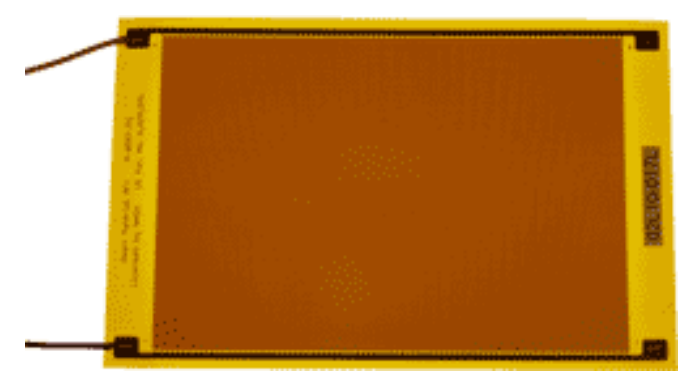

Figure 2.1: MFC Actuator [www.smart-material.com].

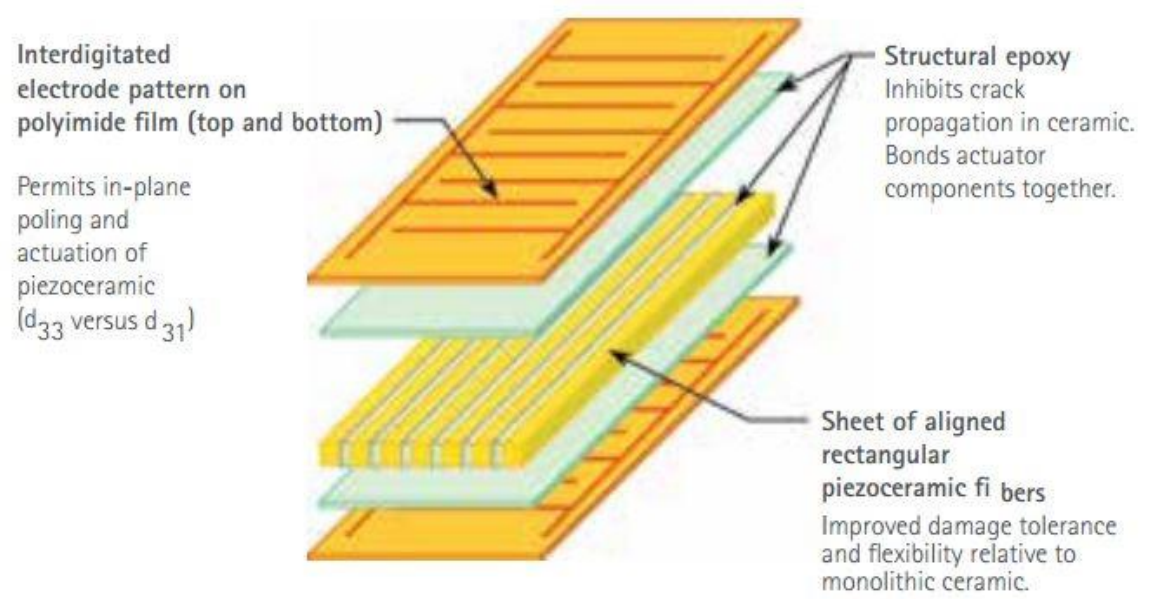

Figure 2.2: Schematic of MFC [www.smart-material.com]. 
MFC Actuators have been utilized for a lot of different applications to wing morphing and vibration reduction. Bilgen at Virginia Tech has performed a lot of research in relation to MFC actuators [12]. An important section of this research involved utilizing the MFC in a unimorph or bimorph configuration. The MFC is bonded to a thin substrate material to form an assembly. The assembly will be bent when the actuator is excited. Since the substrate material is usually a lot thinner than the MFC material, the shift in the neutral axis of both pieces causes them to bend when the actuator extends. In the unimorph configuration, one MFC actuator is bonded to the thin substrate, causing deflection to occur in one direction when the actuator is excited. The bimorph configuration is where two MFC actuators are bonded to the thin substrate at each side. Having two actuators provides the ability to achieve upward or downward deflection, depending on which actuator is excited. Bilgen tested three different materials as the substrate for the unimorph configuration, aluminum, brass, and stainless steel. 3M DP460 epoxy was used for bonding the two materials. Stainless steel substrate was found to have the best deflection. A model was developed to predict the natural frequency of the unimorph and compared to experimental results. The stainless steel was found very favorable since the sheet metals have uniform thickness and are readily available with the thicknesses required. He then went on to perform experiments on the bimorph, the simply-supported thin airfoil experiment consisted of two MFC's pinned at two points, which were determined by optimizing the locations for these points, with the two actuators connected with the thin stainless steel substrate. The results showed an increase of 1.46 in $\mathrm{C}_{\mathrm{L}}$, purely due to the peak to peak actuation voltage. Modelling piezoelectric actuators in the unimorph and bimorph set ups has been typically performed under the assumption that it acts as a beam in bending. Figure 2.3 shows a unimorph rigidly supported with the following equations formulated to predict the tip deflection [13]: 


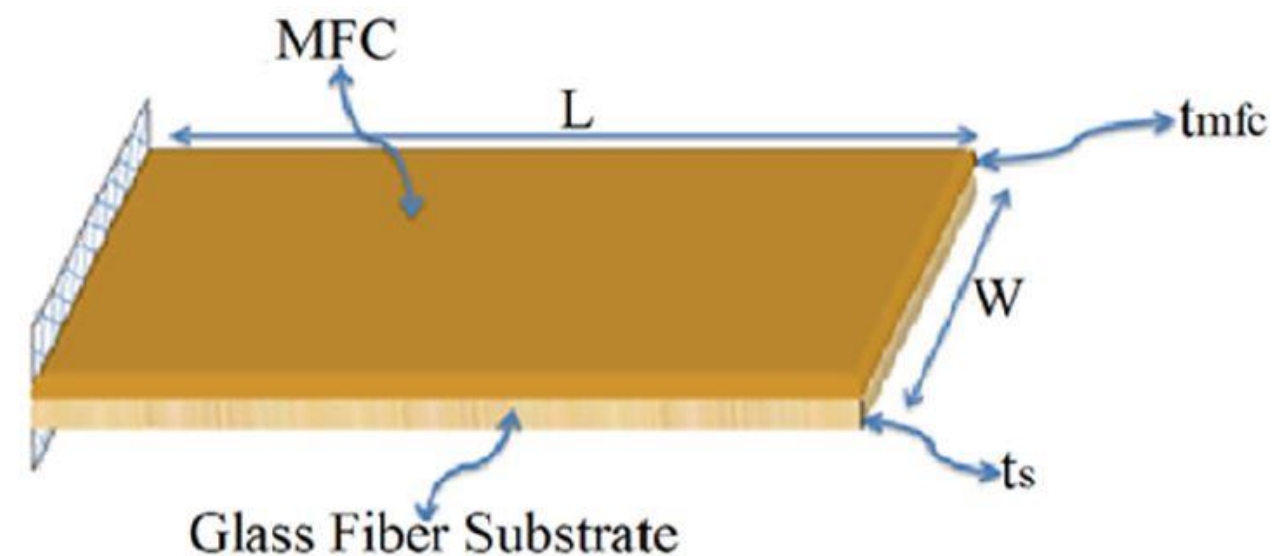

Figure 2.3: Unimorph Actuator (Prazenica, Kim, Moncayo, Azizi, \&Chan, 2014).

$$
\delta=-\frac{F L^{3}}{3 w D_{1}}
$$

Where $\mathrm{F}$ is the blocking force and $\mathrm{D}_{1}$ is the bending modulus per unit width and they can be calculated using:

$$
\begin{gathered}
D_{1}=\frac{E_{s}^{2} t_{s}^{4}+E_{M F C}^{2}+t_{M F C}^{4}+2 E_{s} E_{M F C} t_{s} t_{M F C}\left(2 t_{s}^{2}+2 t_{M F C}^{2}+3 t_{s} t_{M F C}\right)}{12\left(E_{s} t_{s}+E_{M F C} t_{M F C}\right)} \\
F=\frac{3 w E_{s} t_{s} E_{M F C} t_{M F C}\left(t_{m}+t_{M F C}\right)}{4 L\left(E_{s} t_{s}+E_{M F C} t_{M F C}\right)} d_{33} E_{3}
\end{gathered}
$$

Where $d_{33}$ and $E_{3}$ are the piezoelectric coupling effect coefficient and electric field in the third direction respectively, with the E3 calculated using:

$$
E_{3}=\frac{V_{a p p}}{t_{M F C}}
$$

Where $\mathrm{V}_{\text {app }}$ is the applied voltage to the MFC actuator.

The development of these equations is a very important step which can help predict the behavior of unimorph, with different materials chosen as the substrate and studying the effects of changing the material and thickness on the deflection obtained. The researchers went on to experimentally validate the model by analyzing different materials. A glass weave composite 
was chosen as the material for the substrate and from there different material thicknesses were evaluated and $0.17 \mathrm{~mm}$ was found to have the largest deflection. Bimorph, which is where a thin substrate material has an actuator attached to it on either side, had a lower deflection than the unimorph, which is contradictory to the results obtained by the model. The reason being is that the model does not account for the epoxy thickness, thus, a bimorph would be stiffer than a unimorph due to the extra layer of epoxy attaching the other actuator. In this particular study, the idea was for the development of an aileron for a UAV, wind tunnel tests were performed to study the effects of the unimorph on the $\mathrm{C}_{\mathrm{L}}$ and $\mathrm{C}_{\mathrm{D}}$. Results showed that the aileron acts as a spoiler and reduces the lift causing a rolling moment, with the next step being open loop flight test. In [14], Bilgen et al. developed a variable camber airfoil by utilizing a compliant mechanism and MFC actuators. The design had two active surfaces one at the top and one at the bottom, forming the surfaces of the airfoil. A complaint parallelogram box structure is what the two actuators attach to. The complaint box is a 4-bar mechanism, two parallel bars connecting the top and bottom surfaces, a change in camber will cause the box to comply and shear, thus, exaggerating the effect of the MFC. The parallelogram arrangement insures that the top and bottom surfaces remain parallel and have the same slope. Xfoil analysis was performed to predict the aerodynamic characteristics for different thicknesses, based on the applied voltage. Theoretical results showed the best lift to drag ratio is obtained at $10 \%$ thickness, whereas, $2 \%$ had the worst, due to stall. The experiment consisted of $8 \mathrm{MFC}$ 's, bimorphs side by side forming the top and bottom surfaces and attached to a rapidly prototyped compliant box. The wind tunnel tests showed an average increase in the $\mathrm{C}_{\mathrm{L}}$ of 1.54 , purely due to the peak to peak actuation and a max L/D ratio of 13.4 was obtained through voltage excitation, all very favourable results, especially for a UAV, which is the targeted application for this particular design. Bilgen, et al. used the 
cascading airfoil design as the baseline for a new morphing wing design [15]. The new design proposes pinning the airfoil at two points, one being where it is attached to the mechanism and another at the trailing edge. Instead a complaint hinge at the trailing edge is proposed and the thin substrate used composes the entire surface, thus, creating a continuous surface for the airfoil. The performed analytical results showed that pinning the airfoil at $10 \%$ and $55 \%$ would provide the highest $\mathrm{C}_{\mathrm{L}}$ value, which was found to be 1.79 . The new design, however, was found to have a slightly lower lift to drag ration, the next step was to perform an experimental study and compare the results to the analytical model developed. Another research conducted by utilizing bimorph and unimorph was the continuous inextensible surface, variable camber wing [16]. A staticaeroelastic optimization is performed to determine the internal passive structure, which acts as the spar supporting the partially active skin. The genetic algorithm is used for the optimization with the fitness function being the change in the ratio of $C_{L}$ to the root of $C_{D}$. The main parameters used in the optimization are the boundary conditions and how they are distributed along the wing, the substrate thickness distribution, and the distribution of the actuators. Based on the optimized shape a prototype is developed, the passive core acts as the spar with the actuators attached to the thin substrate which forms the skin around the spar. The actuators are not attached in a straight configuration, but attached at an angle along the span, thus not only providing a change in the camber but in the twist as well. Initial results showed a tip deflection of $20 \mathrm{~mm}$ between the $-100 \%$ and $100 \%$ voltage limits, which correspond to a positive limit of $1500 \mathrm{v}$ and a negative limit of $-500 \mathrm{v}$. The prototype is then placed and tested in a wind tunnel which showed an improvement in the $\mathrm{C}_{\mathrm{L}}$.

Panjonien and Inman performed an experimental study on the morphing trailing edge concept(SMTE) [17]. The study researched the use of smart material for morphing applications, 
such as SMA and MFC. This allows for the trailing edge to morph and reduce the drag under different conditions and redistribute the span wise loading for high $\mathrm{g}$ turns, and the smooth nature of the trailing edge allows for drag reduction due to the minimizations of the gaps existing in the trailing edge. It builds on the compliant airfoil idea and allows for a modular design for ease of maintenance and modification. Unimorphs are chosen over bimorphs for weight reduction and a flexural box was produced using a 3D printer with the material being a mix of elastomeric material and rigid plastic. Different flexure box thicknesses were studied and compared to the original hinged design, with a cellular hexagonal honeycomb core. The results showed bubbling at speeds as low as $10 \mathrm{~m} / \mathrm{s}$ for silicon skin and $20 \mathrm{~m} / \mathrm{s}$ for the honeycomb. Panjonien, et al. took the cascading airfoil designed by Bilgen et al. and modified it to come up with a morphing aileron [18]. SMA's offer large displacements, however they have a slow response time until they heat up or cool down, while MFC's have very quick response time but offer a smaller displacement. The research focuses on combining the 2 effects into one mechanism to maximize the amount of deflection obtained, while increasing the response time. The hinged complaint box designed by Bilgen et al. is taken and the hinges were removed with a flexural mechanism, similar to the previous study. The flexural mechanism is obtained by using a 3D printer capable of printing using different materials, thus providing a flexural hinge and using SMA wires with the new mechanism. The SMA wires are used to actuate the airfoil about a hinge located in between the complaint box and the front of the airfoil, thus connecting the methods in series and magnifying the deflection and the morphing effect. The two methods are compared individually by looking at the maximum tip deflection and a prototype is developed to test dynamic effects in a wind tunnel. The results showed that the response of the system is actually improved, along with the deflection, by combining the two effects. Another study is 
performed to look at using MFC actuators to replace servos for control surfaces of an unmanned aerial vehicle [19]. The motivation behind this change is to reduce the size and the weight, since the servos are bigger, whereas, the MFC patches can conform to the shape of the wing, thus eliminating excess parts and essentially not taking up any volume. The reliability is also increased due to the MFC having no moving parts that can be worn out or contaminated. Another advantage over typical servos is the reduction in drag due to the elimination of the hinge, which causes flow to separate around it. The design composed of a foam core with a composite shell, with the MFC bimorph forming the top section and a fiberglass wiper at the bottom. The wiper was cured in a mold giving it an initial curve, which will cause it to follow the curvature of the MFC as it moves up and down. Selig S1210 airfoil is selected for the unmorphed configuration and the morphing will cause an increase in camber to the baseline airfoil. The MFC is attached to the airfoil by laying up both components in a mold of the desired airfoil shape, thus eliminating any changes in shape caused by the MFC, and the laminate is placed in a vacuum bag and cured, to allow for an even distribution in epoxy and eliminate any air bubbles. A model with the servo driven control surfaces is also built, to offer an experimental comparison between the two methods of actuation. The results showed that using the MFC actuation method a change in the $C_{L}$ of 2.25 is obtained, whereas the servo model has a change in $C_{L}$ of 1.5 . The study briefly discusses hysteresis in MFC actuators, which is a common phenomenon, especially when going from peak to peak actuation. Hysteresis is where the MFC would not reach the same peak it did when varying it from peak to peak. The paper offered two solutions for the phenomenon in this particular application, the first being having the autopilot compensate the deflection based on the performance, and the second being to add a 3rd MFC as a sensor and thus having feedback so a closed loop system could be obtained. Ohanian III, et al. performed further research on the topic 
previously mentioned [20]. The design had the same concept, where a foam core with a composite shell composed the base for the airfoil with the top having a bimorph configuration and the bottom has a fiberglass wiper to follow the curve. Hysteresis and creep nonlinearities are also looked at. As mentioned before, hysteresis implies that the deflection state of the morphing control surface is affected by its history. Creep causes the actuator deflection to change slowly over longtime scales. These effects must be carefully studied to make sure they are accounted for in the design. Experimental study is performed in a small low speed open circuit wind tunnel. The results show an increase in the $\mathrm{C}_{\mathrm{L}}$ due to morphing, but drag results are inconclusive, due to the difference in the fabrication process between the servo and the MFC models. To look at the drag, two rapidly prototyped models are produced. Lift is higher for the continuous design, versus the flapped one and the drag is lower. The next step in the research is to perform a flight test. Wickramasinghe, et al. performed a study on the design of a smart wing for an extremely agile micro air vehicle. The smart wing design utilizes MFC's for aileron to replace the already existing discrete system which is usually associated with a bigger weight penalty [21]. The deign required the use of bimorph ribs in the trailing edge of the airfoil to achieve a defection of 30 degrees in the trailing edge, while remaining light. Same as the previous studies, the MFC is attached to a thin substrate of aluminum to form the bimorph. Multiple MFC's are placed along the span to provide a continuous deflection, thus eliminating gaps found in discrete designs. Electroactive Polymer (EAP) is the material selected for the skin, which deforms under high electric field. Deforming the skin is thought to have an amplifying effect on the deflection, when combined with the MFC deflection. A NACA 0009 airfoil with 4 MFC actuators formed the active trailing edge. The developed analytical model showed that a deflection of 30 degrees is possible if a 5 layer EAP film is axially preloaded with $20 \mathrm{~N}$. An aerodynamic analysis is then 
carried out using xfoil to determine the aerodynamic loads acting on the wing. Results show that loss of deflection due to aerodynamic loading was insignificant. Finite Element Analysis is performed on the MFC with the substrate sandwiched in between and the results were in agreement with the model. For the experimental results, a deflection of 9.4 degrees is achieved without any force. Compressive preloading was applied using rubber bands, which cause the deflection to increase to 11.7 degrees. This disagreement in results is due to not being able to attach the EAP skin properly to the latex skin. Therefore, such a mechanism still needs to be developed for the design to be functional. Another paper looked at utilizing MFC actuators for a flap design used on an inflatable wing [22]. The MFC is bonded to a thin substrate, just as mentioned previously, to form a unimorph configuration. The paper looks at finding some method of adding a control surface to an inflatable wing. The unimorph is attached to the wing and weights were attached via a hanger to study the effects of aerodynamic loads on the deflection. A curvature is obtained; however, more force is required to obtain the desired outcome. A tip deflection of 2.5 degrees is achieved. The MFC is also attached directly to the wing, however not much deflection is obtained. Therefore, as can be seen in this section, the most common utilization for MFC in morphing is the unimorph or bimorph configuration. This allows for a lot of deflection to be achieved, but so far it is only applied for small scale applications, such as UAV's. If many MFC actuators in unimorph or bimorph configuration are placed along the entire span of a wing, then a large-scale application might be achieved with a lot of morphing capabilities. However, the hysteresis phenomenon must be carefully studied and accounted for when designing such a configuration, the best solution to account for this nonlinearity would be the development of a closed loop system which can compensate for the reduction in performance. 


\subsection{Bi-Stable Composites}

Bi-stable composites refers to composites which have two stable configurations, thus power is required only to change them from the first stable state to the second. This phenomenon occurs due to the difference between the coefficients of thermal expansion in the longitudinal and transverse directions. After the laminate is cured at a high temperature, thermal stresses due to the cooling process cause it to bend. Since the laminate is unsymmetric and the coefficients are different depending on the direction, bistability is achieved. If the laminate is symmetric, however, this effect is eliminated. The main benefit of bistability is that it allows for shape change without using an additional mechanism; and the actuator is only utilized when going from one stable position to the next [23]. A lot of research was done to come up with modelling techniques to predict the behaviour of bistable composites and the snap-through behaviour, which is where the laminate buckles and moves from one stable position to another. Tawfik, et al. performed a study on modelling using ABAQUS [24]. The bi-stable morphing is performed using a piezoelectric actuator to achieve the snap-through. The analysis is performed by modelling the piezoelectric actuator using the thermal analogy approach, where the applied electric field is applied as a thermal load with the equivalent piezoelectric constants used to replace the thermal coefficients. The equation relating strain $(\varepsilon)$ and stress $(\sigma)$ is:

$$
\{\varepsilon\}=[S]\{\sigma\}+\{\alpha\} \Delta T
$$

Where $[\mathrm{S}]$ is the compliance matrix and $\alpha$ is the coefficients of thermal expansion. Transforming this equation, the piezoelectric coefficients can be used yields:

$$
\{\varepsilon\}=[S]\{\sigma\}+\{d\} \frac{\psi_{3}}{t}
$$

where $d$ is the equivalent piezoelectric constants, $t$ is the actuator thickness, $\psi 3$ is the electrical potential across the thickness, transformed using: 


$$
\begin{aligned}
& \alpha_{1}=\frac{d_{31}}{t} \\
& \alpha_{2}=\frac{d_{32}}{t} \\
& \alpha_{12}=0 \\
& \Delta T=\psi_{3}
\end{aligned}
$$

After using the above transformations, a model for the bi-stable plate is created and analyzed in ABAQUS to find the required voltage to achieve snap-through and the snap back action for the carbon fiber/epoxy laminate, $85 \times 65 \mathrm{~mm}$ in size. The MFC bonded is 40x10 mm in size, bonding the MFC to the plate lead to achieving lower curvature in the plate. The model predicted the required voltages very well. Schultz \& Hyer performed studies on the modelling of unsymmetric composite laminates using MFC to achieve snap-through as well [25]. In the study an unsymmetric crossply $[0 / 90]_{\mathrm{T}}$ was cured in a flat press-clave, which uses mechanical pressure applied on the laminate. The MFC is vacuum bonded to the bi-stable plate with MFC fibers in the zero-degree direction. Strain gauges are placed on the other side of the laminate, positioned in such a way so as to measure the strain in the transverse direction of the fibers. The snapthrough voltage is found to be $1695 \mathrm{~V}$ based on experimental studies. Three models are developed using the Rayleigh-Ritz technique. The models developed predict the shape very well, however, the snap-through voltage was off. This could have been attributed to many reasons associated with the fabrication and layup of the laminate or the attachment to the MFC, which can cause a reduction in the curvature and would stiffen the composite, especially with the layer of epoxy used to attach the two together. This can increase the voltage required to achieve snapthrough. Another paper explored the modelling and characterization of a bi-stable plate with a MFC actuator used to achieve snap-through [26]. The three-dimensional compliance, piezoelectric, and relative permittivity matrices are developed, to be utilized in the model. In 
order to compare the finite element model predictions with experimental data, an aluminum cantilevered beam with two MFC actuators attached is used. One MFC is used as an actuator, while the other as a sensor. The deflection is measured with a laser based on the initial position of the beam. The beam deflection as a function of MFC voltage clearly showed a linear trend, which is predicted by the beam theory. The predicted finite element values are in excellent agreement with the experimental values to within $2 \%$, therefore, it was concluded that the matrices formulated are appropriate. The experiments performed consisted of 2 bi-stable plates, a $[0 / 90]_{\mathrm{T}}$ laminate and a $[-30 / 60]_{\mathrm{T}}$. The MFC is attached on top in the zero direction, thus, causing the laminated to have $[0 / 90 / 0 \mathrm{MFC}]_{\mathrm{T}}$ and $[-30 / 60 / 0 \mathrm{MFC}]_{\mathrm{T}}$ configurations. The voltage applied to the MFC is varied until snap-through action is achieved. Video cameras and physical markers allows for the digitization of the plates, in order to compare the behaviour of the laminate to the FE model developed. The results show that the maximum deflection predicted is $12.1 \%$ higher than the one measured, this difference can be attributed to the imperfect manufacturing process used in laying up the composite. The model predicts snap-through action to occur at $645 \mathrm{~V}$, whereas in the experiment snap-through is achieved at 670V.This slight difference could be attributed to the fact that the MFC stiffens the plate and thus more force is required to compensate and cause the snap-through to occur. In the previous studies, the MFC actuator used to induce snap-through is usually a single actuator located in the middle of the laminate. A study by Dano, et al. [27] explored using more than one actuator distributed along the laminate. Typical bi-stable plates which use a large rectangular actuator in the centre tend to cause a reduction in the curvature of the plate. Therefore, instead the use of multiple thin MFC strips attached to both sides will help preserve the curvature, while allowing snap through between the two stable states. A finite element model is developed with three different stages. The first one is 
of the laminate at the curing temperature, where it is flat and stress free. The second is where voltage is applied to the MFC strips and the third is the laminate in the second stable position, snap-through voltage was predicted to $1180 \mathrm{~V}$. The experiment consists of bonding the MFC strips to the uncured laminate, with the assembly placed in a vacuum bag and cured together at $177^{\circ} \mathrm{C}$. After curing, the laminate is removed from the oven and a cylindrical shape is obtained and snap-through showed a second stable position did exist. However, the laminate did not stay in that configuration and it snapped back to the initial stable configuration. This is attributed to uneven MFC spacing, uneven ply thickness, and excess adhesive. The excess adhesive is probably the main reason, since the epoxy and the strips provided a distributed stiffening all over the laminate, making it hard to stay in the second stable position and causing it to snap back. The developed model showed very good correlation up until the snap-through point. Bi-stable applications seem limited at this point and further research is required to see the interaction between multi-stable modes and how they can be controlled. However, they offer the potential to be a very economical method of achieving wing morphing, especially due to the fact that actuation is only required to achieve snap-through. Tailoring the laminate so that it snaps to a specific position would be the ultimate goal.

\subsection{Winglet Morphing}

Winglets are found at the end of the wing to form the wingtip, and they are used to reduce the effect of wingtip vortices, caused by the difference in pressure between the top and bottom surfaces of the wing. These wingtip vortices can produce a lot of induced drag, which in turn lowers the efficiency of the flight and would require more fuel. Winglets reduce this effect by eliminating the vortices. The application of morphing on winglets would lead to an improvement in this improvement. A study is performed by Bristol University [28] to explore the requirements 
for winglet morphing depending on the flight profile. The study uses multi-disciplinary design optimization(MDO) to optimize a design considering a number of disciplines. The performance indices for optimization are the maximum blocking force, maximum strain, stiffness, frequency, size, and power. Genetic algorithm (GA) is used as the optimizer and Tornado is used for the aerodynamic solver. The results provided the required shapes for the morphing of the winglet which varied from a level flat configuration to a $33^{\circ}$ upward bend angle. Kim, et al. [29] performed a study on using bi-stable material to achieve morphing in a UAV winglet. This morphing winglet requires two major different geometries, one being planar and conforming to the wing shape and the other being an upwardly bent shape. While bi-stable composites are usually the material chosen for morphing application, the low aspect ratio of the winglet would produce a deflection which is lower than required. Alternatively, a metallic bi- stable structure could be used, where it is formed by passing the metallic sheet through two rollers, a urethane one a metal one. The upper roller presses the sheet onto the lower roller and deforms it, which results in the sheet having bi-stable properties. For the final results two stable configurations were achieved, a flat configuration, and a $60^{\circ}$ bent angle one. The snap-through forces are found to be $0.4 \mathrm{~N}$ for the flat state and $1.3 \mathrm{~N}$ for the curved one. Another paper explores the use of an independently controlled variable cant angle winglet [30]. This change in cant angle would create a rolling moment due to the change in lift on one side and yawing moment due to the side force generated. Maneuver control can be achieved by balancing the moment so that the desired moment could be achieved and in turn the rolling moment is obtained. A baseline wing is modified to add a winglet capable of rotating via a hinge and actuator design. The initial study shows the winglet could be used as an alternative to rudder, elevator, and ailerons. However, it is still a discrete method. For it to become a truly morphing winglet, smart materials can be applied 
to the same concept so that the winglet would change its angle, which in turn changes the forces, which can be used for maneuvering or to increase the efficiency of the flight. Therefore, morphing winglets can have many benefits and different methods mentioned above can be applied or combined to achieve it. The utilization of MFC actuators oriented in a specific configuration might results in obtaining a variable cant angle winglet.

\subsection{Other Morphing Techniques}

This study discusses wing morphing by looking at the materials used without talking about the method of actuation. For example, Yokozeki, et al. [31] researched corrugated composites as a material for flexible wing applications. The use of these corrugated composited allows a material be stiff in the span direction and flexible in the camber direction. This allows for variable camber while maintaining the structural integrity of the wing. The corrugated material was obtained using $r$ plain woven carbon fabric prepreg, cured in a corrugated pattern. Stress and strain tests are performed on the specimen through tensile and flexural testing. The material is found to have ultra-anisotropic properties. Modifications are made to include adding CFRP rods in the valley region, or filling one side with flexible rubber material. The addition of the CFRP rods provides an increased longitudinal stiffness without a loss in flexibility in the transverse directions. Another study looks at the development of a flexible matrix composite skin [32]. This skin is developed for morphing wing application, where the requirements are low in-plane stiffness for low actuation requirements and high strain capabilities, while having high out-of-plane stiffness to handle the aerodynamic loads. The flexible matrix composite uses a flexible matrix and glass or carbon fibers. Glass fibers and dragon skin shore 10A elastomer are used for the matrix. The resultant composite behaves like a membrane, but is able to carry the loads. It allows for large pretension in the non-morphing fiber direction, allowing large deformation and low actuation 
required for the morphing direction. Future works could include testing the developed material in a wing application and performing wind tunnel testing to look at the effects of aerodynamic loads and to see whether bubbling in the skin occurs or not.

\subsection{Elastic Buckling and Flexible Rods}

When a slender bar is subjected to a compressive force, the bar tends to bend sideways until a critical force is reached and failure occurs. Many studies have been performed on trying to model this behaviour and predict the shape of the bar. Figure 2.4shows a typical bucking problem. When a column is subject to a centrally applied load, the critical load can be calculated as follows.

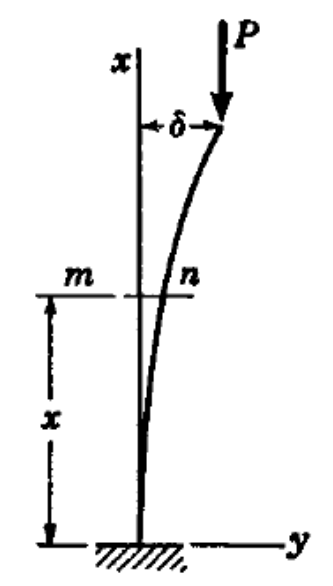

Figure 2.4: Buckling bar[47].

If a load $\mathrm{P}$ is applied to a bar of length 1 , the general solution for the differential equation which describes the shape of the bar is:

$$
y=A \cos k x+B \sin k x+\delta
$$


Where $\mathrm{k}$ is given by:

$$
k=\sqrt{\frac{P}{E I}}
$$

and $\mathrm{A}$ and $\mathrm{B}$ are constants of integration and can be found using the boundary conditions of the statement. $\delta$ is the side deflection of the bar. The critical buckling force for a bar of length 1, with compressive forces $\mathrm{P}$ acting on it with fixed supports at both ends is:

$$
P_{c r}=\frac{4 \pi^{2} E I}{l^{2}}
$$

Considering a bar fixed at two ends, the solution in eq.2.11would be changed, since no deflection is possible. The deflection term is replaced with a reaction moment $\mathrm{M}$ on the ends, thus, making the solution:

$$
y=A \cos k x+B \sin k x+\frac{M}{P}
$$

Using the boundary conditions, $y=0$ at $x=0$ and $d y / d x=0$ at $x=0$, the general solution equation becomes:

$$
y=\frac{M}{P_{c r}}(1-\cos k x)
$$

Using the above equation, the buckled shape of the bar can be determined. This is useful for obtaining an analytical representation of a buckled bar, and to find the deflection. Buckling however, can be a nonlinear problem, which can be very hard to represent. This is why assumptions are placed to linearize the problem so that a simple solution could be obtained.

Buckling analysis is used to determine the failure load at which compressive failure occurs, however, if the rod is slender and flexible, the post buckling analysis can be very useful. Wang [33] performed a study on the post buckling analysis of an elastic rod with one end fixed and the 
other pinned. After the formulation of the equations which describe the post buckling behaviour, the load-deflection curve is plotted and the relationship is shown to be non-linear. Several interesting phenomena are discovered such as limit load, jump hysteresis, bifurcation, and nonuniqueness in the relationship between the load and the deflection. Therefore, it is suggested to try and idealize the situation as much as possible for the analysis to be carried out linearly, which would simplify it a lot. Otherwise an exact solution may be difficult to find and an approximate solution must be developed.

The concept for buckling an elastic rod could also be applied if instead of applying a force at the end of the rod, a rod supported by at the end by a fixed link would buckle when subjected to an increase in its length. This concept has been studied for the purposes of developing a continuum robot concept. Continuum robots essentially replace the articulated spine found in snake like robots with a flexible member. Some of the challenges that must be addressed typically are finding the actuation length of the flexible components with regard to the desired orientation and finding the internal load distribution [34]. The research Xu and Simaan [34] performed focused on stiffness modeling for the continuum robot and finding analytical models to predict the shape after it deforms. They assume that each flexible segment bends into a circular shape to simplify the analysis and use elliptical integrals to express the backbone's deflected shape. A modelling method using elliptical integrals vs using a finite element method allows an analytical solution which would converge faster, which is very beneficial since for a real-time application, computation time is a very important factor. A different study explores the analysis of continuum robot consisting of flexible rods [35]. The topic researches the design of a bionic continuum robot, using flexible glass fiber rods, replacing the rigid structure which is typically found in a traditional robot. The position and posture of the end part, which is essentially the main area of 
focus, can be controlled by changing the length of every rod. A prototype was developed using 3 active and 3 passive rods. The active ones change length from 1.2 to 1.5 meters. A kinematic model was analyzed and the simulation of the forward and reverse kinematics was derived, along with the relationship between the length of each active rod and the position of the end-effector, since any variation in the length would cause a change in the location due to the constraints imposed by the passive rods not changing their lengths. 


\section{DESIGN OF A FLEXIBLE PANEL TRAILING EDGE}

As previously discussed, when it comes to camber morphing the goal is to change the aerodynamic characteristics of the wing constantly to achieve the optimum L/D ratio for efficiency enhancement. The same concept applied to a winglet would have a similar result. The main purpose of the study is to design a mechanism capable of changing the camber of a winglet, keeping all the required constraints and minimizing weights. After the literature review, key morphing technologies are identified. It is determined that a parametric design is needed to combine different morphing concepts.

\subsection{Design Requirements}

The main mechanism required is one that allows for producing a deflection and a deflection angle when actuated. The design process starts with essentially modifying a four-bar mechanism so that it conforms to the requirements. The proposed mechanism is to be able to provide a significant trailing edge deflection, which is set to be at least half of the maximum thickness of the airfoil section. The first technology considered was the utilization of the MFC unimorph with a compliant mechanism [36]. However, after the literature review and initial experimental results, the MFC technology is found to provide a deflection lower than the ones required. For a drastic shape change, many patches had to be put together and controlled in a uniform manner. Another limitation found is the hysteresis phenomenon. The requirements also include a design which can be easily controlled and implemented. The required mechanism is inspired by the continuum robot design [35]. 


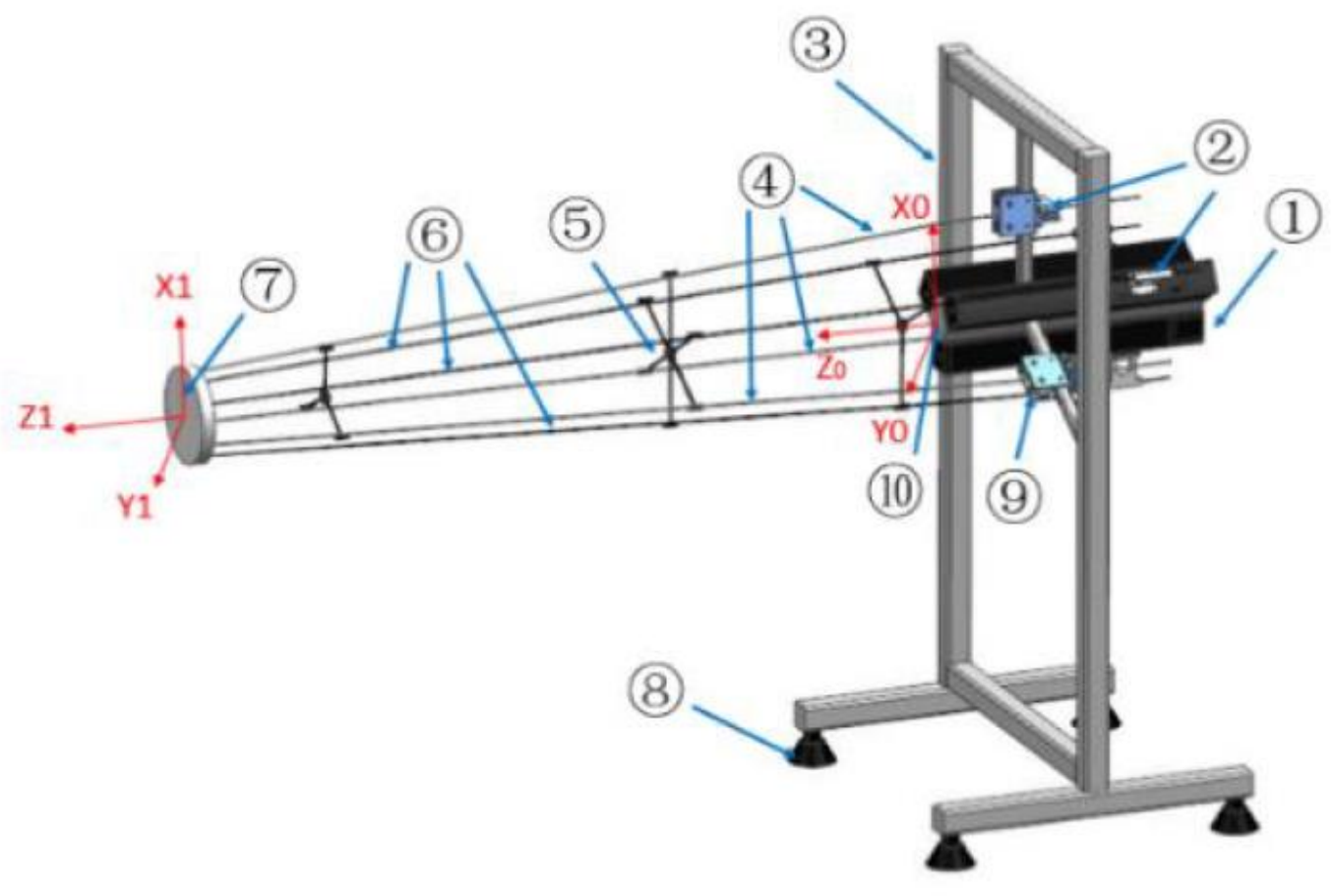

Figure 3.1:Continuum Robot Mechanism [36]

Fig. 3.1 shows a prototype designed by Tian et al. [36] which utilizes the idea of a flexible rod bending due to the constraints imposed by passive rods. When a rod is increased in length, the fixed rod will try to hold it in place. However, as the length increases so does the force, which will cause this rod to buckle and apply a bending force on the other rod to bend, thus deforming the whole assembly. The flexible material used is what makes this phenomenon to occur.

In order to modify the proposed mechanism into a concept applicable for varying the camber, a couple of parameters must be identified. Firstly, the purpose of the mechanism is to produce a downward deflection of the end part, while introducing a deflection angle, giving these two parameters as an output of the actuation. The actuation introduces a modification for the length of the links. The input which determines the produced deflection and deflection angle is the change in the lengths of the links. The flexible rod mechanism employs a lot of rods, to achieve more degrees of freedom when it comes to the motion. For the purposes of the variable camber 
design, the movement required is planar, thus, only a top and bottom symmetric rods are required. The rods must support the skin. However, if the rods are given some width and turned into panels, they form an active skin section. The panels must be flexible enough so they can bend without breaking. They must also be strong enough to handle aerodynamic loads acting on them. Varying the lengths of the two panels produces deflection in the end support and a deflection angle. The end support is a rigid constraint between the top and bottom panels.

\subsection{Parametric Design Concept}

Based on the points discussed above, the overall idea of how the mechanism would operate is obtained. It consists of top and bottom flexible panels, constrained together by a rigid support, both allowed to slide to change their lengths. The design has a number of variables which can be considered to obtain different deformation results. These variables include the thickness and material property of the panels, the distance between the top and bottom panels at the root, the distance between the top and bottom panels at the tip, the width of the panel, and the shape of the rigid support since it has an effect on the overall shape of the panel. The mechanism is not difficult to implement; however, the goal is to study the behaviour and deformation of the flexible panel experimentally. Hence a parametric design concept is needed.

The function requirements of the mechanism are the ability to produce a deflection and a deflection angle of the end support, by varying the lengths of the two panels. The table below provides the requirements and the design parameters. 
Table 3-1:Design Requirements and Parameters.

\begin{tabular}{|c|c|}
\hline Design Requirements & Design Parameters \\
\hline $\begin{array}{l}\text { - } \quad \text { Produce end support deflection } \\
\text { - } \quad \text { Produce end support deflection angle }\end{array}$ & $\begin{array}{l}\text { - End support lengths, which is the distance } \\
\text { between the two panels at the end (h2) } \\
\text { - Distance between the two plates at the root } \\
\text { (h1) } \\
\text { - Width of the panels } \\
\text { - Length ranges of the top and bottom panels }\end{array}$ \\
\hline
\end{tabular}

The dimensions of the mechanism are defined as follows:

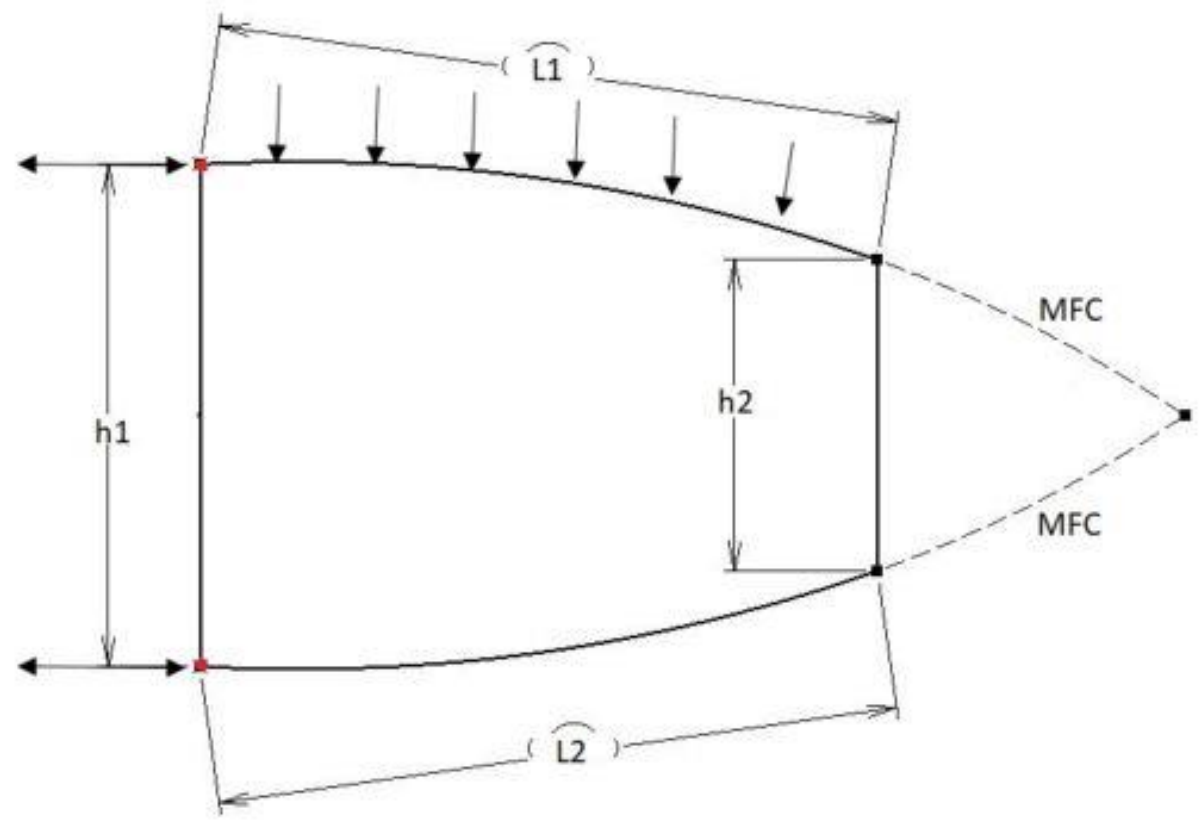

Figure 3.2:Mechanism Dimensions. 
The distance between the two panels at the root $h_{1}$ and at the tip $h_{2}$ is related by a taper ratio $\lambda$ and the two are related using:

$$
h_{2}=\lambda h_{1}
$$

The tapering is introduced so that the overall shape of the mechanism resembles the crosssectional shape of an airfoil, instead of being a simple rectangle. To achieve significant tip deflection, the mechanism must have an aspect ratio, which offers more length and in turn more deflection. When there is no deflection, the lengths of the top and bottom panels $\mathrm{L}_{1}$ and $\mathrm{L}_{2}$ are equal to length $\mathrm{L}$. The aspect ratio $\mathrm{AR}$ is defined as:

$$
A R=\frac{L}{h_{1}}
$$

The length of the panels must vary significantly in order to achieve significant deflection. A four time increase in the length is selected to provide a wide range of motion to study this motion effects on the end support motion.

The following parameters are selected for the base of the design:

- $\mathrm{h}_{1}: 200 \mathrm{~mm}$

- $\quad$ AR: $0.4-1.75$

- $\lambda: 0.75$

In the design, $\mathrm{h}_{1}$ is adjustable and selected so that other parameters can be determined, along with the aspect ratio and the taper ratio, and then the dimensions of the mechanism can be formulated. The taper ratio is selected so that the mechanism tapers to resemble an airfoil, while still having some length at the end for the rigid support. The rigid support connects the two panels and constrains them, forcing the mechanism to deflect, when the lengths of the panels are changed. What differentiates this design from a typical mechanism is that the links are given widths, 
becoming panels, to form the skin. The mechanism incorporates a MFC unimorph attached to the rigid support to form the tip. The unimorph provides increased deflection to the tip. The width of the panels is selected to be $80 \mathrm{~mm}$ to go along the width of the MFC patch. The panel width, however, can be selected to span the entire winglet, or it can be composed of panels. The design process is outlined in a flow chart with the following steps taken into consideration:

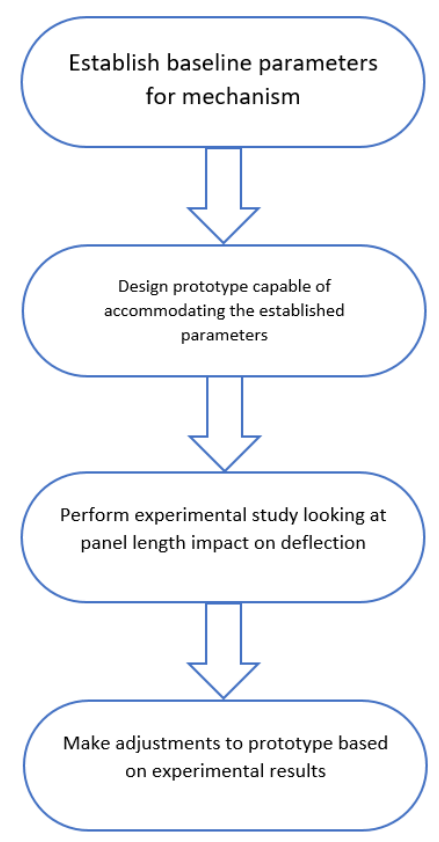

Figure 3.3:Design Flow Chart.

\subsection{Prototype Design}

After the initial dimensions of the mechanism are obtained, the prototype design can be started. Before actually building the prototype, a CAD design must be produced, in order to make the assembly process easier and to assure compatibility between the different components. The design process must incorporate the different aspects to conform to the required design parameters, such as adhering the design to the proposed boundary conditions. The boundary conditions are defined as having the red points visible in Figure 3.2 constrained vertically to prevent any upward motion, ensuring the panels slide horizontally. Another boundary condition 
is the attachment point to the rigid support being rigid, so no deformations occur between the panel and the rigid support.

The first step is selecting a material to build the frame, which will house the actuation system and provide support for the mechanism. A T slotted aluminum bar is selected as the material of choice.

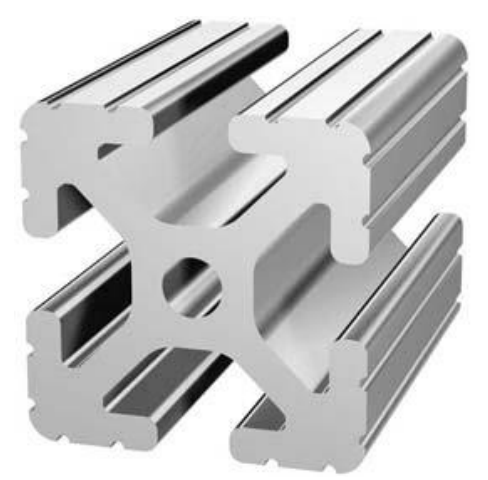

Figure 3.4: T slotted bar 〈http://www.globalindustrial.ca〉.

The bar shown in Figure 3.4 is very widely used for experimental set up, since it offers great freedom when it comes to the fabrication. The set up can have a custom length, width, and height with different levels. The structure would have two levels, one for each actuator top and bottom, and allow the flexible panel to extend and retract. The support frame is set up as a cage like structure with the mechanism extending out freely and housing all the parts inside. Having a reconfigurable set up allows for adjusting the mechanism parameters easily, without having to start the design process from scratch, in case a different configuration is to be studied. Allowing for varying $\mathrm{h}_{1}$ easily and thus, varying the aspect ratio of the airfoil section, simply by changing the location of the plate on the frame. 


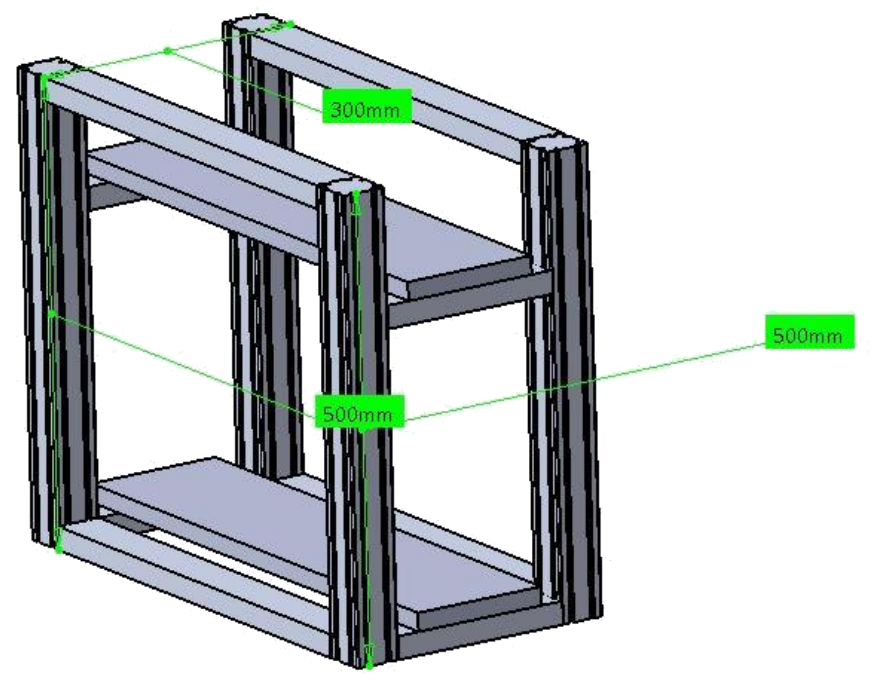

Figure 3.5: Frame Design.

Two linear actuators are used one on the top and one at the bottom. The actuators will be responsible for controlling the deflection by extending and retracting the flexible panels. An increase in length in the top actuator and a decrease in length in the bottom one will lead to a deflection downwards and vice versa. In order to keep the panel from translating in the vertical direction and obtain the deflection behaviour due to the length change required, a roller design was proposed to constraint it, thus satisfying the established boundary condition. The design is composed of two rollers placed in front of each actuator, and the panel would slide between the two rollers, thus only moving horizontally but constrained vertically. The length of the panels, which is the parameter being controlled, is measured from the roller and outwards. The location where the panel sits on the actuator must be level with the location between the two rollers, to ensure that the panels are horizontal before the rollers, so that no pre-stresses act on the panel and deform them. 
In order to achieve the desired effect, the top and bottom panels must be constrained at the end by a rigid material. This condition allows for the deflection to occur when there is a change in
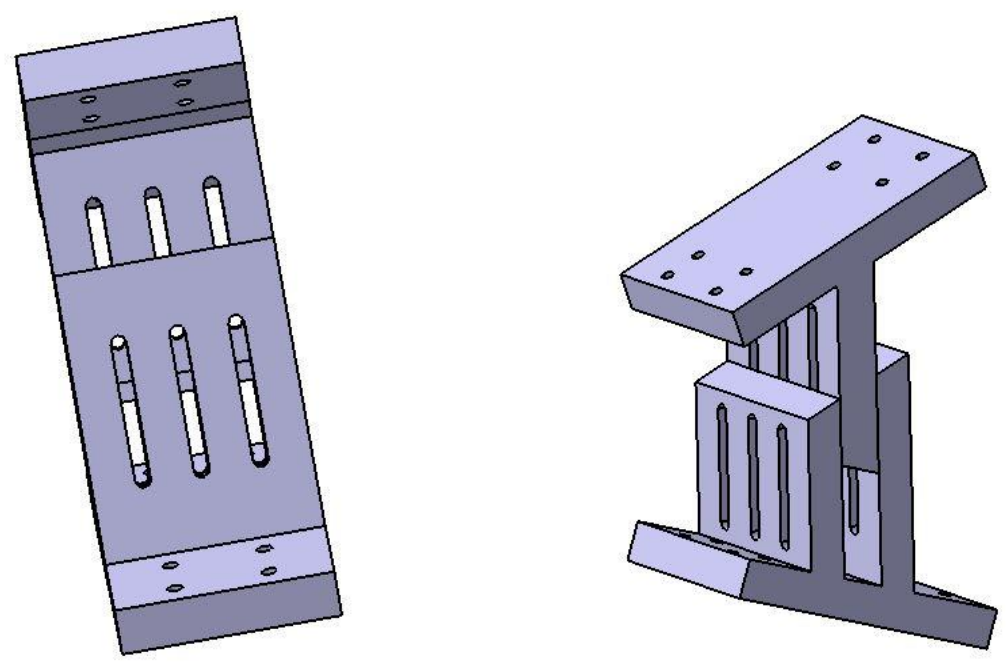

Figure 3.6: End Support Initial Design.

length. An end support is designed to allow for this constraint to be applied. The support is composed of two parts which are attached to one another through screws, it has 3 slits on its surface to allow for changing the length of the support, thus, giving the ability to change $\mathrm{h}_{2}$. The design of the supports incorporates having the boundary condition for attaching the panels rigidly, utilizing four mounting points for each panel.

Looking at Figure 3.6, the parametric nature is evident that the slits are used to change the vertical distance between the two panels. The support has an angle surface added so that the two panels would form a shape familiar to an airfoil, since $h_{1}$ and $h_{2}$ are different. This design is solely to focus on the behaviour of the mechanism, therefore, the actual shape is not as important, because the interest is developing a control method for the mechanism. A modification is made to the end support, where holes are added instead of the slots to allow easier mounting, so that it doesn't slide if the screws are not very tight. 


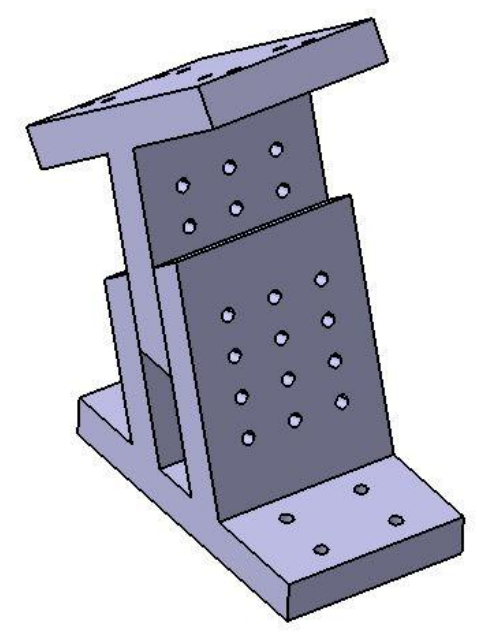

Figure 3.7: Modified Design for End Support.

A second support was proposed in the design to support the middle section, especially when the panel is extended all the way. This supports the panel from the bending moment acting on it, due to the panel weight and the end support weight. The design is similar to the end support, with the difference being the removal of the top part on which the flexible panel sits, since the panel is free to slide along the support and not attached rigidly. The entire support is attached to the end support via three threaded rods that secure the supports at the required height, while acting as a support for the middle section. This support provides extra structural support for the panels, preventing them from deforming. This will be essential when the mechanism has high values for $\mathrm{AR}$, however, for normal AR values, such as the ones in this design ranging from 0.4 to 2 , it would not be required. 


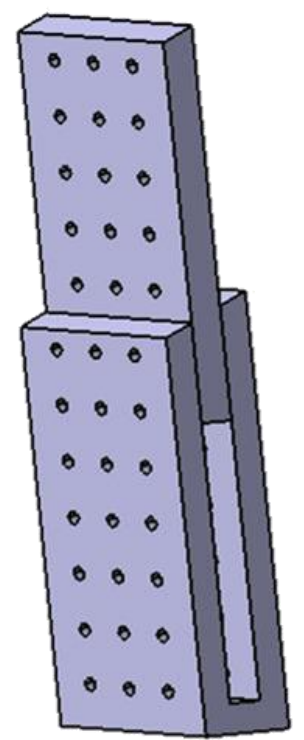

Figure 3.8: Middle Support.

The end support has two sections on the top; one is where the flexible panel will be attached, and the other one is where the MFC unimorph patch will be mounted. The idea is to obtain more deflection at the tip using the MFC on the top of the one obtained by the mechanism. Combining all the components above, the design was finalized as shown in Figure 3.9. The area of interest is the panel highlighted in yellow. It represents the mechanism proposed. That part of the design varies in length to change the values of $L_{1}$ and $L_{2}$ to produce a deflection at the end support shown. The different parts are in place to restrict the panels and constraint them so that they can behave in the manner required. 


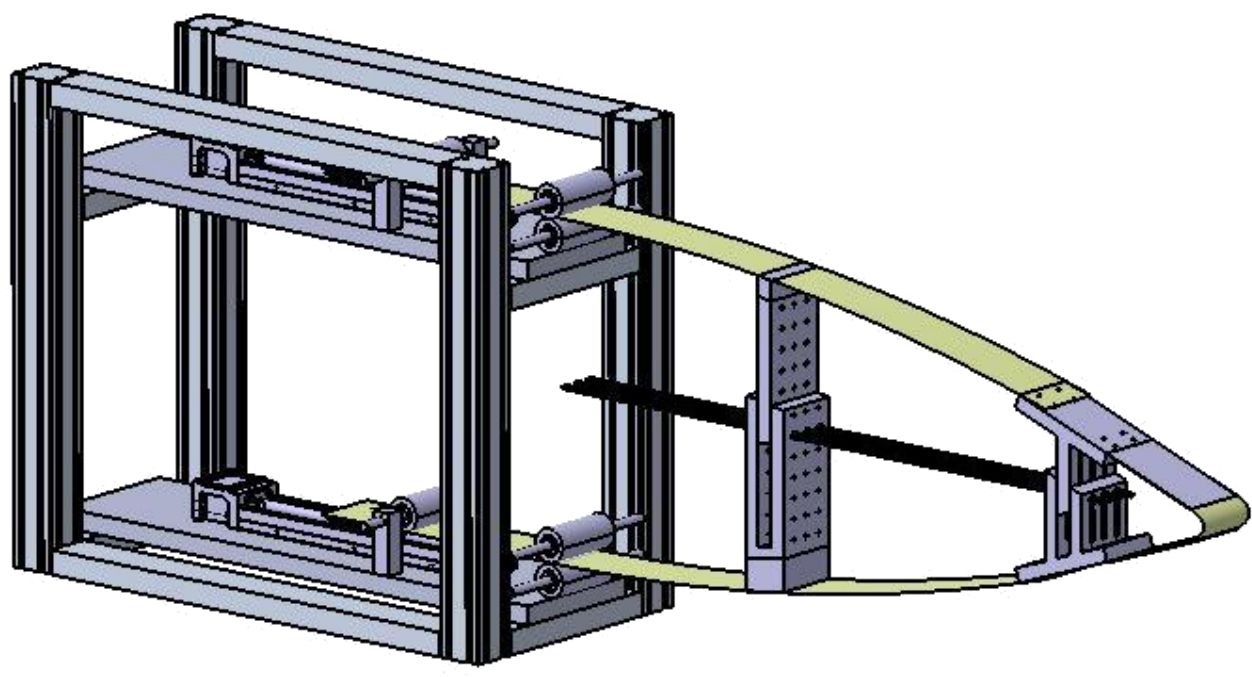

Figure 3.9: Flexible Panel Mechanism.

Referring to Figure 3.9, the panel is made to be the same width as the MFC patch, which is 70 $\mathrm{mm}$, to have a uniform width. The assembly shows how all the different components are attached to one another, with the supports attached via the rods, the rollers responsible for constraining the panel, and the MFC patch at the end. 


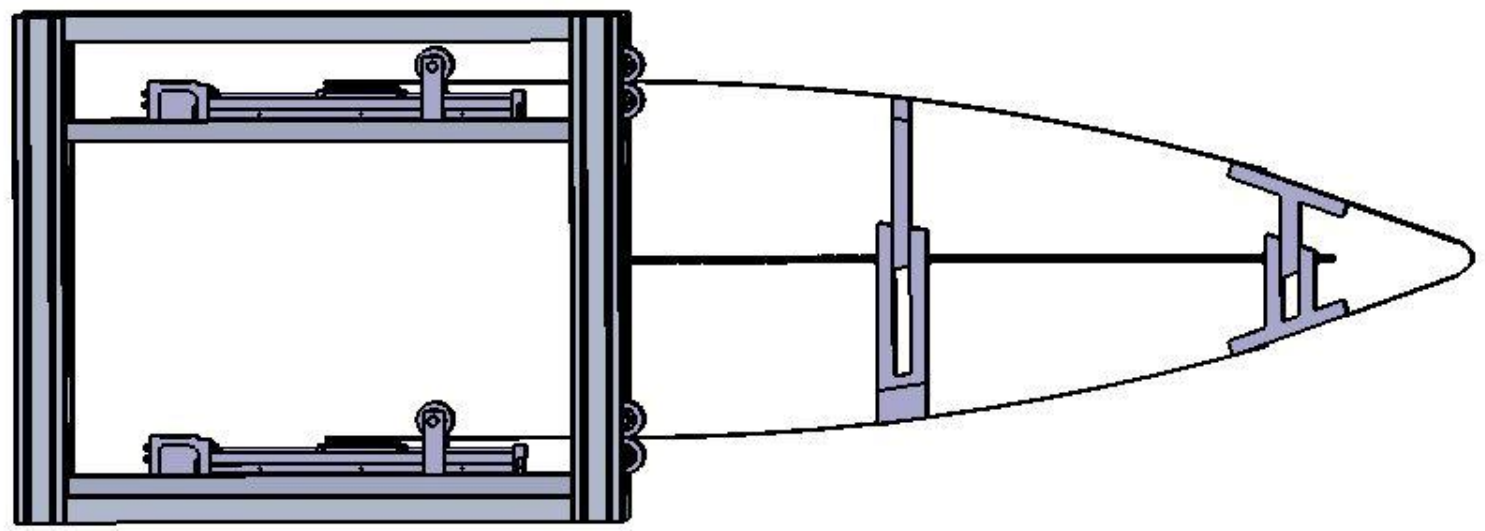

Figure 3.10: Side View of Mechanism.

The drawings for the design were all completed using CATIA v5. The sizing of the parts is made according to the frame dimensions, which are determined after the initial mechanism parameters are obtained. Detailed engineering drawings of the components can be found in the appendices. The next section will discuss building the prototype and the assembly and fabrication procedure for all the different components.

\subsection{Prototype Assembly}

After the CAD design was completed, the next stage is to obtain the different components, fabricating the flexible panels and assembling everything together to make sure the design operates as required so that the experimental study can be performed.

\subsubsection{Component Selection}

The prototype requires a lot of different components that have to be integrated together. Mechanical components including the housing and the actual mechanism, and electrical components, responsible for actuating the mechanism and controlling the motion. All of the different components serve a purpose to make sure the mechanism behaved in the required manner, whether constraining it or moving it. As mentioned above, the frame was assembled 
using a T slotted bar two inches by two inches, the plates which the actuators sit on are made of a quarter inch thick plywood sheet. The sheet is cut so that it sat on the aluminum frame and secured by screws. This allows for changing the height by moving the plate to the desired location then tightening it again, so that different AR values can be tested.

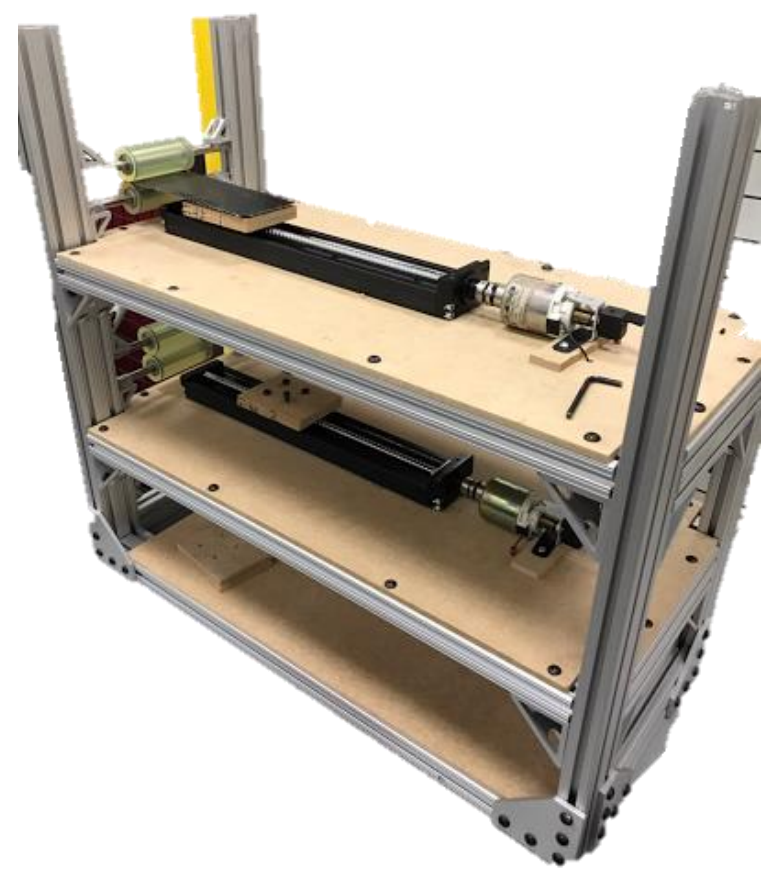

Figure 3.11: Aluminum Frame Assembly.

A Misumi LX3005-B1-F-350 linear axis system is chosen as a linear motion system [37]. This system has a $5 \mathrm{~mm}$ lead with a $300 \mathrm{~mm}$ stroke, which was found to be sufficient for the purposes of this prototype. The actuation must be level with the roller, so that the panels are horizontal and no pre-stresses affect the shape of the panels, having a linear actuation system ensures that. Two systems are used one for the top section and one for the bottom, to vary $L_{1}$ and $L_{2}$ respectively. Together they give the ability of upward and downward deflection as well as chord extension and reduction. The actuators are placed on the plywood flooring and secured via screws. 


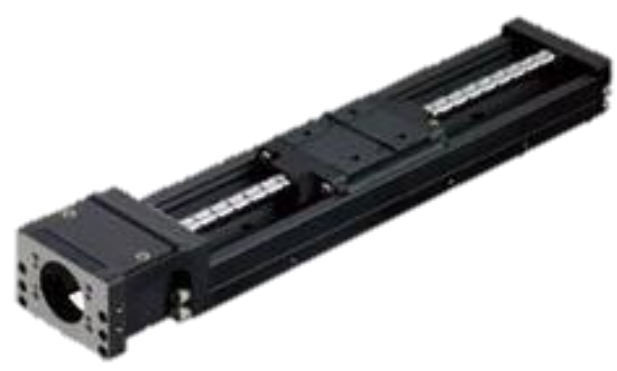

Figure 3.12: Linear Axis Motion System

Brushed DC motors are selected to turn the linear motion systems. Crouzet 89810908 24V brushed DC motors [38] are chosen, which have a shaft $6 \mathrm{~mm}$ in diameter, as they were found to have sufficient force to drive the linear system. In order to drive the motion system with motor, a coupler is required. The coupler is chosen to be Misumi MCGL 20-6-6 coupler [39], which could accommodate misalignments between the motor and the motion system, ensuring the panel movement is smooth. An optical encoder is also required to track the movement of the motor for control purpose. An encoder essentially converts rotary motion into an electrical signal. The encoders chosen for this prototype were the Bourns ENC1J rotary optical encoders [40], having a resolution of 128 cycles per revolution, means a $5 \mathrm{~mm} / \mathrm{rev}$ actuator can be controlled to within $0.04 \mathrm{~mm}$, offering high precision in controlling $\mathrm{L}_{1}$ and $\mathrm{L}_{2}$ values.

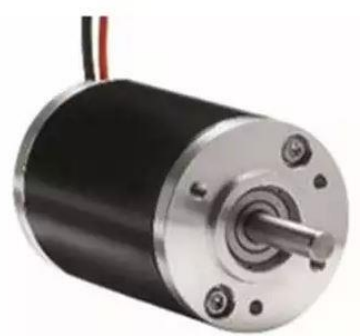

Figure 3.13: Brushed DC Motor 〈www.digikey.ca〉. 


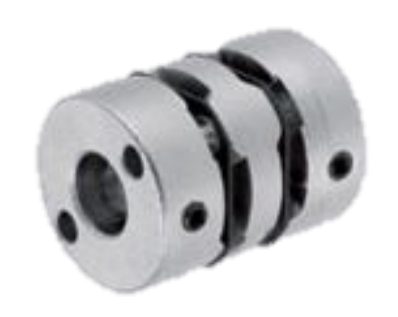

Figure 3.14: Coupler <https://us.misumi-ec.com>.

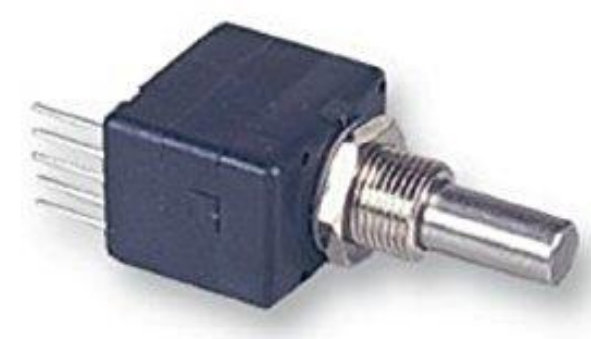

Figure 3.15: Bourns ENC1J <www.bourns.com>.

A controller is required in order to control the motors with integration of the encoders. The controller selected is the RoboteQ brushed DC motor controller MDC2230 [41], which has a maximum output of $30 \mathrm{~V}$ per channel, with two output channels for two motor and two input channels for two encoders. The controller operates on desktop software or using line commands. The user can send commands using software such as MATLAB. Details of the control method will be discussed in details in Chapter 5. The controller will utilize information from the encoders to control the position of the actuators, and in turn the length of the panels, precisely.

The remaining components from the structural and actuation components are the rollers. Misumi Urethane rollers UMJ 35-80 were selected with internal bearings, for ease of assembly [42]. The rollers have an outer diameter of $35 \mathrm{~mm}$, an inner diameter of $10 \mathrm{~mm}$, and a length of $80 \mathrm{~mm}$ to be 
the same width as the flexible panel and MFC assembly. The rollers are selected so that they provide enough friction to hold the panels in place, while allowing them to slide through with sufficient force, enforcing the boundary condition set out in the problem statement, constraining the red points in Figure 3.2. The shafts are also obtained from Misumi pSFHR10-200 rotary shafts [43], with a diameter of $10 \mathrm{~mm}$ to correspond to the rollers and a length of $200 \mathrm{~mm}$, which will make them fit exactly within the aluminum frame.
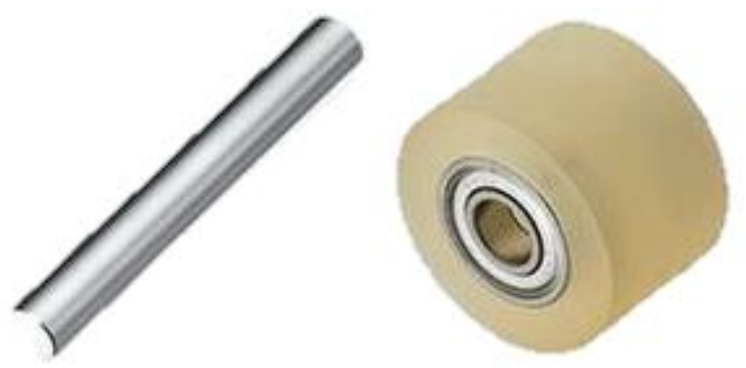

Figure 3.16: Misumi Roller with internal bearing and Shaft 〈https://us.misumi-ec.com〉.

The following sections will discuss the fabrication of the flexible panels, MFC unimorph, and the supports.

\subsubsection{Flexible Panel Fabrication}

In order for the mechanism to function, the skin has to be flexible enough to be bent and deformed. While being able to maintain its shape and support the aerodynamic loads acting on it. The options evaluated are either a thin metallic sheet or a composite material. The composite material is chosen due to the flexibility it offers in terms of fabrication. Since the composite material is going to be laid up in the lab, different material properties, different shapes, and different thicknesses could be achieved. Each different configuration would have a different impact on the results. 
Carbon fiber is chosen as the fiber material and epoxy resin as the matrix, since it is a very popular combination and the main objective is to evaluate the function of the mechanism. The carbon fiber is 9oz IM2 unidirectional carbon fiber obtained from Composites Canada [45]. The epoxy system chosen is the MVS Epoxy 410 plus Hardener 464 (5:1), also obtained from Composites Canada [46]. For the panel fabrication, four layers of Unidirectional CF are used, all in the 0 direction. The resulting thickness of the panel is $1 \mathrm{~mm}$. The thickness plays a vital role in the behaviour of the mechanism. A thicker material offers more strength; however, it requires more force to actuate and it deforms less, thus producing less deflection. Three configurations are fabricated, a $0.5 \mathrm{~mm}, 1 \mathrm{~mm}$, and $1.5 \mathrm{~mm}$ thick panels. The $1 \mathrm{~mm}$ panel is found to have good ability to maintain its shape and good flexibility and thus it is chosen.

The lay-up procedure used is a typical vacuum bagging lay-up, where firstly the 4 carbon fiber sheets are cut to length, from a sheet $12 \times 24$ inches. A metallic plate is used for the lay-up; the surface of the plate is waxed so that the panel does not attach to it. The four sheets are weighed to know the amount of epoxy to be used. The epoxy and hardener are mixed together in the specified ratio and the same weight as the CF was taken, typically this would give a 0.5 ratio, however, due to the vacuum taking out some of the epoxy, the fiber volume fraction of the panel is about 0.6 .

The layers are placed one by one with the epoxy spread all over the sheets, the bottom layers have more epoxy applied, since the vacuum will pull the epoxy towards it, so that not a lot of epoxy is expelled from the laminate. After the four layers are placed on top of one another, a breather fabric is placed on top, so that the laminate would not stick to the bag, and a cloth is placed over the fabric to soak up the excess epoxy. The vacuum bag is placed over the assembly with the valve placed, and is sealed using gum tape. The assembly is kept under -1 atm pressure 
for $24 \mathrm{~h}$ to cure, after it is removed from the vacuum. It is left outside for another $24 \mathrm{~h}$ to fully cure. The sheet obtained was cut into two panels of $400 \mathrm{~mm}$ by $70 \mathrm{~mm}$. All of the experiments performed in this report are done utilizing these panels.

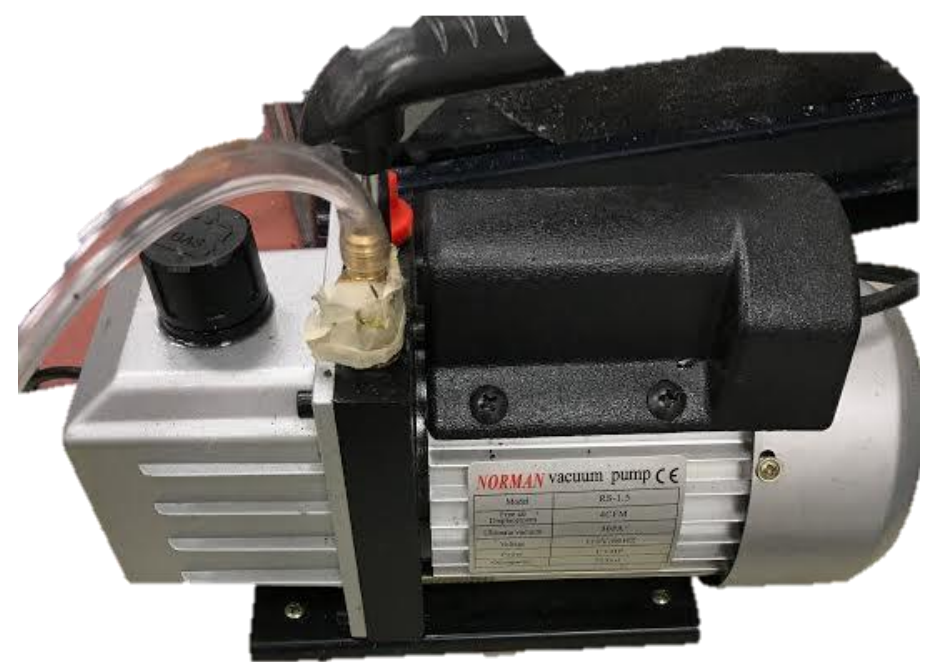

Figure 3.17: Weber Single Stage Vacuum Pump Used.

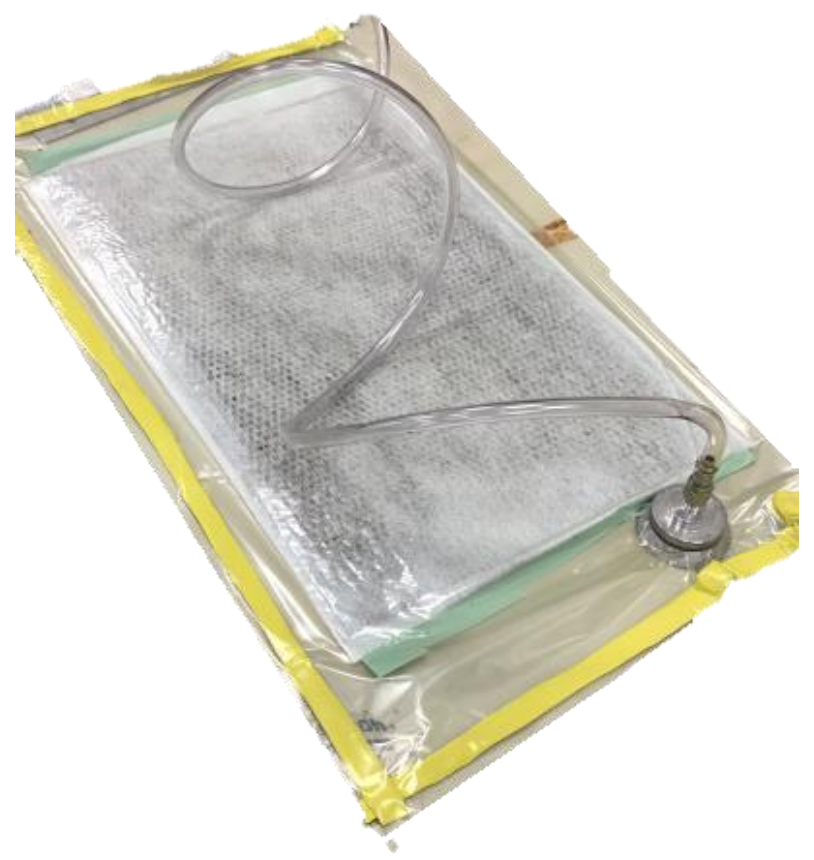

Figure 3.18: The Flexible Panel Assembly During Curing. 
Holes are drilled at both ends to allow for the attachment of the panels to the actuators and the end support. The holes enforce the rigid attachment to the support boundary condition. The flexibility of the panels was found to be a good compromise between strength and flexibility, as they are able to bend easily, while maintaining their shape and not deflecting due to their own weight or the weight of the end support.

\subsubsection{Rigid Support Fabrication}

As discussed before, an end rigid support is required to introduce the coupling factor between the top and bottom panels, thus, provoking a deflection to occur when a change in length is present. This support forms a very important component of the mechanism, since it determines $h_{2}$ and completes the mechanism. After the support is designed using CATIA, several methods of fabrication are suggested, such as machining the support out of aluminum or rapidly prototyping it. Since rapid prototyping is very widespread and cheap it was chosen as the method of fabrication. The first design is printed using PLA at the Digital Media Experience Lab at Ryerson University. The top and bottom parts were printed separately then assembled together for the mechanism. 


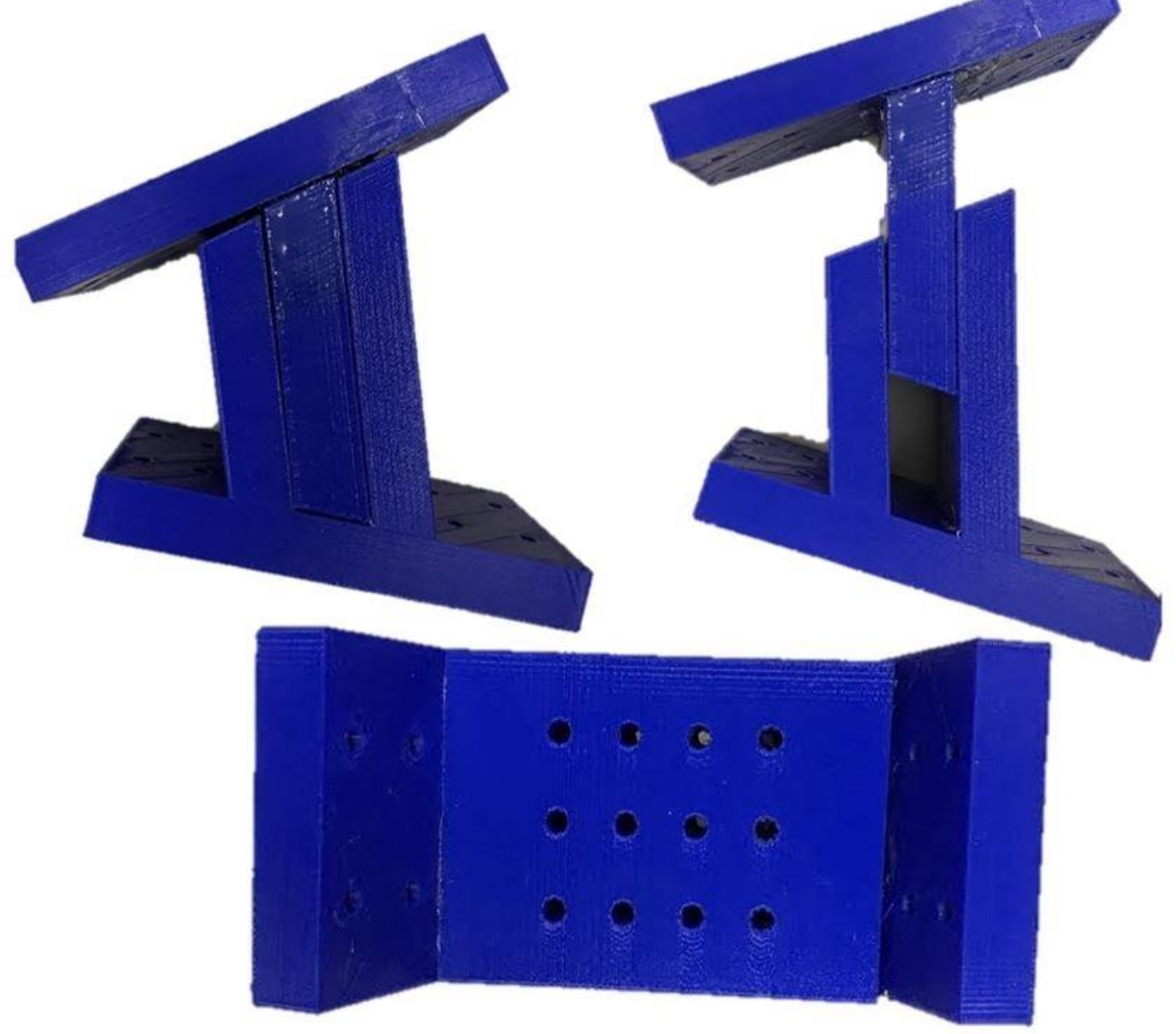

Figure 3.19: The First Iteration of the End Support.

In the design, a middle support which the panel slides on is incorporated, however, that support is removed from the prototype since it was seen unnecessary for the AR values being tested. After running experiments with the support, it was found to be weak especially at the corners, where there was a big stress concentration, affecting the boundary condition. Which is why a second support was designed, this design is composed of a single piece, using round edges. 

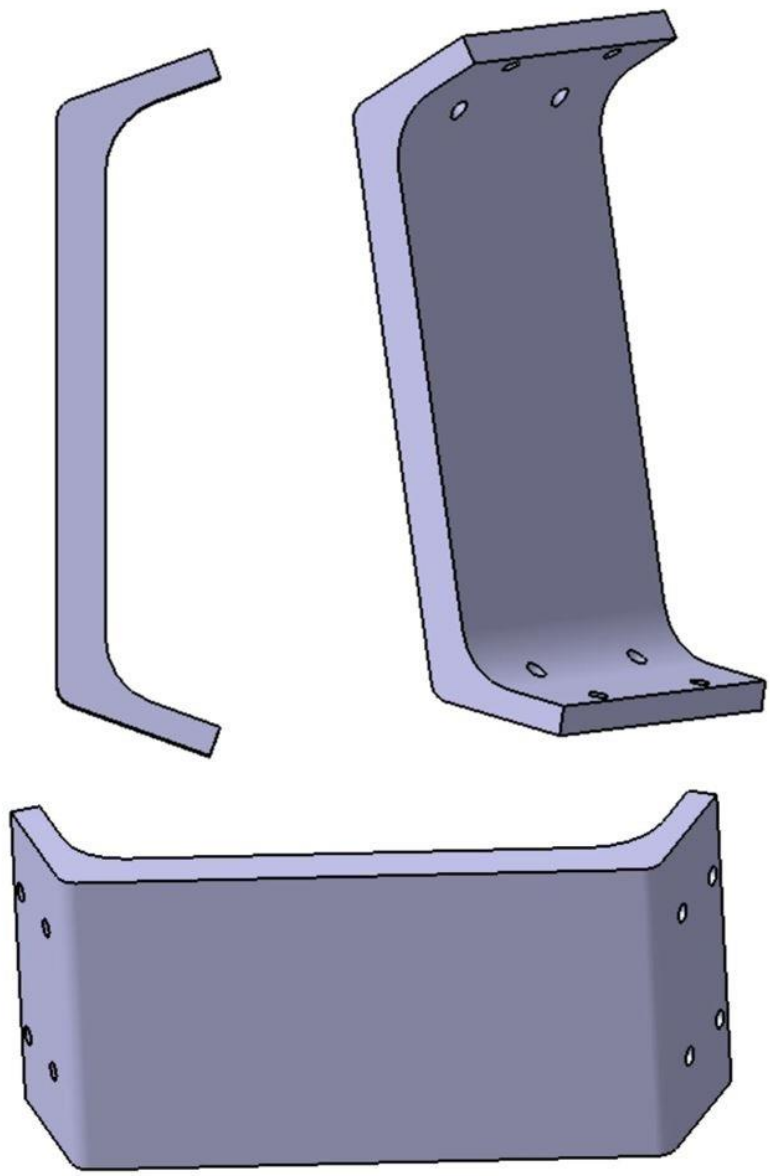

Figure 3.20:Second Support Design.

The second design was then rapidly prototyped at the DME Lab at Ryerson University as well. It is also printed using PLA material, strong enough for the purposes of the experiments performed.

\subsubsection{MFC Unimorph Fabrication}

The MFC patch is obtained from Smart Material Corp. The M8557-P1 is the patch chosen, which is the largest one the company has [44]. As discussed in the literature review, the MFC is able to elongate and contract when voltage is applied to it. The MFC elongates 3 times more than it can contract due to the brittle nature of the piezoelectric fibers. The MFC operates at very high voltages ranging from $+1500 \mathrm{~V}$ to $-500 \mathrm{~V}$. Firstly, the fabrication of the unimorph will be discussed, followed by the electronics responsible for powering and controlling the MFC. 
In order to achieve significant bending from the MFC, a thin substrate must be attached to it in order to make the patch unsymmetric. Thus, when the MFC elongates, the force it introduces will cause a bending moment to act on the MFC and the substrate. The process for fabricating the unimorph followed the procedure used by Pankonien [36]. The substrate is a $25.4 \mu \mathrm{m}$ thick stainless steel shim obtained from McMaster-Carr. The bonding material used to bond the MFC to the shim is Scotch Weld DP-460 Epoxy. The two materials are bonded together in a vacuum bagging procedure, where a stainless-steel shim is cut to a size slightly bigger than the MFC, and then the epoxy was spread on the MFC. The MFC is then placed in the centre of the shim and the assembly is placed in a vacuum bag. A release film and breather fabric are placed on top, the former to make sure that the assembly does not get bonded to the bag and the latter to absorb any excess epoxy. The bag is sealed and kept in a vacuum under about $0.75 \mathrm{~atm}$ of pressure for 24 hours. The vacuum is then turned off and the unimorph is removed.

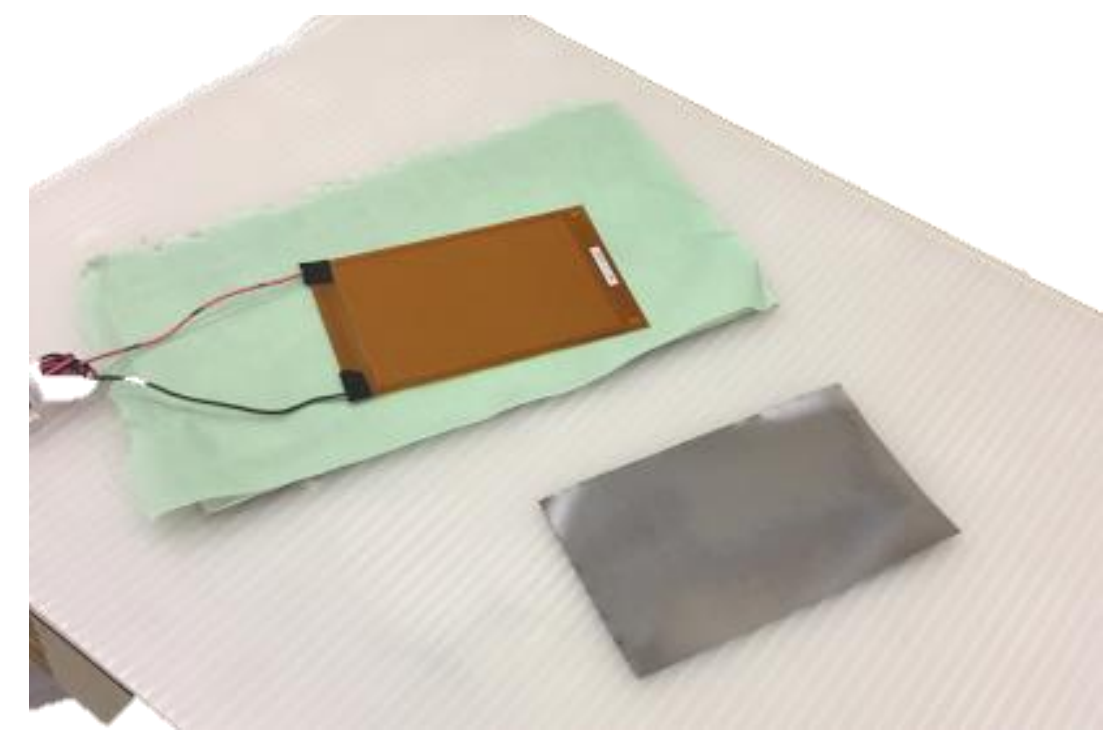

Figure 3.21: Preparing the MFC and SS Shim for lay up. 


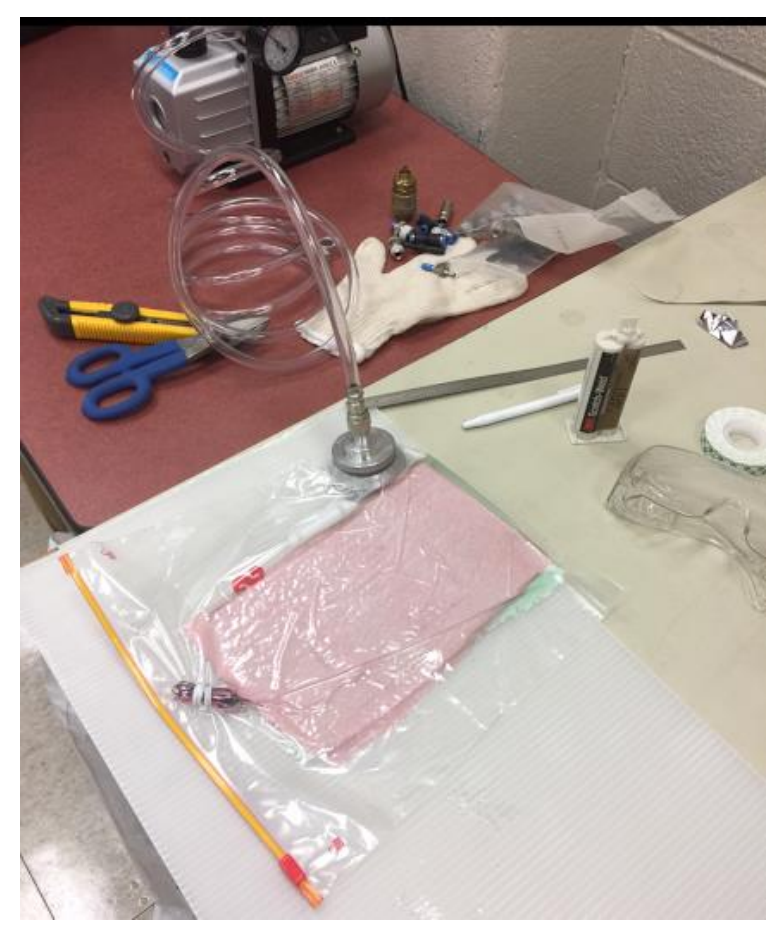

Figure 3.22: Vacuum bagging of unimorph.

In order to operate the newly fabricated unimorph, the MFC actuator requires a high voltage power input and a mean of controlling that voltage in order to achieve different deflections. The first component required was a high voltage amplifier, and the one selected is the AMD2012-CE Dual Output (single MFC channel) Variable Controlled HV Power Supply from Smart Material Corp. The amplifier has dual outputs, one providing a constant $500 \mathrm{~V}$ and the other a variable 0$2 \mathrm{kV}$, for supplying the MFC with $-500 \mathrm{~V}$ up to $1500 \mathrm{~V}$. The voltage supplied can be controlled by supplying the amplifier with voltage from 0-5 volts which corresponds to an output of -500 to 1500 volts respectively. The amplifier needs to be supplied with $12 \mathrm{~V}$ to operate, which can be supplied from a battery. 


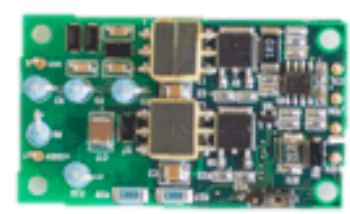

Figure 3.23: AMD2012-CE HV Amplifier 〈www.smart-material.com〉.

Arduino was chosen as the controller board, since it is easy to program. A potentiometer is used to manually vary a $5 \mathrm{~V}$ signal obtained from the Arduino Uno board to the amplifier, thus changing the voltage supplied to the MFC. The circuit diagram is shown below.

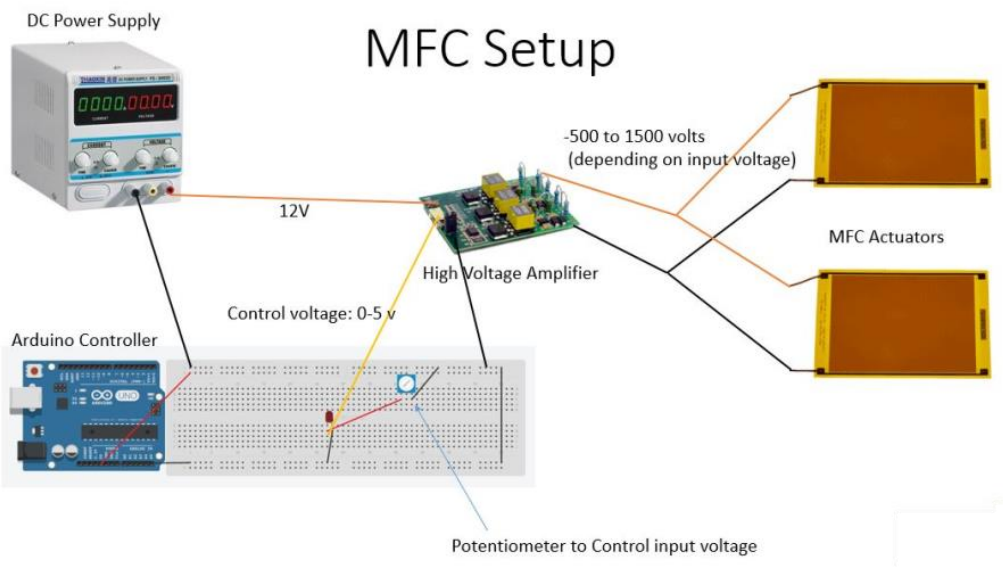

Figure 3.24: Wiring Schematic for Unimorph.

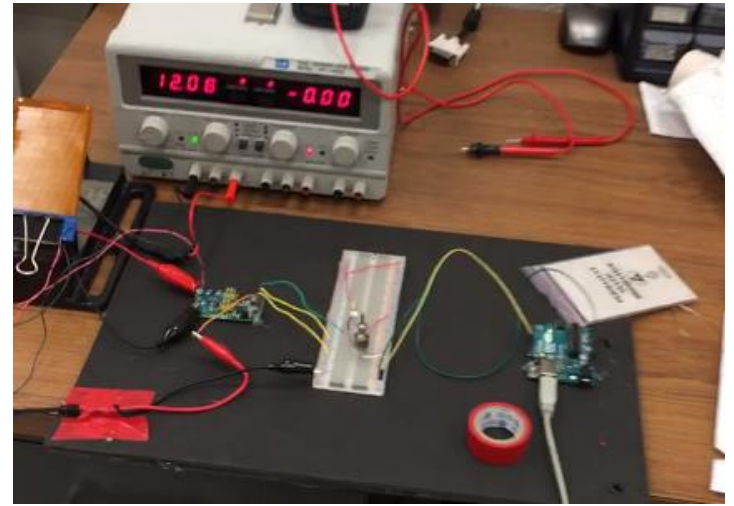

Figure 3.25: Lab set up for Unimorph Circuit. 
Two unimorphs are fabricated and connected to the circuit, to deform the top and bottom tip of the mechanism. Experimental studies showed that during the fabrication process excess epoxy is used, which lead to the unimorph being stiff and the deflection obtained is not very favourable. After evaluating the unimorphs, it is decided that they would be eliminated from the design, since they add more complexity and do not provide a substantial deflection, plus the complexity associated with having extra electronics on board to operate them. This concludes the prototype design and assembly stage and the experimental study can now be performed.
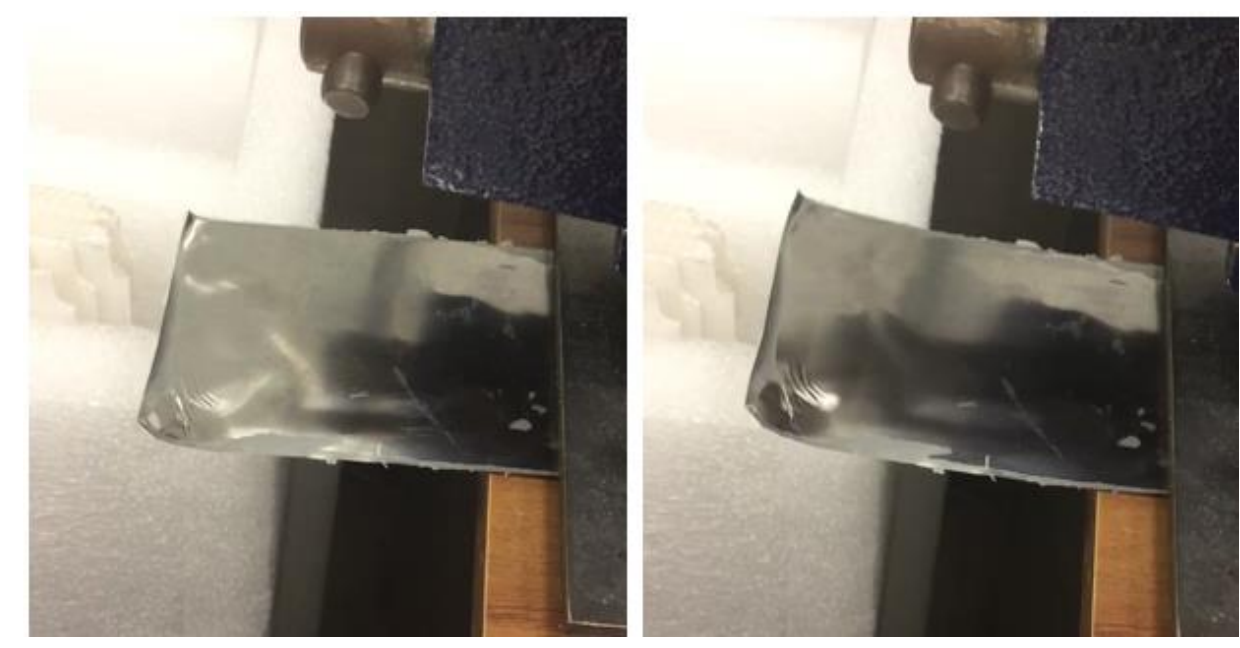

Figure 3.26: Unimorph with -500V supplied (left) and 1500V (right). 


\section{ANALYTICAL AND EXPERIMENTAL STUDY}

After the prototype is successfully designed and built, the next step is to perform the experimental study. The experimental study is performed to establish a forward relation between the input parameters and the output provided. The inputs for the study are the lengths of the top and bottom panels, $\mathrm{L}_{1}$ and $\mathrm{L}_{2}$ respectively. The purpose of the first set of experiments is to see the shape of the panels outputted for different inputs, the deflection, and deflection angle. These output parameters are studied to see if empirical equations can be developed for reverse control. If the shape of the trailing edge can be represented in a function, it would allow a much better control method. According to the aerodynamic conditions, a shape is required. This shape is sent to the controller, which in turn determines the length of the two panels required to produce the desired shape. Thus, providing a reverse control method, based on the experimental data. The first step in the process is to determine if the shape of the panels even can be represented by a function, then the change of this function as a result of different lengths will be looked.

\subsection{Analytical Solution}

Before the experimental study is performed, an analytical solution is explored to see whether the behaviour of the mechanism would have an analytical solution or not. Multiple analyses are attempted to find a solution describing the behaviour of the mechanism, however, due to the complexity of the problem no solution was found. The following analysis is one of the methods attempted. The analysis is started by representing the mechanism in the following configuration: 


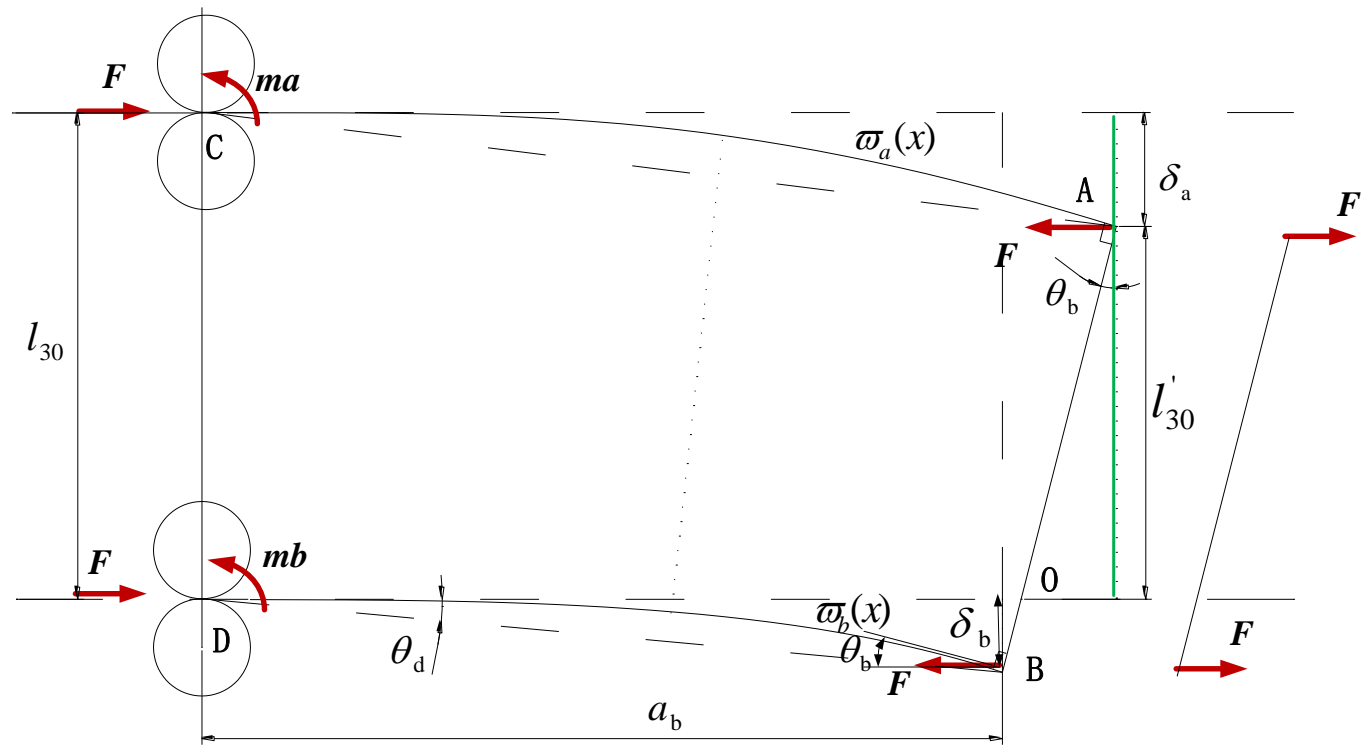

Figure 4.1:Diagram of Mechanism for Analytical Solution.

The mechanism consists of two flexible bars, bars A and B. The bars are constrained in the $\mathrm{y}$ direction using rollers at the root. The two bars are separated by a distance $l_{30}$ and connected to a rigid support at the tip. The assumptions made in this analysis are:

- The weight of the bars is not considered

- The length of bars A and B initially is: $1_{A}+l_{B}=L$

- The distance between the two bars is $1_{30}$

The two bars are undergoing buckling, with the rigid supports reaction force buckling the bars. Analyzing bar A:

The bending moment equation is:

$$
\mathrm{EI} \frac{\mathrm{d}^{2} \omega_{\mathrm{a}}(\mathrm{x})}{\mathrm{dx} \mathrm{x}^{2}}=\mathrm{M}(\mathrm{x})
$$

Where:

$\mathrm{EI}$ is the flexural rigidity;

$\omega_{\mathrm{a}}$ is the shape of bar A;

$\mathrm{M}$ is the bending moment acting on bar A.

And:

$$
\mathrm{M}(\mathrm{x})=\mathrm{m}_{\mathrm{a}}-\mathrm{F} \omega_{\mathrm{a}}
$$

Introducing the notation: 


$$
\mathrm{k}^{2}=\frac{\mathrm{F}}{\mathrm{EI}}
$$

Eq. 4.1 can be rearranged into:

$$
\frac{d^{2} \omega_{a}(x)}{d x^{2}}+k^{2} \omega_{a}(x)=\frac{m_{a}}{E I}
$$

The general solution for this equation is:

$$
\omega_{\mathrm{a}}(\mathrm{x})=\mathrm{C}_{1} \sin \mathrm{kx}+\mathrm{C}_{2} \cos \mathrm{kx}+\frac{\mathrm{m}_{\mathrm{a}}}{\mathrm{F}}
$$

Where $\mathrm{C}_{1}$ and $\mathrm{C}_{2}$ are coefficients which must be determined from the boundary conditions.

Applying the boundary conditions $\mathrm{x}=0,\left.\quad \omega_{\mathrm{a}}(\mathrm{x})\right|_{\mathrm{x}=0}=0$, then:

$$
\mathrm{C}_{2}=-\frac{\mathrm{m}_{\mathrm{a}}}{\mathrm{F}}
$$

applying the boundary conditions $x=0,\left.\frac{d \omega_{a}(x)}{d x}\right|_{x=0}=0$, then:

$$
\mathrm{C}_{1}=0
$$

Thus, it gives:

$$
\omega_{\mathrm{a}}(\mathrm{x})=\frac{\mathrm{m}_{\mathrm{a}}}{\mathrm{F}}(1-\cos \mathrm{kx})
$$

Assuming that at the tip, the bar does not deflect and instead buckles, a third condition exists that $\mathrm{x}=1,\left.\omega_{a}(x)\right|_{x=L}=0$, giving:

$$
\omega_{\mathrm{a}}(\mathrm{L})=\frac{\mathrm{m}_{\mathrm{a}}}{\mathrm{F}}(1-\cos \mathrm{kL})=0
$$

The analysis follows steps taken in [47], which then provides the condition to satisfy eq. 4.9 as:

$\cos \mathrm{kL}=1 \quad \mathrm{~kL}=2 \mathrm{n} \pi, \mathrm{n}=0,1,2 \ldots \ldots$

The lowest critical load for a column with fixed ends is obtained when $\mathrm{n}=1, \mathrm{k}=\frac{2 \pi}{L}$.

Giving the buckled shape of bar A as: 


$$
\omega_{\mathrm{a}}(\mathrm{x})=\frac{\mathrm{m}_{\mathrm{a}}}{\mathrm{F}}\left(1-\cos \frac{2 \pi}{L} \mathrm{x}\right)
$$

The lowest critical load of A bar:

$$
\mathrm{F}_{\mathrm{cr}}=\mathrm{k}^{2} \mathrm{EI}=\frac{4 \pi^{2} \mathrm{EI}}{\mathrm{L}^{2}}
$$

And the rate of change of the deflection is:

$$
\omega_{\mathrm{a}}^{\prime}(\mathrm{x})=\frac{\mathrm{m}_{\mathrm{a}} \mathrm{L}}{2 \pi \mathrm{EI}}\left(\sin \frac{2 \pi}{L} \mathrm{x}\right)
$$

Assuming the bars buckle in the following manner:

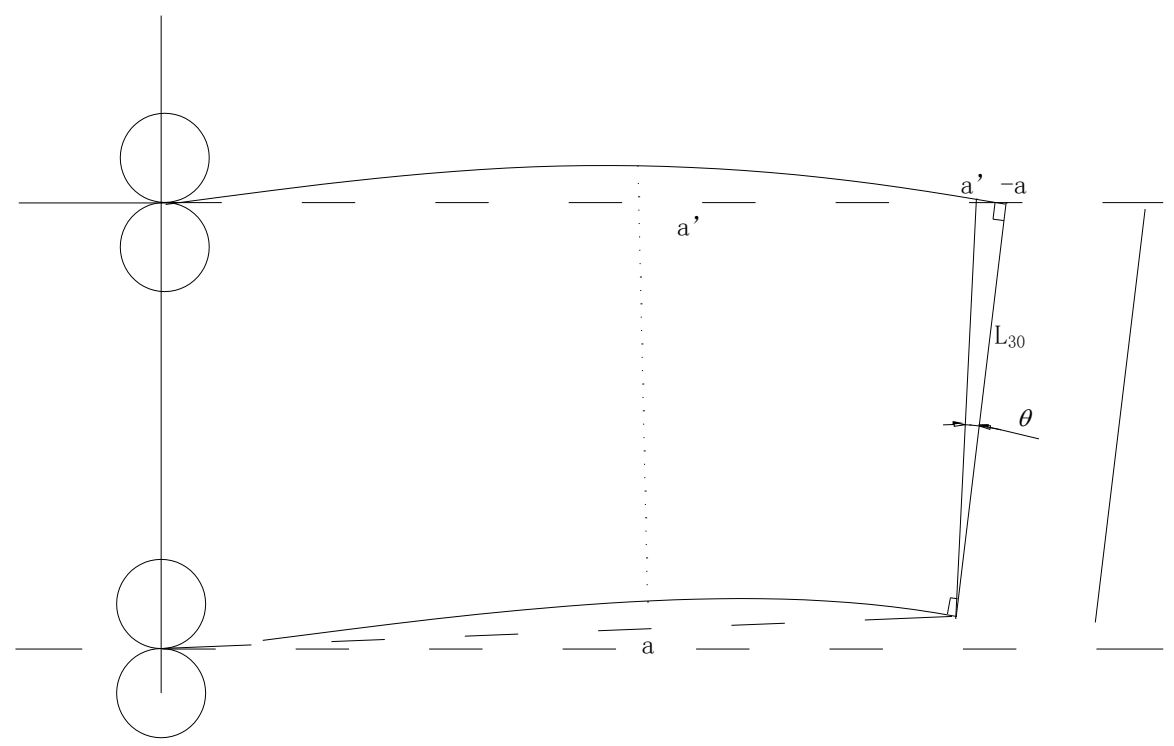

Figure 4.2:Bar Buckling Shape.

The length of bar A will be $\mathrm{L}+\Delta \mathrm{L}$. The chord of bar a will be a', allowing the deflection angle to be obtained using:

$$
\cos \theta=\frac{2 \mathrm{~L}_{30}^{2}-\left(\mathrm{a}^{\prime}-\mathrm{a}\right)^{2}}{2 \mathrm{~L}_{30}^{2}}
$$

In order to determine the chord of bar A using computing the arc length of a function:

$$
\mathrm{L}=\int_{0}^{\mathrm{a} \prime} \sqrt{1+\omega_{\mathrm{a}}^{2}(\mathrm{x})} \mathrm{dx}=\int_{0}^{\mathrm{a} \prime} \sqrt{1+\mathrm{b}^{2} \sin ^{2} \mathrm{kx}} \mathrm{dx}\left(\mathrm{b}=\frac{\mathrm{m}_{\mathrm{a}} \mathrm{L}}{2 \pi \mathrm{EI}}, \mathrm{k}=\frac{2 \pi}{L}\right)
$$


L is the length of bar A which is known. Eq. 4.14 would be solved to find a'. The same process is repeated for bar B to obtain a. However, the method contains a lot of challenges, such as requiring the reaction forces and moments, which are not known. The problem is highly nonlinear. If the force provided is inaccurate the solution might not converge. The problem is a combination of elastic beam buckling and bending, which makes obtaining an analytical solution very difficult. A lot of different approaches are pursued, however, the combination of bending and buckling modes acting on the panels made finding an analytical solution. A visiting scholar from Shenzhen University performed an in-depth study into trying to model the problem analytically. After no viable analytical model was found, an experimental approach is selected. The experimental study will try to use experimental shapes and deflection data to develop empirical equations for deflection and deflection angle predictions based on known panel lengths. Then using these formulations, a reverse control method can be developed to use a known deflection to calculate required panel lengths.

\subsection{Data Acquisition and Digitization}

In order for the analysis to be performed, the data has to be acquired first. In this case, the data required is the shape of the flexible panel, deflection, and deflection angle for different lengths. To digitize the physical shape, a digitizer is required.

\subsubsection{Digitizer}

The digitizer used is the 3D Creator precision optical digitizer, made by Boulders Innovators Group. The digitizer is composed of two parts: the camera bar and the portable probe. The portable probe is used to touch a point to be measurement and the camera is used to measure that point. The measured data are $3 \mathrm{D}$ coordinates $\mathrm{X}, \mathrm{Y}$, and $\mathrm{Z}$ and fed to a computer for data 
processing. The digitizer has an accuracy of $0.001 \mathrm{~mm}$, offering great accuracy to measuring the behaviour of the mechanism [48].

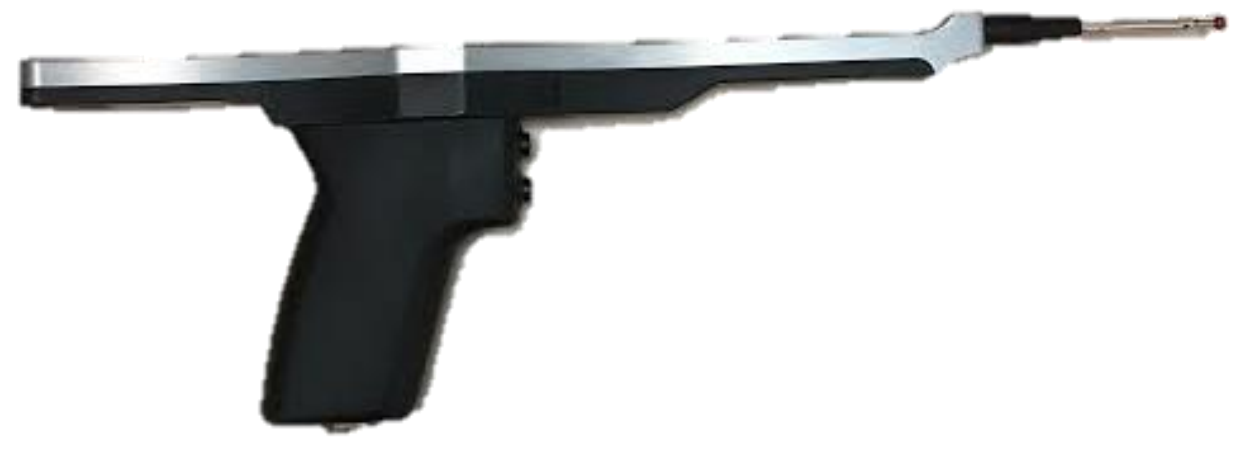

Figure 4.3:The Probe for the 3D Creator.

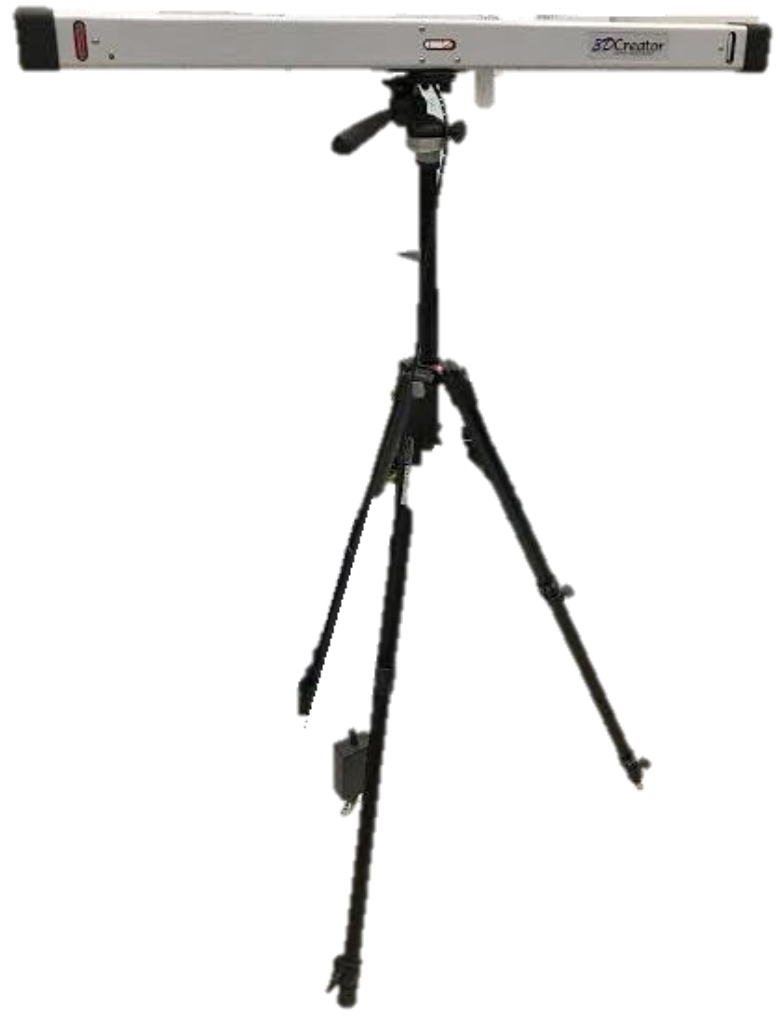

Figure 4.4: The Camera Bar for the 3D Creator. 


\subsubsection{Data Collection}

In order to collect usable data, a system has to be established in order to collect reliable and usable points. Since the data consists of $x, y$, and $z$ coordinates for the entire surface, the data being collected are excessive. Each experiment consists of scanning the shape of the top and bottom flexible panels at several lengths, modified by varying the length of the top panel. Each increment corresponds to a new position which is digitized separately. Note that the length of the bottom panel is not changed during an experiment. At first both panels are the same length, then the length of the top panel is increased in increments until the length desired is obtained.

The first point marked is a fixed point on the frame's corner, which serves as a reference point for the coordinates and will be used as the origin with all the coordinates normalized with respect to it. The second point marked is the starting point of the top panel, third point is the starting point of the bottom panel, fourth point is the end of the top panel, and the fifth point is the end of the bottom panel. 


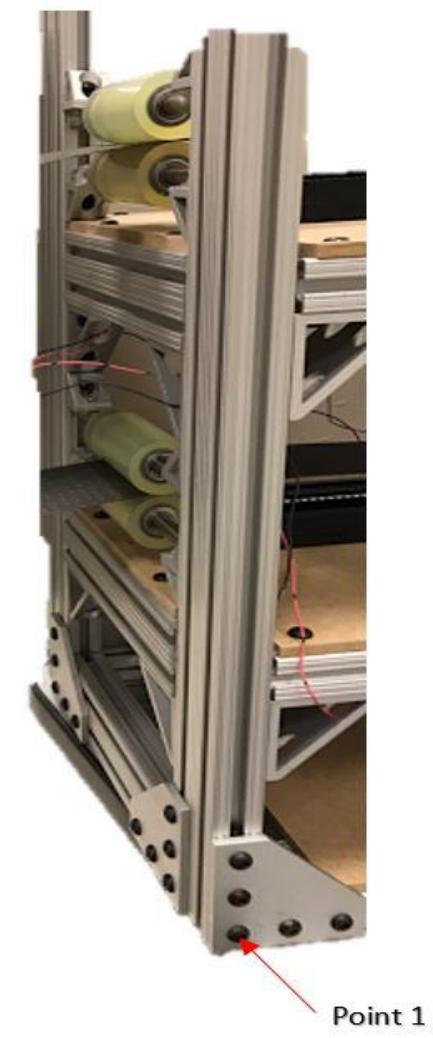

Figure 4.5:Location of Point Used as Reference.

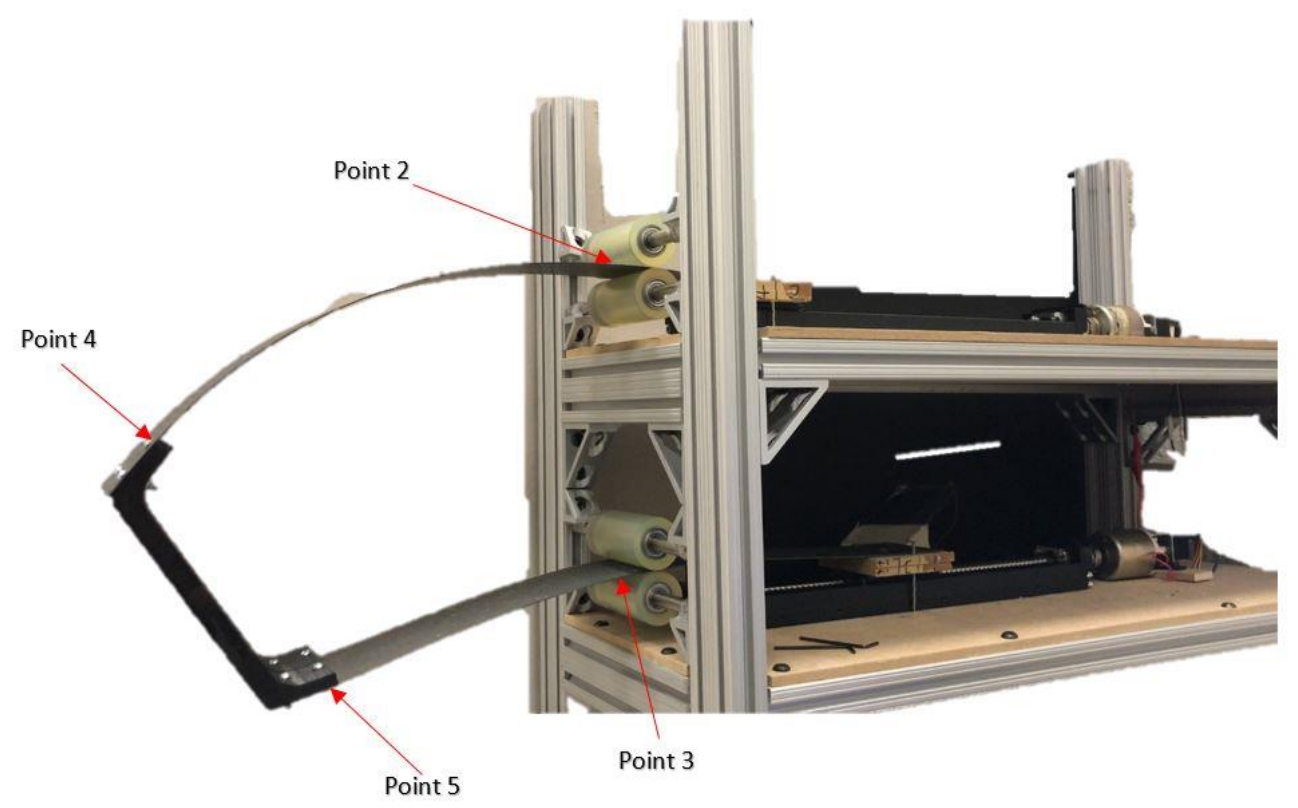

Figure 4.6:Location of Points. 
Figure 4.5 and Figure 4.6 provide a visual representation of the location of the first five points. After the five points have been taken, the probe is placed at the beginning of the top panel and moved towards the end. The probe then is placed on the bottom panel and moved along it, obtaining data for both panels. For each increment this procedure is repeated 2-5 times to obtain a lot of data points in order to achieve more accurate results and limit variations associated with sources of error.

\subsection{Experimentation and Analysis}

In order to obtain results, multiple experiments have to be performed on the prototype and the results from all the experiments analyzed together. The different experiments performed will be discussed, followed by the analysis method.

\subsubsection{Experiments}

In total, five experiments are performed on the flexible trailing edge apparatus. The difference between each one is the length of the bottom panel, which remains fixed, essentially changing the chord length. With each experiment, the bottom panel is held fixed while the top one starts off as the same length and then increased in increments to obtain deflection. Essentially, testing a different aspect ratio for each experiment, while, fixing $h_{1}$ and $h_{2}$. As mentioned before, data is collected 2-5 times for each increment to obtain a good average of the shape. 
Table 4-1:Description of the Experiments Performed.

\begin{tabular}{|c|c|c|c|c|c|}
\hline Experiment & $\mathbf{1}$ & $\mathbf{2}$ & $\mathbf{3}$ & $\mathbf{4}$ & $\mathbf{5}$ \\
\hline $\begin{array}{c}\text { Bottom Panel } \\
\text { Length (mm) }\end{array}$ & 100 & 135 & 180 & 225 & 260 \\
\hline $\begin{array}{c}\text { Top Panel } \\
\text { Length (mm) }\end{array}$ & $100-200$ & $135-275$ & $180-260$ & $225-305$ & $260-340$ \\
\hline Increments (mm) & 20 & 10 & 20 & 20 & 20 \\
\hline
\end{tabular}

Table 4-1 provides an in-depth description of the experiments performed, describing the length at which both of the panels start off with and then the increments by which the top panel is increased, and its final length. For each increment of the different experiment, 2-5 different readings are obtained. In terms of aspect ratios tested, the experiments are:

Table 4-2:Experiments in Terms of Aspect Ratio.

\begin{tabular}{|c|c|c|c|c|c|}
\hline Experiment & 1 & 2 & 3 & 4 & 5 \\
\hline Aspect Ratio & $0.5-1$ & $0.675-1.375$ & $0.9-1.3$ & $1.125-1.525$ & $1.3-1.7$ \\
\hline
\end{tabular}

\subsubsection{Analysis}

The previous section discusses the experiments performed. As one can expect, a lot of points are obtained for the different experiments. In order to make the analysis easier, a MATLAB code is written to perform the analysis required by taking the input from the text files generated by the data readings. Table 4-3 provides a sample of the raw data obtained by the $3 \mathrm{D}$ creator, which must be manipulated before it could be utilized in the analysis. 
Table 4-3:Sample of the Data Collected.

\begin{tabular}{|c|c|c|}
\hline $\mathbf{X}$ & $\mathbf{Y}$ & $\mathbf{Z}$ \\
\hline-5.142375 & 240.0332 & -1740.696 \\
\hline-15.15553 & 239.8039 & -1737.772 \\
\hline-26.72901 & 239.4873 & -1732.398 \\
\hline-39.82606 & 238.8623 & -1726.983 \\
\hline-55.54788 & 237.3888 & -1725.389 \\
\hline-69.98188 & 235.6687 & -1720.938 \\
\hline-78.84975 & 234.4065 & -1719.584 \\
\hline-91.59101 & 232.1355 & -1715.034 \\
\hline-103.2936 & 229.7053 & -1710.824 \\
\hline-111.9109 & 227.7136 & -1706.656 \\
\hline-117.2121 & 226.2343 & -1706.606 \\
\hline-122.1896 & 224.9409 & -1705.544 \\
\hline
\end{tabular}

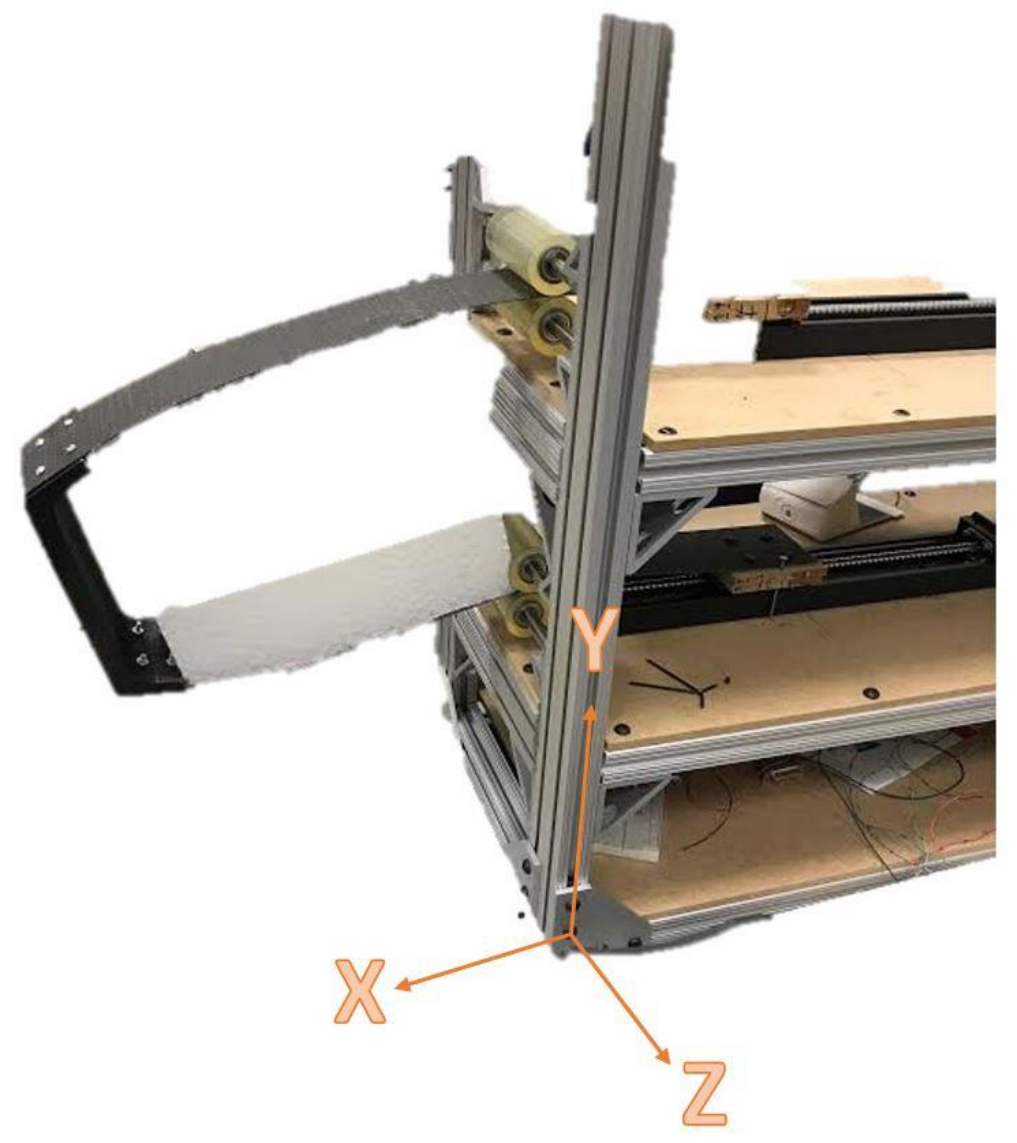

Figure 4.7:Coordinate System. 
In order to utilize the raw data collected using the digitizer, several adjustments must be made. The full script of the MATLAB code can be found in the appendices. For each experiment, the data is organized in matrices and undergoes several transformations before it is utilized for the study. The reference point coordinates are stored in the following matrices for $\mathrm{n}$ number of points:

$$
\begin{aligned}
& \mathrm{R}_{\mathrm{x}}=\left[\begin{array}{lll}
\mathrm{R}_{\mathrm{x} 1} & \ldots & \mathrm{R}_{\mathrm{xn}}
\end{array}\right] \\
& \mathrm{R}_{\mathrm{y}}=\left[\begin{array}{llll}
\mathrm{R}_{\mathrm{y} 1} & \ldots & \mathrm{R}_{\mathrm{yn}}
\end{array}\right]
\end{aligned}
$$

$\mathrm{R}_{\mathrm{x}}$ and $\mathrm{R}_{\mathrm{y}}$ correspond to the $\mathrm{X}$ and $\mathrm{Y}$ coordinates of the reference point respectively.

The reference point coordinates are then averaged to obtain a single value, since multiple readings were obtained:

$$
\begin{aligned}
& R_{\text {avgX }}=\frac{1}{n} \sum_{i=1}^{n} R_{x i} \\
& R_{\text {avgY }}=\frac{1}{n} \sum_{i=1}^{n} R_{y i}
\end{aligned}
$$

The data for the shape of the panels are organized as follows, for each increment of $\Delta \mathrm{L}$ :

$$
\begin{aligned}
& X_{\text {Top }}=\left[\begin{array}{lll}
X_{\text {Top } 1} \ldots & X_{\text {Topn }}
\end{array}\right] \\
& Y_{\text {Top }}=\left[\begin{array}{lll}
Y_{\text {Top } 1} \ldots & Y_{\text {Topn }}
\end{array}\right] \\
& X_{\text {Bot }}=\left[\begin{array}{lll}
X_{\text {Bot1 } 1} \ldots & X_{\text {Botn }}
\end{array}\right] \\
& Y_{\text {Bot }}=\left[\begin{array}{lll}
Y_{\text {Bot1 }} & \ldots & Y_{\text {Botn }}
\end{array}\right]
\end{aligned}
$$

Where: $\mathrm{X}_{\text {Top }}$ contains the $\mathrm{X}$ coordinates of the top panel; $\mathrm{Y}_{\text {Top }}$ contains the $\mathrm{Y}$ coordinates of the top panel; $\mathrm{X}_{\mathrm{Bot}}$ contains the $\mathrm{X}$ coordinates of the bottom panel; $\mathrm{Y}_{\mathrm{Bot}}$ contains the $\mathrm{Y}$ coordinates of the bottom panel. 
The data for the location of the end support is organized as

$$
\begin{aligned}
& \mathrm{E}_{\mathrm{TopX}}=\left[\begin{array}{l|ll}
\mathrm{E}_{\mathrm{TopX} 1} \ldots & \mathrm{E}_{\mathrm{TopXn}}
\end{array}\right] \\
& E_{\mathrm{TopY}}=\left[\begin{array}{l}
E_{\mathrm{TopY} 1} \ldots \mathrm{E}_{\mathrm{TopYn}}
\end{array}\right] \\
& \mathrm{E}_{\mathrm{BotX}}=\left[\begin{array}{l}
\mathrm{E}_{\mathrm{BotX} 1} \ldots \mathrm{E}_{\mathrm{BotXn}}
\end{array}\right] \\
& E_{\mathrm{Bot}} \mathrm{Y}=\left[\begin{array}{l}
\mathrm{E}_{\mathrm{Bot} Y 1} \ldots \mathrm{E}_{\mathrm{Bot} Y \mathrm{n}}
\end{array}\right]
\end{aligned}
$$

The average of the readings is then taken:

$$
\begin{aligned}
& E_{\text {avgTopX }}=\frac{1}{n} \sum_{i=1}^{n} E_{\text {TopXi }} \\
& E_{\text {avgTopY }}=\frac{1}{n} \sum_{i=1}^{n} E_{\text {TopYi }} \\
& E_{\text {avgBotX }}=\frac{1}{n} \sum_{i=1}^{n} E_{\text {BotXi }} \\
& E_{\text {avgBotY }}=\frac{1}{n} \sum_{i=1}^{n} E_{\text {BotYi }}
\end{aligned}
$$

In order to use the data, it must be normalized with regards to the reference point, which is established as the origin, coinciding with the coordinate system established in Figure 4.7. The normalization involves taking the data and subtracting from it the coordinates of the reference point, therefore, establishing it as the origin. The values are multiplied by negative one to align them with the established coordinate system. The data is normalized using:

$$
\begin{gathered}
X_{T}=-\left(X_{\text {Top }}-R_{a v g X}\right) \\
Y_{T}=-\left(Y_{\text {Top }}-R_{a v g Y}\right) \\
X_{B}=-\left(X_{\text {Bot }}-R_{\text {avgX }}\right) \\
Y_{B}=-\left(Y_{\text {Bot }}-R_{\text {avgY }}\right) \\
E_{T X}=-\left(E_{\text {avgTopX }}-R_{\text {avg }}\right) \\
E_{T Y}=-\left(E_{\text {avgTop }}-R_{\text {avgY }}\right)
\end{gathered}
$$




$$
\begin{aligned}
& E_{B X}=-\left(E_{\text {avgBotX }}-R_{a v g} X\right) \\
& E_{B Y}=-\left(E_{\text {avgBotY }}-R_{\text {avgY }}\right)
\end{aligned}
$$

Now the data can be used to analyze the behaviour of the mechanism. The data is then plotted and then using linear least square method, the data is curve fitted. The method for which is outlined in [49], which describes using a linear method to find the fit. Supposedly a linear line is fit to the $\mathrm{X}$ and $\mathrm{Y}$ data obtained in Eq. 4.31 and 4.32. The slope of that line can be found using:

$$
\text { Slope }=\frac{n \sum_{i=1}^{n} X_{T i} Y_{T i}-\sum_{i=1}^{n} X_{T i} \sum_{i=1}^{n} Y_{T i}}{n \sum_{i=1}^{n} X_{T i}^{2}-\left(\sum_{i=1}^{n} X_{T i}\right)^{2}}
$$

And the intercept can be found using:

$$
\text { Intercept }=\frac{1}{n}\left(\sum_{i=1}^{n} Y_{T i}-\text { Slope } \sum_{i=1}^{n} X_{T i}\right)
$$

Due to the nonlinear nature of the shape, $2^{\text {nd }}$ degree polynomials are used to represent the shape of the deformation of the panels. Higher order polynomials will have oscillations, thus not applicable to represent the morphing shape under study. Now that for each difference in length $(\Delta \mathrm{L})$ between the panels a polynomial exists, the coefficients from the generated polynomials are extracted. A $2^{\text {nd }}$ degree polynomial has the following format:

$$
\mathrm{y}=\mathrm{Ax} \mathrm{x}^{2}+\mathrm{Bx}+\mathrm{C}
$$

Where $\mathrm{x}$ and $\mathrm{y}$ are the coordinates of the points, defined in the coordinate system in Figure 4.7. The A, B, and C coefficients for all the different $\Delta \mathrm{L}$ 's for the top panels and bottom panel are now compiled into matrices separately. The coefficients for the top panel are stored in $\left[\mathrm{A}_{\mathrm{t}}\right],\left[\mathrm{B}_{\mathrm{t}}\right]$, and $\left[\mathrm{C}_{\mathrm{t}}\right]$ while the coefficients for the bottom panel in $\left[\mathrm{A}_{b}\right],\left[\mathrm{B}_{\mathrm{b}}\right]$, and $\left[\mathrm{C}_{b}\right]$. A polynomial is then fitted to each of the six coefficients, which results in six different functions, each describing its corresponding coefficient as a function of $\Delta \mathrm{L}$. The result would allow for obtaining the shape of the top and bottom panels based on the inputs of the two panel lengths. 
Equations 4.35-4.38 provide the coordinates for the end support for each increment of $\Delta \mathrm{L}$. Populating four matrices with the results will give the coordinates of the support for the entire experiment. These matrices are defined as:

$$
\begin{aligned}
\mathrm{S}_{\mathrm{TX}} & =\left[\begin{array}{lll}
\mathrm{E}_{\mathrm{TX} 1} & \ldots & \mathrm{E}_{\mathrm{TX}}
\end{array}\right] \\
\mathrm{S}_{\mathrm{TY}} & =\left[\begin{array}{lll}
\mathrm{E}_{\mathrm{TY} 1} & \ldots & \mathrm{E}_{\mathrm{TY}}
\end{array}\right] \\
\mathrm{S}_{\mathrm{BX}} & =\left[\begin{array}{lll}
\mathrm{E}_{\mathrm{BX} 1} & \ldots & \mathrm{E}_{\mathrm{BX}}
\end{array}\right] \\
\mathrm{S}_{\mathrm{BY}} & =\left[\begin{array}{llll}
\mathrm{E}_{\mathrm{BY} 1} & \ldots & \mathrm{E}_{\mathrm{BY}}
\end{array}\right]
\end{aligned}
$$

Where $\mathrm{j}$ is the number of increments of $\Delta \mathrm{L}$ for that experiment.

In order to calculate the tip deflection, the change in the $\mathrm{Y}$ position of the midpoint of the end support is used. This change which represents the deflection $(\delta)$ can be found for each increment using:

$$
\delta_{j}=\left(\frac{S_{T Y j}+S_{B Y j}}{2}\right)-\left(\frac{S_{T Y 1}+S_{B Y 1}}{2}\right)
$$

$[\delta]$ is now populated with the deflection values for the experiment. The data is fitted in the same manner mentioned above to obtain a function relating the deflection to $\Delta \mathrm{L}$. The deflection angle $(\theta)$ can be calculated using the coordinates of the end support. Looking at the following figure: 


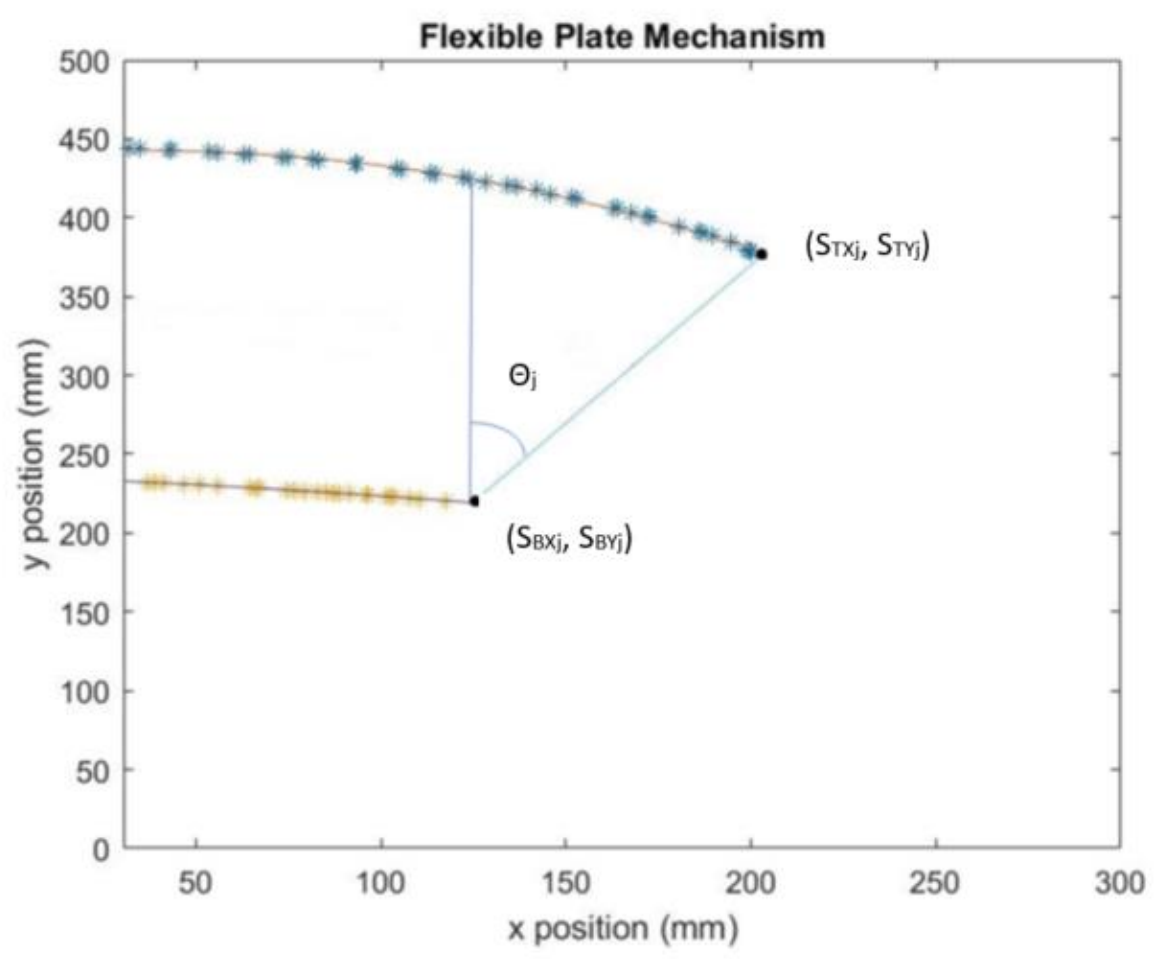

Figure 4.8:Deflection Angle.

It is evident that using trigonometric properties, the deflection theta for each increment $\left(\theta_{\mathrm{j}}\right)$ can be calculated using:

$$
\theta_{j}=\tan ^{-1}\left(\frac{S_{T X j}-S_{B X j}}{S_{T Y j}-S_{B Y j}}\right)
$$

\subsection{Results}

The results obtained from the five experiments will be presented and discussed in the subsequent sections. The first section deals with fitting a 2nd degree polynomial to the shape data collected for the deflections and deflection angles.

\subsubsection{Shape Results and Curve Fitting}

The results from each experiment are plotted and the points are curve fitted with a 2nd degree polynomial. The reason a 2 nd degree polynomial is used is because it was found to fit the data the best. Table 4-1 contains the details of the individual experiments performed. The experiments 
are performed by setting $\mathrm{L}_{2}$ value and incrementally increasing the difference in length, until the limit was reached based on the capabilities of the two panels. If more length is introduced, the panel connection with the support would have failed.

\section{Experiment 1}
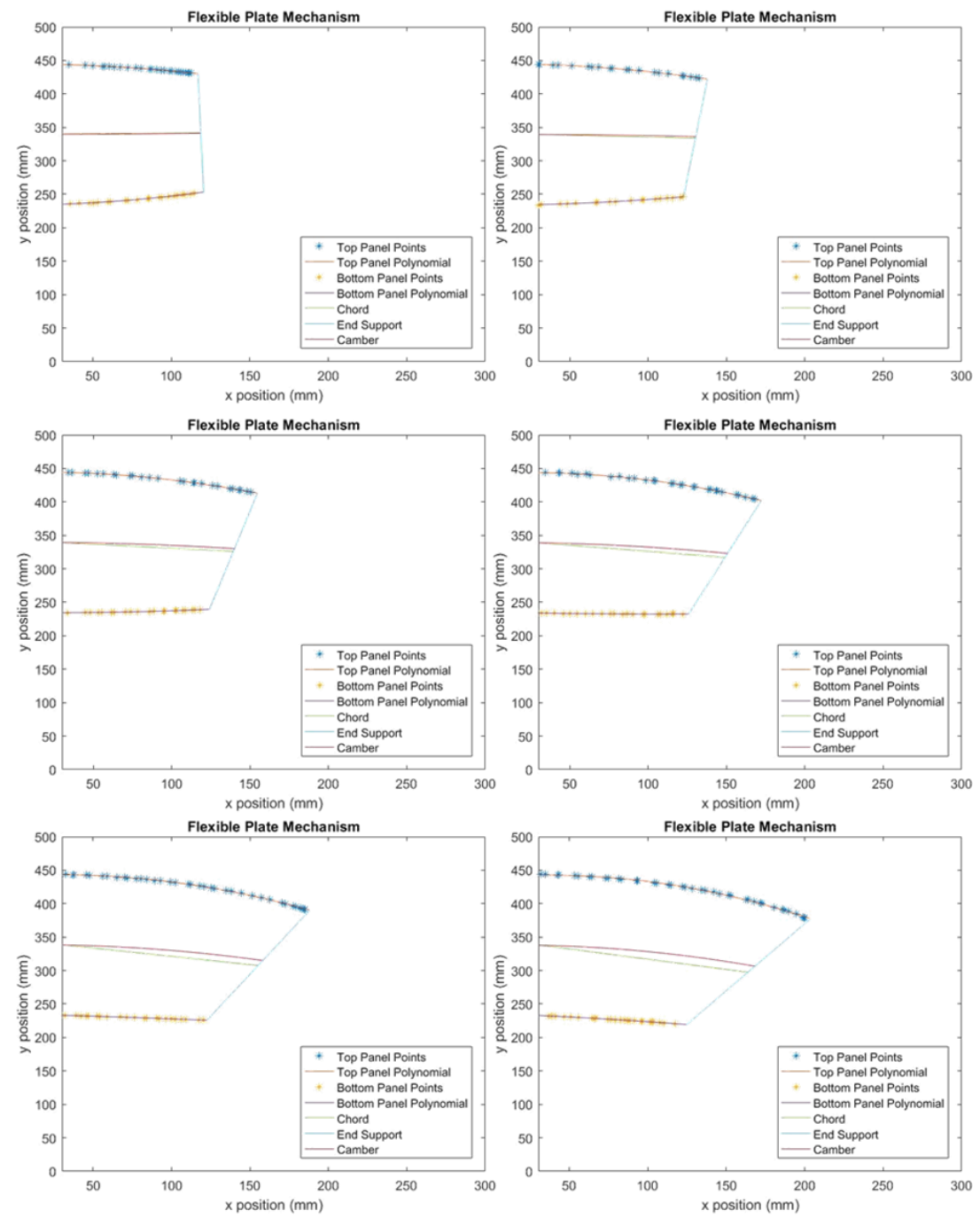

Figure 4.9:Shape Results of Experiment 1.

Figure 4.9 provides the digitization and curve fitting for experiment 1 . Each subplot presents a different $\Delta \mathrm{L}$ value, showing the shape of the mechanism. As $\Delta \mathrm{L}$ is increased, it is evident that the mechanism deflects downwards and rotates, producing an angle. 


\section{Experiment 2}
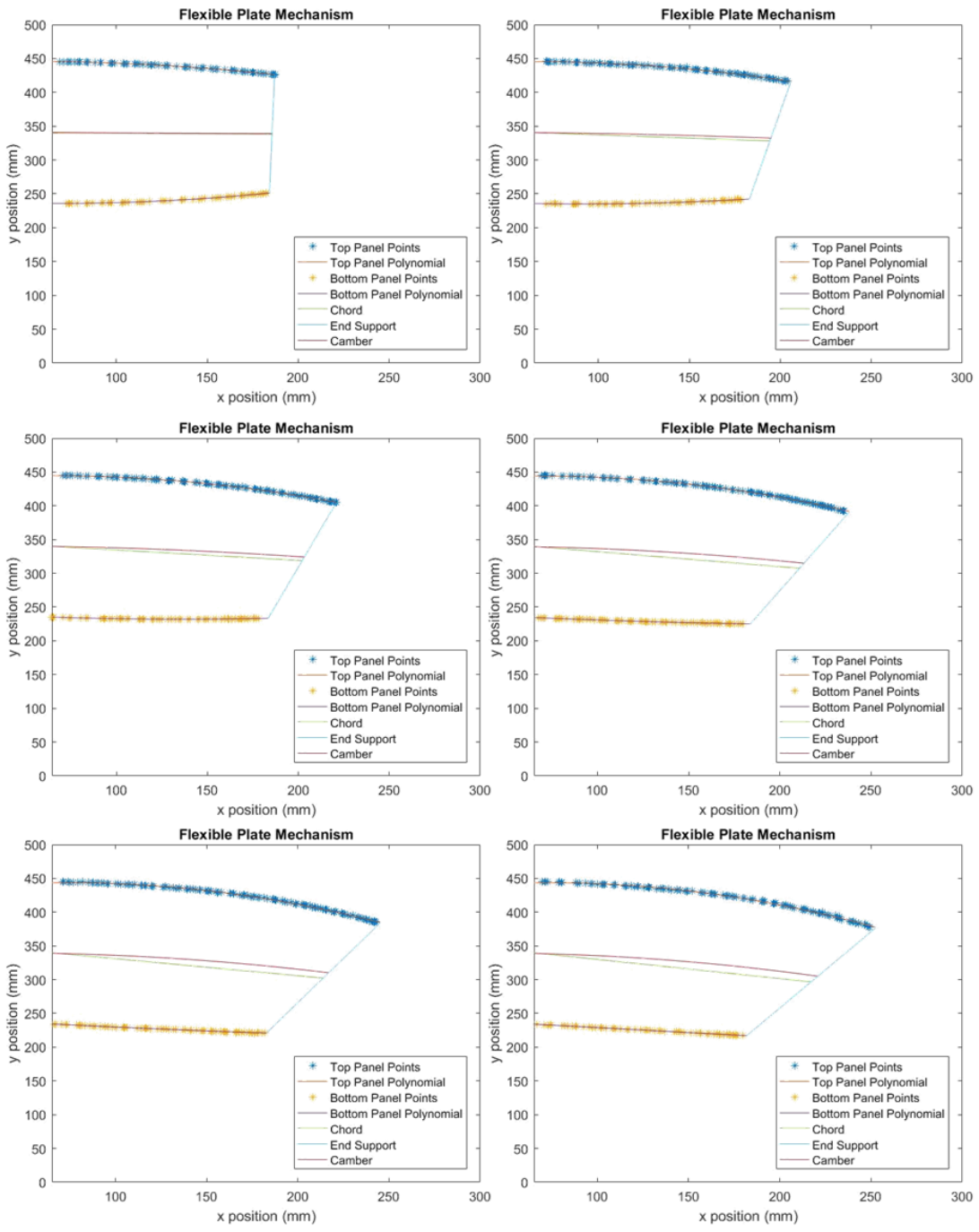

Figure 4.10: Shape Results of Experiment 2 Part 1. 

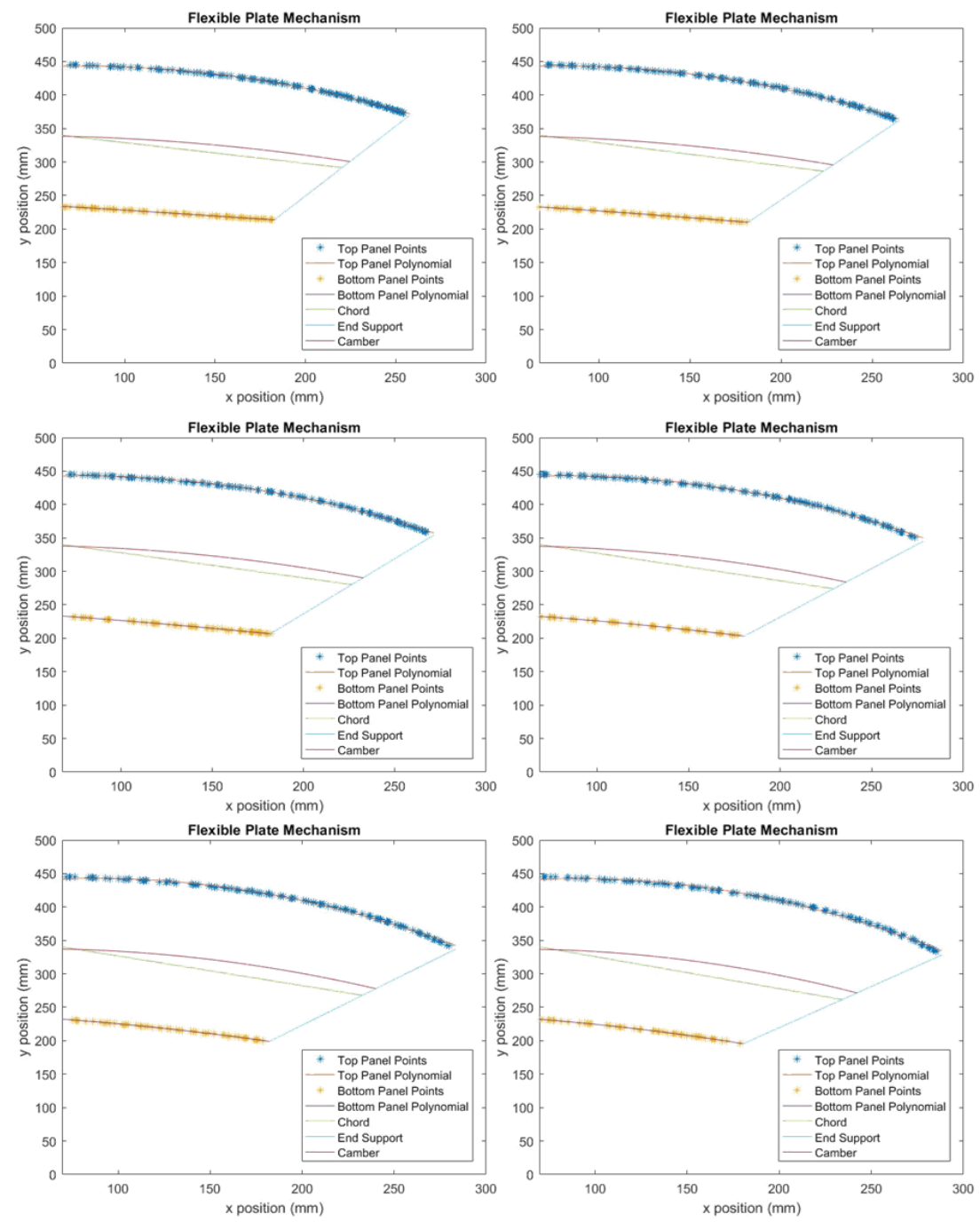

Figure 4.11: Shape Results of Experiment 2 Part 2.

Experiment 2 shows the same trend as experiment 1 . As the change in length is increased, so do the deflection and deflection angle. Note that for the experiments, $\Delta \mathrm{L}$ is not increased to the maximum value, to ensure the panels did not break at the connection with the rigid support. Due to the high stress concentration. An increase of stress in that region will lead to the panel breaking from the support, which in turn violates the set boundary condition in Figure 3.2. 


\section{Experiment 3}
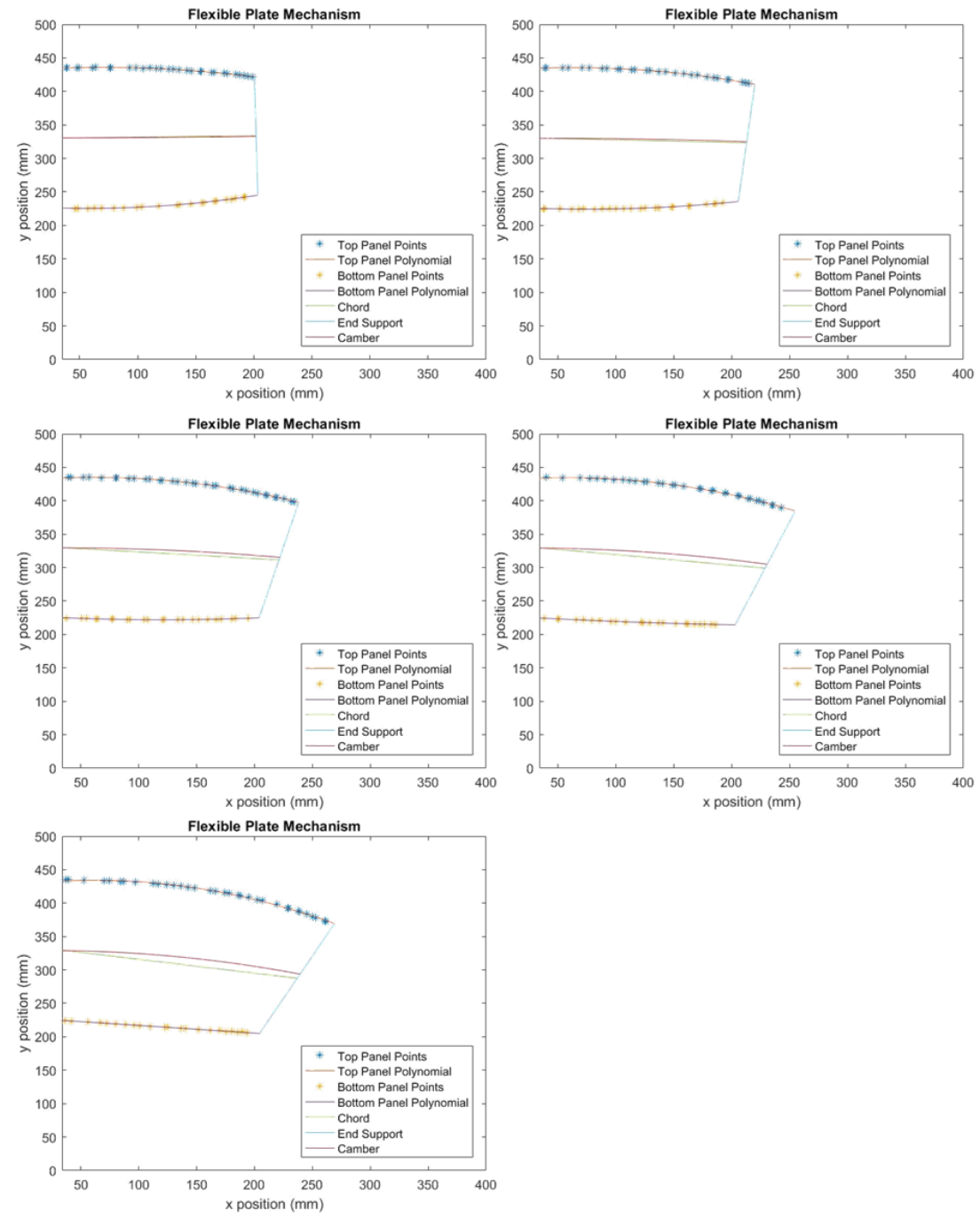

Figure 4.12: Shape Results of Experiment 3.

As $\Delta \mathrm{L}$ increases, the top panel exerts a force on the support, which in turn produces a reaction force onto the bottom panel. If the difference in length increases beyond a certain threshold, it will cause failure at the attachment point. 


\section{Experiment 4}
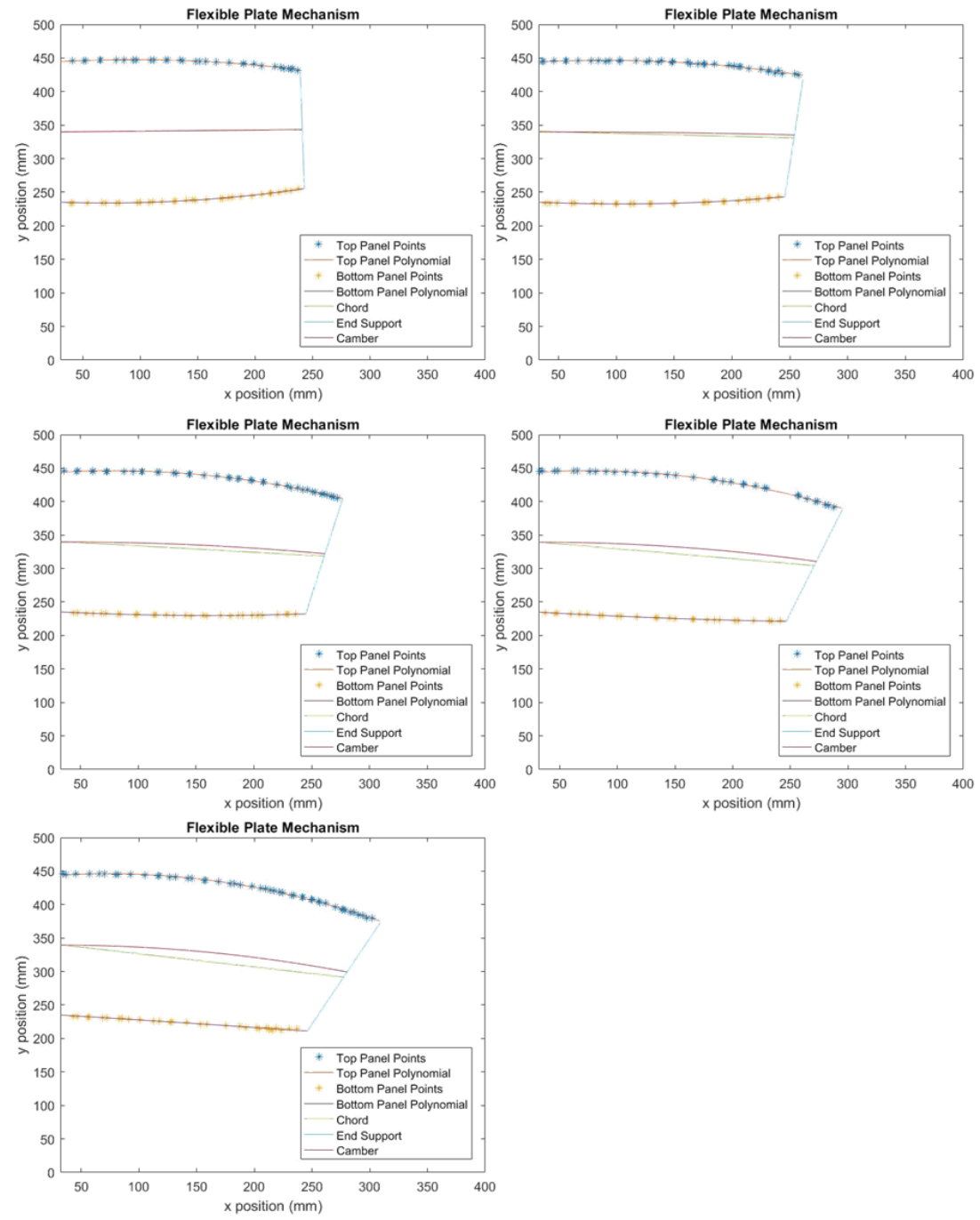

Figure 4.13: Shape Results of Experiment 4. 


\section{Experiment 5}
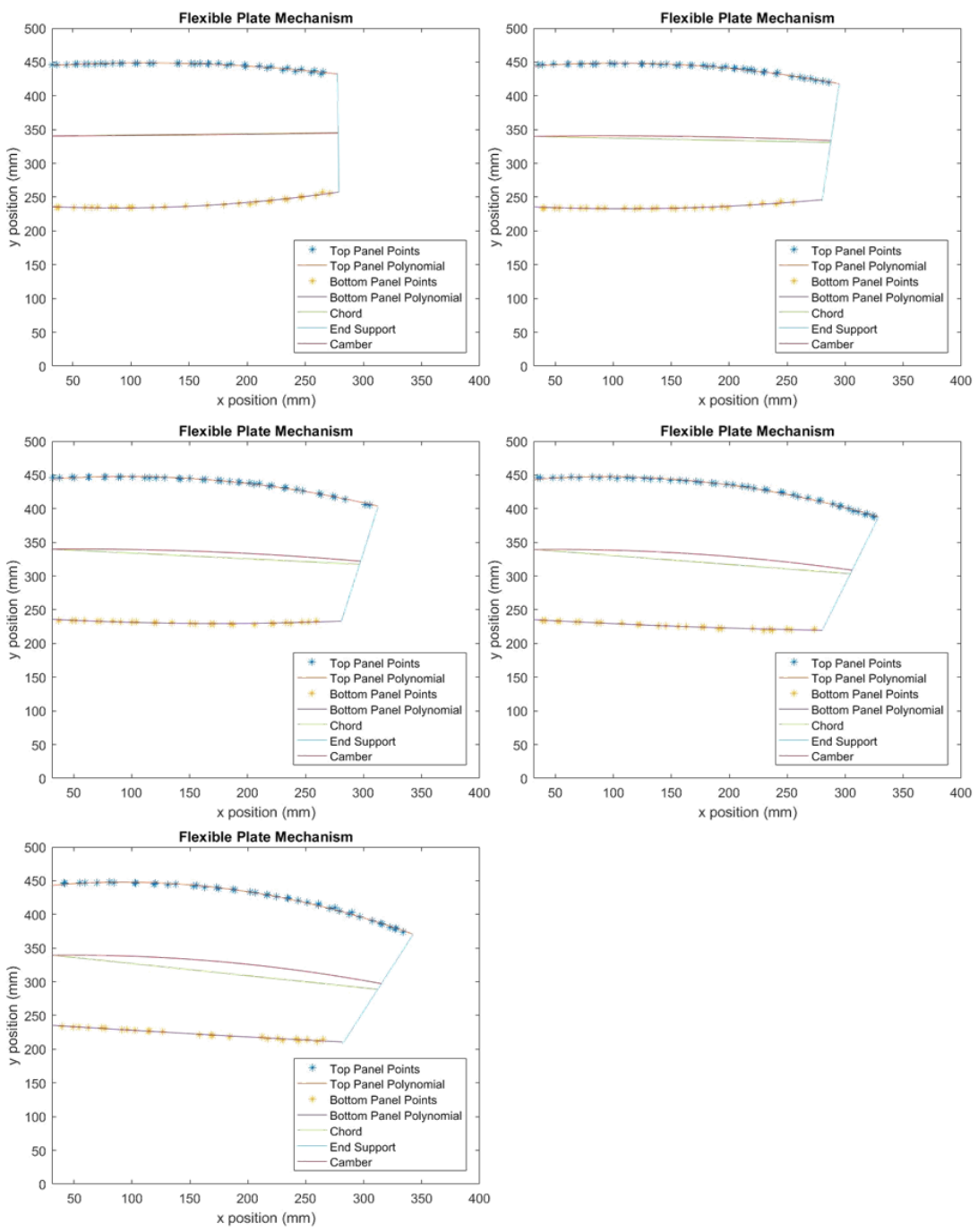

Figure 4.14:Shape Results for Experiment 5.

As seen in the figures above, for all 5 experiments, a $2^{\text {nd }}$ degree polynomial is able to fit the data very closely and the shape prediction seems to closely follow the experimental points. The five experiments explore the limitations and behaviour of the mechanism under different aspect ratios. The experimental shape results can be utilized to see the relationship between shape and $\Delta \mathrm{L}$ and whether the shape can be reversely controlled or not. In order to quantify the behaviour 
of the fitted functions, the error must be obtained by computing the points and looking at the difference in the y values. The errors are found to be:

Table 4-4:Error for Shape Curve Fitting.

\begin{tabular}{|c|c|c|c|c|c|}
\hline Experiment & 1 & 2 & 3 & 4 & 5 \\
\hline $\begin{array}{c}\text { Max Error for } \\
\text { Top Panel } \\
(\mathrm{mm})\end{array}$ & 1.72 & 5.1 & 1.93 & 2.2 & 3.45 \\
\hline $\begin{array}{c}\text { Max Error for } \\
\text { Bottom Panel } \\
(\mathrm{mm})\end{array}$ & 0.4 & 1.17 & 0.67 & 2.3 & 3.5 \\
\hline
\end{tabular}

The error is associated with variations in reading the points, since the digitizer is very accurate, therefore, any small movement of the probe would produce a variation.

\subsubsection{Deflection and Deflection Angle}

In addition to obtaining the shape data, for each experiment, the deflection and deflection angles are measured for each increment of $\Delta \mathrm{L}$. The deflection and deflection angle for each experiment are plotted against the $\Delta \mathrm{L}$ values. The results are curve fitted with linear functions, concluding that the relationship between the two is linear. This will make finding a reverse control method easier and less complex. The resulting plots are as follows: 


\section{Deflection:}

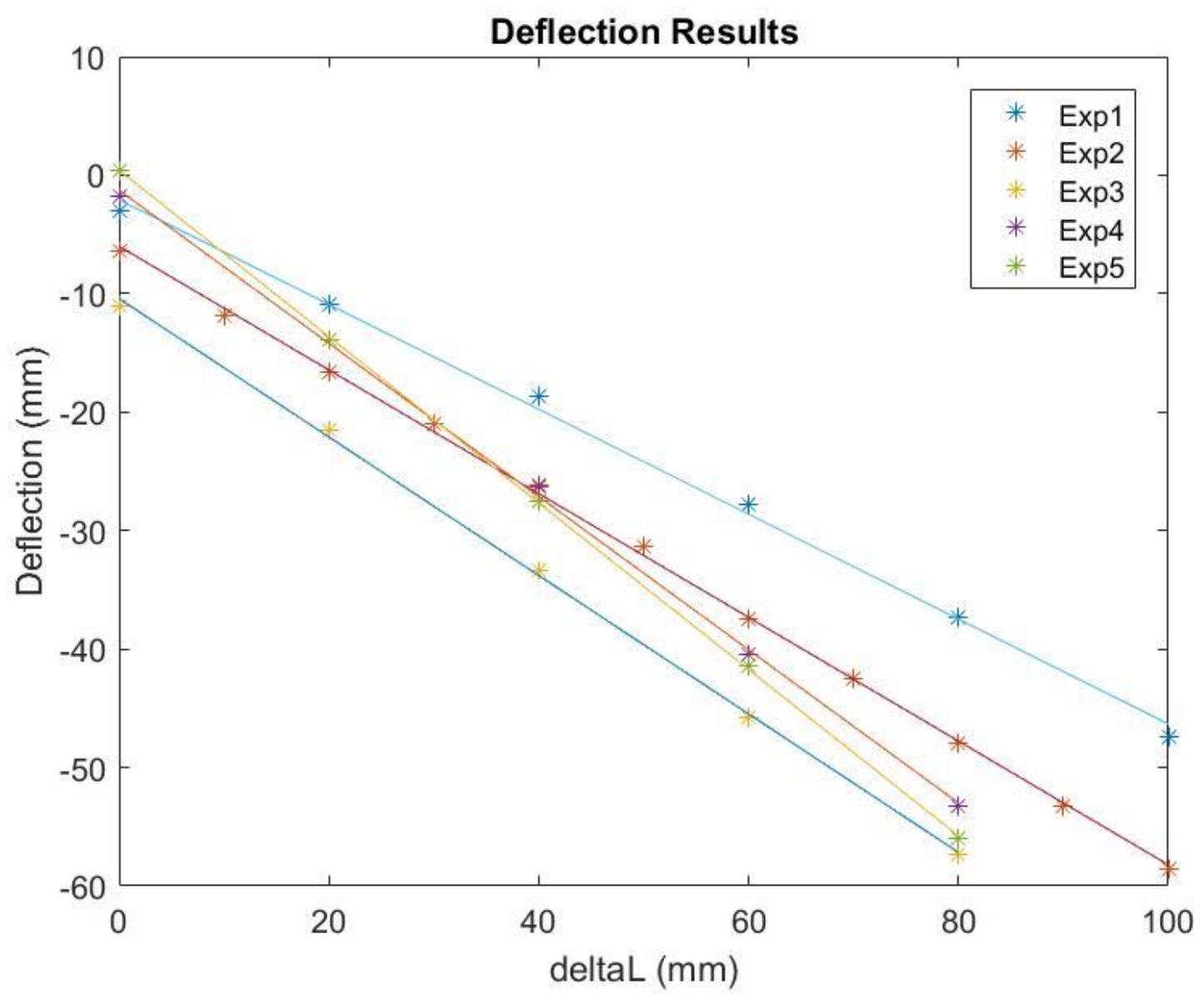

Figure 4.15:Deflection Results for Various Experiments. 


\section{Deflection Angle:}

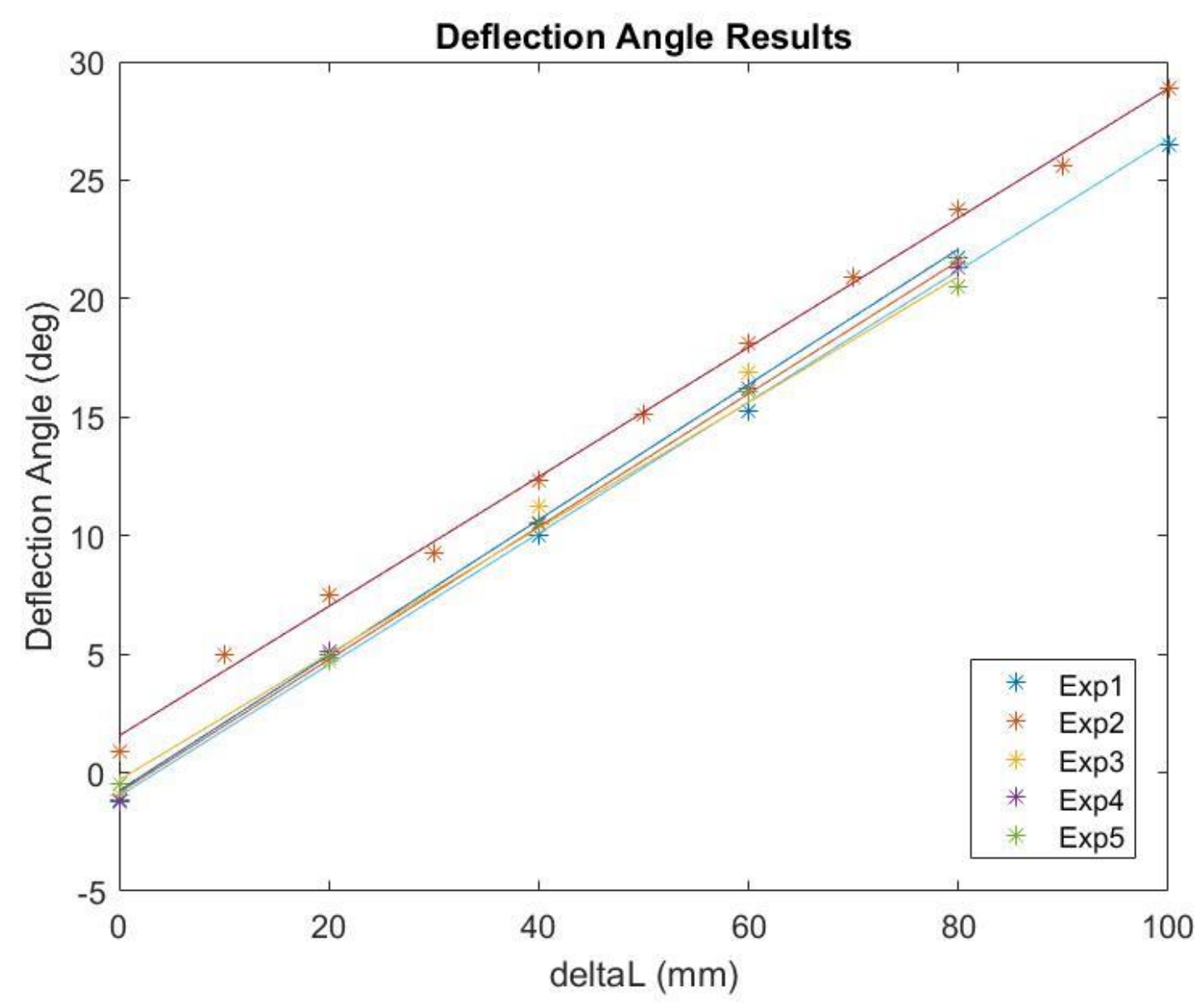

Figure 4.16:Deflection Angle Results for Various Experiments.

As seen in Figure 4.15 and Figure 4.16, the deflections and deflection angle results vary linearly in each experiment with regards to $\Delta \mathrm{L}$. The data follows the linear trendline very closely, with slight variation which is to be expected in experimental data, with the errors found to be:

Table 4-5:Max Error for Deflection and Deflection Angle Results.

\begin{tabular}{|c|c|c|c|c|c|}
\hline Experiment & 1 & 2 & 3 & 4 & 5 \\
\hline $\begin{array}{c}\text { Deflection } \\
\text { Error (mm) }\end{array}$ & 1.07 & 1.9 & 0.65 & 0.84 & 0.28 \\
\hline $\begin{array}{c}\text { Deflection } \\
\text { Angle Error } \\
\text { (deg) }\end{array}$ & 0.54 & 0.8 & 0.6 & 0.35 & 0.48 \\
\hline
\end{tabular}


At $\Delta \mathrm{L}$ values of zero both the deflection and deflection angle should be equal to zero, since no deflection occurs when the panels are the same length. This is not the case in the experimental data, since the measurement probe is never going to capture the exact same $\mathrm{x}$ coordinated for the top and bottom points of the support. The offset from zero is very minimal and can be neglected. When the analysis is performed, only the slope of the trendline would be of interest. In the next chapter, a controller is developed to control the mechanism based on the deflection results obtained. Having linear results allows for easier and faster control, since relationship between the inputs and output is a simple linear relationship, which can be obtained using a factor derived from the experimental data. The development of this controller will establish a reverse control method, in which the user will be able to input a required deflection and the controller will compute the required lengths for the top and bottom panel.

Establishing this method allows obtaining the length inputs using a deflection as an input. Thus, classifying it as a reverse control. The functions obtained for the deflection are linear functions with the form:

$$
\delta=\mathrm{m} \Delta \mathrm{L}+\mathrm{b}
$$

The $\mathrm{m}$ is the slope of the line whereas the $\mathrm{b}$ is the $\mathrm{y}$-intercept of the function. The functions for each experiment are given in Table 4.6. 
Table 4-6:Deflection Functions for Each Experiment.

\begin{tabular}{|l|l|l|}
\hline Experiment & $\begin{array}{c}\text { Length of } \\
\text { Bottom Panel } \\
(\mathbf{m m})\end{array}$ & Function \\
\hline 1 & 100 & $\delta=-0.4425 \Delta \mathrm{L}-2.0714$ \\
\hline 2 & 135 & $\delta=-0.545 \Delta \mathrm{L}-5.1367$ \\
\hline 3 & 180 & $\delta=-0.584 \Delta \mathrm{L}-10.4543$ \\
\hline 4 & 225 & $\delta=-0.6469 \Delta \mathrm{L}-1.2778$ \\
\hline 5 & 260 & $\delta=-0.7028 \Delta \mathrm{L}-0.4247$ \\
\hline
\end{tabular}

Since at a $\Delta \mathrm{L}$ of zero the deflection must also be zero, the intercept of the functions must be zero as well. The $b$ values in the functions found in Table 4-6 are due to small inaccuracies associated with the data readings. These values are not taken into consideration and only the slopes for each function are taken. In order to develop a reverse controller function for the whole mechanism, a relationship between the different slopes and lengths must be established, thus, allowing for the use of that relationship in the controller function. The slopes vary due to the change in the length of the bottom panel. In Figure 4.15, it is evident that the slope for each length is different. In order to find a relationship, the slopes are plotted against the length of the bottom panel to see what sort of relationship exists between them. 


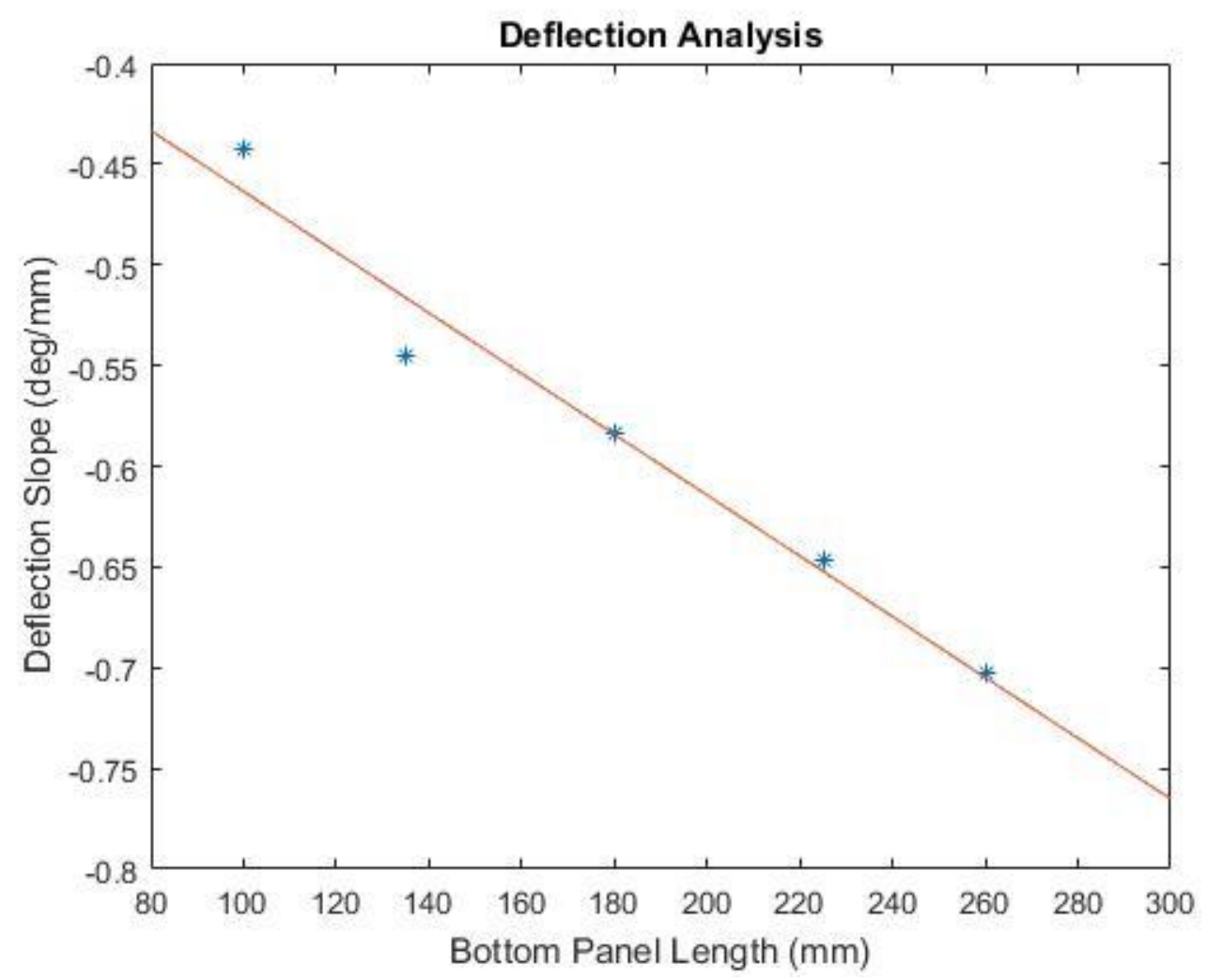

Figure 4.17:Slope of Deflection Functions Vs. The Bottom Panel Lengths.

As shown in Figure 4.17, a linear relationship is found to be the best fit for the data gathered. However, the linear function did not catch all of the data points, having a maximum error of 0.0286 from the measured values. It was found to be sufficient, since it was going to be refined with further experimental testing. The function describing the slope is:

$$
S=-0.0015 L_{2}-0.3128
$$

where $\mathrm{S}$ is the slope of the deflection equation; and $\mathrm{L}_{2}$ is the length of the bottom panel.

The above equation provides a relationship between the bottom panel length and the slope of the deflection equation. Which is the relationship between the deflection and the difference in length between the two panels. Using the following equation: 


$$
\delta=S \Delta L
$$

Where $\delta$ is the midpoint deflection in $\mathrm{mm}$; and $\Delta \mathrm{L}$ is the difference in length between the top and bottom panels.

Combining the above two equations and rearranging for $\Delta \mathrm{L}$ yields

$$
\Delta L=\frac{\delta}{-0.0015 L_{2}-0.3128}
$$

Thus, a direct equation relating the difference in length to the deflection is obtained. This empirical equation can be used to control the actuators to obtain the desired deflection and bottom panel length based on user input.

The deflection angle results are of linear correlation to the difference in length as well and can be utilized to develop an empirical equation for reverse control in the same manner as the deflection results. The first step in developing the empirical equation is seeing the effect of $\mathrm{L}_{2}$ on the slope of the deflection angle line. This can be done by taking the slopes of the lines of best fit and plotting them against the $\mathrm{L}_{2}$ values, in a similar fashion to what was done for the deflection previously. However, by looking at Figure 4.16, the slope seems to be the same for all experiments. The plot relating the slopes is given in Fig. 4.26. 


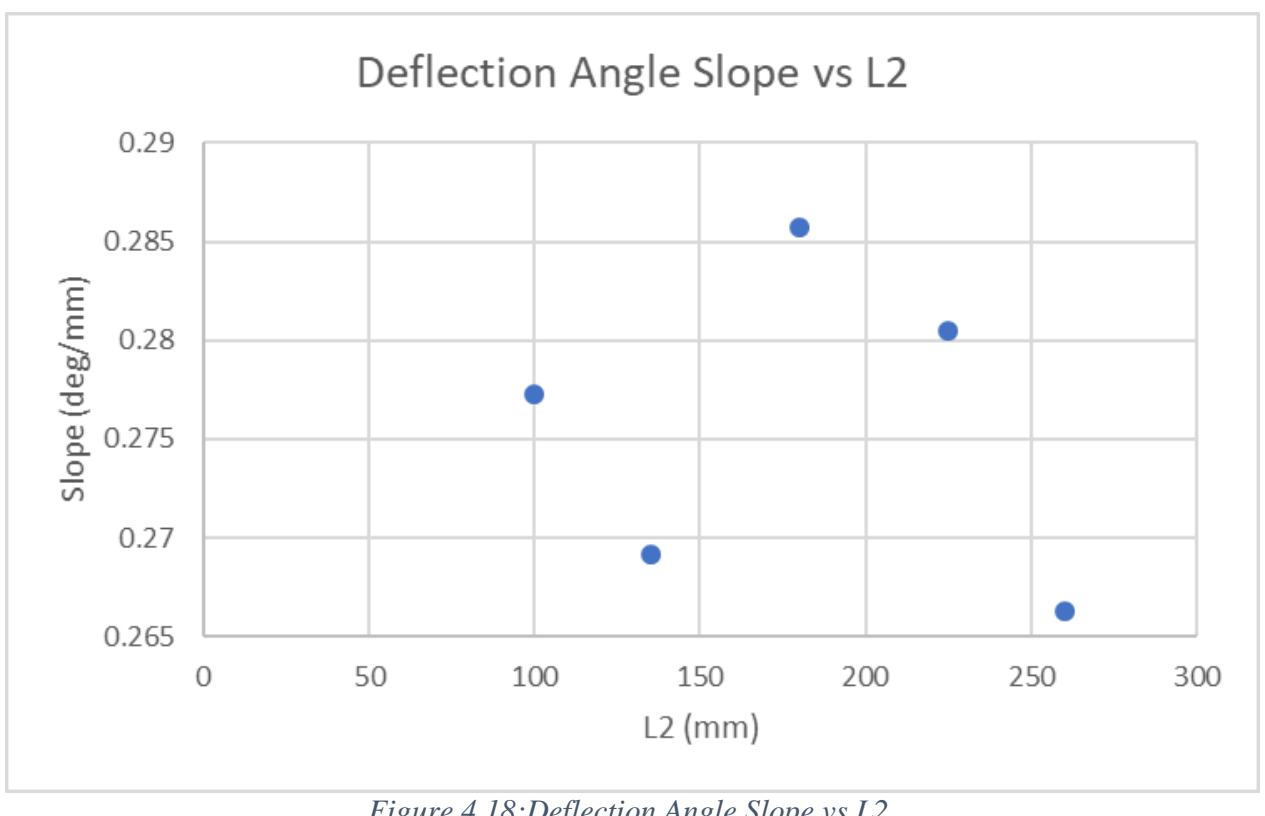

Figure 4.18:Deflection Angle Slope vs L2.

As can be seen in the plot above, there is no correlation between the slope of the deflection angle slope $\left(\theta_{\mathrm{S}}\right)$ and the length of the bottom panel. It can be concluded that the slope of the deflection line is independent of the length of the bottom panel. Taking the average of the slopes using:

$$
\theta_{\text {SAvg }}=\frac{\sum \theta_{S}}{\# \text { of points }}
$$

The average slope can be used in the empirical equation for reversely controlling the mechanism, using a deflection angle input. Using Eq. 4.51, the average slope is calculated to be 0.2758. Implementing the slope into an empirical equation relating the deflection angle to the difference in length:

$$
\Delta L=\frac{\theta}{0.2758}
$$

This equation offers a direct relationship between the deflection angle and the difference in length, thus enabling reverse control of the mechanism by obtaining the required lengths based on a user input of deflection angle. 


\subsection{Shape Coefficients Analysis}

The functions describing the deformation of the top and bottom panels are all $2^{\text {nd }}$ degree polynomials, consisting of 3 coefficients each. Using these coefficients, the y coordinate of the panel can be obtained based on an x-coordinate input. However, as previously mentioned, these coefficients are different for each $\Delta \mathrm{L}$ increment. In this section, a relationship between these coefficients with regards to $\Delta \mathrm{L}$ is explored. To see if the experimental data can be used to develop a function relating each of these coefficients to the difference in length. The A coefficient affects the quadratic portion of the function, where it changes the width of the curve and whether the parabola opens up or down. The B coefficient constitutes the linear portion, effecting the vertical and horizontal location of the parabola. Whereas, the $\mathrm{C}$ coefficient is responsible for the constant portion, determining the y-intercept of the function, which in this case is the location of the rollers. Each of the 3 coefficients for the top and bottom panel are plotted versus $\Delta \mathrm{L}$ and then a polynomial is fitted into the results. The polynomials had different degrees depending on the which one is found to fit the experimental data best. 


\section{Experiment 1}
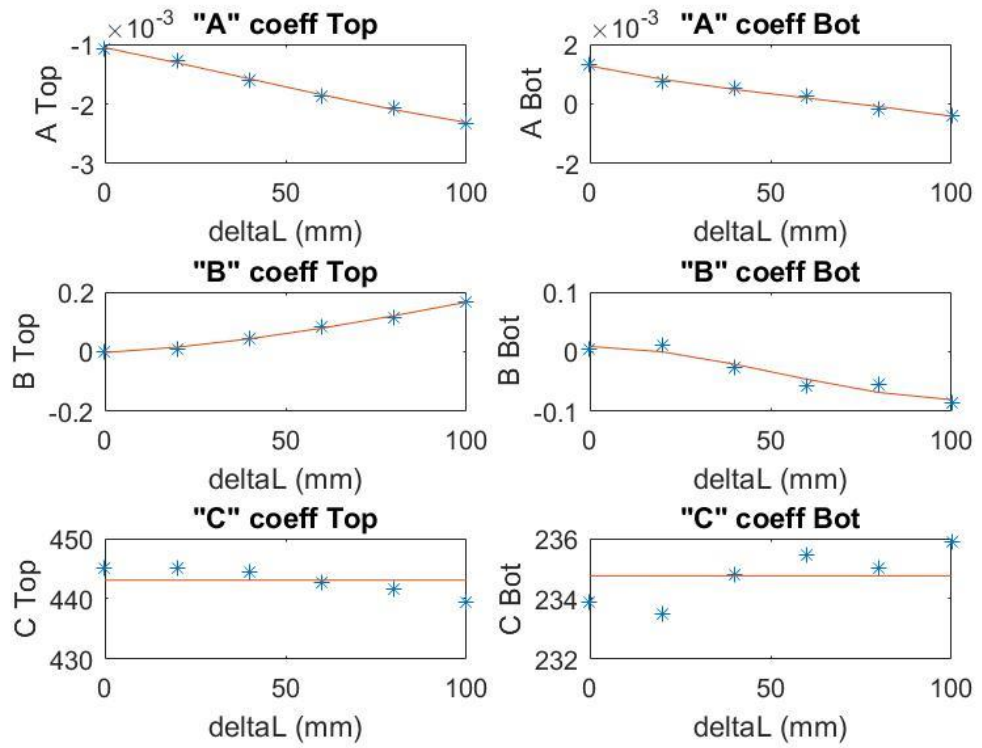

Figure 4.19: Coefficient Data for Experiment 1.

\section{Experiment 2}
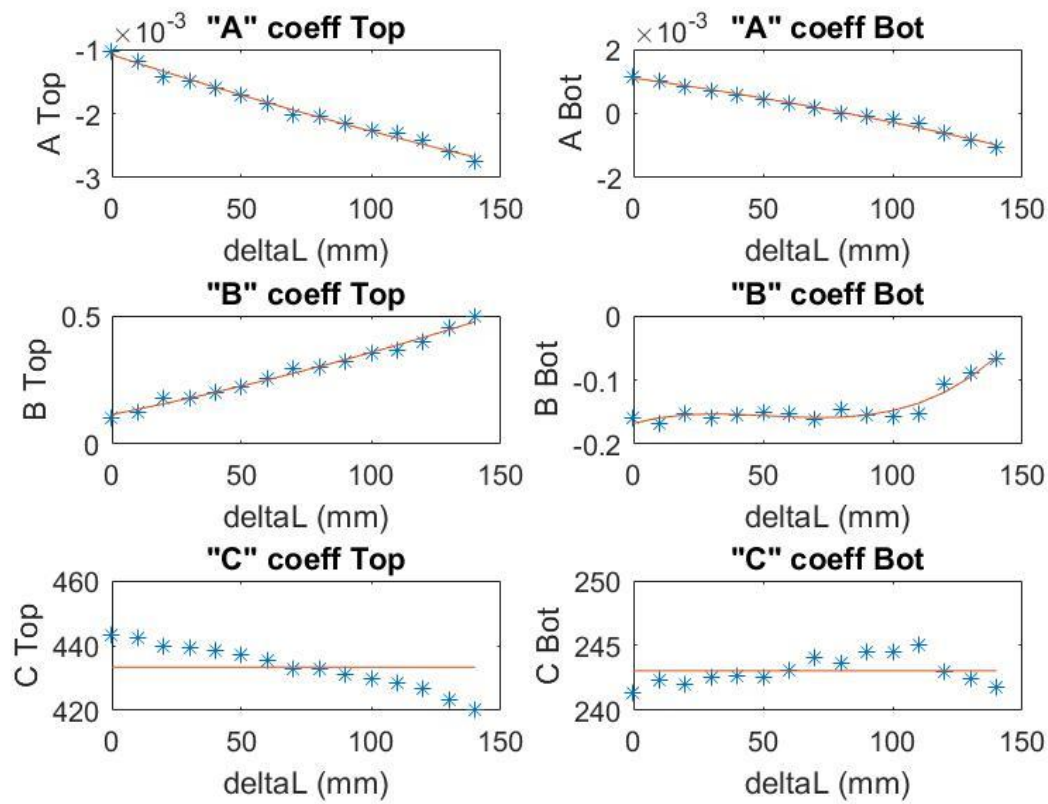

Figure 4.20:Coefficient Data for Experiment 2. 


\section{Experiment 3}
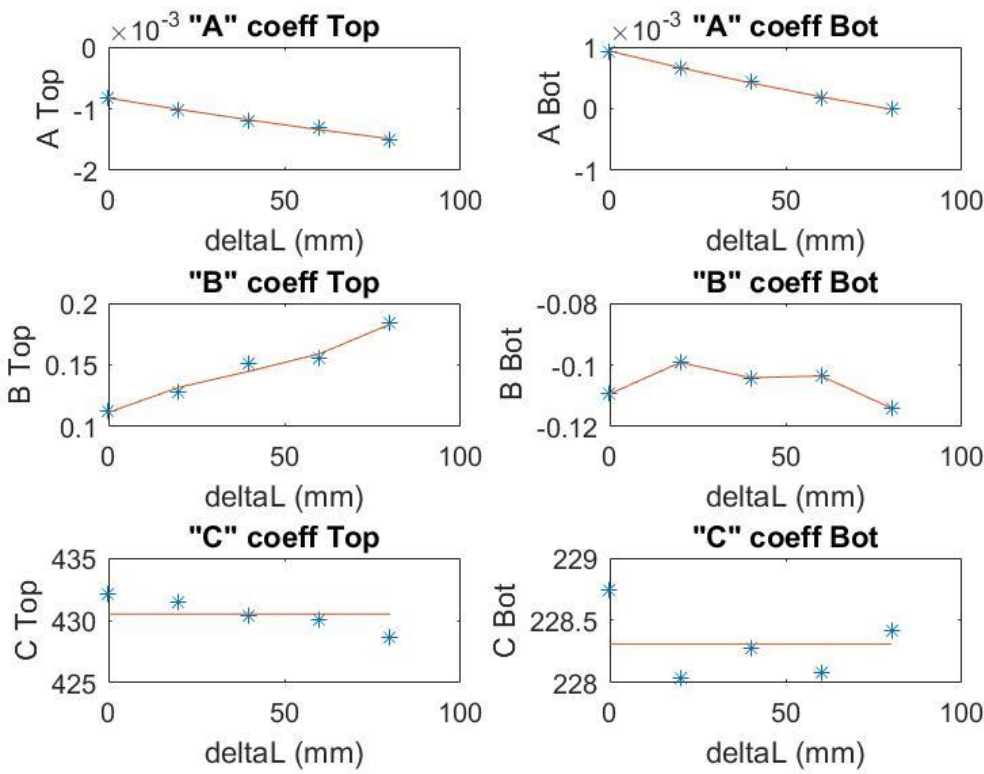

Figure 4.21: Coefficient Data for Experiment 3.

\section{Experiment 4}
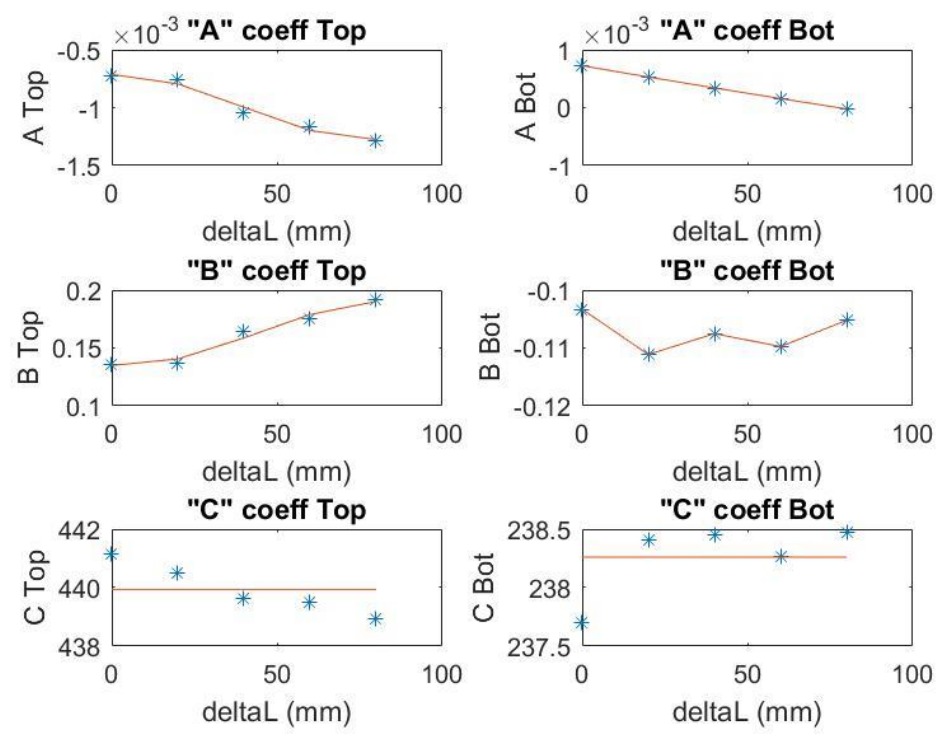

Figure 4.22: Coefficient Data for Experiment 4. 


\section{Experiment 5}
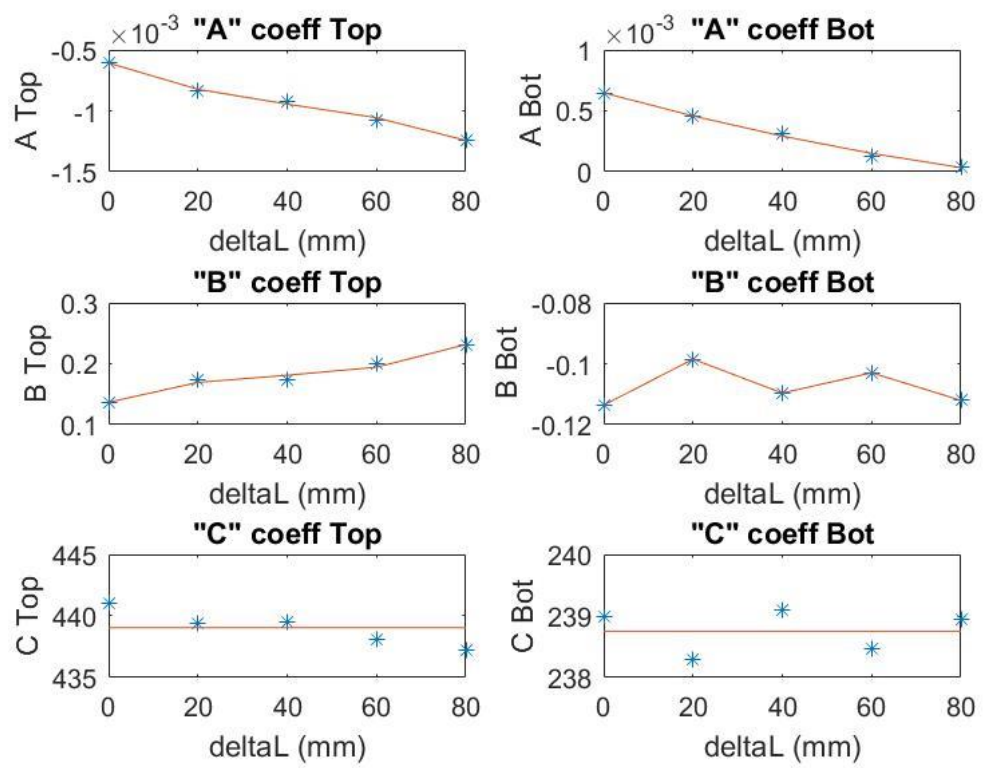

Figure 4.23:Coefficient Data for Experiment 5.

As seen in the above figures, multi degree polynomials are able to fit the data for the coefficients which describe the deformation of the panels. The $\mathrm{C}$ coefficients for the top and bottom panel are fitted with a zero-degree polynomial. Since these values correspond to the start position of the panels, which should be a constant value. These variations are due to the variation in readings when obtaining the data. The functions are obtained from MATLAB's polyfit function, which returns the coefficients of a polynomial of degree $n$ that is a best fit for the data inputted [50] using the linear least square method, from which the maximum errors are obtained to be: 
Table 4-7:Max Error for Shape Coefficients.

\begin{tabular}{|c|c|c|c|c|}
\hline Experiment & $\mathrm{A}_{\mathrm{t}}$ Max Error & $\mathrm{A}_{\mathrm{b}}$ Max Error & $\mathrm{B}_{\mathrm{t}}$ Max Error & $\mathrm{B}_{\mathrm{b}}$ Max Error \\
\hline 1 & $3.56 \times 10^{-5}$ & $9.14 \times 10^{-5}$ & 0.0073 & 0.0142 \\
\hline 2 & $8.85 \times 10^{-5}$ & $1.21 \times 10^{-4}$ & 0.0239 & 0.0164 \\
\hline 3 & $3.68 \times 10^{-5}$ & $1.55 \times 10^{-5}$ & 0.0058 & $1.17 \times 10^{-16}$ \\
\hline 4 & $5.27 \times 10^{-5}$ & $5.56 \times 10^{-6}$ & 0.006 & $1.8 \times 10^{-16}$ \\
\hline 5 & $2.29 \times 10^{-5}$ & $2.52 \times 10^{-5}$ & 0.007 & $3.33 \times 10^{-6}$ \\
\hline
\end{tabular}

The functions obtained are presented in the tables below, all a function of $\Delta \mathrm{L}$ :

Table 4-8: Coefficient Results for Experiment 1.

\begin{tabular}{|l|l|c|}
\hline Coefficient & Degree & Function \\
\hline $\mathrm{A}_{\text {Top }}$ & 3 & $354.4 \times 10^{-12} \Delta L^{3}-40.8 \times 10^{-9} \Delta L^{2}-12.006 \times 10^{-6} \Delta L-1.057 \times 10^{-3}$ \\
\hline $\mathrm{B}_{\mathrm{Top}}$ & 3 & $-43.13 \times 10^{-9} \Delta L^{3}+15.146 \times 10^{-6} \Delta L^{2}+607.43 \times 10^{-6} \Delta L-2.642 \times 10^{-3}$ \\
\hline $\mathrm{C}_{\text {Top }}$ & 0 & 443 \\
\hline $\mathrm{A}_{\text {Bot }}$ & 3 & $-984.69 \times 10^{-12} \Delta L^{3}+185 \times 10^{-9} \Delta L^{2}-25.5 \times 10^{-6} \Delta L+1.27 \times 10^{-3}$ \\
\hline $\mathrm{B}_{\text {Bot }}$ & 3 & $153.4 \times 10^{-9} \Delta L^{3}-23.95 \times 10^{-6} \Delta L^{2}-31.9 \times 10^{-6} \Delta L+8.882 \times 10^{-3}$ \\
\hline $\mathrm{C}_{\text {Bot }}$ & 0 & 235 \\
\hline
\end{tabular}

Table 4-9: Coefficient Results for Experiment 2.

\begin{tabular}{|l|l|c|}
\hline Coefficient & Degree & Function \\
\hline $\mathrm{A}_{\text {Top }}$ & 2 & $13.1 \times 10^{-9} \Delta L^{2}-13.22 \times 10^{-6} \Delta L-1.09 \times 10^{-3}$ \\
\hline $\mathrm{B}_{\mathrm{Top}}$ & 2 & $4.11 \times 10^{-6} \Delta L^{2}+2.01 \times 10^{-3} \Delta L+115.17 \times 10^{-3}$ \\
\hline $\mathrm{C}_{\text {Top }}$ & 0 & 433 \\
\hline $\mathrm{A}_{\text {Bot }}$ & 2 & $-26.02 \times 10^{-9} \Delta L^{2}-11.22 \times 10^{-6} \Delta L+1.1 \times 10^{-3}$ \\
\hline $\mathrm{B}_{\text {Bot }}$ & 3 & $160.25 \times 10^{-9} \Delta L^{3}-24.92 \times 10^{-6} \Delta L^{2}+1.087 \times 10^{-3} \Delta-167.57 \times 10^{-3}$ \\
\hline $\mathrm{C}_{\text {Bot }}$ & 0 & 243 \\
\hline
\end{tabular}


Table 4-10: Coefficient Results for Experiment 3.

\begin{tabular}{|l|l|c|}
\hline Coefficient & Degree & Function \\
\hline $\mathrm{A}_{\text {Top }}$ & 2 & $14.78 \times 10^{-9} \Delta L^{2}-9.443 \times 10^{-6} \Delta L-828.06 \times 10^{-6}$ \\
\hline $\mathrm{B}_{\mathrm{Top}}$ & 3 & $176.7 \times 10^{-9} \Delta L^{3}-19.68 \times 10^{-6} \Delta L^{2}+1.34 \times 10^{-3} \Delta L+111.54 \times 10^{-3}$ \\
\hline $\mathrm{C}_{\text {Top }}$ & 0 & 430.5 \\
\hline $\mathrm{A}_{\text {Bot }}$ & 2 & $27.5 \times 10^{-9} \Delta L^{2}-13.985 \times 10^{-6} \Delta L+933.69 \times 10^{-6}$ \\
\hline $\mathrm{B}_{\text {Bot }}$ & 4 & $-9.69 \times 10^{-9} \Delta L^{4}+1.594 \times 10^{-6} \Delta L^{3}-87.38 \times 10^{-6} \Delta L^{2}+1.697 \times 10^{-3} \Delta L$ \\
& & $-109.4 \times 10^{-3}$ \\
\hline $\mathrm{C}_{\text {Bot }}$ & 0 & 228 \\
\hline
\end{tabular}

Table 4-11: Coefficient Results for Experiment 4.

\begin{tabular}{|l|l|c|}
\hline Coefficient & Degree & Function \\
\hline $\mathrm{A}_{\text {Top }}$ & 3 & $2.52 \times 10^{-9} \Delta L^{3}-301.12 \times 10^{-9} \Delta L^{2}+908.29 \times 10^{-9} \Delta L-712.3 \times 10^{-6}$ \\
\hline $\mathrm{B}_{\mathrm{Top}}$ & 3 & $-223.8 \times 10^{-9} \Delta L^{3}+29.25 \times 10^{-6} \Delta L^{2}-215.44 \times 10^{-6} \Delta L+134.89 \times 10^{-3}$ \\
\hline $\mathrm{C}_{\text {Top }}$ & 0 & 440 \\
\hline $\mathrm{A}_{\text {Bot }}$ & 2 & $6.596 \times 10^{-9} \Delta L^{2}-9.85 \times 10^{-6} \Delta L+724.54 \times 10^{-6}$ \\
\hline $\mathrm{B}_{\text {Bot }}$ & 4 & $7.78 \times 10^{-9} \Delta L^{4}-1.293 \times 10^{-6} \Delta L^{3}+70.07 \times 10^{-6} \Delta L^{2}-1.337 \times 10^{-3} \Delta L$ \\
& & $-103.31 \times 10^{-3}$ \\
\hline $\mathrm{C}_{\text {Bot }}$ & 0 & 238 \\
\hline
\end{tabular}

Table 4-12: Coefficient Results for Experiment 5.

\begin{tabular}{|l|l|c|}
\hline Coefficient & Degree & Function \\
\hline $\mathrm{A}_{\text {Top }}$ & 3 & $-1.763 \times 10^{-9} \Delta L^{3}+223.93 \times 10^{-9} \Delta L^{2}-14.586 \times 10^{-6} \Delta L-606.9 \times 10^{-6}$ \\
\hline $\mathrm{B}_{\mathrm{Top}}$ & 3 & $465.59 \times 10^{-9} \Delta L^{3}-54.02 \times 10^{-6} \Delta L^{2}+2.526 \times 10^{-3} \Delta L+136.69 \times 10^{-3}$ \\
\hline $\mathrm{C}_{\mathrm{Top}}$ & 0 & 439 \\
\hline $\mathrm{A}_{\text {Bot }}$ & 2 & $30.47 \times 10^{-9} \Delta L^{2}-10.11 \times 10^{-6} \Delta L+647.97 \times 10^{-6}$ \\
\hline $\mathrm{B}_{\text {Bot }}$ & 4 & $-20.21 \times 10^{-9} \Delta L^{4}+3.3434 \times 10^{-6} \Delta L^{3}-176.8 \times 10^{-6} \Delta L^{2}+3.116 \times 10^{-3} \Delta L$ \\
& & $-113.596 \times 10^{-3}$ \\
\hline $\mathrm{C}_{\text {Bot }}$ & 0 & 238 \\
\hline
\end{tabular}


Each coefficient had to be fitted with its own function, all with varying degrees, specific to the data obtained. As seen above, all of the functions are a function of $\Delta \mathrm{L}$, meaning if the shape of the panels is to be predicted for any of the experiments, the $\Delta \mathrm{L}$ is substituted into the coefficients equation and the quadratic function describing the shape is obtained. Note that this has to be performed for each experiment separately, since no relationship was found between the coefficient functions and different experiments. Due to the increased complexity of having different degree functions for each experiment. Therefore, in order to utilize this method for shape prediction, a data base of different lengths must be first established. Then, for each length, shape data is collected for different $\Delta \mathrm{L}$ values. Thus, a user input would first be the length, to determine which set of data to use. Then, the shape, which in turn will give the $\Delta \mathrm{L}$ required to obtain that shape for that specific length.

\subsubsection{Shape Reverse Control}

As discussed previously, coefficient polynomials describing the coefficients of the quadratic function are obtained from experimental data. The functions take the difference in length as an input and each function outputs a coefficient used in the shape function. After the functions are obtained, the reverse relationship has to be evaluated to see how closely it represents the experimental data. The experimental points are plotted along with the polynomials computed from the derived functions for each increment.

The plots obtained for the shape based on the derived functions: 


\section{Experiment 1:}
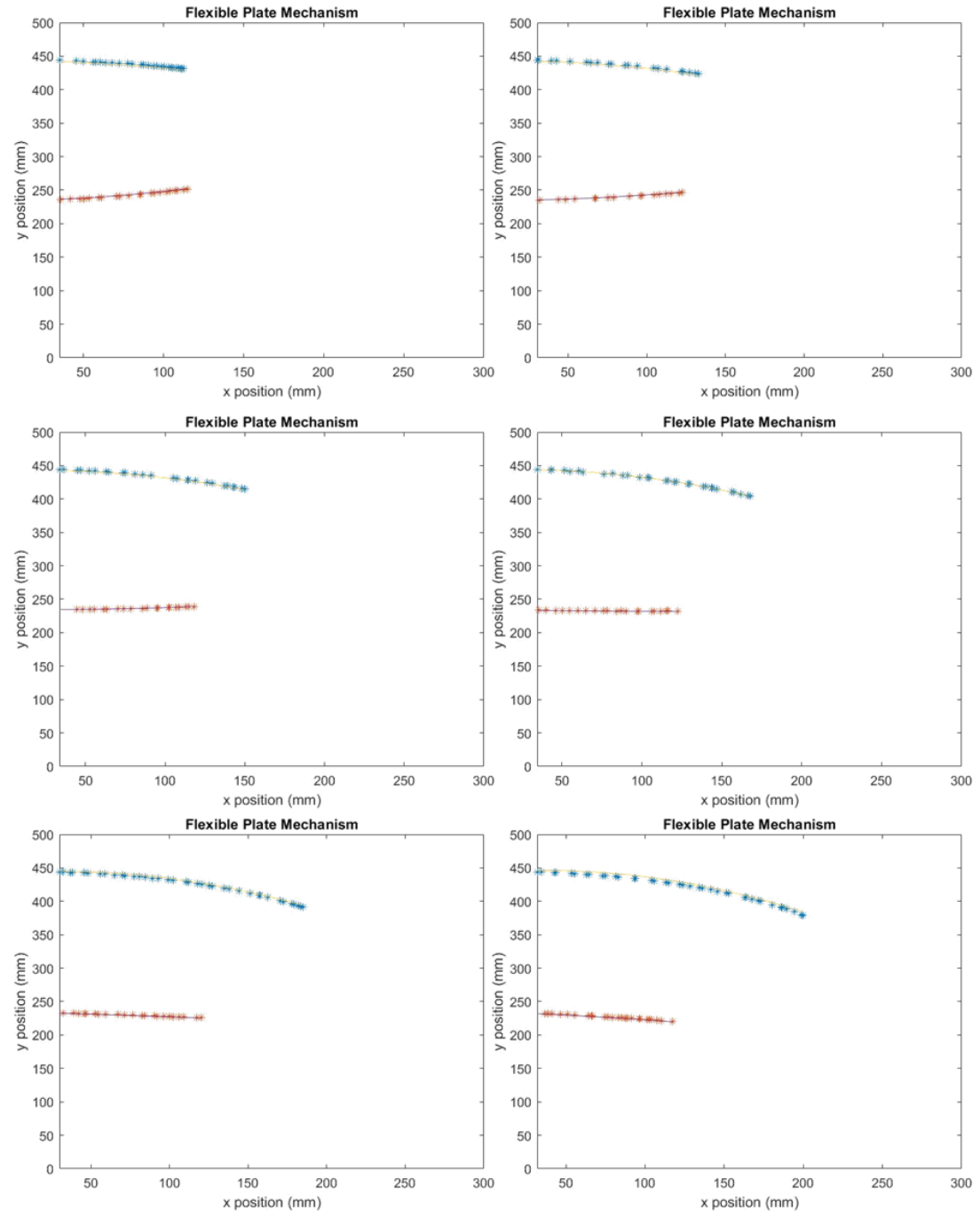

Figure 4.24:Coefficient Validation for Experiment 1.

Functions derived in Table 4-8 are used for shape prediction and plotted vs experimental data to see how well the derived functions perform. Figure 4.24 shows the shape as $\Delta \mathrm{L}$ is increased incrementally. 


\section{Experiment 2:}
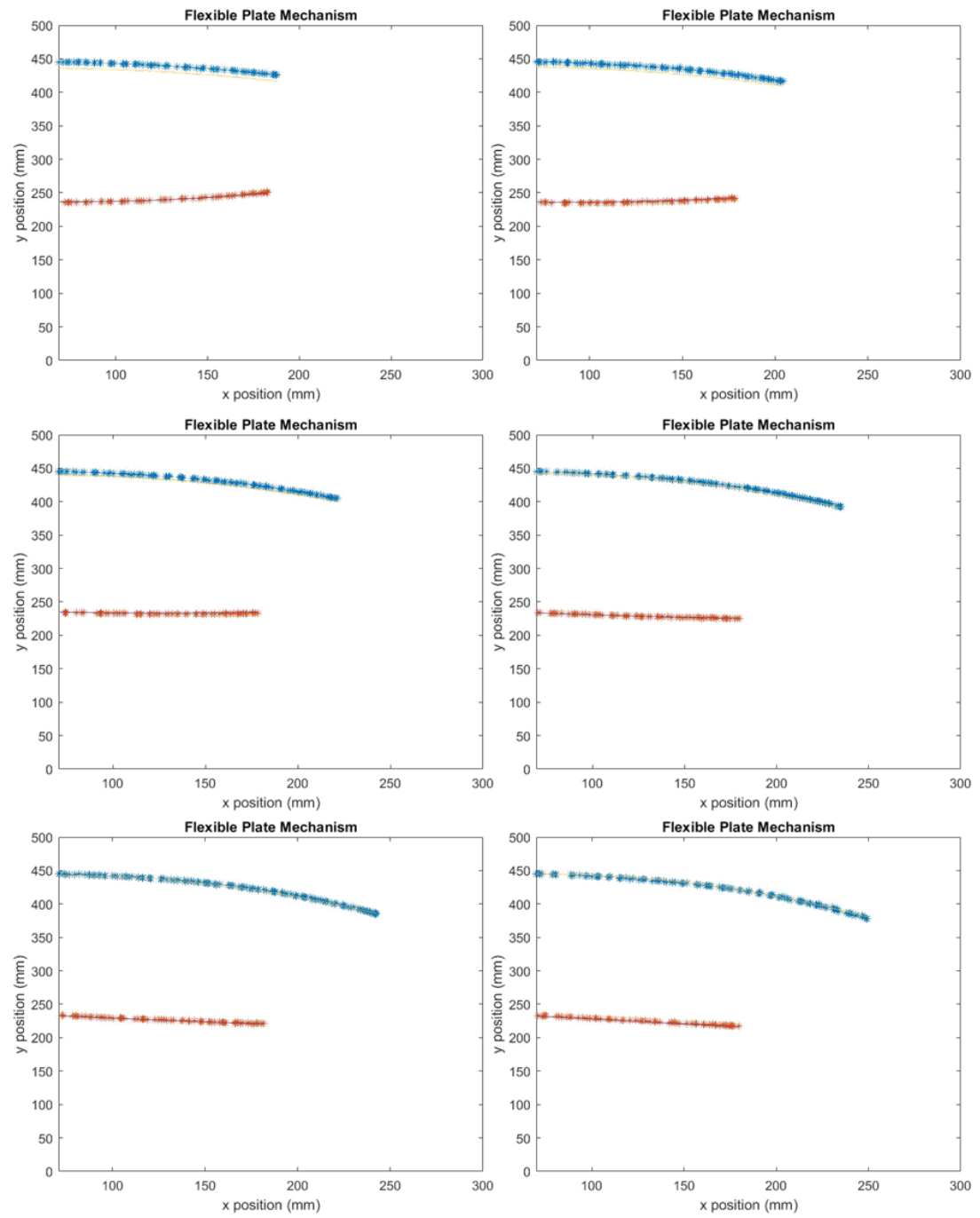

Figure 4.25:Coefficient Validation for Experiment 2 Part 1. 

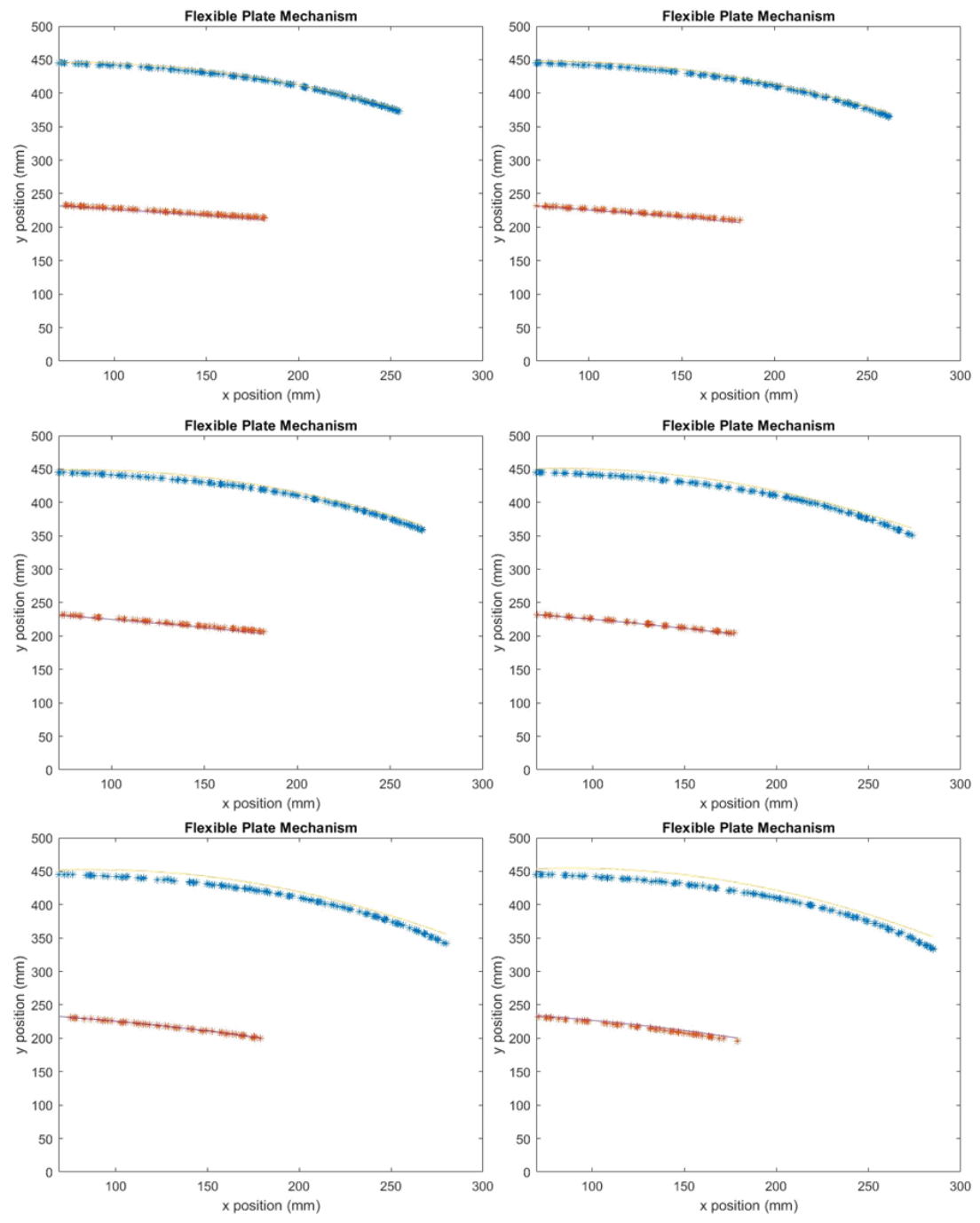

Figure 4.26: Coefficient Validation for Experiment 2 Part 2.

For each experiment, the corresponding functions are used, since there was no unified function found to describe the shape for all of the experiments. 


\section{Experiment 3:}
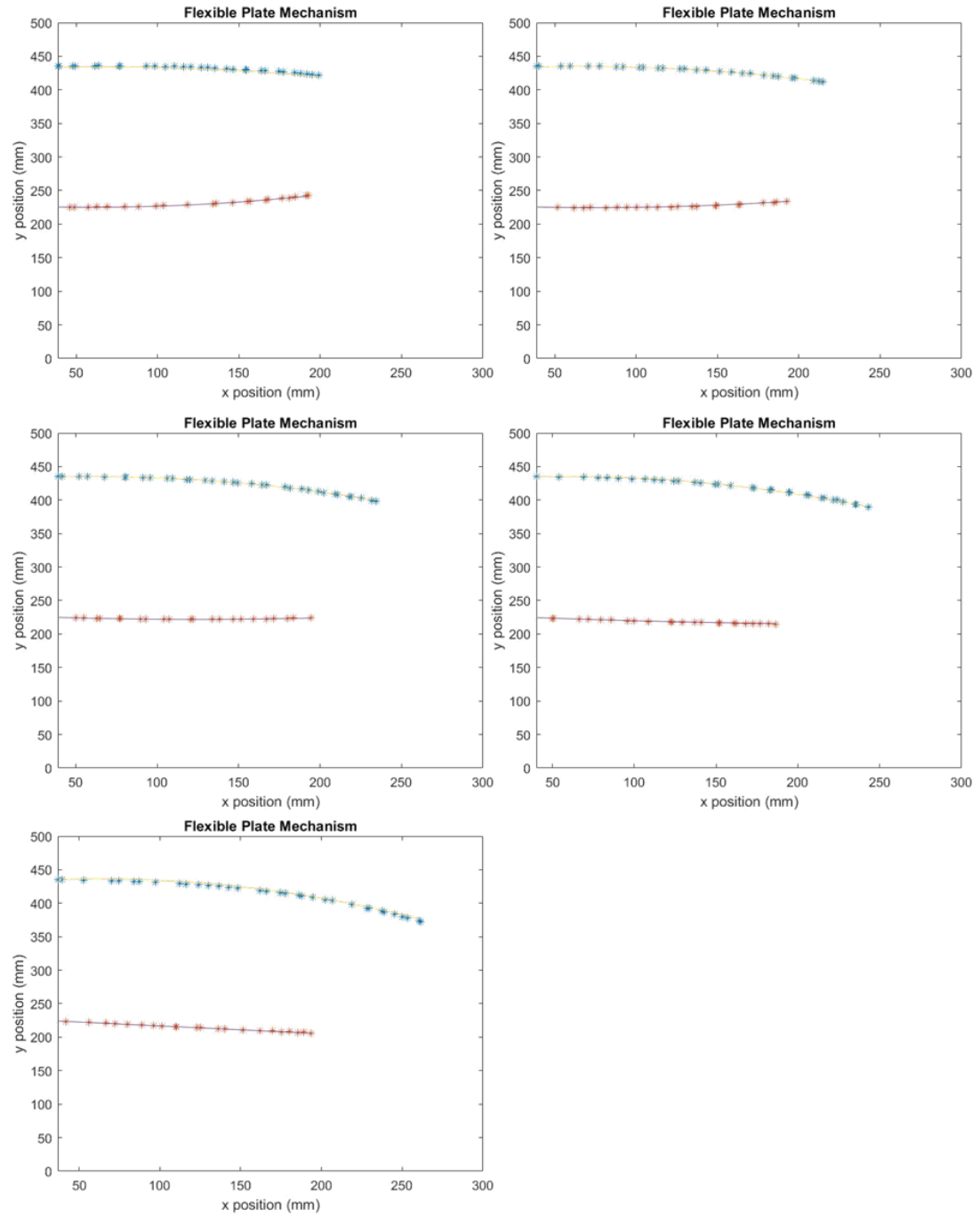

Figure 4.27: Coefficient Validation for Experiment 3. 


\section{Experiment 4:}
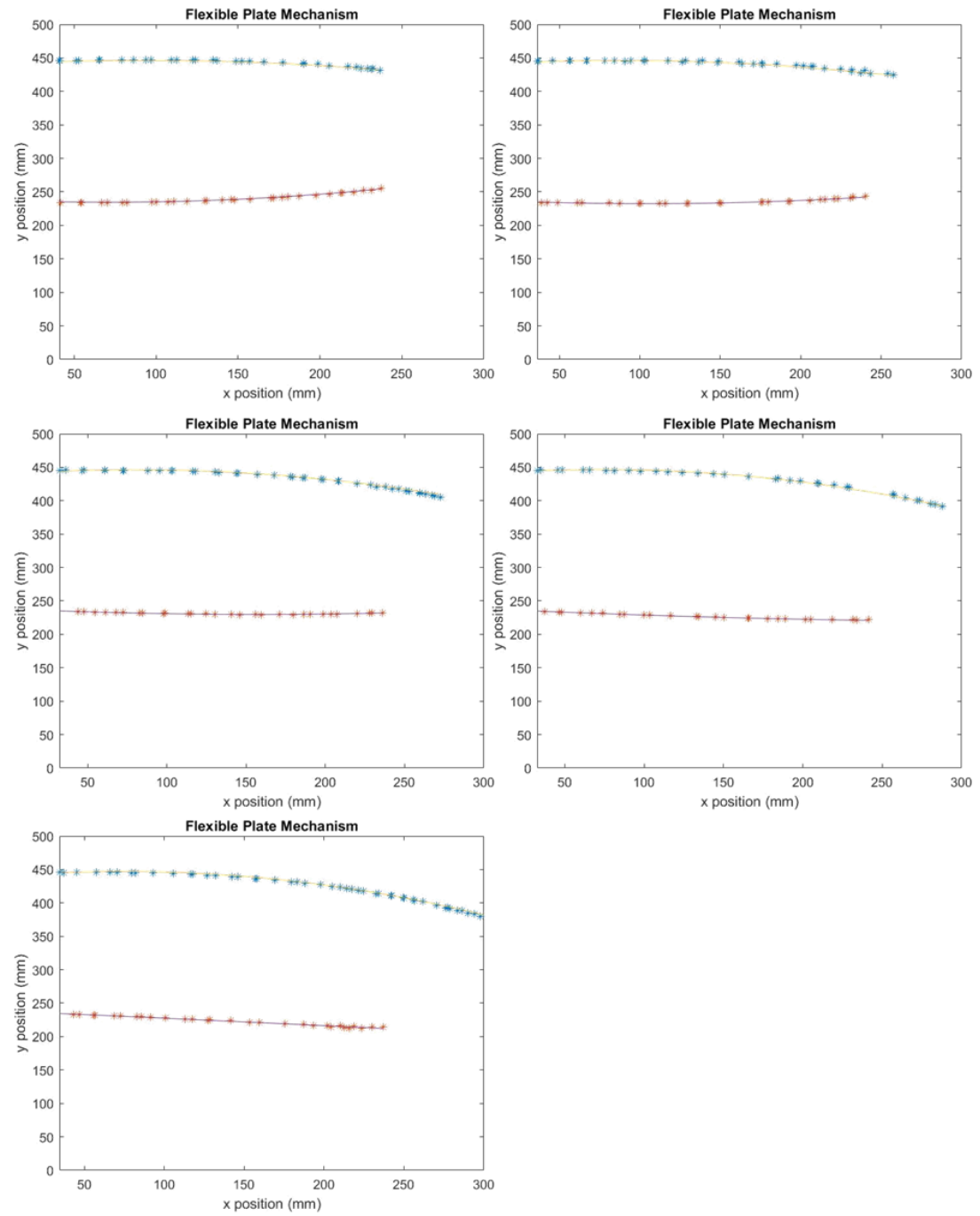

Figure 4.28: Coefficient Validation for Experiment 4. 


\section{Experiment 5:}
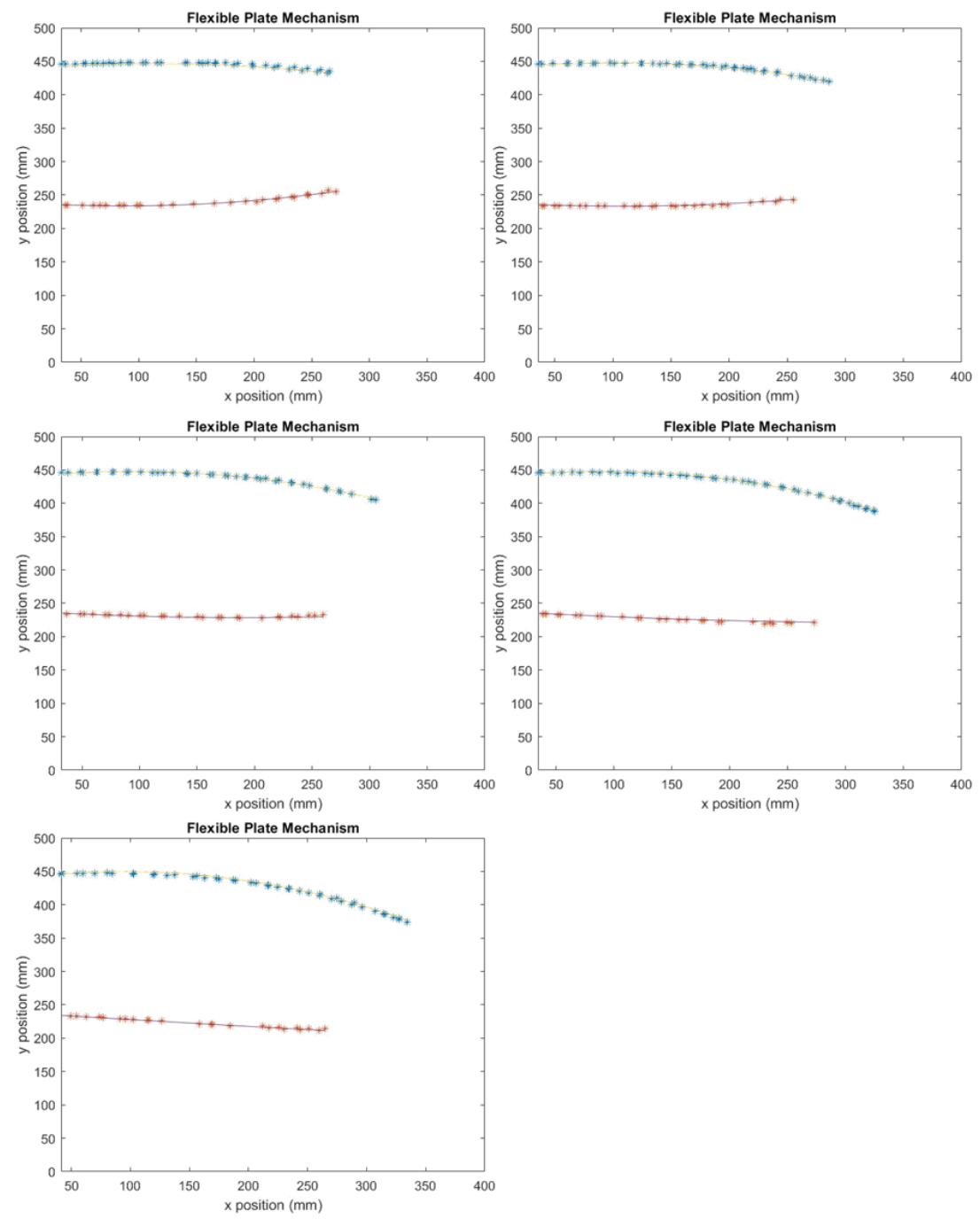

Figure 4.29: Coefficient Validation for Experiment 5.

Figure 4.24 to Figure 4.29 show how the shape functions, derived from the coefficient functions compare to the experimental data. Overall, the functions represent the data very well, capturing most of the points. Slight variations do exist, mostly due to inaccuracies associated with placing the probe on the surface. Since it is moved over the surface by hand, any perturbation or movement would be reflected in the experimental data. In some of the plots, the function seems to be a little offset by the data. This is due to variations in the $\mathrm{C}$ coefficients which dictate the location of the panel at the start. Since this location is based on the readings obtained for each 
run, there is a slight variation in the value for each trail. For a future analysis, the reference point and the starting points of the panel would be based on one value. Ensuring variations in readings do not contribute to the variations in the points. The offset could be associated with the panel being pushed down, since the point is taken from the front of the roller. However, that can be solved by taking the starting point as the centre of the rollers, this way it is assured that the point will not be affected by the deflection motion pulling the panel down. A relationship between the bottom panel length and the coefficient functions was explored. This would allow a unified function for all the experiments. However, due to the varying degree of the polynomials describing the coefficients and the complexity of the functions, no relationship was discovered. Which means experimental trails must be run for all of the lengths required, to teach the controller the shapes that could be produced. Then, based on the shape required for that particular length, the controller would output the change in length required. Having these equations developed would allow for real time control with a quick response time, since the controller database would already contain the possible shapes. After the flight conditions determine which shape is optimal, that input is transferred to a required $\Delta \mathrm{L}$ which would be sent to the actuators.

This chapter presented the experiments performed on the mechanism. The results are obtained and analyzed to see the relationship between the length change and the shape, deflection, and deflection angle. Shape coefficients are curve fitted using varying degree polynomials, however, no relationship is found between the coefficients for different experiments. The deflection and deflection angle results are used to develop empirical relations which will be used in the next chapter for inverse control. 


\section{DEFLECTION AND DEFLECTION ANGLE INVERSE CONTROL}

The previous chapter studies the behaviour of the shape of the flexible panels and how it can be utilized for reverse control applications. In this chapter, the focus will be on using the deflection and deflection angle as the method for inverse control. Instead of the user specifying the shape required, the input would be the bottom panel length and deflection or deflection angle. The controller will be developed using the experimental data obtained in the five experiments. A graphic user interface is developed to ease the control method and to make controlling the mechanism user friendly. This is a reverse control problem, since the user will input the deflection, which is the output parameter in the mechanism; and the controller will compute the lengths of the panels, which are the inputs.

\subsection{Controller and GUI}

The software selected for the development of the controller and GUI is MATLAB. Since it is a powerful tool, which can be used for the analysis, as well as for sending the commands to the controller. As previously mentioned, the RoboteQ MDC2230 dual channel controller is used. The controller is able to control both motors and in turn, both actuators simultaneously. The controller can be controlled with different methods, such as the RoboteQ software, a microscript code installed on the controller, or analog or digital inputs. For the purposed control, in order to obtain an automated control system, a microscript code has to be written. Since user input is required for the length and the deflection, simply placing the code within the controller would not be an option. In a real-world application, however, the flight computer would send the required deflection and length to the controller unit. Which would compute the required length difference and send the appropriate commands to the motors. 
Using the GUI, allows the user to input the required parameters while making it easy to send the appropriate microscript commands to the controller. The required microscript commands are all obtained from RoboteQ Controller user manual [51]. In order to build the GUI, the graphic user interface development environment (GUIDE) is utilized [52]. It allows for building the GUI by placing preexisting models and then modifying the source code to tailor them to the specific user needs. This allows for the integration of the microscript commands easily with the GUI.

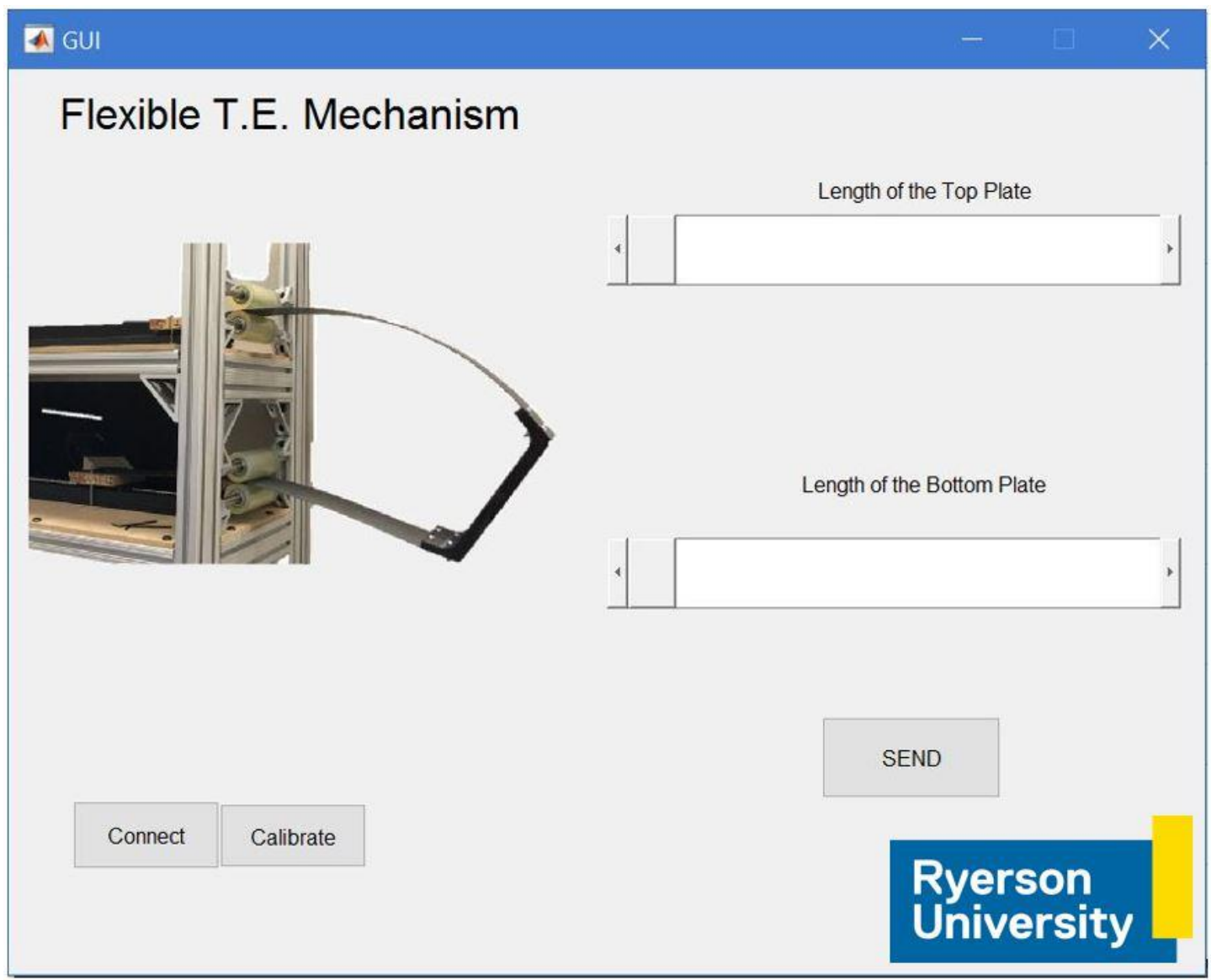

Figure 5.1: Flexible T.E. GUI Version 1.

The first GUI developed is very simple and it is used to control the actuators for the first set of experiments, where the lengths of the top and bottom panels are specified and the motors moved the actuators to the appropriate positions corresponding to the specified lengths. The GUI 
contains a connect button. When clicked, the button triggers a code which connects MATLAB to the serial port connected to the controller. After the connection is established, the calibration button is activated. When clicked, it initiates the code responsible for calibrating the actuators so that input commands can be transformed accurately. The calibration process starts with sending the command for the motors to operate in open loop mode. The motors are run on reverse at full speed for 5 seconds, to ensure that the actuators are in the stowed position. After 5 seconds, the motors are turned off and the count of the encoders is set to zero, establishing a starting location of the encoder count. Next, a command is sent out to the motors to turn at full speed for 5 seconds, causing the actuators to be in the fully deployed position. The count at the end (K) is then obtained from the controller. Which is essentially how many turns it took to get to that location. The command is then sent to place the motors in the closed loop count mode and a ratio is computed using:

$$
R=\frac{K}{260}
$$

The 260 is the stroke of the actuator. The count is divided by that number to obtain a ratio relating the count per mm of motion for the actuator. This concludes the calibration process. The user is now able to input the length of the top and bottom panels using the sliders corresponding to each one and once the send button is pressed, the input lengths are converted to a count using:

$$
\begin{aligned}
& K_{L 1}=L_{1} \times R \\
& K_{L 2}=L_{2} \times R
\end{aligned}
$$

The required count is now sent to the controller to move the actuator to that position.

This is the basic version of the GUI developed in order to run the experiments easily. The controller does not use any equations to compute the location, except for a simple conversion 
from the ratio obtained. After the experimental results from the deflection analysis are used to design a reverse control method, the GUI will be modified to reflect the required parameters for the new controller.

\subsection{Deflection Reverse Control Analysis}

In the previous chapter, the control method proposed is using the required deformation and experimental data to determine the difference in length required. However, the prototype built is merely to study the deformation of the mechanism and the relationship between the deflection, shape, and changes in lengths. Since it did not utilize the shape of an actual airfoil, the shape prediction control method still needs to be developed, so that it could be applied to an aerodynamic cross section. In the meantime, a different approach is required to simplify the control process and to perhaps use something other than shape as the parameter. Deflection and deflection angle are the parameters chosen, since varying one of them essentially changes the camber of the panels. Therefore, if a method is developed to control the mechanism by specifying the deflection or deflection angle, it would make the control process easier. Empirical relationships (Eq. 4.50 and Eq. 4.52) between the deflection and $\Delta \mathrm{L}$ and the deflection angle and $\Delta \mathrm{L}$, developed in the previous chapter can be used to implement a reverse controller. 


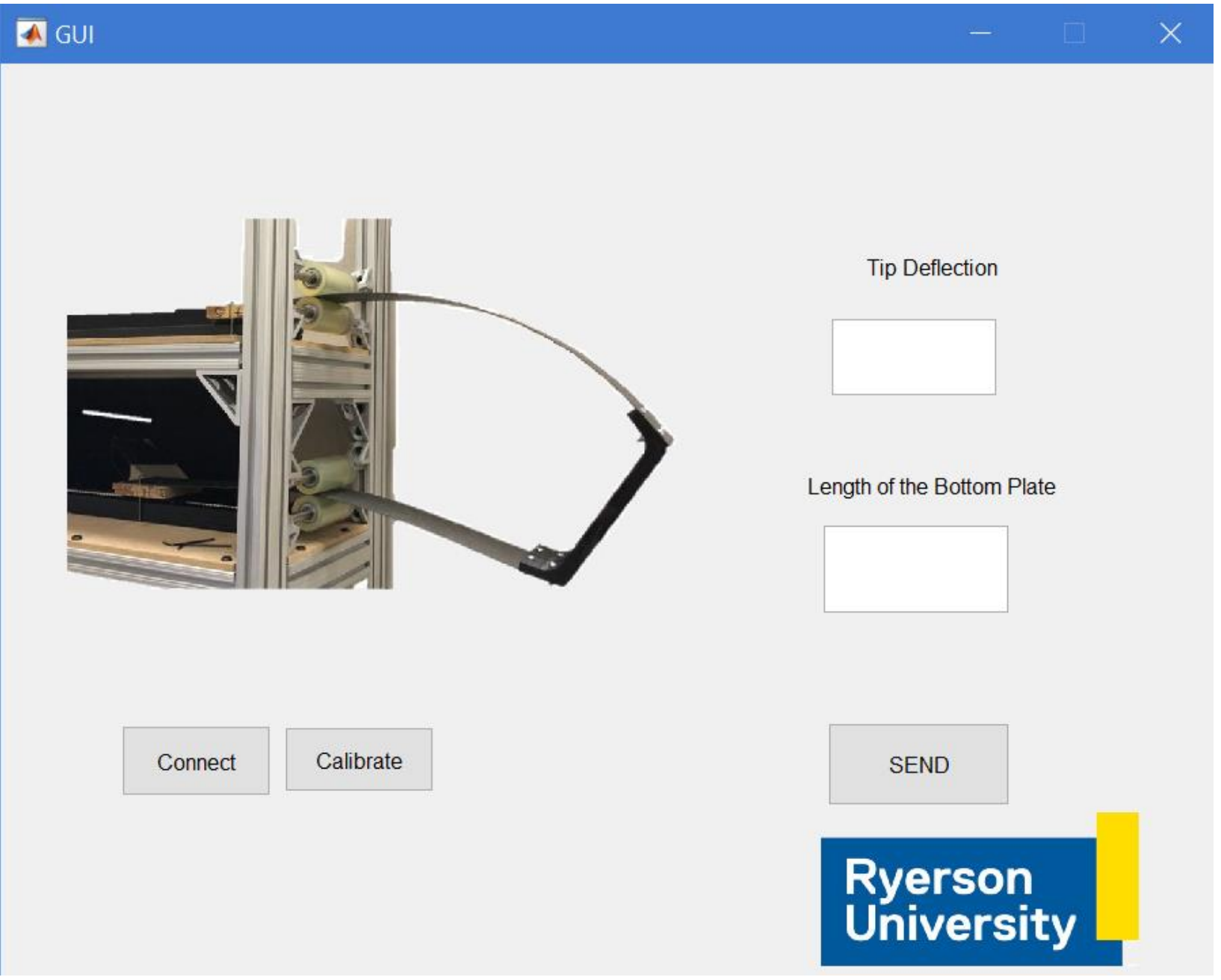

Figure 5.2:Modified Graphic User Interface.

The GUI has the same first two steps, involving the connection to the serial port and the calibration process. However, instead of the user inputting the lengths for each panel, the length of the bottom panel is input, followed by the desired deflection. Based on the relationship developed, the difference in length is computed and is added to the length of the bottom panel to give the required length of the top panel. The length of the bottom panel is provided by the user, then using Eq. 4.50, the required difference in length is calculated. The difference in length is:

$$
\Delta \mathrm{L}=\mathrm{L}_{1}-\mathrm{L}_{2}
$$

Using Eq. 5.4 the length of the top panel, $\mathrm{L}_{1}$, is calculated and then transformed into a count using Eq.5.2. The count is now sent to the controller. Note that deflection is positive upwards, 
therefore, a negative value will cause the top panel to have more length than the bottom one and a downward deflection is achieved. Whereas, a positive deflection will have the opposite effect. After establishing the relationship, the next step is to experimentally test the controller and refine it using more experimental data. In order to see if it provides a practical control method for the flexible panel mechanism.

\subsection{Deflection Reverse Controller Performance}

In order to evaluate the performance of the new controller, experimental trials are performed for several deflection and lengths. The measured deflection is then compared to what it is supposed to be. The deflections tests range from 0 to $-50 \mathrm{~mm}$ in increments of $-5 \mathrm{~mm}$. The lengths were 80 to $260 \mathrm{~mm}$ in increments of $20 \mathrm{~mm}$. The first step of the validation process is inputting those deflections and lengths into the controller. Then, using the 3D scanner, the actual deflection is measured to evaluate how well the controller is behaving. The results are obtained shown in Table 5-1.

Table 5-1:Controller Deflection Results.

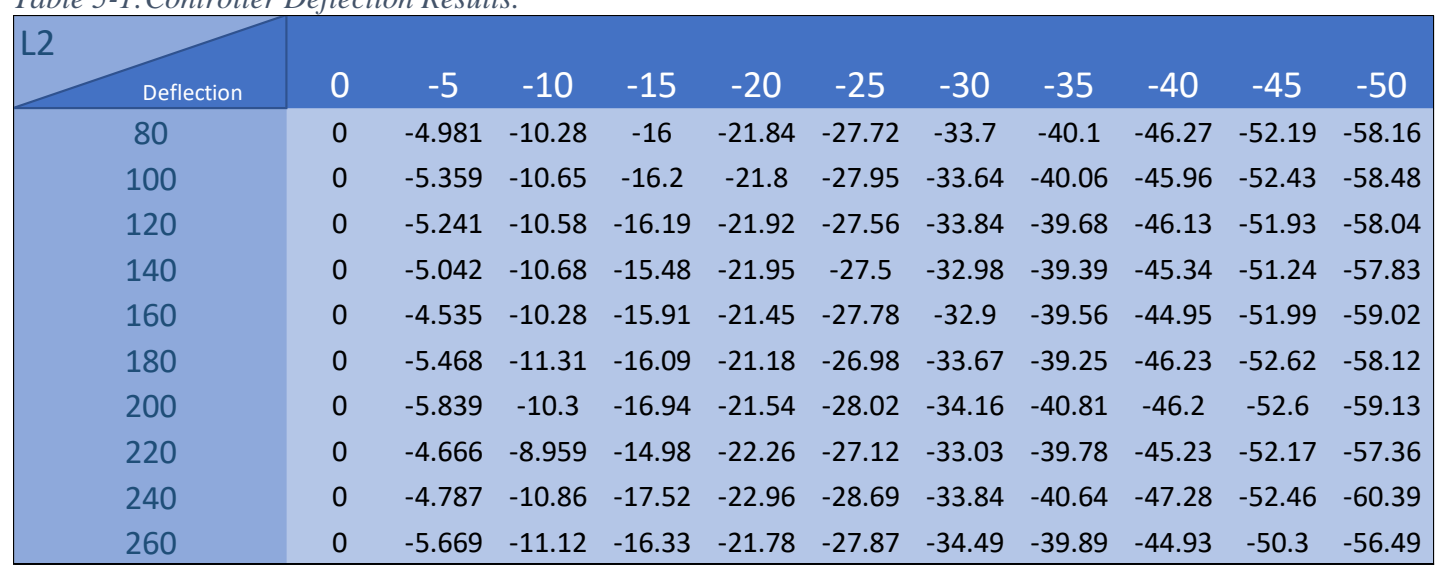

The above table shows the actual deflection obtained with regards to the deflection input into the reverse controller. As the deflection increases, the variation between the two values increases as well. This data can be utilized to further refine the developed controller by establishing a 
correction factor. In order to find that correction factor, first the desired deflection is plotted against the measured one and a line of best fit was established.

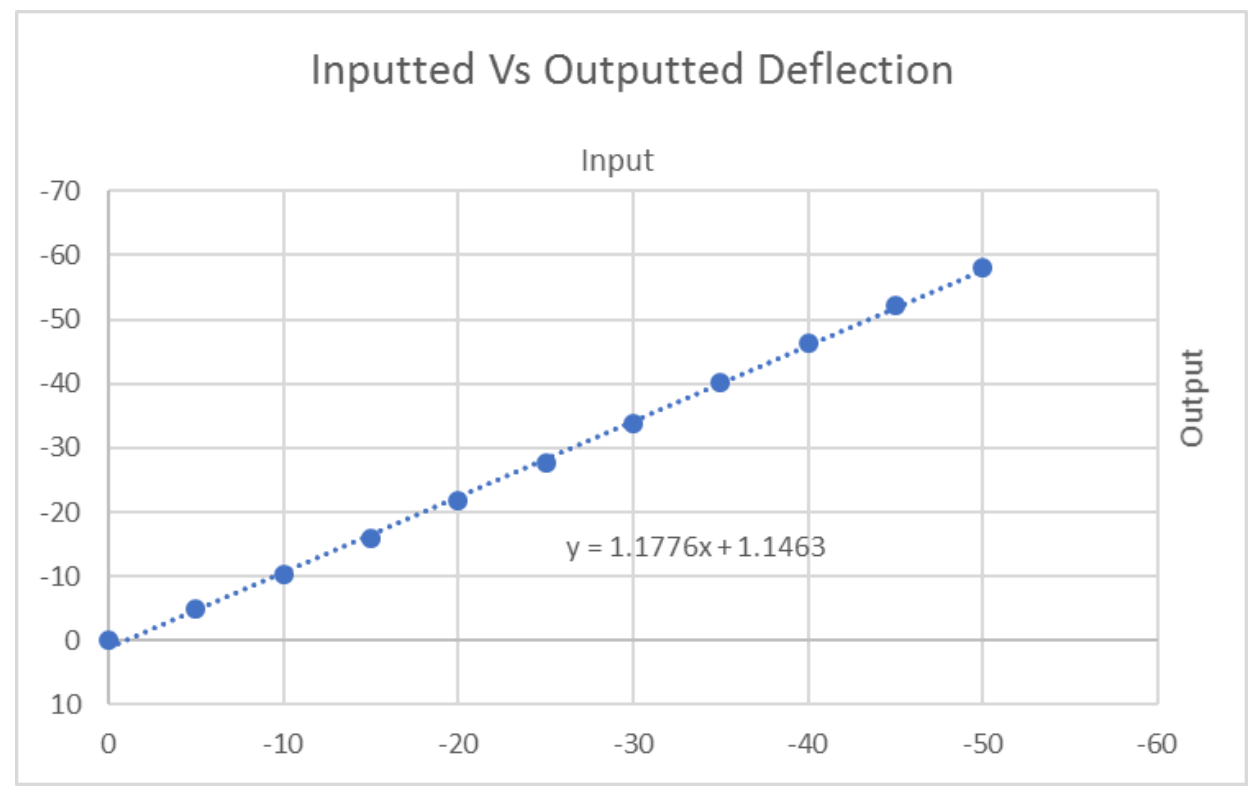

Figure 5.3:Desired Deflection Vs Measured Deflection.

Figure 5.3 provides a visual representation of the relationship between the desired and measured deflections. The desired deflection, which is the input, is in the $\mathrm{x}$ axis and the measured one is in the $y$ axis. The slope of the line of best fit is supposed to be 1, corresponding to an output equal to the input, however, the slope is 1.1776 . This value can be used as a correction factor and applied to the controller for more accurate results. The above results are for only one of the lengths tested. In order to get a proper correction factor, the process must be repeated for all lengths. The correction factors for the different lengths are found and listed in Table 5-2. 
Table 5-2:Functions of Correction Plot for Different Lengths.

\begin{tabular}{|c|c|c|}
\hline L2 & Slope & Intercept \\
\hline 80 & 1.1312 & 0.202 \\
\hline 100 & 1.1982 & 0.917 \\
\hline 120 & 1.1746 & 1.5858 \\
\hline 140 & 1.1832 & 0.894 \\
\hline 160 & 1.1687 & 0.9517 \\
\hline 180 & 1.1776 & 1.4068 \\
\hline 200 & 1.1578 & 0.996 \\
\hline 220 & 1.1682 & 0.9212 \\
\hline 240 & 1.1749 & 0.9605 \\
\hline 260 & 1.1776 & 1.1463 \\
\hline
\end{tabular}

The correction factor for each increment must be applied to the controller to obtain results as accurate as possible. The equations in Table 5-2 are used to fine tune the controller in order to obtain better results. The factors are applied for each range of $L_{2}$ values accordingly. Thus, the empirical equation is obtained by modifying Eq. 4.50 to implement the correction factors in Table 5-2 to inversely control the mechanism by inputting the deflection:

$$
\Delta L=\left(\frac{\frac{\delta}{C F}-\text { Interc. }}{-0.0015 L_{2}-0.3128}\right)
$$

With the values for the different $\mathrm{CF}$ and Interc. taken from Table 5-2 according to the $\mathrm{L}_{2}$ range.

After the correction factor is integrated into the controller, another set of experiments is performed to make sure the performance of the controller is satisfactory. The same deflection and lengths values are used for the trials and the results obtained are given in Table 5-3. 
Table 5-3:Results from Refined Controller.

\begin{tabular}{|c|c|c|c|c|c|c|c|c|c|c|c|}
\hline$\delta$ & 0 & -5 & -10 & -15 & -20 & -25 & -30 & -35 & -40 & -45 & -50 \\
\hline 80 & 0.00 & -5.06 & -9.92 & -14.89 & -20.06 & -24.89 & -30.14 & -35.06 & -39.93 & -44.68 & -49.45 \\
\hline 100 & 0.00 & -5.07 & -10.05 & -15.10 & -19.99 & -24.94 & -30.23 & -34.94 & -40.03 & -45.29 & -50.75 \\
\hline 120 & 0.00 & -5.02 & -10.10 & -14.89 & -20.18 & -25.77 & -29.86 & -35.84 & -39.55 & -44.62 & -50.99 \\
\hline 140 & 0.00 & -4.95 & -9.97 & -15.12 & -19.60 & -25.99 & -30.44 & -34.75 & -40.10 & -44.91 & -50.50 \\
\hline 160 & 0.00 & -4.89 & -10.20 & -15.14 & -20.12 & -24.77 & -30.39 & -35.61 & -40.43 & -45.05 & -50.13 \\
\hline 180 & 0.00 & -5.09 & -9.93 & -15.00 & -19.98 & -24.82 & -30.31 & -35.19 & -40.01 & -44.96 & -51.09 \\
\hline 200 & 0.00 & -4.98 & -10.20 & -15.24 & -20.05 & -25.11 & -30.30 & -35.65 & -40.37 & -45.45 & -50.89 \\
\hline 220 & 0.00 & -5.03 & -10.16 & -15.24 & -19.81 & -24.71 & -29.73 & -35.40 & -40.05 & -44.18 & -49.21 \\
\hline 240 & 0.00 & -4.97 & -10.18 & -15.41 & -20.32 & -24.84 & -29.78 & -35.39 & -40.02 & -45.19 & -50.64 \\
\hline 260 & 0.00 & -4.91 & -10.07 & -14.74 & -20.24 & -24.91 & -29.78 & -35.34 & -39.75 & -44.81 & -50.55 \\
\hline
\end{tabular}

The percent error is calculated for each of the values obtained using:

$$
\% \text { error }=\frac{\mid \text { measured deflection }- \text { inputted deflection } \mid}{\mid \text { inputted deflection } \mid} \times 100 \%
$$

The percent error is found to be:

Table 5-4:Percent Error for Obtained Deflection.

\begin{tabular}{|c|c|c|c|c|c|c|c|c|c|c|c|}
\hline$\delta$ & 0 & -5 & -10 & -15 & -20 & -25 & -30 & -35 & -40 & -45 & -50 \\
\hline 80 & 0.00 & 1.13 & 0.83 & 0.75 & 0.32 & 0.45 & 0.46 & 0.16 & 0.18 & 0.72 & 1.10 \\
\hline 100 & 0.00 & 1.31 & 0.55 & 0.68 & 0.05 & 0.25 & 0.75 & 0.16 & 0.09 & 0.64 & 1.50 \\
\hline 120 & 0.00 & 0.41 & 1.02 & 0.71 & 0.89 & 3.07 & 0.48 & 2.40 & 1.13 & 0.85 & 1.98 \\
\hline 140 & 0.00 & 1.08 & 0.33 & 0.82 & 2.02 & 3.96 & 1.46 & 0.72 & 0.25 & 0.19 & 0.99 \\
\hline 160 & 0.00 & 2.14 & 2.04 & 0.92 & 0.61 & 0.90 & 1.30 & 1.73 & 1.08 & 0.12 & 0.25 \\
\hline 180 & 0.00 & 1.76 & 0.69 & 0.02 & 0.09 & 0.70 & 1.04 & 0.54 & 0.03 & 0.09 & 2.18 \\
\hline 200 & 0.00 & 0.38 & 2.01 & 1.61 & 0.25 & 0.44 & 0.99 & 1.85 & 0.93 & 0.99 & 1.77 \\
\hline 220 & 0.00 & 0.63 & 1.56 & 1.63 & 0.94 & 1.15 & 0.89 & 1.14 & 0.14 & 1.83 & 1.58 \\
\hline 240 & 0.00 & 0.57 & 1.75 & 2.72 & 1.59 & 0.66 & 0.74 & 1.12 & 0.06 & 0.41 & 1.28 \\
\hline 260 & 0.00 & 1.71 & 0.72 & 1.74 & 1.22 & 0.34 & 0.73 & 0.96 & 0.61 & 0.43 & 1.09 \\
\hline
\end{tabular}

The performance of the refined version of the controller is found very accurate, with slight deviations, satisfying the reverse control problem. The overall performance follows the desired deflection closely. The slight variations are attributed to variations reading the data, due to the high accuracy of the scanner, which is the reason extra care must be taken when reading data. 
Now that the deflection can be controlled, real time camber change would be very quick, especially with the relationships being linear, thus minimizing computation time. These results are very significant, since they show that such a mechanism can be controlled using data obtained from experimental trials. Once the flight prototype is built, the range of motion would be known and the same experiments can be performed on obtaining the data specific to that design. The flight conditions would then determine the requirements for the trailing edge deflection and that number is sent to the controller, which would then compute the associated change of lengths between the two panels. The design in this thesis employs top and bottom actuators, allowing for more freedom in terms of deflection. Meaning if the change of length is reversed, an upward deflection is produced. The controller developed would still be used. Since the panel is symmetric, the difference being instead of inputting a negative value for deflection, a positive value is input instead, causing the panels to deflect upwards.
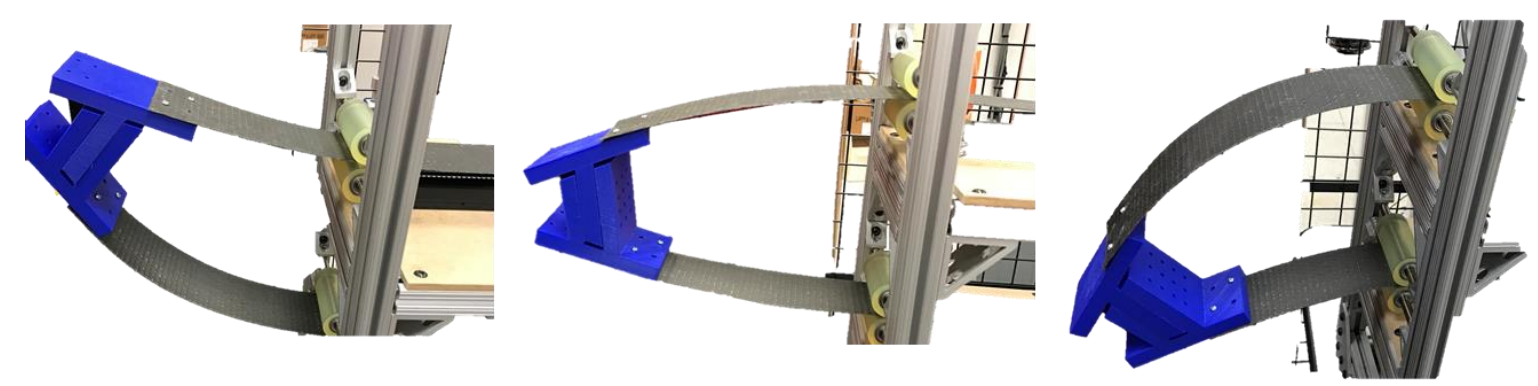

Figure 5.4:Different Deflection Modes.

In a real-life application, if only a downward deflection is required, the bottom actuator can be eliminated and replaced with a fixed bottom panel, the top panel would in turn solely control deflection by imposing a bending force on the fixed panel using the rigid support at the end.

\subsection{Deflection Angle Reverse Control}

The previous section dealt with establishing a reverse control method to use experimental data to find a relationship between deflection and the difference in length and use that relationship to 
reversely control the mechanism by inputting the deflection. In this section, another parameter is looked at for reverse control, the deflection angle $\theta$. The deflection angle is another parameter which can be specified for reverse control, essentially, specifying the angle of the end support.

Eq. 4.52 is implemented into the controller to test how accurate it is in obtaining the desired angle. Since in the previous chapter the deflection angle is found to be independent from the bottom panel length, the equation is simply a ratio relating the deflection angle to the required $\Delta \mathrm{L}$. An experiment is performed with $\mathrm{L}_{2}$ values ranging from 80 to $260 \mathrm{~mm}$ in increments of 20 $\mathrm{mm}$. With deflection angles of 0 to 30 degrees in increments of 5 degrees tested. The results obtained from this experiment are given in Table 5-5.

Table 5-5:Deflection Angle Reverse Controller Results.

\begin{tabular}{|c|c|c|c|c|c|c|c|c|c|c|}
\hline \multicolumn{1}{|l|}{$\mathrm{L} 2$} & 80 & 100 & 120 & 140 & 160 & 180 & 200 & 220 & 240 & 260 \\
\hline 0 & 0.41 & 0.56 & 0.51 & 0.55 & 0.57 & 0.56 & 0.49 & 0.51 & 0.52 & 0.65 \\
\hline 5 & 5.43 & 5.46 & 5.47 & 5.52 & 5.56 & 5.42 & 5.49 & 5.41 & 5.40 & 5.47 \\
\hline 10 & 10.30 & 10.37 & 10.57 & 10.48 & 10.64 & 10.49 & 10.37 & 10.42 & 10.39 & 10.37 \\
\hline 15 & 15.27 & 15.44 & 15.51 & 16.20 & 15.63 & 15.57 & 15.40 & 15.41 & 15.37 & 15.26 \\
\hline 20 & 20.40 & 20.56 & 20.70 & 21.28 & 20.65 & 20.67 & 20.39 & 20.18 & 20.49 & 20.06 \\
\hline 25 & 25.60 & 25.75 & 25.87 & 26.41 & 25.76 & 25.59 & 25.43 & 25.55 & 25.39 & \\
\hline 30 & 30.82 & 30.92 & 30.92 & 31.49 & 30.67 & 30.66 & 30.55 & 30.24 & 28.22 & \\
\hline
\end{tabular}

Looking at Table 5-5, there seems to be a small variation of about 0.5 degrees for the zerodegree deflection values. This variation is associated with the actual geometry of the prototype, since the set-up is not perfectly symmetric. Using this offset as the zero degree reference the results are presented in Table 5-6. 
Table 5-6:Corrected Deflection Angle Results.

\begin{tabular}{|c|c|c|c|c|c|c|c|c|c|c|}
\hline \multicolumn{1}{|l|}{$\mathrm{L2}$} & 80 & 100 & 120 & 140 & 160 & 180 & 200 & 220 & 240 & 260 \\
\hline 0 & 0.00 & 0.00 & 0.00 & 0.00 & 0.00 & 0.00 & 0.00 & 0.00 & 0.00 & 0.00 \\
\hline 5 & 5.02 & 4.90 & 4.96 & 4.97 & 4.99 & 4.86 & 5.00 & 4.90 & 4.88 & 4.82 \\
\hline 10 & 9.89 & 9.81 & 10.06 & 9.93 & 10.07 & 9.93 & 9.88 & 9.91 & 9.87 & 9.72 \\
\hline 15 & 14.86 & 14.88 & 15.00 & 15.65 & 15.06 & 15.01 & 14.91 & 14.90 & 14.85 & 14.61 \\
\hline 20 & 19.99 & 20.00 & 20.19 & 20.73 & 20.08 & 20.11 & 19.90 & 19.67 & 19.97 & 19.41 \\
\hline 25 & 25.19 & 25.19 & 25.36 & 25.86 & 25.19 & 25.03 & 24.94 & 25.04 & 24.87 & \\
\hline 30 & 30.41 & 30.36 & 30.41 & 30.94 & 30.10 & 30.10 & 30.06 & 29.73 & 29.70 & \\
\hline
\end{tabular}

Table 5-6 shows the results adjusted for that physical offset. The results follow the inputted deflection very closely and show that the controller can be used very accurately for reverse deflection angle control. Using the following equation, the percent error can be computed:

$$
\% \text { error }=\frac{\mid \text { measured deflection angle }- \text { inputted deflection angle } \mid}{\mid \text { inputted deflection angle } \mid} \times 100 \%
$$

The percent errors obtained for the deflection angle experiment are given in Table 5-7.

Table 5-7:Percent Error for Angle Deflection Experiment.

\begin{tabular}{|c|c|c|c|c|c|c|c|c|c|c|}
\hline \multicolumn{1}{|l|}{ L2 } & 80 & 100 & 120 & 140 & 160 & 180 & 200 & 220 & 240 & 260 \\
\hline 0 & & & & & & & & & & \\
\hline 5 & 0.35 & 1.93 & 0.78 & 0.59 & 0.22 & 2.83 & 0.04 & 1.97 & 2.39 & 3.65 \\
\hline 10 & 1.07 & 1.89 & 0.58 & 0.66 & 0.71 & 0.68 & 1.23 & 0.93 & 1.27 & 2.76 \\
\hline 15 & 0.92 & 0.83 & 0.01 & 4.36 & 0.37 & 0.06 & 0.60 & 0.69 & 0.98 & 2.58 \\
\hline 20 & 0.03 & 0.00 & 0.95 & 3.65 & 0.39 & 0.54 & 0.50 & 1.65 & 0.15 & 2.94 \\
\hline 25 & 0.78 & 0.76 & 1.44 & 3.44 & 0.76 & 0.13 & 0.24 & 0.16 & 0.52 & \\
\hline 30 & 1.36 & 1.19 & 1.36 & 3.14 & 0.35 & 0.32 & 0.21 & 0.91 & 0.99 & \\
\hline
\end{tabular}

The results show that the developed deflection angle is very effective and can be utilized for reversely controlling the deflection angle. Small variations do exist, which are associated with variations in data reading, due to the scanner being extremely sensitive. Thus, the mechanism can now be controlled either by inputting the deflection required or the deflection angle required. 
What is of interest is the linear nature of the deflection and deflection angle results, the next section explores why this relationship may be linear and what limitations are associated with it.

\subsection{Arc Representation}

In the previous sections, very interesting results are obtained, where a non-linear system produces linear deflection and deflection angle results. This section explores the problem analytically based on the results from the experimental study.

The experimental results found that the deflection and deflection angle linearly vary with $\Delta \mathrm{L}$. The deflection angle is found to be independent from the length of the bottom panel, $\mathrm{L}_{2}$, and the deflection is found to differ with varying values of $L_{2}$. Assuming a quasi-rigid model of the mechanism resembles the following:

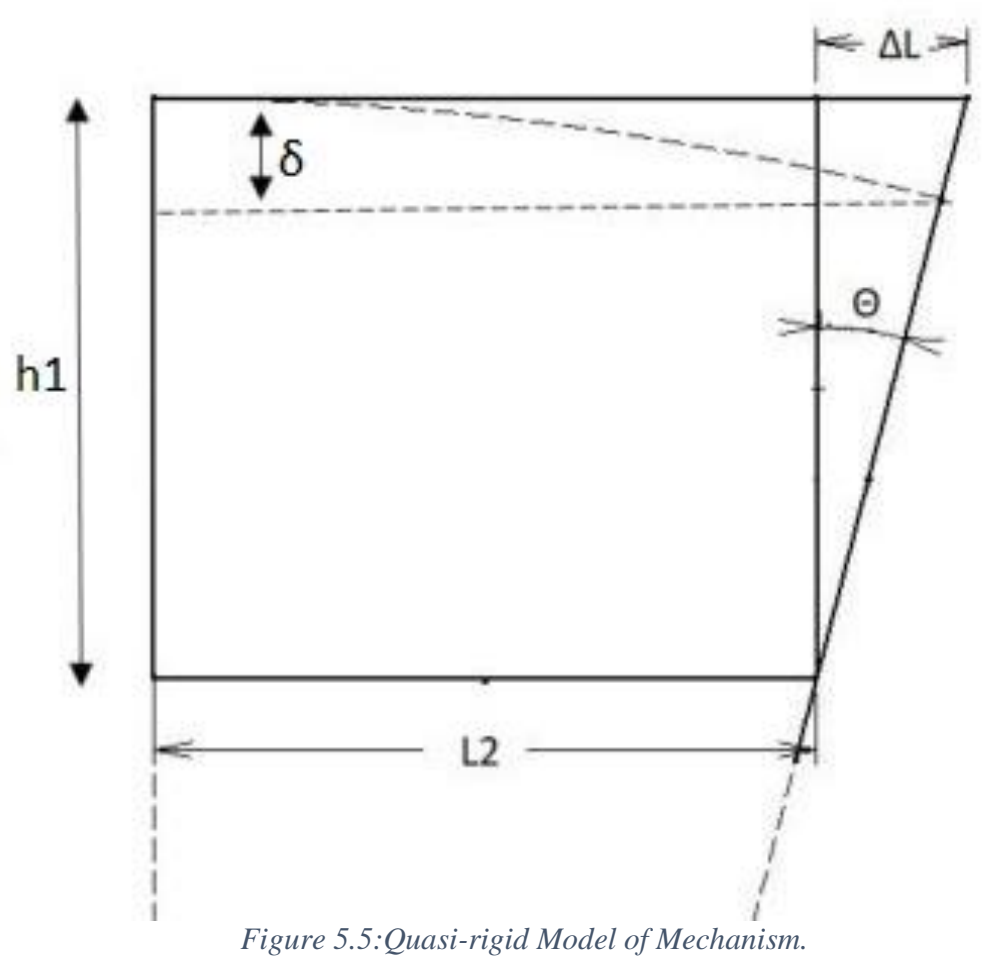

Where the panel moves in a circular $\operatorname{arc}$ of radius $\mathrm{r}$, as $\Delta \mathrm{L}$ is increased: 


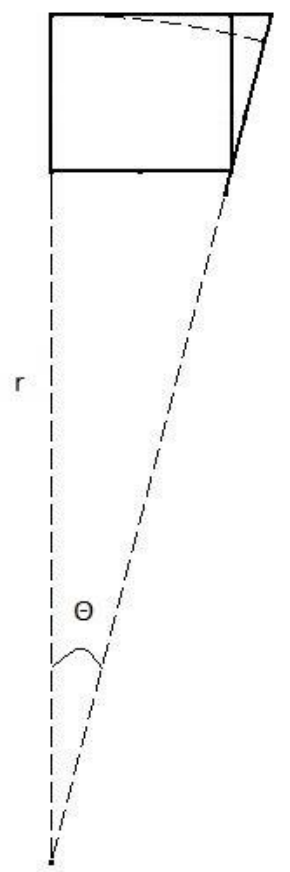

Figure 5.6:Circular Arc Motion of the Panel.

From Figure 5.5, the deflection angle can be calculated using:

$$
\theta=\tan ^{-1}\left(\frac{\Delta L}{h_{1}}\right)
$$

From Eq. 5.8, it can be seen that the deflection angle is a function of the length change and the distance between the two panels. If this ratio is small enough, it can be in the linear region of the inverse tan function. By looking at the plot for the inverse tan function, this linear region is valid for ratios approximately less than 0.2. Since the experiments did not have big $\Delta \mathrm{L}$ values, with regards to $h_{1}$, the values for the deflection angle are fairly linear, which confirms this assumption. This assumption identifies the limitation of the design and for which ranges it can be properly controlled.

Using the characteristics of arc geometry, the deflection can also be obtained. The length of an arc can be calculated using:

$$
L=\theta r
$$


Where $\mathrm{r}$ is the radius of the arc. In this case, the arc length is essentially the length of the bottom panel with the difference in length added to it:

$$
L=L_{2}+\Delta L
$$

Combining Eq. 5.9 and Eq. 5.10 and solving for $\mathrm{r}$ yields

$$
r=\frac{L_{2}+\Delta L}{\theta}
$$

The deflection can now be obtained by finding the difference in $r$ due to the deflection angle, using:

$$
\delta=r(1-\cos \theta)
$$

This analysis goes in agreement with the experimental results, since the deflection is not only effected by the difference in length, but by the length of the bottom panel $\mathrm{L}_{2}$ as well.

The analytical results and the experimental results for angles are given in Table 5-8.

Table 5-8:Calculated Deflection Angle vs Measured.

\begin{tabular}{|c|c|c|c|c|c|c|}
\hline$\Delta \mathrm{L}$ & Calculated & Exp1 & Exp2 & Exp3 & Exp4 & Exp5 \\
\hline 20.00 & 5.44 & 4.95 & 7.48 & 4.67 & 5.09 & 4.87 \\
\hline 40.00 & 10.79 & 9.99 & 12.35 & 11.22 & 10.50 & 10.53 \\
\hline 60.00 & 15.95 & 15.28 & 18.10 & 16.90 & 16.20 & 16.10 \\
\hline 80.00 & 20.87 & 21.70 & 23.80 & 21.50 & 21.30 & 20.50 \\
\hline
\end{tabular}

Comparing the calculated deflection angle to the measured one in Table 5-8, it can be seen that the results are close, with some variations, suggesting that the mechanism does deform in a circular pattern for the aspect ratios tested. As discussed above changing the aspect ratio would impact the linear behaviour, since it would be out of the linear region of the inverse tan function. The deflection results compared to the calculated deflection using Eq. 5.12 are given in Table 59. 
Table 5-9:Calculated Deflection vs Measured.

\begin{tabular}{|c|c|c|c|c|c|c|c|c|c|c|}
\hline$\Delta \mathrm{L}$ & Calc & Exp1 & Calc & Exp2 & Calc & Exp3 & Calc & Exp4 & Calc & Exp5 \\
\hline 20.0 & 5.7 & 10.9 & 7.4 & 16.7 & 9.5 & 21.5 & 11.6 & 13.9 & 13.3 & 13.9 \\
\hline 40.0 & 13.1 & 18.7 & 16.4 & 26.1 & 20.6 & 33.4 & 24.9 & 23.6 & 28.1 & 27.5 \\
\hline 60.0 & 22.1 & 27.8 & 27.0 & 37.4 & 33.2 & 45.8 & 39.4 & 40.4 & 44.2 & 41.5 \\
\hline 80.0 & 32.4 & 37.3 & 38.7 & 48.0 & 46.8 & 57.3 & 54.9 & 53.2 & 61.2 & 56.0 \\
\hline
\end{tabular}

The results in Table 5-9 show an offset for the deflection in the first 3 experiments, whereas, for experiments 4 and 5 the results seem very close. This could be an indication that for larger lengths, the mechanism behaves in a more circular manner, in comparison to smaller lengths. The difference can also be associated with the quasi-rigid model differing in configuration from the actual experimental set up. In the experimental set up, a taper ratio is introduced, making the distance between the panels at the root different from the tip. This could be affecting the analytical results. However, looking at the results for the angle calculations vs the measured ones and the nature of the inverse tan function, it can be concluded that the mechanism behaves linearly due to the ranges of aspect ratio studied and due that the mechanism deforms in a circular pattern. 


\section{CONCLUSIONS}

\subsection{Summary}

The flexible trailing edge concept presented, brings a camber modification method for a morphing wing concept. The mechanism takes advantage of a rigid connection constraint at the end of two flexible panels to produce an upward or downward deflection by changing the lengths of the two panels. A prototype to demonstrate the concept and perform an experimental analysis on is designed and built. The flexible panels are hand lay-up carbon fiber/epoxy laminates, capable of bending while being strong to carry loads, with the end rigid support rapidly prototyped. The entire assembly was housed within an aluminum frame with two single axis linear actuators with a DC motor driving each actuator. The motors were controlled using a brushless DC motor controller.

After the functioning prototype is built and tested, an experimental study is performed by reading the deformation of the two flexible panels using a 3D scanner, which provided coordinates specific to a fixed reference point. The shape data is gathered for different lengths and difference in lengths between the two panels. Based on the experimental data a function is developed for predicting the panel deformations based on the change in length input, which can be used for real time shape control.

The next part of the experimental study consisted of using the deflection and deflection angle results to develop a reverse control method. The deflection is found to be linearly correlated to the difference in length between the top and bottom panels. However, that relationship is different for each length for the bottom panel, therefore, a relationship is established to relate the length of the bottom panel to the slop of the relationship between the difference in length and the deflection. All of which is incorporated into a script written in MATLAB which sends 
microscript commands to the controller via serial connection. A graphic user interface is developed to simplify the control process. A couple of trails are performed using the newly developed controller to obtain a correction factor to further refine the performance of the controller, which is incorporated into the controller. The deflection angle is found to be independent from the bottom panel length and an empirical equation is successfully developed to reversely control the mechanism, using the deflection angle as an input.

\subsection{Contributions}

The work in this thesis combines several concepts to come up with a controllable variable camber trailing edge concept for a morphing wing. The first contribution is the design and fabrication of the mechanism, using a parametric approach. The design utilizes a flexible panel system to produce a deflection when a difference in length is present, due to defined boundary conditions.

The second contribution is using experimental data collected to produce shape prediction functions. The functions provide a relationship to the coefficients for the fitting lines used to fit the experimental data. Each length produces different functions, making finding a unified shape prediction technique difficult.

Lastly, utilizing experimental data to examine the relationship between the length of the panels and the deflection and deflection angle. Then, using those relationships, developing a reverse control method. The method uses user input to calculate required lengths to obtain the desired deflection and deflection angles. Further experimental data is then used to fine tune the

controller. Based on the experimental data analysis, an analytical model is developed to simplify the deformation of the mechanism. The model uses basic geometric relations to try and quantify the behaviour of the mechanism. 


\subsection{Future Work}

The topics presented in this thesis present the idea for the flexible trailing edge mechanism, while demonstrating how the behaviour of the mechanism can be controlled using empirical equations developed from experimental data. However, there is still a lot to be done in order for the concept to be fully implementable in flight.

The design and analysis was performed on a small width section, with constant dimensions throughout. The next step would be to apply the same concept to a larger flexible panel, which tapers along its width and study the effects the taper has on the deformation and whether the results obtained for the constant cross section would resemble those obtained for the tapered and wide design. The rigid end support would act as a rear spar running through the span of the flexible panel onto which the two panels are attached. Since the current design incorporates the actuation units in a large rectangular frame, the next step would be reducing the space taken up by the actuators in order to fit everything with the rigid structure of the wing. A possible solution to this would be the elimination of the bottom actuator and fixing the bottom panel onto the rigid frame, thus, having the top panel exert a bending moment as it changes its length and produce a deflection. This would also allow the design to be tweaked in order to remove the rollers and replace them with a mounting method which can be easily transferred to a wing cross section, since the roller would require a lot of modifications to the existing wing cross section in order to be implemented. Essentially, most of the future work for this project would involve taking the demonstrated concept and tweaking it so that it could be easily integrated into a wing section, in order to replace the traditional trailing edge, with all the actuation fitted within the available geometry. Another area of interest would be using an airfoil mold in the lay-up process for the flexible panels and to see how if the airfoil shape deforms differently from the flat panel. 
An observation made during the experimentation process was that the structure was too flexible or shaky, meaning any small disturbance would cause the two panels to shake up and down, which brings up a lot of questions about how the mechanism would behave under vibrations and aerodynamic loads. This is an area that must be addressed in the future, where a collapsible mechanism can be used to provide extra support. A concept tested and found to significantly reduce this phenomenon was attaching honeycomb core plastic sheet to the ends of the two panels towards the end section, however, the effects this support has on the deformation of the panels must be studied. A modification to this idea would be using a honeycomb structure capable of shearing, thus, not effecting the deformation while giving the structure rigidity.

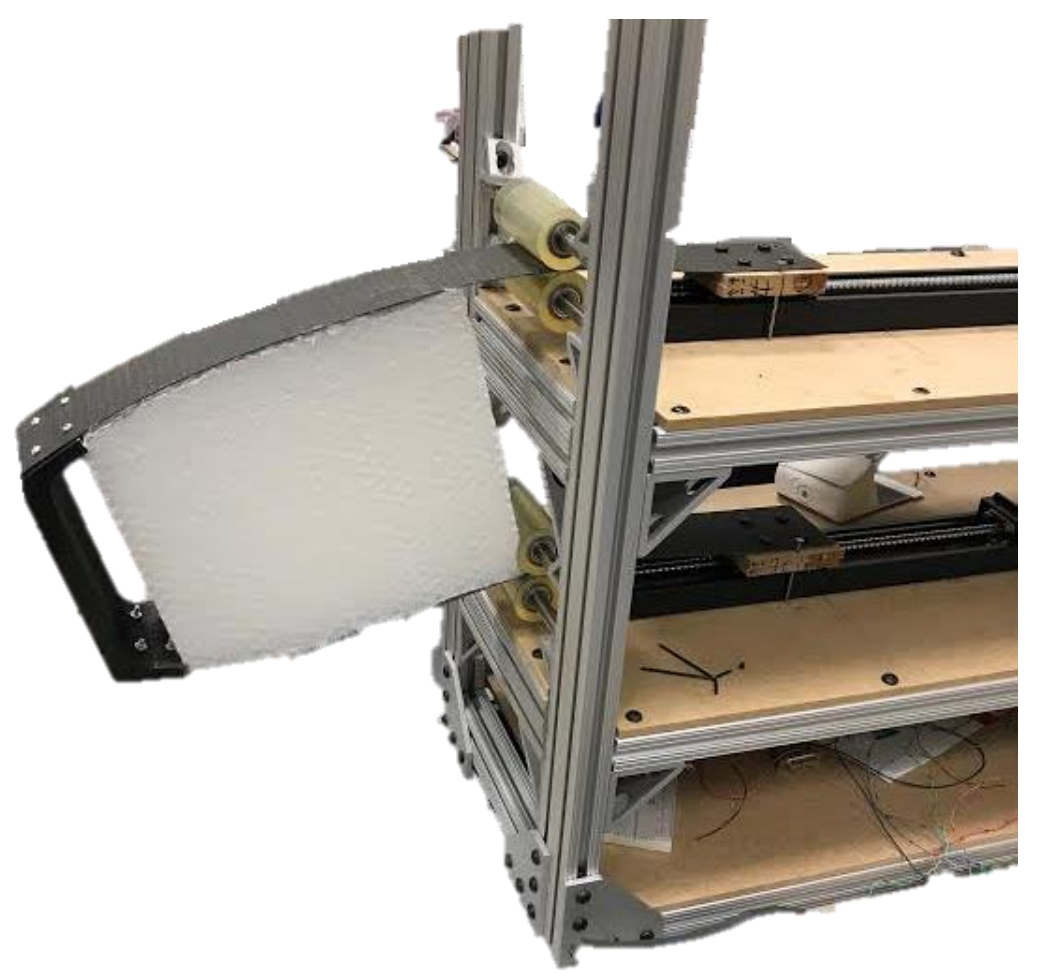

Figure 6.1:Honeycomb Core for Increased Rigidity. 


\section{APPENDICES}

Engineering Drawings

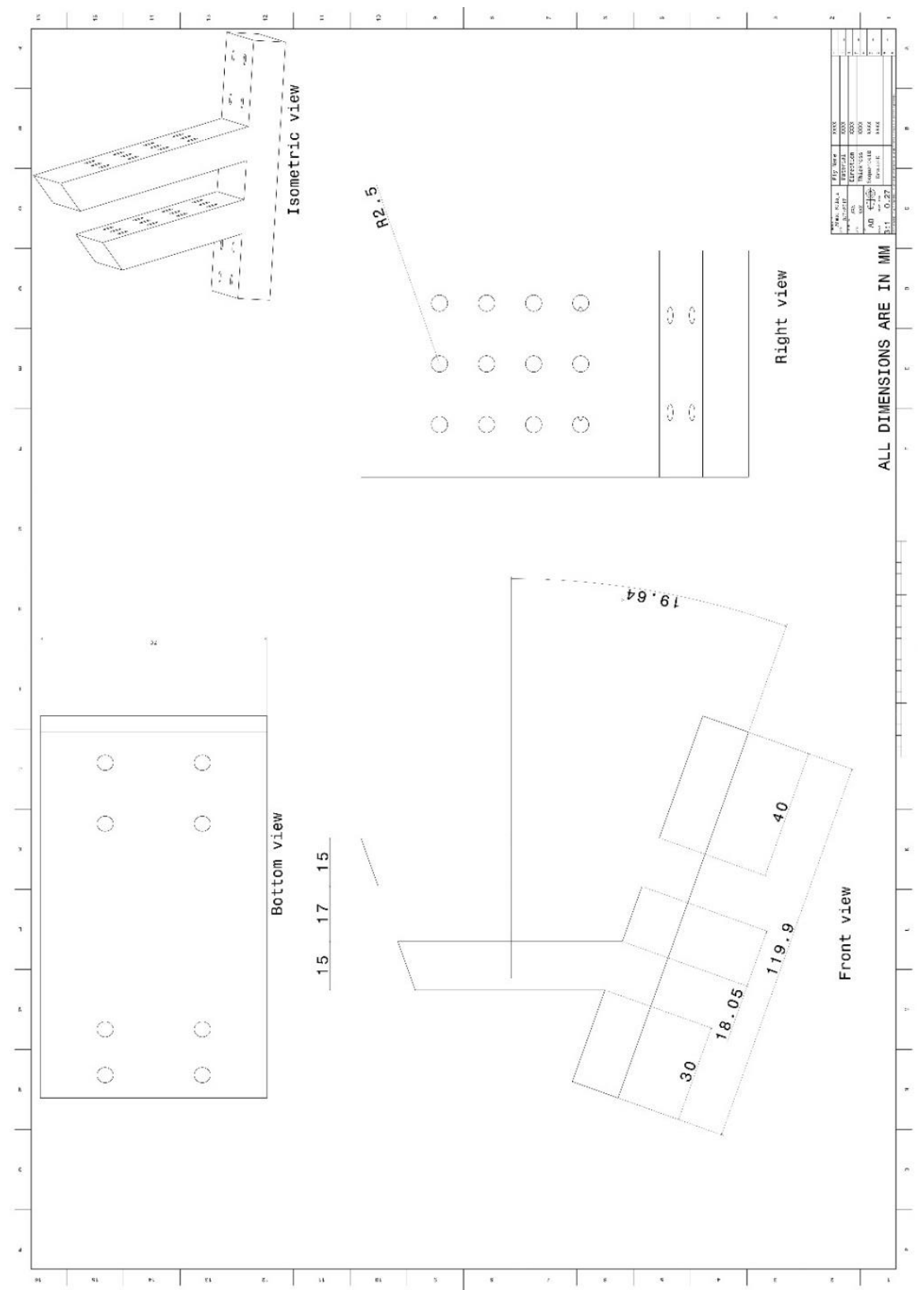

Figure A.0.1:Engineering Drawings for First Support Part 1. 


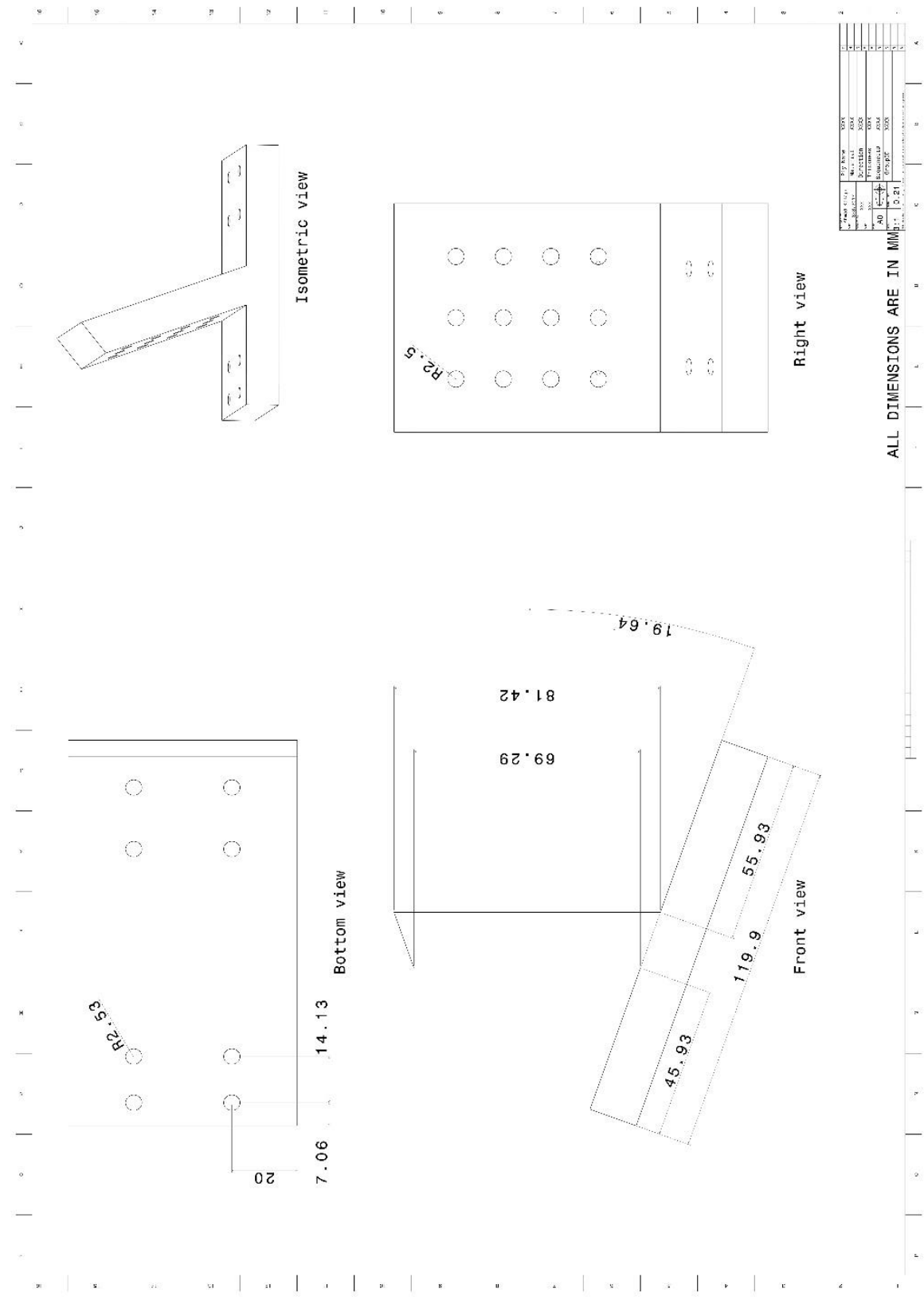

Figure A.0.2: Engineering Drawings for First Support Part 2. 


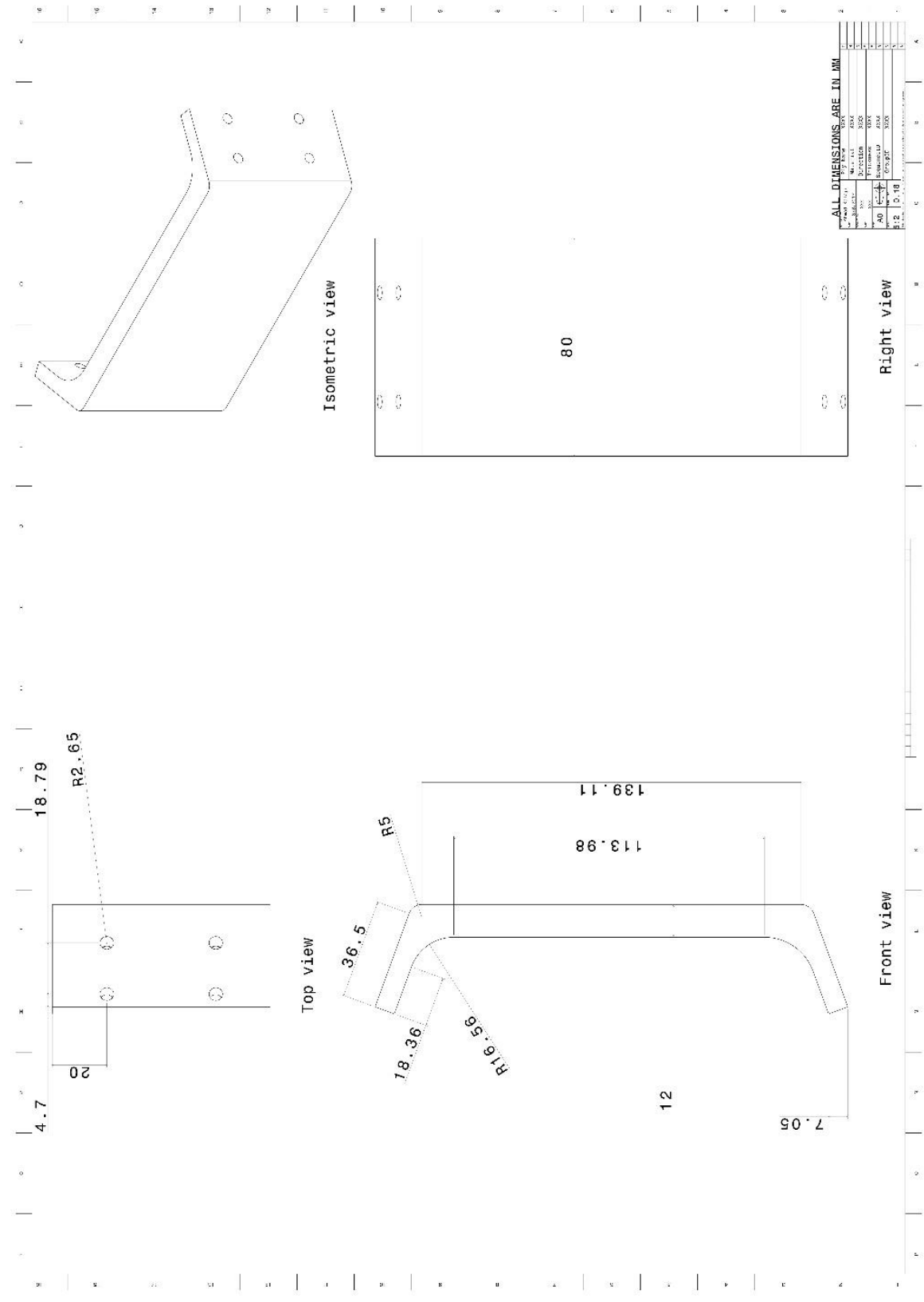

Figure A.0.3:Engineering Drawings for Second Support. 


\section{Software}

This section contains all the codes used in this thesis. The first code is the data processing one, in charge of obtaining the raw data and processing it for each one of the experiments.

\section{Raw Data Processing and Analysis}

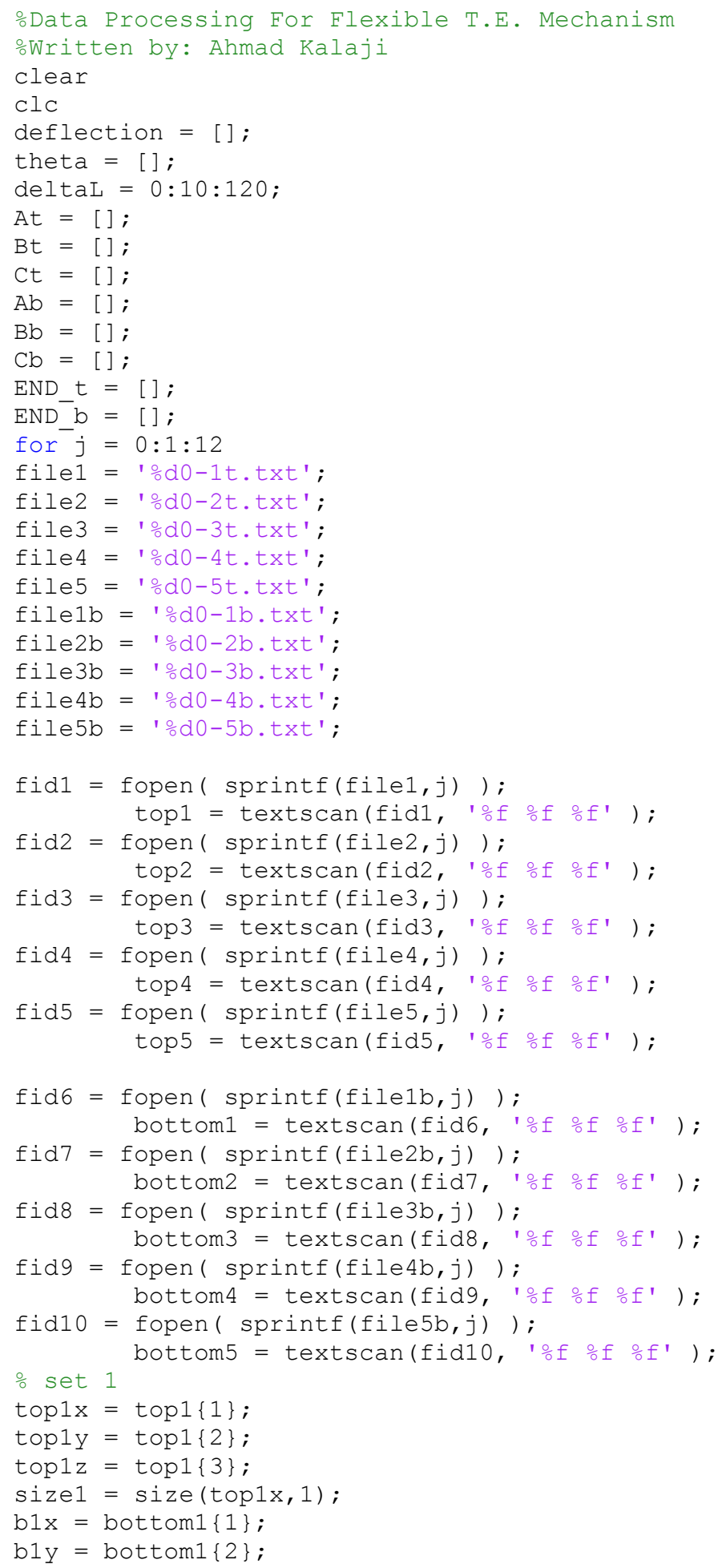




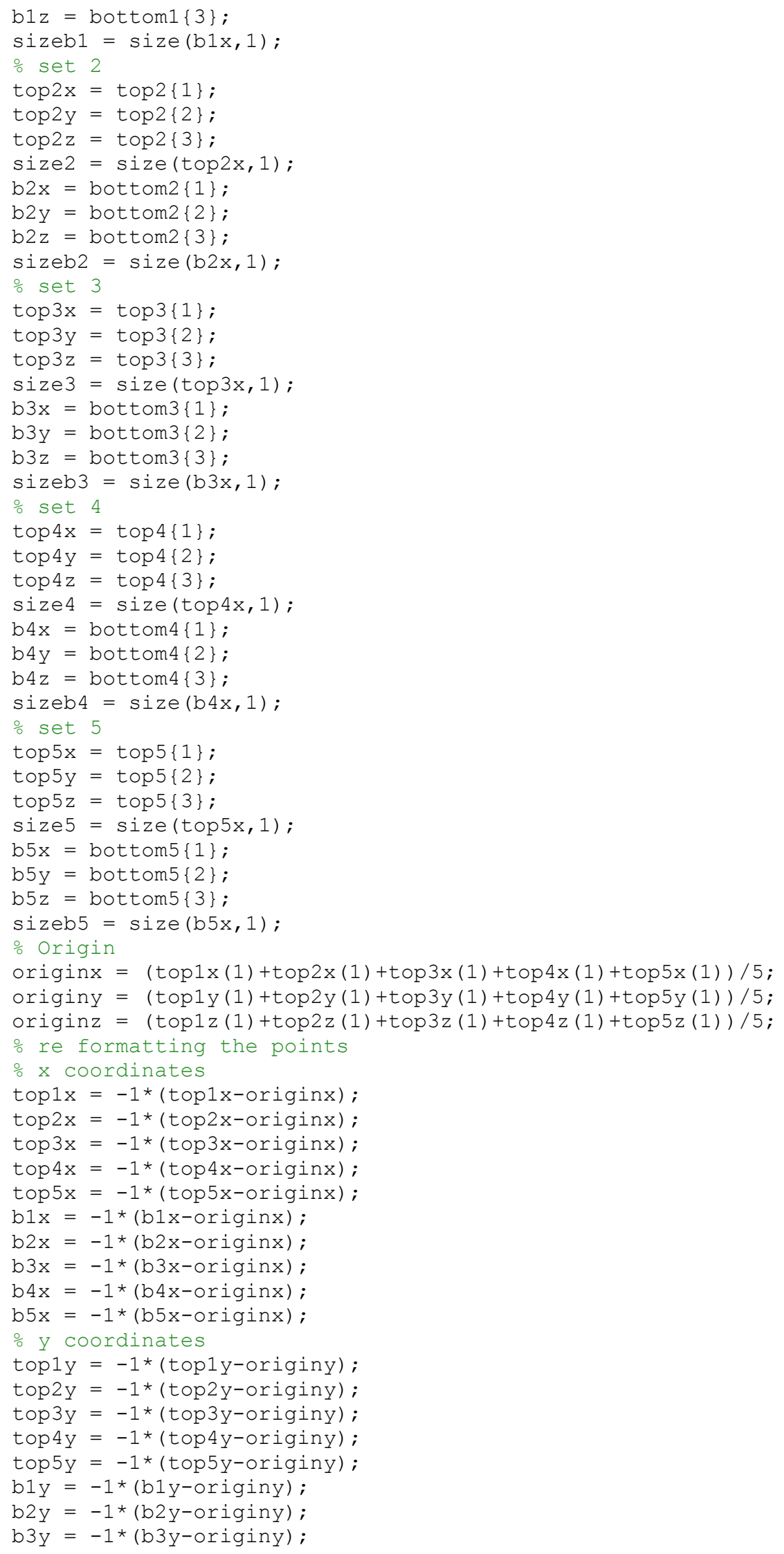




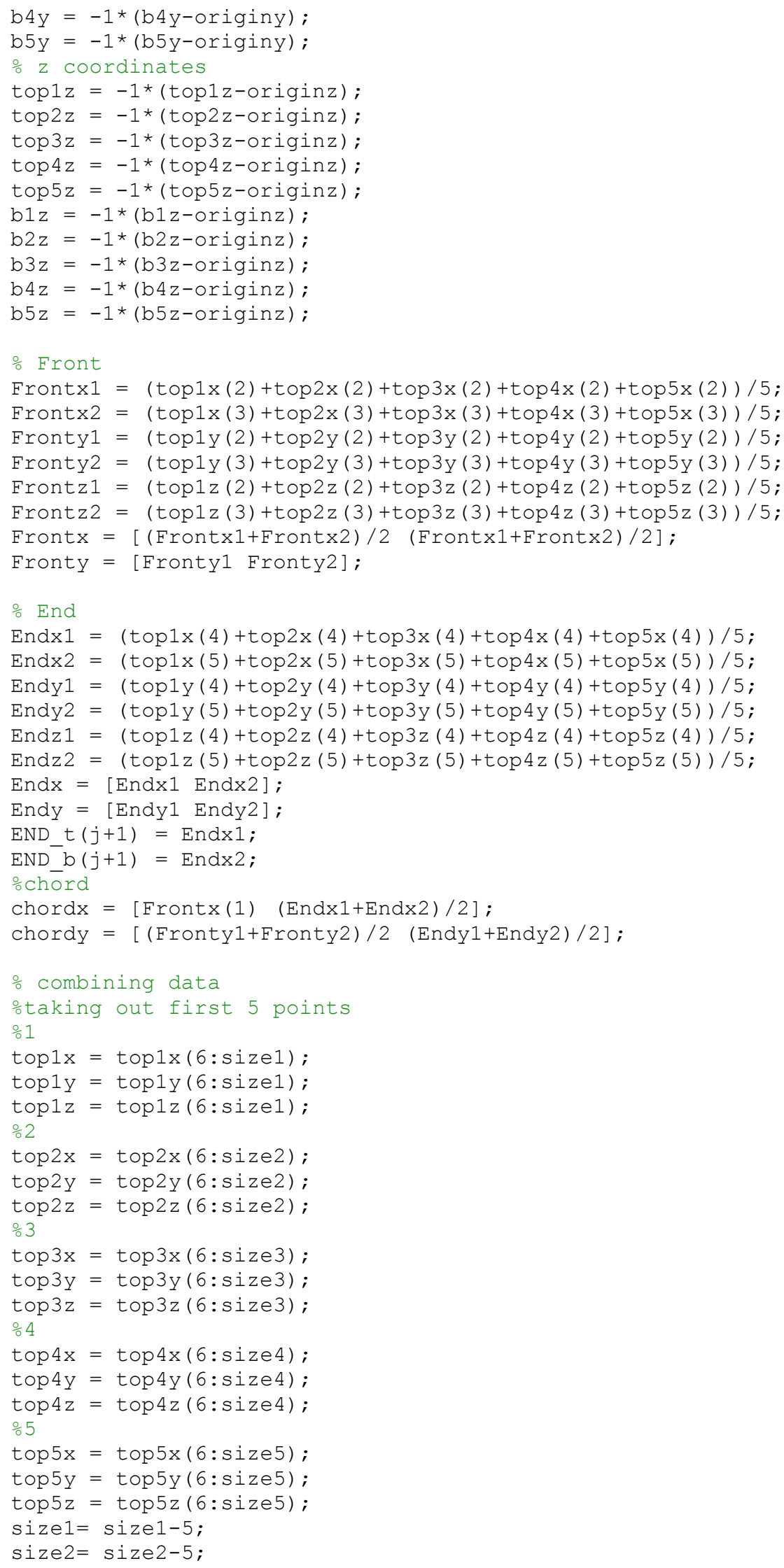




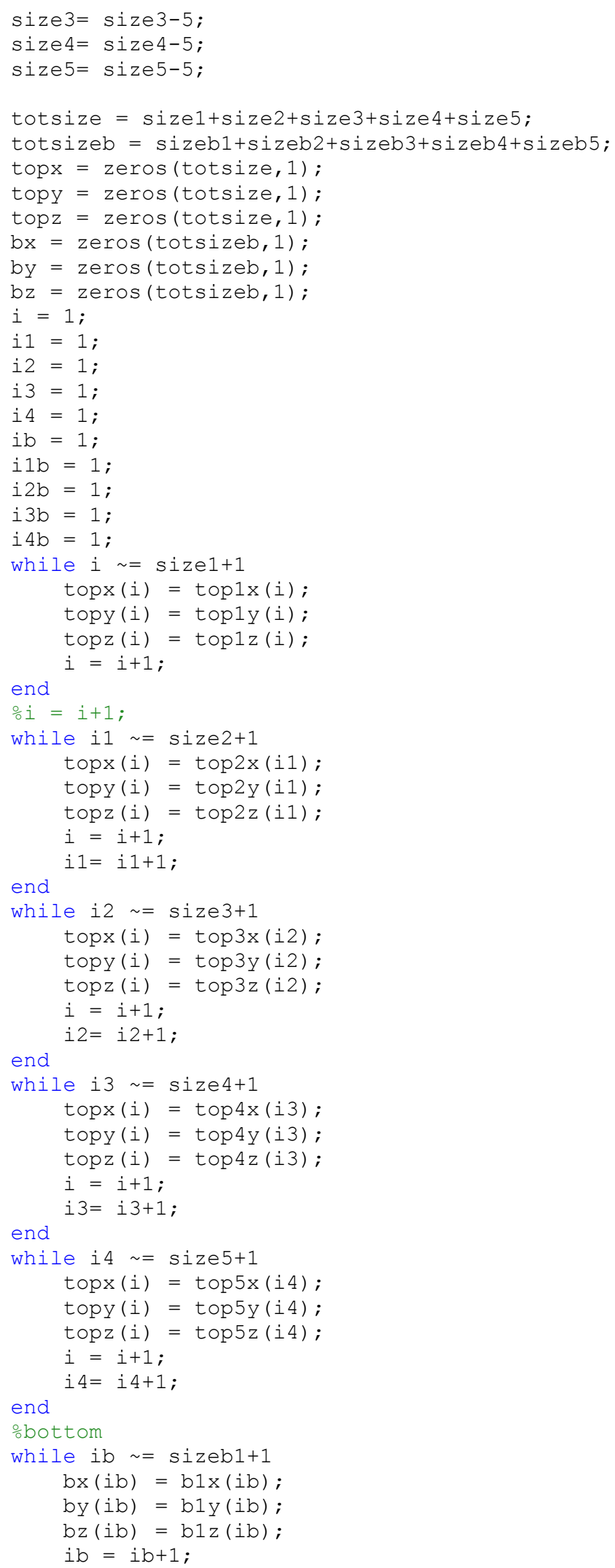




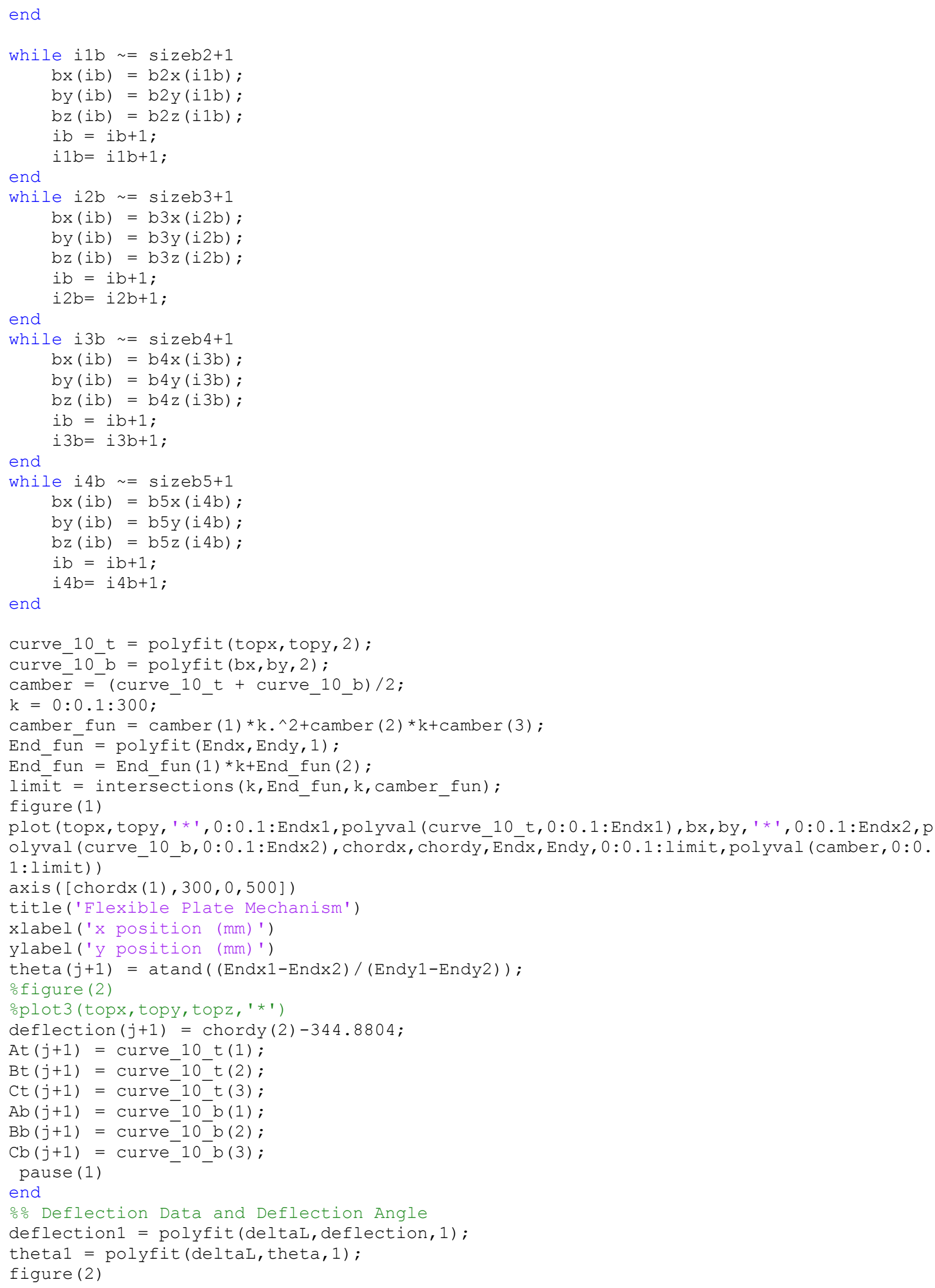




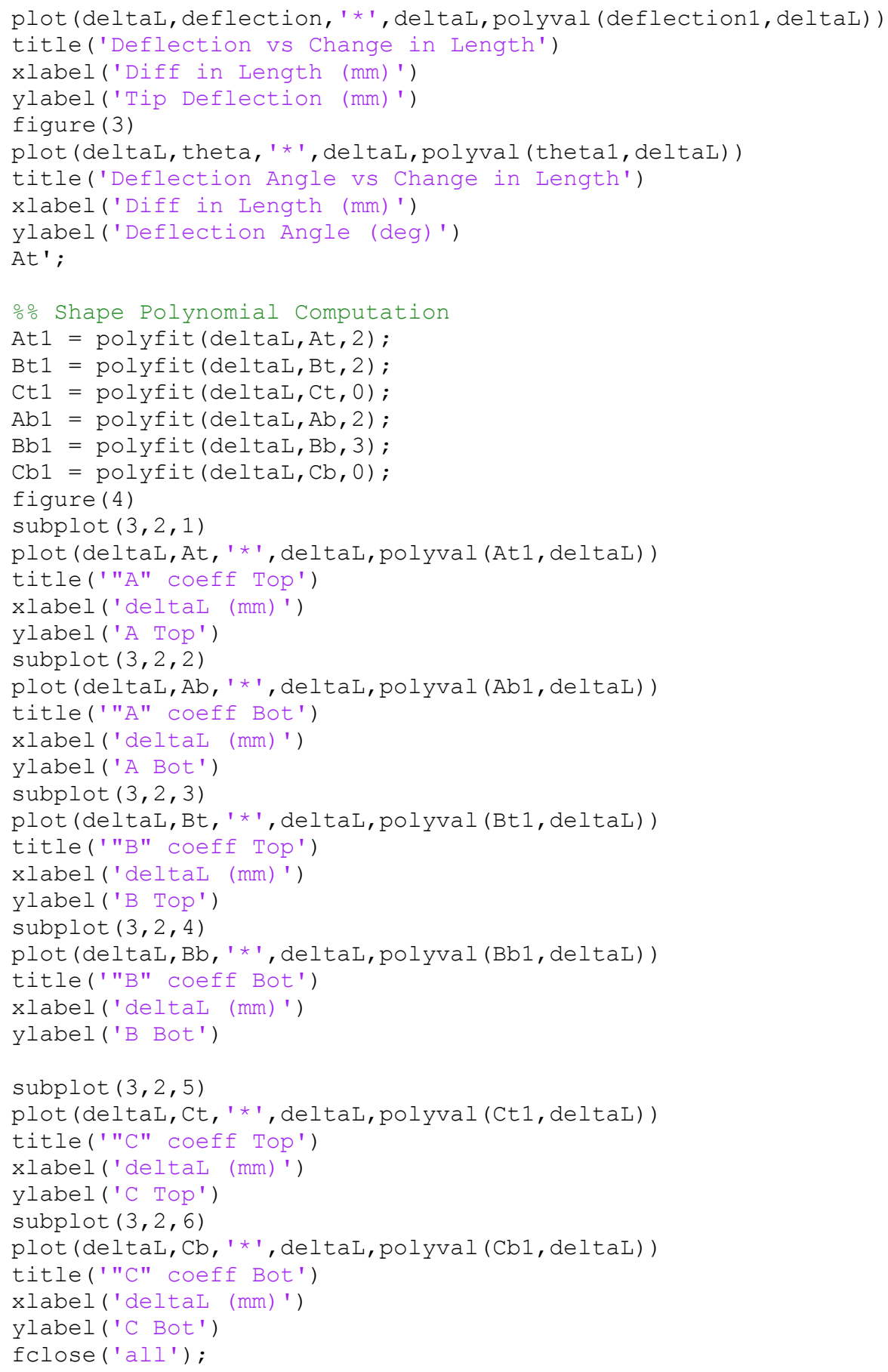




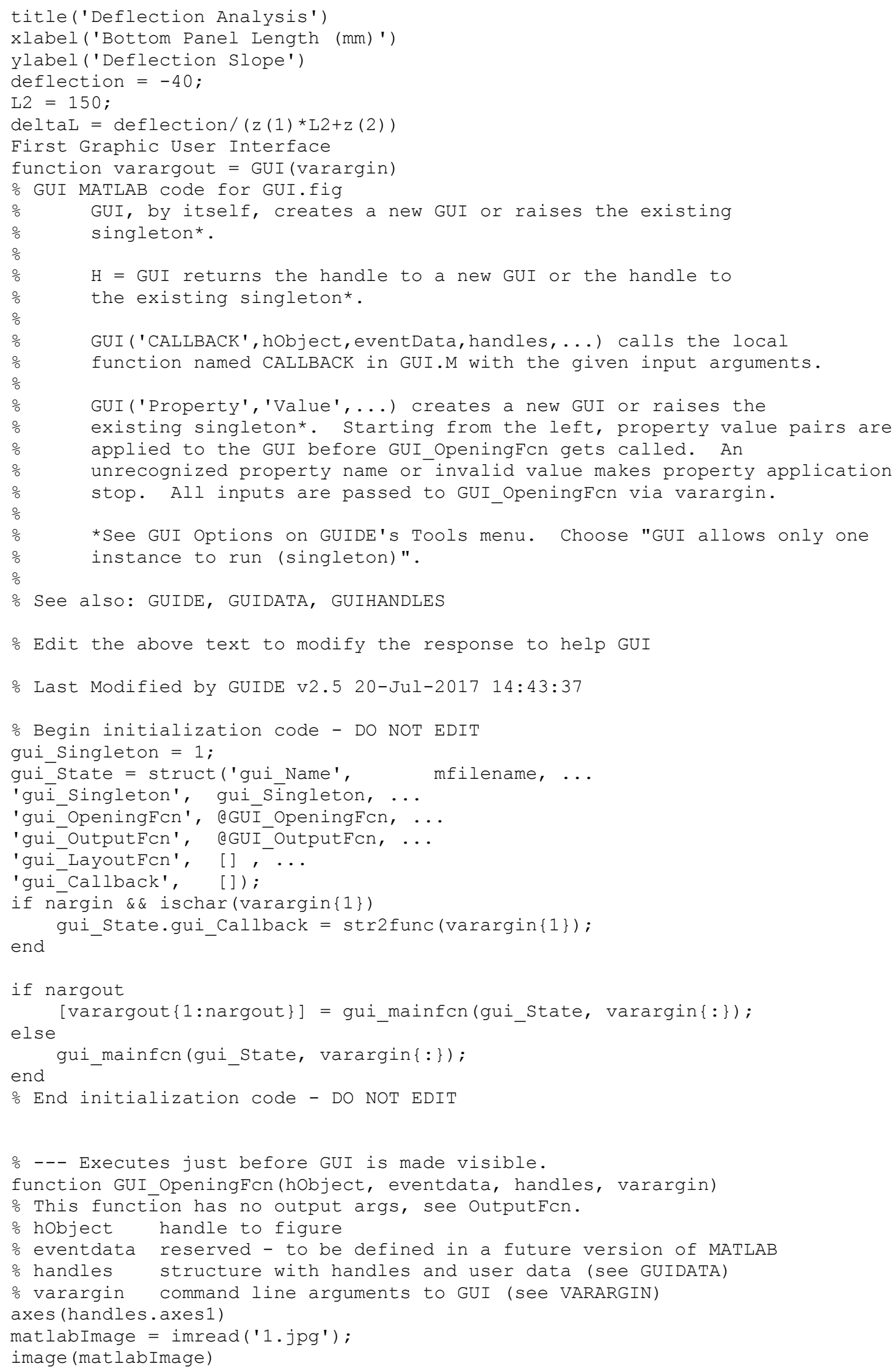




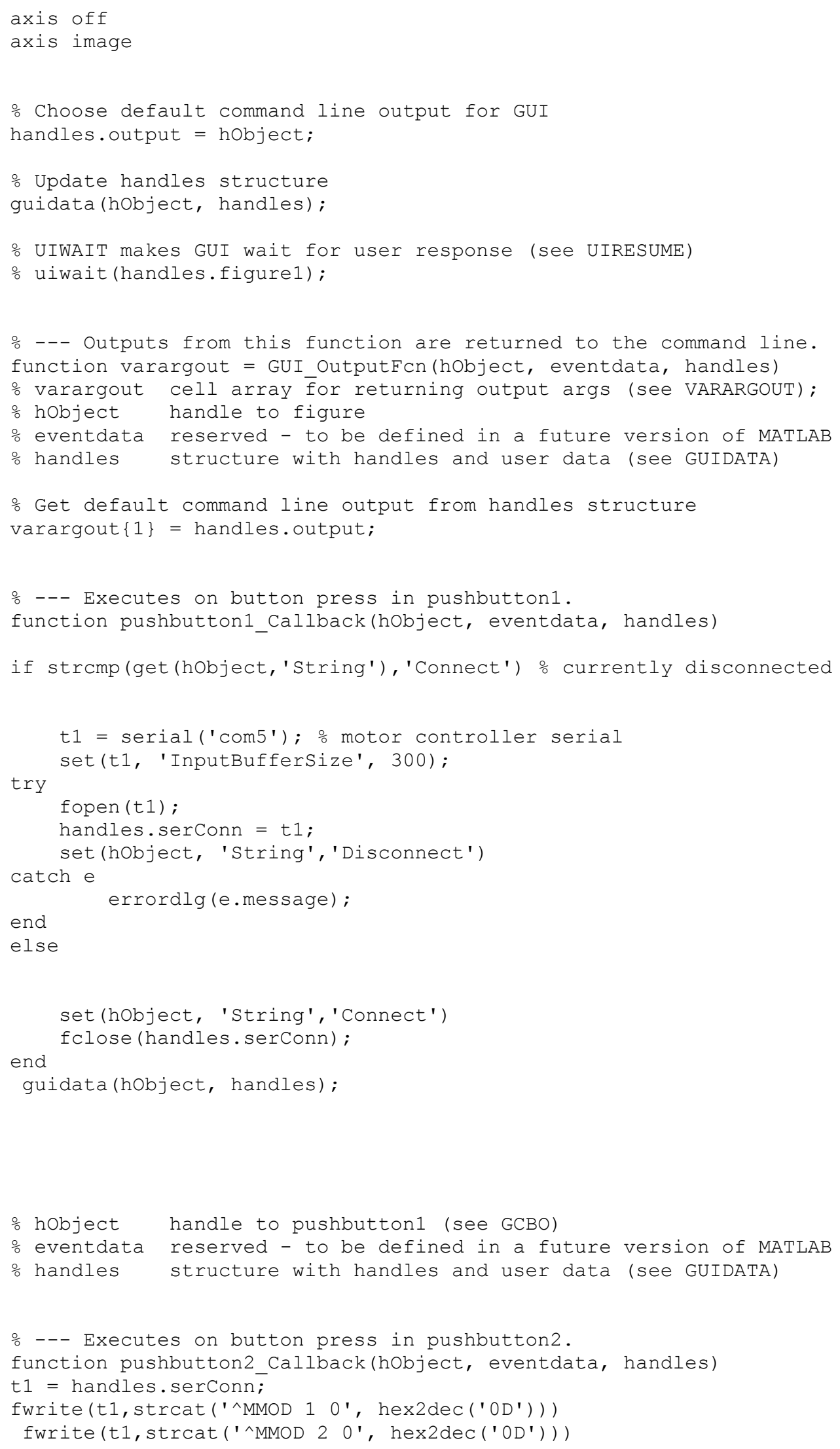




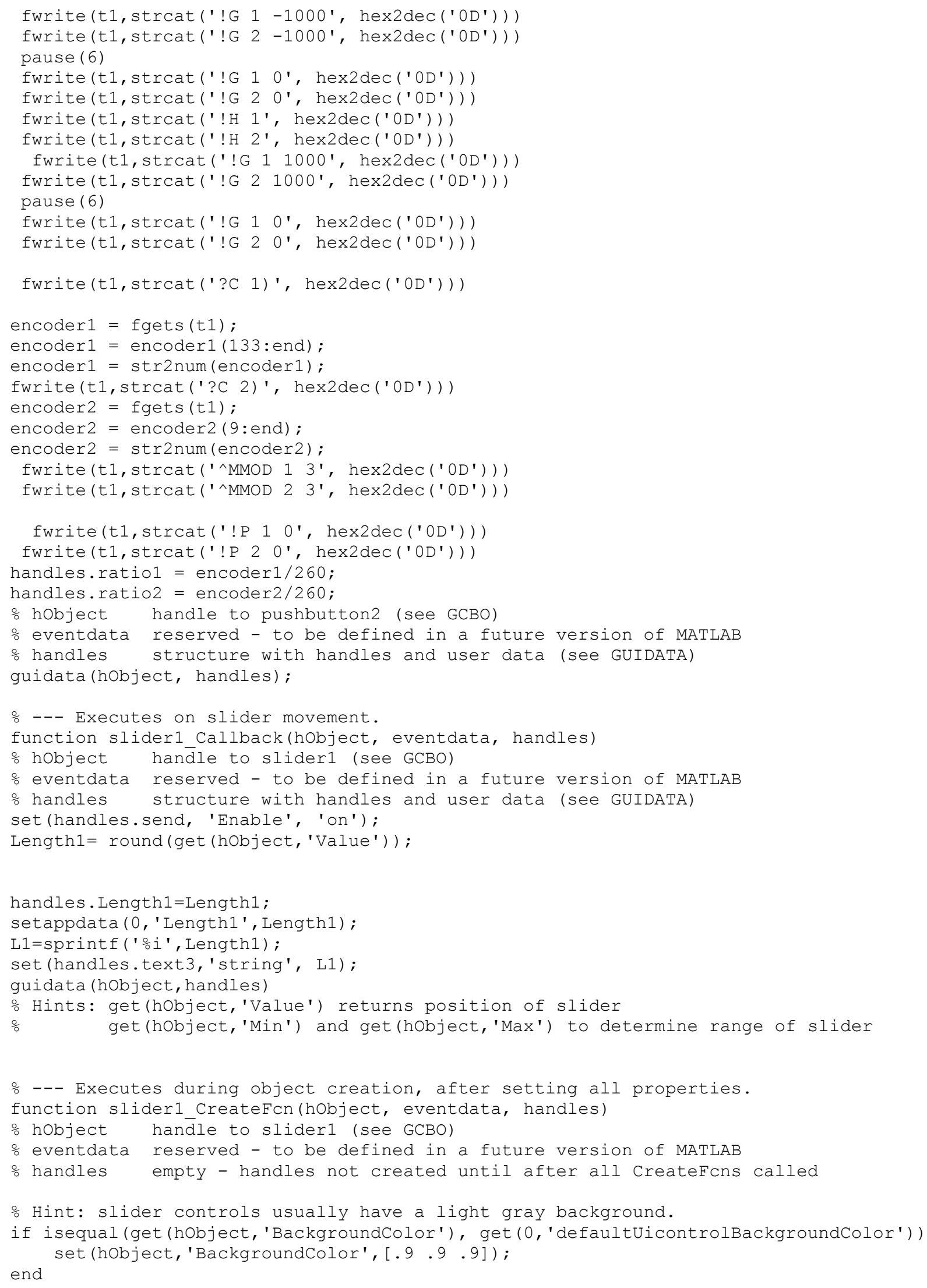




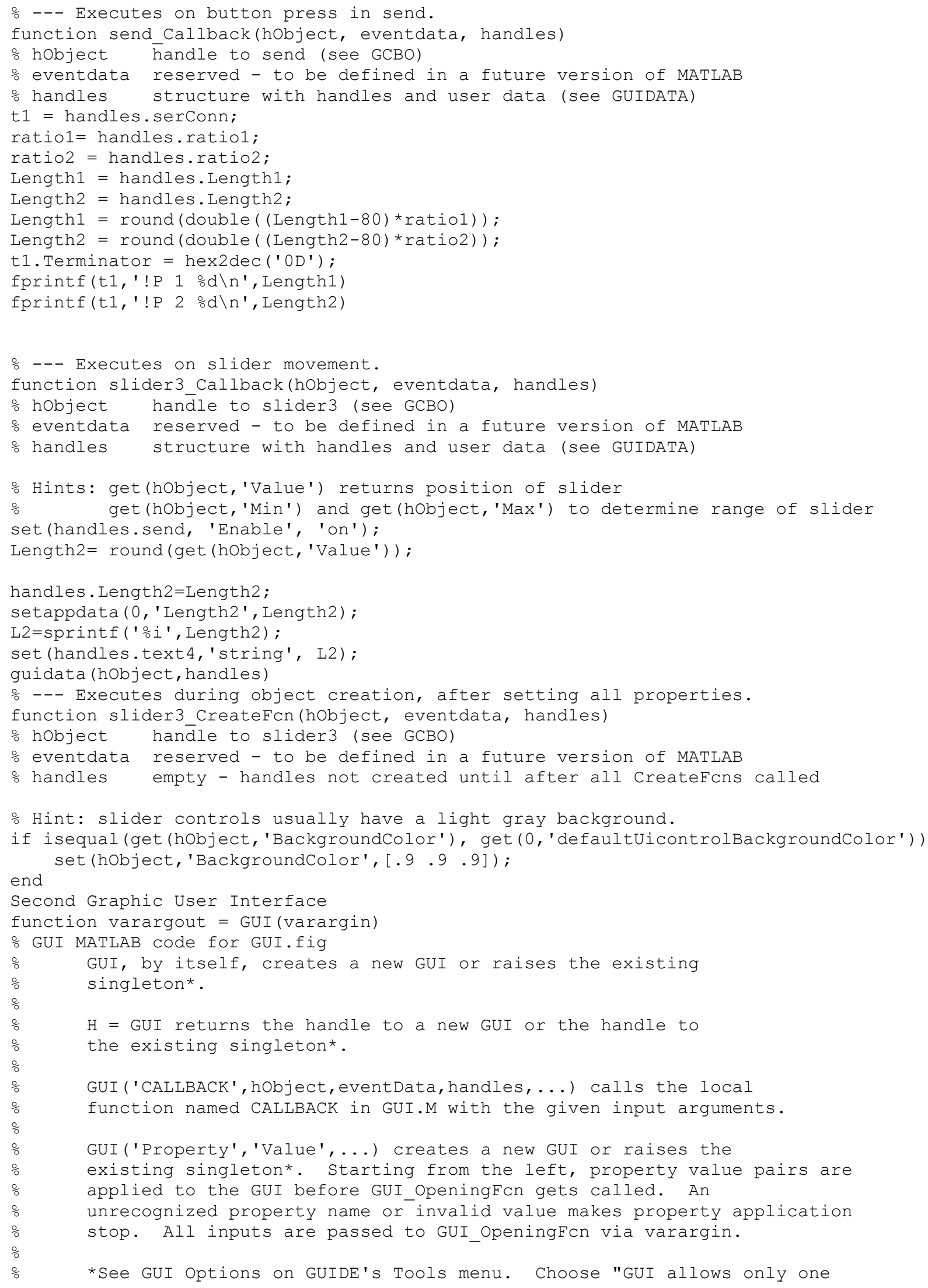




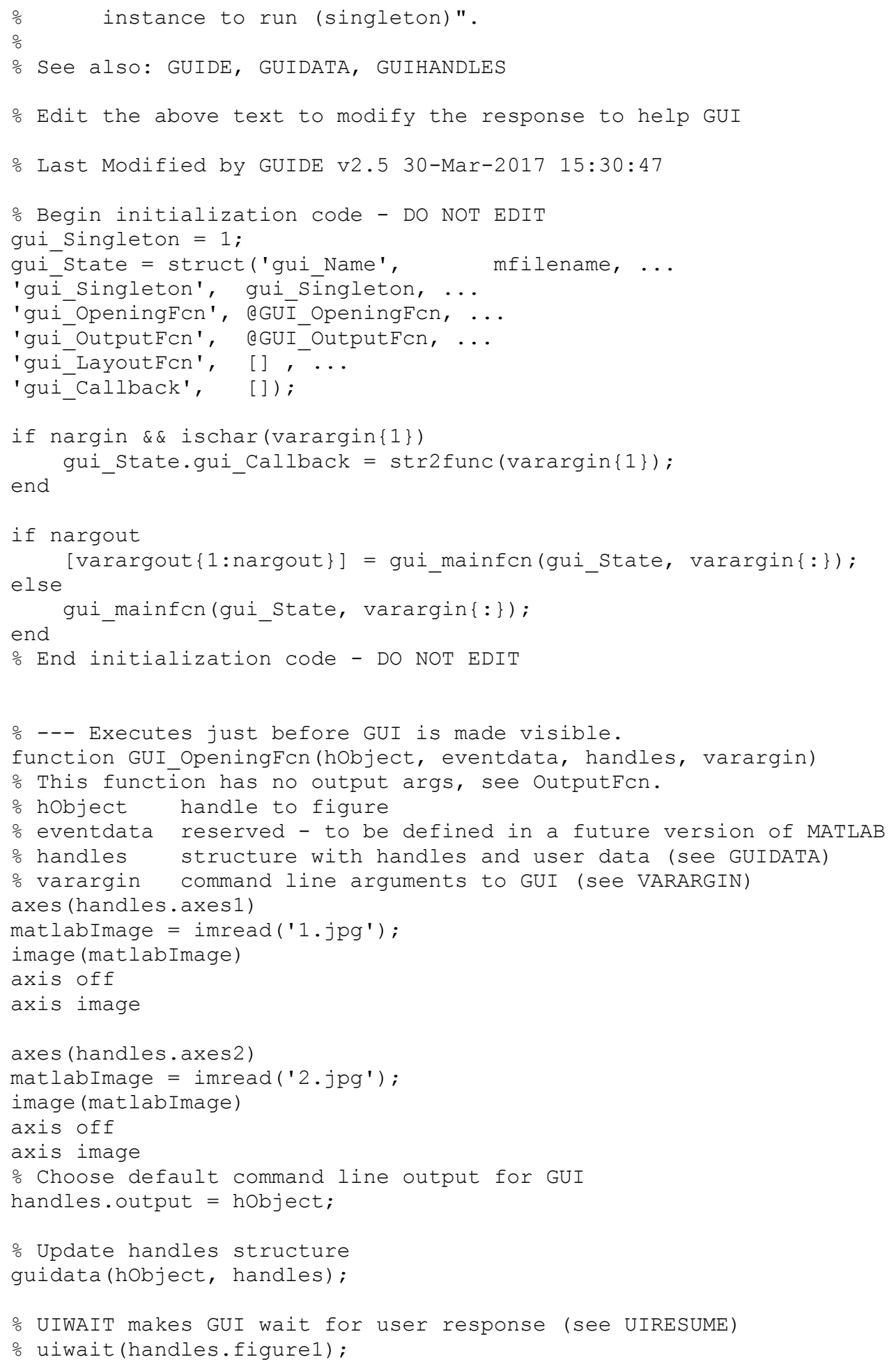


\% Get default command line output from handles structure

varargout $\{1\}=$ handles.output;

\%--- Executes on button press in pushbutton1.

function pushbutton1 Callback(hobject, eventdata, handles)

set (handles.send, 'Eñable', 'off');

if strcmp (get(hobject, 'String'), 'Connect') \% currently disconnected

t1 = serial ('com5'); $\%$ motor controller serial

set(t1, 'InputBufferSize', 300);

try

fopen (t 1$)$;

handles.serconn $=$ t 1 ;

set (hobject, 'String', 'Disconnect')

catch e

end

errordlg (e.message);

else

set (hobject, 'String', 'Connect')

end

fclose (handles. serConn);

guidata (hobject, handles);

\% hobject handle to pushbuttonl (see GCBO)

\% eventdata reserved - to be defined in a future version of MATLAB

\% handles structure with handles and user data (see GUIDATA)

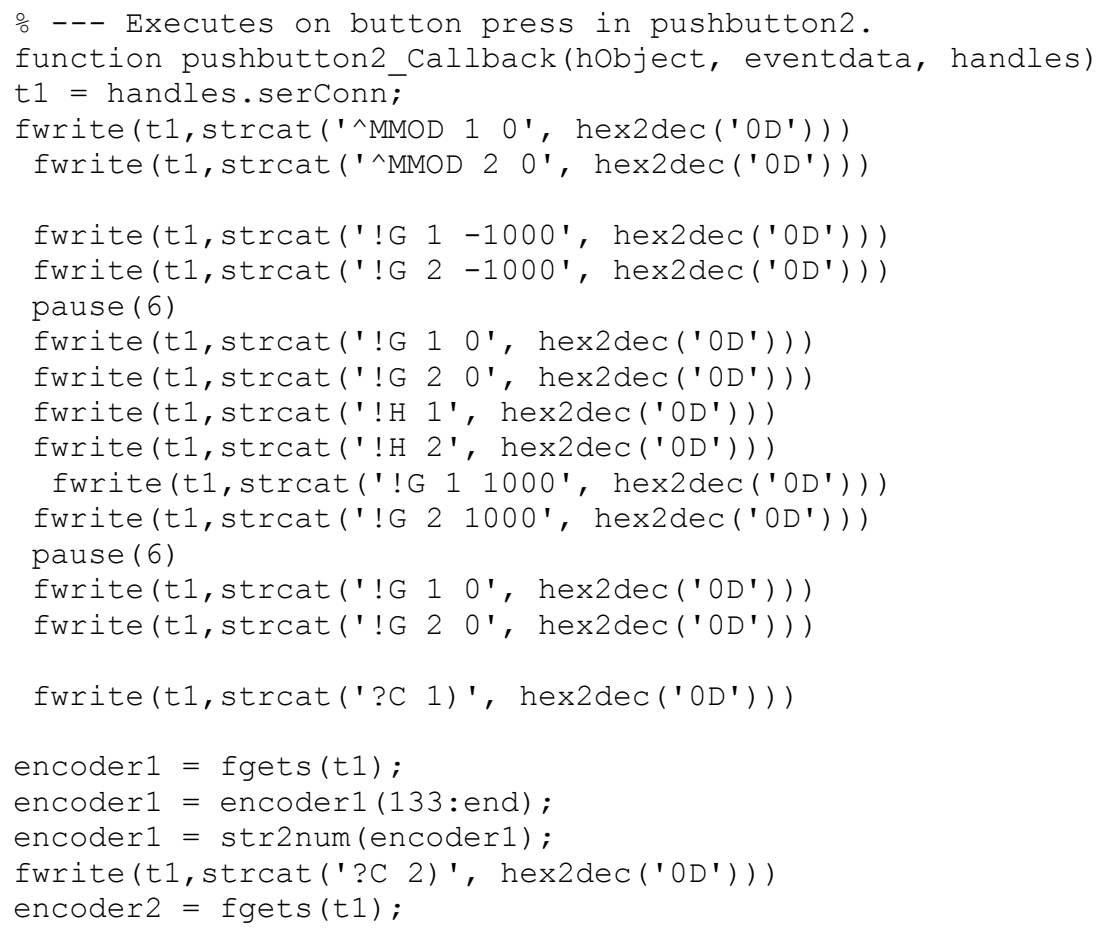




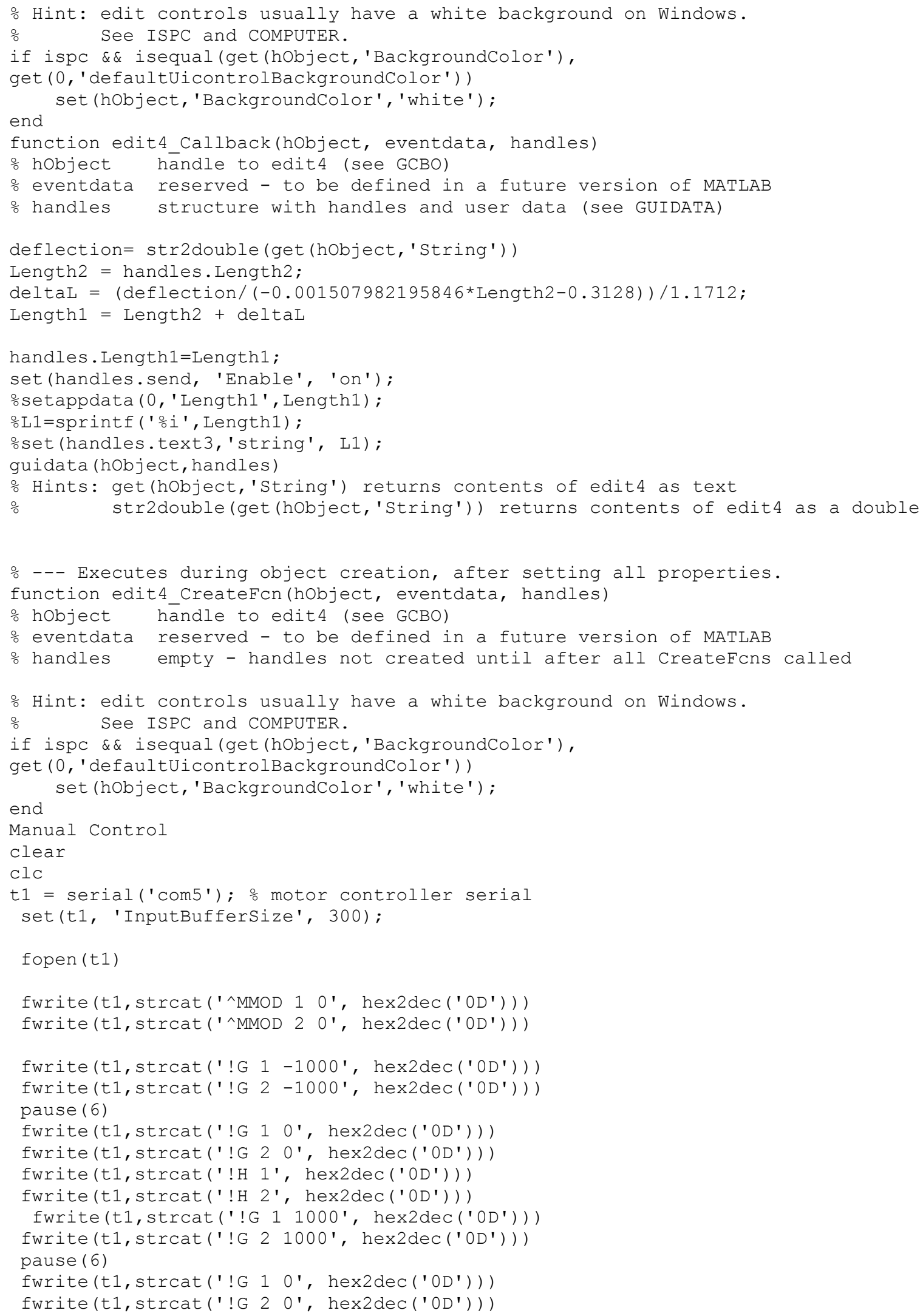




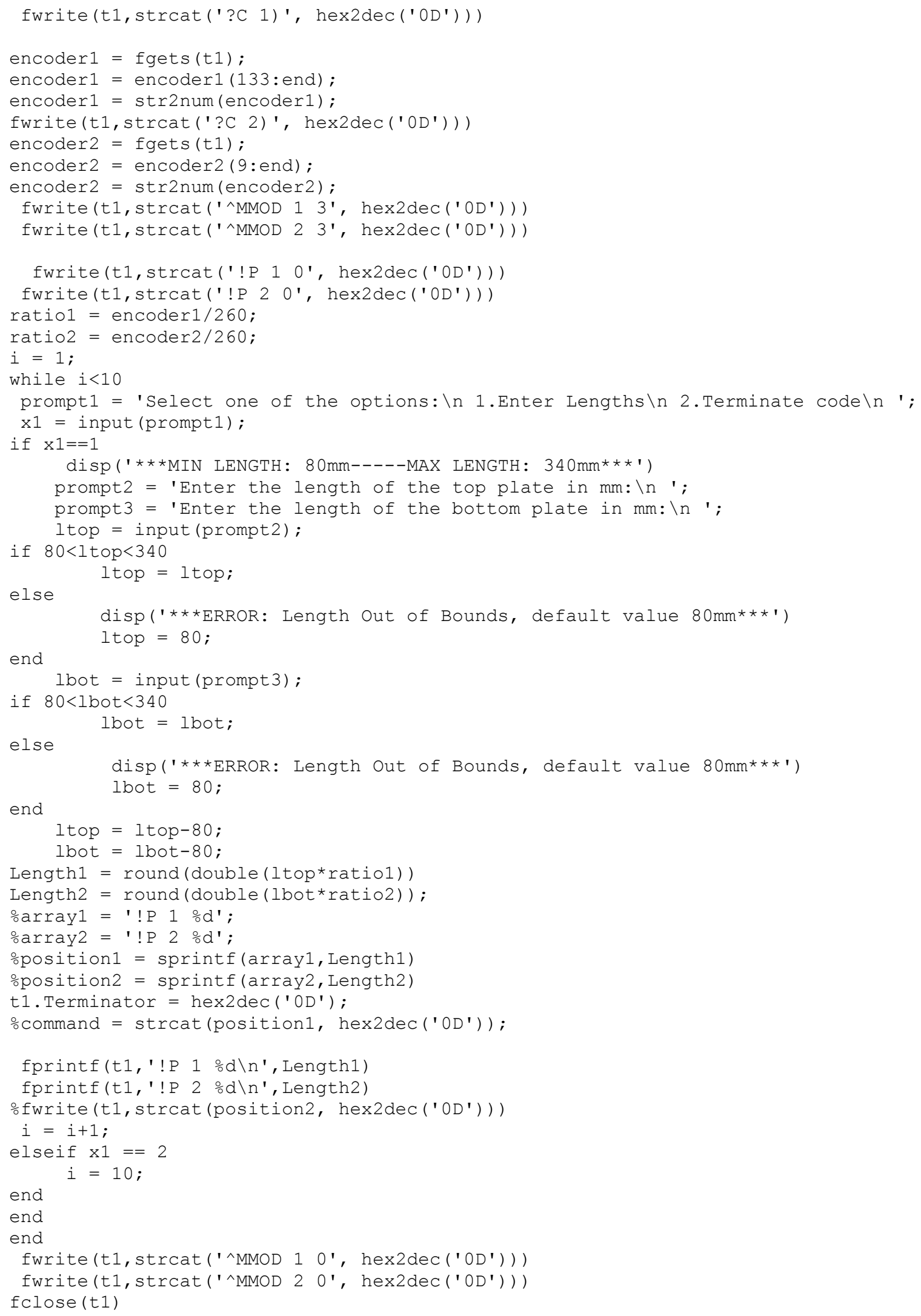


Raw Data Coordinates

Experiment 1

Table C-0-1:Experiment 1 Data.

\begin{tabular}{|l|l|l|l|l|l|}
\hline X-Cord. & Y-Cord. & $Z$-Cord. & X-Cord. & $Y$-Cord. & $Z-C o r d$. \\
\hline $2.60 E+02$ & $5.26 E+02$ & $-1.42 E+03$ & $2.04 E+02$ & $8.50 E+01$ & $-1.55 E+03$ \\
\hline $2.30 E+02$ & $8.19 E+01$ & $-1.56 E+03$ & $1.99 E+02$ & $8.51 E+01$ & $-1.56 E+03$ \\
\hline $2.27 E+02$ & $2.90 E+02$ & $-1.58 E+03$ & $1.92 E+02$ & $8.61 E+01$ & $-1.56 E+03$ \\
\hline $1.45 E+02$ & $9.55 E+01$ & $-1.55 E+03$ & $1.82 E+02$ & $8.75 E+01$ & $-1.56 E+03$ \\
\hline $1.40 E+02$ & $2.74 E+02$ & $-1.55 E+03$ & $1.72 E+02$ & $8.95 E+01$ & $-1.55 E+03$ \\
\hline $2.25 E+02$ & $8.28 E+01$ & $-1.56 E+03$ & $1.66 E+02$ & $9.08 E+01$ & $-1.55 E+03$ \\
\hline $2.15 E+02$ & $8.36 E+01$ & $-1.56 E+03$ & $1.61 E+02$ & $9.18 E+01$ & $-1.55 E+03$ \\
\hline $2.10 E+02$ & $8.40 E+01$ & $-1.56 E+03$ & $1.55 E+02$ & $9.30 E+01$ & $-1.55 E+03$ \\
\hline $2.02 E+02$ & $8.50 E+01$ & $-1.56 E+03$ & $1.51 E+02$ & $9.40 E+01$ & $-1.55 E+03$ \\
\hline $1.96 E+02$ & $8.60 E+01$ & $-1.56 E+03$ & $1.47 E+02$ & $9.50 E+01$ & $-1.54 E+03$ \\
\hline $1.87 E+02$ & $8.73 E+01$ & $-1.56 E+03$ & $2.18 E+02$ & $2.90 E+02$ & $-1.55 E+03$ \\
\hline $1.79 E+02$ & $8.87 E+01$ & $-1.55 E+03$ & $2.12 E+02$ & $2.89 E+02$ & $-1.55 E+03$ \\
\hline $1.74 E+02$ & $8.96 E+01$ & $-1.55 E+03$ & $2.06 E+02$ & $2.88 E+02$ & $-1.55 E+03$ \\
\hline $1.69 E+02$ & $9.04 E+01$ & $-1.55 E+03$ & $1.99 E+02$ & $2.87 E+02$ & $-1.55 E+03$ \\
\hline $1.64 E+02$ & $9.15 E+01$ & $-1.55 E+03$ & $1.89 E+02$ & $2.86 E+02$ & $-1.55 E+03$ \\
\hline $1.60 E+02$ & $9.25 E+01$ & $-1.55 E+03$ & $1.82 E+02$ & $2.84 E+02$ & $-1.54 E+03$ \\
\hline $1.57 E+02$ & $9.29 E+01$ & $-1.55 E+03$ & $1.75 E+02$ & $2.83 E+02$ & $-1.55 E+03$ \\
\hline $1.54 E+02$ & $9.36 E+01$ & $-1.55 E+03$ & $1.68 E+02$ & $2.81 E+02$ & $-1.55 E+03$ \\
\hline $1.52 E+02$ & $9.40 E+01$ & $-1.55 E+03$ & $1.62 E+02$ & $2.80 E+02$ & $-1.55 E+03$ \\
\hline $1.49 E+02$ & $9.47 E+01$ & $-1.55 E+03$ & $1.56 E+02$ & $2.78 E+02$ & $-1.55 E+03$ \\
\hline $1.48 E+02$ & $9.47 E+01$ & $-1.55 E+03$ & $1.51 E+02$ & $2.77 E+02$ & $-1.55 E+03$ \\
\hline $2.24 E+02$ & $2.91 E+02$ & $-1.55 E+03$ & $1.45 E+02$ & $2.75 E+02$ & $-1.54 E+03$ \\
\hline $2.09 E+02$ & $2.89 E+02$ & $-1.55 E+03$ & $2.60 E+02$ & $5.26 E+02$ & $-1.42 E+03$ \\
\hline $2.00 E+02$ & $2.88 E+02$ & $-1.55 E+03$ & $2.30 E+02$ & $8.19 E+01$ & $-1.56 E+03$ \\
\hline $1.87 E+02$ & $2.86 E+02$ & $-1.54 E+03$ & $2.30 E+02$ & $2.92 E+02$ & $-1.55 E+03$ \\
\hline $1.74 E+02$ & $2.83 E+02$ & $-1.54 E+03$ & $1.22 E+02$ & $1.04 E+02$ & $-1.54 E+03$ \\
\hline $1.66 E+02$ & $2.81 E+02$ & $-1.55 E+03$ & $1.34 E+02$ & $2.80 E+02$ & $-1.54 E+03$ \\
\hline $1.58 E+02$ & $2.79 E+02$ & $-1.55 E+03$ & $2.29 E+02$ & $8.22 E+01$ & $-1.56 E+03$ \\
\hline $1.52 E+02$ & $2.77 E+02$ & $-1.55 E+03$ & $2.17 E+02$ & $8.33 E+01$ & $-1.56 E+03$ \\
\hline $1.47 E+02$ & $2.76 E+02$ & $-1.55 E+03$ & $2.08 E+02$ & $8.43 E+01$ & $-1.56 E+03$ \\
\hline $2.60 E+02$ & $5.26 E+02$ & $-1.42 E+03$ & $1.98 E+02$ & $8.56 E+01$ & $-1.55 E+03$ \\
\hline $2.30 E+02$ & $8.18 E+01$ & $-1.56 E+03$ & $1.91 E+02$ & $8.68 E+01$ & $-1.55 E+03$ \\
\hline $2.31 E+02$ & $2.91 E+02$ & $-1.55 E+03$ & $1.82 E+02$ & $8.83 E+01$ & $-1.55 E+03$ \\
\hline $1.41 E+02$ & $9.69 E+01$ & $-1.54 E+03$ & $1.72 E+02$ & $9.03 E+01$ & $-1.55 E+03$ \\
\hline
\end{tabular}




\begin{tabular}{|c|c|c|c|c|c|}
\hline $1.38 \mathrm{E}+02$ & $2.73 \mathrm{E}+02$ & $-1.55 E+03$ & $1.66 \mathrm{E}+02$ & $9.16 \mathrm{E}+01$ & $-1.55 E+03$ \\
\hline X-Cord. & Y-Cord. & Z-Cord. & X-Cord. & Y-Cord. & Z-Cord. \\
\hline $1.55 \mathrm{E}+02$ & $9.40 \mathrm{E}+01$ & $-1.55 E+03$ & $1.52 \mathrm{E}+02$ & $2.83 \mathrm{E}+02$ & $-1.55 E+03$ \\
\hline $1.47 \mathrm{E}+02$ & $9.61 \mathrm{E}+01$ & $-1.55 E+03$ & $1.44 \mathrm{E}+02$ & $2.82 \mathrm{E}+02$ & $-1.54 E+03$ \\
\hline $1.38 \mathrm{E}+02$ & $9.89 \mathrm{E}+01$ & $-1.55 \mathrm{E}+03$ & $2.60 \mathrm{E}+02$ & $5.27 \mathrm{E}+02$ & $-1.42 E+03$ \\
\hline $1.33 \mathrm{E}+02$ & $1.01 \mathrm{E}+02$ & $-1.55 E+03$ & $2.30 \mathrm{E}+02$ & $8.23 \mathrm{E}+01$ & $-1.56 \mathrm{E}+03$ \\
\hline $1.29 \mathrm{E}+02$ & $1.02 \mathrm{E}+02$ & $-1.55 E+03$ & $2.30 \mathrm{E}+02$ & $2.92 \mathrm{E}+02$ & $-1.55 E+03$ \\
\hline $1.27 \mathrm{E}+02$ & $1.03 \mathrm{E}+02$ & $-1.55 E+03$ & $1.05 \mathrm{E}+02$ & $1.14 \mathrm{E}+02$ & $-1.54 E+03$ \\
\hline $2.29 \mathrm{E}+02$ & $2.92 \mathrm{E}+02$ & $-1.54 \mathrm{E}+03$ & $1.35 \mathrm{E}+02$ & $2.87 \mathrm{E}+02$ & $-1.55 E+03$ \\
\hline $2.11 E+02$ & $2.91 \mathrm{E}+02$ & $-1.55 E+03$ & $2.23 \mathrm{E}+02$ & $8.24 \mathrm{E}+01$ & $-1.56 E+03$ \\
\hline $1.93 \mathrm{E}+02$ & $2.89 \mathrm{E}+02$ & $-1.56 \mathrm{E}+03$ & $2.13 E+02$ & $8.36 \mathrm{E}+01$ & $-1.56 E+03$ \\
\hline $1.84 \mathrm{E}+02$ & $2.88 \mathrm{E}+02$ & $-1.56 \mathrm{E}+03$ & $2.04 \mathrm{E}+02$ & $8.47 \mathrm{E}+01$ & $-1.56 E+03$ \\
\hline $1.63 \mathrm{E}+02$ & $2.85 \mathrm{E}+02$ & $-1.55 E+03$ & $1.95 \mathrm{E}+02$ & $8.61 \mathrm{E}+01$ & $-1.56 E+03$ \\
\hline $1.55 \mathrm{E}+02$ & $2.84 \mathrm{E}+02$ & $-1.55 \mathrm{E}+03$ & $1.85 \mathrm{E}+02$ & $8.78 \mathrm{E}+01$ & $-1.56 E+03$ \\
\hline $1.47 \mathrm{E}+02$ & $2.82 \mathrm{E}+02$ & $-1.55 E+03$ & $1.74 \mathrm{E}+02$ & $9.02 \mathrm{E}+01$ & $-1.55 E+03$ \\
\hline $1.39 E+02$ & $2.81 \mathrm{E}+02$ & $-1.55 E+03$ & $1.52 \mathrm{E}+02$ & $9.59 \mathrm{E}+01$ & $-1.55 E+03$ \\
\hline $1.37 \mathrm{E}+02$ & $2.80 \mathrm{E}+02$ & $-1.55 E+03$ & $1.46 \mathrm{E}+02$ & $9.79 \mathrm{E}+01$ & $-1.55 E+03$ \\
\hline $2.60 \mathrm{E}+02$ & $5.27 \mathrm{E}+02$ & $-1.42 \mathrm{E}+03$ & $1.41 \mathrm{E}+02$ & $9.93 \mathrm{E}+01$ & $-1.55 E+03$ \\
\hline $2.30 \mathrm{E}+02$ & 8. & -1.5 & 02 & +02 & 03 \\
\hline $2.28 \mathrm{E}+02$ & 2.91 & $-1.57 E+03$ & $1.21 \mathrm{E}+02$ & +02 & 03 \\
\hline $1.21 \mathrm{E}+02$ & $1.05 \mathrm{E}+02$ & +03 & $1.17 \mathrm{E}+02$ & $3 \mathrm{E}+02$ & $-1.54 E+03$ \\
\hline $1.40 \mathrm{E}+02$ & $2.81 \mathrm{E}+02$ & $-1.55 E+03$ & $1.12 \mathrm{E}+02$ & $1.11 \mathrm{E}+02$ & $-1.54 E+03$ \\
\hline $2.29 \mathrm{E}+02$ & $8.23 E+01$ & $-1.56 \mathrm{E}+03$ & $2.15 \mathrm{E}+02$ & $2.92 \mathrm{E}+02$ & $-1.55 E+03$ \\
\hline $2.20 \mathrm{E}+02$ & $8.30 \mathrm{E}+01$ & $-1.56 \mathrm{E}+03$ & $2.07 \mathrm{E}+02$ & $2.92 \mathrm{E}+02$ & $-1.55 E+03$ \\
\hline $2.08 \mathrm{E}+02$ & $8.46 \mathrm{E}+01$ & $-1.55 E+03$ & $1.98 \mathrm{E}+02$ & $2.91 \mathrm{E}+02$ & $-1.55 E+03$ \\
\hline $1.95 \mathrm{E}+02$ & $8.65 \mathrm{E}+01$ & $-1.55 E+03$ & $1.89 \mathrm{E}+02$ & $2.91 \mathrm{E}+02$ & $-1.55 E+03$ \\
\hline $1.84 \mathrm{E}+02$ & $8.83 E+01$ & $-1.55 E+03$ & $1.81 \mathrm{E}+02$ & $2.91 \mathrm{E}+02$ & $-1.55 E+03$ \\
\hline $1.74 \mathrm{E}+02$ & $9.00 \mathrm{E}+01$ & $-1.55 E+03$ & $1.71 \mathrm{E}+02$ & $2.90 \mathrm{E}+02$ & $-1.55 E+03$ \\
\hline $1.53 \mathrm{E}+02$ & $9.51 \mathrm{E}+01$ & $-1.55 E+03$ & $1.64 \mathrm{E}+02$ & $2.90 \mathrm{E}+02$ & $-1.55 E+03$ \\
\hline $1.37 \mathrm{E}+02$ & $9.97 \mathrm{E}+01$ & $-1.54 \mathrm{E}+03$ & $1.57 \mathrm{E}+02$ & $2.89 \mathrm{E}+02$ & $-1.55 E+03$ \\
\hline $2.28 \mathrm{E}+02$ & $2.92 \mathrm{E}+02$ & $-1.55 E+03$ & $1.53 \mathrm{E}+02$ & $2.89 \mathrm{E}+02$ & $-1.55 E+03$ \\
\hline $2.16 \mathrm{E}+02$ & $2.91 \mathrm{E}+02$ & $-1.55 E+03$ & $1.47 \mathrm{E}+02$ & $2.88 \mathrm{E}+02$ & $-1.55 E+03$ \\
\hline $2.06 \mathrm{E}+02$ & $2.90 \mathrm{E}+02$ & $-1.55 E+03$ & $1.41 \mathrm{E}+02$ & $2.88 \mathrm{E}+02$ & $-1.55 E+03$ \\
\hline $1.92 \mathrm{E}+02$ & $2.89 \mathrm{E}+02$ & $-1.55 E+03$ & $2.60 \mathrm{E}+02$ & $5.27 \mathrm{E}+02$ & $-1.42 E+03$ \\
\hline $1.80 \mathrm{E}+02$ & $2.87 \mathrm{E}+02$ & $-1.55 E+03$ & $2.30 \mathrm{E}+02$ & $8.20 \mathrm{E}+01$ & $-1.56 E+03$ \\
\hline $1.71 \mathrm{E}+02$ & $2.86 \mathrm{E}+02$ & $-1.55 E+03$ & $2.29 \mathrm{E}+02$ & $2.92 \mathrm{E}+02$ & $-1.55 E+03$ \\
\hline $1.63 \mathrm{E}+02$ & $2.85 E+02$ & $-1.55 E+03$ & $1.05 E+02$ & $1.14 \mathrm{E}+02$ & $-1.54 E+03$ \\
\hline
\end{tabular}




\begin{tabular}{|c|c|c|c|c|c|}
\hline X-Cord. & Y-Cord. & Z-Cord. & X-Cord. & Y-Cord. & Z-Cord. \\
\hline $1.36 \mathrm{E}+02$ & $2.87 E+02$ & $-1.55 \mathrm{E}+03$ & $1.61 \mathrm{E}+02$ & $9.38 \mathrm{E}+01$ & $-1.55 E+03$ \\
\hline $2.26 \mathrm{E}+02$ & $8.24 \mathrm{E}+01$ & $-1.56 \mathrm{E}+03$ & $1.55 \mathrm{E}+02$ & $9.51 E+01$ & $-1.55 E+03$ \\
\hline $2.15 E+02$ & $8.34 \mathrm{E}+01$ & $-1.56 \mathrm{E}+03$ & $1.45 \mathrm{E}+02$ & $9.88 \mathrm{E}+01$ & $-1.55 E+03$ \\
\hline $2.07 E+02$ & $8.43 E+01$ & $-1.56 \mathrm{E}+03$ & $1.39 \mathrm{E}+02$ & $1.01 E+02$ & $-1.55 E+03$ \\
\hline $1.97 \mathrm{E}+02$ & $8.58 \mathrm{E}+01$ & $-1.56 \mathrm{E}+03$ & $1.31 \mathrm{E}+02$ & $1.03 E+02$ & $-1.55 E+03$ \\
\hline $1.86 \mathrm{E}+02$ & $8.77 E+01$ & $-1.56 \mathrm{E}+03$ & $1.21 \mathrm{E}+02$ & $1.08 \mathrm{E}+02$ & $-1.55 E+03$ \\
\hline $1.79 E+02$ & $8.93 E+01$ & $-1.55 \mathrm{E}+03$ & $1.16 \mathrm{E}+02$ & $1.10 E+02$ & $-1.54 \mathrm{E}+03$ \\
\hline $1.68 \mathrm{E}+02$ & $9.17 \mathrm{E}+01$ & $-1.55 \mathrm{E}+03$ & $1.02 \mathrm{E}+02$ & $1.17 \mathrm{E}+02$ & $-1.54 \mathrm{E}+03$ \\
\hline $1.54 \mathrm{E}+02$ & $9.47 \mathrm{E}+01$ & $-1.55 \mathrm{E}+03$ & $9.31 \mathrm{E}+01$ & $1.22 \mathrm{E}+02$ & $4 E+03$ \\
\hline $1.45 \mathrm{E}+02$ & $9.77 \mathrm{E}+01$ & $-1.55 \mathrm{E}+03$ & $2.28 \mathrm{E}+02$ & $2.93 E+02$ & $E+03$ \\
\hline $1.30 \mathrm{E}+02$ & $1.03 E+02$ & $-1.55 E+03$ & $2.20 \mathrm{E}+02$ & $2.93 E+02$ & $E+03$ \\
\hline $1.23 E+02$ & $1.07 E+02$ & $-1.54 \mathrm{E}+03$ & $2.09 \mathrm{E}+02$ & $2.93 E+02$ & $E+03$ \\
\hline & & $-1.54 \mathrm{E}+03$ & & & $-1.55 E+03$ \\
\hline & & & $1.89 \mathrm{E}+02$ & $2.94 \mathrm{E}+02$ & $-1.55 E+03$ \\
\hline $2.26 \mathrm{E}+02$ & $2.92 \mathrm{E}+02$ & $-1.55 E+03$ & $1.81 \mathrm{E}+02$ & $2.94 \mathrm{E}+02$ & $-1.55 E+03$ \\
\hline $2.12 \mathrm{E}+02$ & $2.92 \mathrm{E}+02$ & $-1.55 \mathrm{E}+03$ & $1.73 \mathrm{E}+02$ & $2.94 \mathrm{E}+02$ & $-1.56 \mathrm{E}+03$ \\
\hline $2.04 \mathrm{E}+02$ & $2.92 \mathrm{E}+02$ & $-1.55 E+03$ & $1.63 \mathrm{E}+02$ & $2.94 \mathrm{E}+02$ & $-1.55 E+03$ \\
\hline $1.96 \mathrm{E}+02$ & $2.91 \mathrm{E}+02$ & $-1.55 \mathrm{E}+03$ & $1.52 \mathrm{E}+02$ & $2.94 \mathrm{E}+02$ & $-1.55 E+03$ \\
\hline $1.86 \mathrm{E}+02$ & $2.91 \mathrm{E}+02$ & $-1.55 \mathrm{E}+03$ & $1.43 \mathrm{E}+02$ & $2.94 \mathrm{E}+02$ & $-1.55 E+03$ \\
\hline $1.74 \mathrm{E}+02$ & $2.90 \mathrm{E}+02$ & $-1.55 \mathrm{E}+03$ & $1.37 \mathrm{E}+02$ & $2.94 \mathrm{E}+02$ & $-1.55 E+03$ \\
\hline $1.65 E+02$ & $2.90 \mathrm{E}+02$ & $-1.55 \mathrm{E}+03$ & $2.60 \mathrm{E}+02$ & $5.27 \mathrm{E}+02$ & $-1.42 E+03$ \\
\hline $1.57 \mathrm{E}+02$ & $2.89 E+02$ & $-1.55 E+03$ & $2.30 \mathrm{E}+02$ & $8.18 \mathrm{E}+01$ & $-1.56 E+03$ \\
\hline $1.51 \mathrm{E}+02$ & $2.89 \mathrm{E}+02$ & $-1.55 \mathrm{E}+03$ & $2.29 \mathrm{E}+02$ & $2.93 E+02$ & $-1.55 E+03$ \\
\hline $1.45 E+02$ & $2.88 \mathrm{E}+02$ & $-1.55 E+03$ & $8.72 \mathrm{E}+01$ & $1.25 \mathrm{E}+02$ & $-1.54 \mathrm{E}+03$ \\
\hline $2.60 \mathrm{E}+02$ & $5.27 \mathrm{E}+02$ & $-1.42 \mathrm{E}+03$ & $1.34 \mathrm{E}+02$ & $2.94 \mathrm{E}+02$ & $-1.55 E+03$ \\
\hline $2.30 \mathrm{E}+02$ & $8.22 \mathrm{E}+01$ & $-1.56 \mathrm{E}+03$ & $2.16 \mathrm{E}+02$ & $8.29 E+01$ & $-1.56 E+03$ \\
\hline $2.29 E+02$ & $2.93 \mathrm{E}+02$ & $-1.55 \mathrm{E}+03$ & $2.08 \mathrm{E}+02$ & $8.36 E+01$ & $-1.57 \mathrm{E}+03$ \\
\hline $8.79 E+01$ & $1.24 \mathrm{E}+02$ & $-1.54 \mathrm{E}+03$ & $1.99 \mathrm{E}+02$ & $8.48 \mathrm{E}+01$ & $-1.57 E+03$ \\
\hline $1.34 \mathrm{E}+02$ & $2.94 \mathrm{E}+02$ & $-1.55 \mathrm{E}+03$ & $1.78 \mathrm{E}+02$ & $8.87 E+01$ & $-1.56 \mathrm{E}+03$ \\
\hline $2.25 E+02$ & $8.30 E+01$ & $-1.56 \mathrm{E}+03$ & $1.69 \mathrm{E}+02$ & $9.13 E+01$ & $-1.56 E+03$ \\
\hline $2.16 \mathrm{E}+02$ & $8.39 E+01$ & $-1.55 E+03$ & $1.56 \mathrm{E}+02$ & $9.46 \mathrm{E}+01$ & $-1.56 \mathrm{E}+03$ \\
\hline $2.05 E+02$ & $8.54 \mathrm{E}+01$ & $-1.55 \mathrm{E}+03$ & $1.44 \mathrm{E}+02$ & $9.91 E+01$ & $-1.55 E+03$ \\
\hline $1.97 \mathrm{E}+02$ & $8.66 \mathrm{E}+01$ & $-1.55 E+03$ & $1.38 \mathrm{E}+02$ & $1.01 \mathrm{E}+02$ & $-1.55 E+03$ \\
\hline $1.83 \mathrm{E}+02$ & $8.89 \mathrm{E}+01$ & $-1.55 \mathrm{E}+03$ & $1.30 \mathrm{E}+02$ & $1.04 \mathrm{E}+02$ & $-1.55 E+03$ \\
\hline $1.72 \mathrm{E}+02$ & $9.13 E+01$ & $-1.55 E+03$ & $1.20 \mathrm{E}+02$ & $1.08 \mathrm{E}+02$ & $-1.55 E+03$ \\
\hline
\end{tabular}




\begin{tabular}{|l|l|l|l|l|l|}
\hline$X-C o r d$. & $Y-C o r d$. & $Z-C o r d$. & $X-C o r d$. & $Y-C o r d$. & $Z-C o r d$. \\
\hline $1.16 E+02$ & $1.10 E+02$ & $-1.55 E+03$ & $1.15 E+02$ & $1.11 E+02$ & $-1.55 E+03$ \\
\hline $1.13 E+02$ & $1.11 E+02$ & $-1.55 E+03$ & $1.02 E+02$ & $1.18 E+02$ & $-1.54 E+03$ \\
\hline $1.03 E+02$ & $1.16 E+02$ & $-1.54 E+03$ & $9.72 E+01$ & $1.21 E+02$ & $-1.54 E+03$ \\
\hline $9.77 E+01$ & $1.19 E+02$ & $-1.54 E+03$ & $8.72 E+01$ & $1.27 E+02$ & $-1.54 E+03$ \\
\hline $9.19 E+01$ & $1.22 E+02$ & $-1.54 E+03$ & $8.20 E+01$ & $1.30 E+02$ & $-1.54 E+03$ \\
\hline $2.24 E+02$ & $2.93 E+02$ & $-1.55 E+03$ & $7.77 E+01$ & $1.33 E+02$ & $-1.54 E+03$ \\
\hline $2.14 E+02$ & $2.93 E+02$ & $-1.55 E+03$ & $7.48 E+01$ & $1.35 E+02$ & $-1.54 E+03$ \\
\hline $2.05 E+02$ & $2.94 E+02$ & $-1.55 E+03$ & $2.28 E+02$ & $2.93 E+02$ & $-1.55 E+03$ \\
\hline $1.95 E+02$ & $2.94 E+02$ & $-1.55 E+03$ & $2.17 E+02$ & $2.94 E+02$ & $-1.55 E+03$ \\
\hline $1.84 E+02$ & $2.94 E+02$ & $-1.55 E+03$ & $2.13 E+02$ & $2.95 E+02$ & $-1.55 E+03$ \\
\hline $1.76 E+02$ & $2.94 E+02$ & $-1.55 E+03$ & $2.05 E+02$ & $2.95 E+02$ & $-1.55 E+03$ \\
\hline $1.69 E+02$ & $2.94 E+02$ & $-1.55 E+03$ & $1.88 E+02$ & $2.96 E+02$ & $-1.55 E+03$ \\
\hline $1.62 E+02$ & $2.94 E+02$ & $-1.55 E+03$ & $1.77 E+02$ & $2.97 E+02$ & $-1.55 E+03$ \\
\hline $1.54 E+02$ & $2.94 E+02$ & $-1.54 E+03$ & $1.69 E+02$ & $2.98 E+02$ & $-1.55 E+03$ \\
\hline $1.48 E+02$ & $2.94 E+02$ & $-1.55 E+03$ & $1.63 E+02$ & $2.98 E+02$ & $-1.55 E+03$ \\
\hline $1.44 E+02$ & $2.94 E+02$ & $-1.55 E+03$ & $1.57 E+02$ & $2.99 E+02$ & $-1.55 E+03$ \\
\hline $2.60 E+02$ & $5.27 E+02$ & $-1.42 E+03$ & $1.51 E+02$ & $3.00 E+02$ & $-1.55 E+03$ \\
\hline $2.31 E+02$ & $8.24 E+01$ & $-1.55 E+03$ & $1.42 E+02$ & $3.00 E+02$ & $-1.54 E+03$ \\
\hline $2.28 E+02$ & $2.93 E+02$ & $-1.55 E+03$ & $1.39 E+02$ & $3.01 E+02$ & $-1.54 E+03$ \\
\hline $7.17 E+01$ & $1.37 E+02$ & $-1.54 E+03$ & $2.60 E+02$ & $5.26 E+02$ & $-1.42 E+03$ \\
\hline $1.34 E+02$ & $3.01 E+02$ & $-1.55 E+03$ & $2.30 E+02$ & $8.24 E+01$ & $-1.56 E+03$ \\
\hline $2.30 E+02$ & $8.24 E+01$ & $-1.56 E+03$ & $2.29 E+02$ & $2.94 E+02$ & $-1.55 E+03$ \\
\hline $2.23 E+02$ & $8.31 E+01$ & $-1.55 E+03$ & $7.18 E+01$ & $1.37 E+02$ & $-1.54 E+03$ \\
\hline $2.14 E+02$ & $8.39 E+01$ & $-1.56 E+03$ & $1.40 E+02$ & $3.01 E+02$ & $-1.55 E+03$ \\
\hline $2.04 E+02$ & $8.55 E+01$ & $-1.55 E+03$ & $2.27 E+02$ & $8.25 E+01$ & $-1.56 E+03$ \\
\hline $1.95 E+02$ & $8.69 E+01$ & $-1.55 E+03$ & $2.22 E+02$ & $8.32 E+01$ & $-1.55 E+03$ \\
\hline $1.88 E+02$ & $8.80 E+01$ & $-1.55 E+03$ & $2.12 E+02$ & $8.42 E+01$ & $-1.55 E+03$ \\
\hline $1.82 E+02$ & $8.91 E+01$ & $-1.55 E+03$ & $2.01 E+02$ & $8.58 E+01$ & $-1.55 E+03$ \\
\hline $1.75 E+02$ & $9.03 E+01$ & $-1.55 E+03$ & $1.89 E+02$ & $8.76 E+01$ & $-1.55 E+03$ \\
\hline $1.67 E+02$ & $9.24 E+01$ & $-1.55 E+03$ & $1.79 E+02$ & $8.97 E+01$ & $-1.55 E+03$ \\
\hline $1.57 E+02$ & $9.47 E+01$ & $-1.55 E+03$ & $1.70 E+02$ & $9.17 E+01$ & $-1.55 E+03$ \\
\hline $1.48 E+02$ & $9.76 E+01$ & $-1.55 E+03$ & $1.60 E+02$ & $9.41 E+01$ & $-1.55 E+03$ \\
\hline $1.39 E+02$ & $1.01 E+02$ & $-1.55 E+03$ & $1.49 E+02$ & $9.75 E+01$ & $-1.55 E+03$ \\
\hline $1.34 E+02$ & $1.02 E+02$ & $-1.55 E+03$ & $1.42 E+02$ & $9.97 E+01$ & $-1.55 E+03$ \\
\hline $1.21 E+02$ & $1.08 E+02$ & $-1.55 E+03$ & $1.32 E+02$ & $1.03 E+02$ & $-1.55 E+03$ \\
\hline
\end{tabular}




\begin{tabular}{|c|c|c|c|c|c|}
\hline & $-5+2+$ & & 다. & Cord. & \\
\hline & & +03 & 1 & +02 & ( \\
\hline & & & & & \\
\hline & & & & & \\
\hline & & & & & \\
\hline & & & & & \\
\hline & & & & & \\
\hline & & & & & \\
\hline & & & & & \\
\hline & & & & & \\
\hline & & & & & \\
\hline & & & & & \\
\hline & & & & & \\
\hline & & & & & \\
\hline & & & & & \\
\hline & & & & & \\
\hline & & & & & \\
\hline & & & & & \\
\hline & & & & & \\
\hline & & & & & \\
\hline & & $E+03$ & & & \\
\hline & & $4 E+03$ & & & \\
\hline & & & & & \\
\hline & & & & & \\
\hline & & & & & \\
\hline 2.0 & $0.50 \mathrm{LT}+\mathrm{O} \perp$ & & & & \\
\hline & & & & & \\
\hline & & & & & \\
\hline & & & & & \\
\hline & & & & & \\
\hline & 9.5 & & & 8.9 & \\
\hline+02 & +01 & +03 & $E+02$ & 01 & \\
\hline & & & & & \\
\hline & & & & $9.80 \mathrm{E}+01$ & \\
\hline & & & & & \\
\hline $1.07 \mathrm{E}+02$ & $1.14 \mathrm{E}+02$ & $-1.55 E+03$ & $1.31 \mathrm{E}+02$ & $1.04 \mathrm{E}+02$ & $-1.55 E+03$ \\
\hline
\end{tabular}

\begin{tabular}{|l|r|r|}
\hline X-Cord. & Y-Cord. & Z-Cord. \\
\hline $1.26 \mathrm{E}+02$ & $1.06 \mathrm{E}+02$ & $-1.55 \mathrm{E}+03$ \\
\hline $1.18 \mathrm{E}+02$ & $1.09 \mathrm{E}+02$ & $-1.55 \mathrm{E}+03$ \\
\hline
\end{tabular}




\begin{tabular}{|l|l|r|}
\hline $1.08 \mathrm{E}+02$ & $1.14 \mathrm{E}+02$ & $-1.55 \mathrm{E}+03$ \\
\hline $9.68 \mathrm{E}+01$ & $1.21 \mathrm{E}+02$ & $-1.54 \mathrm{E}+03$ \\
\hline $9.22 \mathrm{E}+01$ & $1.23 \mathrm{E}+02$ & $-1.55 \mathrm{E}+03$ \\
\hline $8.69 \mathrm{E}+01$ & $1.27 \mathrm{E}+02$ & $-1.54 \mathrm{E}+03$ \\
\hline $7.37 \mathrm{E}+01$ & $1.35 \mathrm{E}+02$ & $-1.55 \mathrm{E}+03$ \\
\hline $7.03 \mathrm{E}+01$ & $1.38 \mathrm{E}+02$ & $-1.54 \mathrm{E}+03$ \\
\hline $6.01 \mathrm{E}+01$ & $1.47 \mathrm{E}+02$ & $-1.54 \mathrm{E}+03$ \\
\hline $2.23 \mathrm{E}+02$ & $2.95 \mathrm{E}+02$ & $-1.55 \mathrm{E}+03$ \\
\hline $2.19 \mathrm{E}+02$ & $2.95 \mathrm{E}+02$ & $-1.55 \mathrm{E}+03$ \\
\hline $2.09 \mathrm{E}+02$ & $2.96 \mathrm{E}+02$ & $-1.55 \mathrm{E}+03$ \\
\hline $1.95 \mathrm{E}+02$ & $2.98 \mathrm{E}+02$ & $-1.55 \mathrm{E}+03$ \\
\hline $1.93 \mathrm{E}+02$ & $2.98 \mathrm{E}+02$ & $-1.55 \mathrm{E}+03$ \\
\hline $1.85 \mathrm{E}+02$ & $2.99 \mathrm{E}+02$ & $-1.55 \mathrm{E}+03$ \\
\hline $1.77 \mathrm{E}+02$ & $3.01 \mathrm{E}+02$ & $-1.55 \mathrm{E}+03$ \\
\hline $1.72 \mathrm{E}+02$ & $3.01 \mathrm{E}+02$ & $-1.55 \mathrm{E}+03$ \\
\hline $1.71 \mathrm{E}+02$ & $3.01 \mathrm{E}+02$ & $-1.55 \mathrm{E}+03$ \\
\hline $1.64 \mathrm{E}+02$ & $3.02 \mathrm{E}+02$ & $-1.55 \mathrm{E}+03$ \\
\hline $1.57 \mathrm{E}+02$ & $3.03 \mathrm{E}+02$ & $-1.55 \mathrm{E}+03$ \\
\hline $1.49 \mathrm{E}+02$ & $3.05 \mathrm{E}+02$ & $-1.55 \mathrm{E}+03$ \\
\hline $1.42 \mathrm{E}+02$ & $3.06 \mathrm{E}+02$ & $-1.55 \mathrm{E}+03$ \\
\hline & & \\
\hline
\end{tabular}


Experiment 2

Table C-0-2:Data for Experiment 2.

\begin{tabular}{|c|c|c|c|c|c|}
\hline rd. & Cord. & Cord. & X-Cord. & Y-Cord. & -Cord. \\
\hline+00 & $\mathrm{OE}+02$ & $.74 \mathrm{E}+03$ & $-5.79 E+01$ & $37 E+02$ & $-1.73 E+03$ \\
\hline$=01$ & $40 \mathrm{E}+02$ & $.74 \mathrm{E}+03$ & $-6.88 \mathrm{E}+01$ & $36 \mathrm{E}+02$ & $-1.73 E+03$ \\
\hline$-2.67 E+01$ & $2.39 \mathrm{E}+02$ & $-1.73 E+03$ & $-7.87 E+01$ & $2.35 \mathrm{E}+02$ & $-1.72 \mathrm{E}+03$ \\
\hline-3.5 & $39 \mathrm{E}+02$ & $1.73 E+03$ & $-8.83 E+01$ & $34 \mathrm{E}+02$ & 03 \\
\hline$-5.55 E+01$ & $2.37 \mathrm{E}+02$ & $-1.73 E+03$ & $-9.78 \mathrm{E}+01$ & $2.32 \mathrm{E}+02$ & -03 \\
\hline$-7.00 \mathrm{E}+01$ & $2.36 \mathrm{E}+02$ & $-1.72 E+03$ & $-1.06 \mathrm{E}+02$ & $30 \mathrm{E}+02$ & $E+03$ \\
\hline$-7.88 \mathrm{E}+01$ & $2.34 \mathrm{E}+02$ & $-1.72 E+03$ & $E+02$ & $3 E+02$ & $E+03$ \\
\hline$-9.16 \mathrm{E}+01$ & $2 \mathrm{E}+02$ & $E+03$ & $E+02$ & & +03 \\
\hline$-1.03 E+02$ & 02 & $=03$ & +02 & 2 & +03 \\
\hline-1 . & 02 & 3 & 22 & & -03 \\
\hline-1 . & 02 & & 01 & & +03 \\
\hline & & & & & \\
\hline $5.71 E+01$ & & & $E+00$ & & \\
\hline$-1.19 E+01$ & $2.99 \mathrm{E}+01$ & $-1.74 E+03$ & $-1.31 E+02$ & 4.9JLTU1 & $-1.71 E+03$ \\
\hline$-2.42 \mathrm{E}+00$ & $2.40 \mathrm{E}+02$ & $1.74 \mathrm{E}+03$ & $-1.28 \mathrm{E}+02$ & $.25 \mathrm{E}+02$ & $E+03$ \\
\hline$-1.29 E+02$ & $4.92 \mathrm{E}+01$ & $-1.70 E+03$ & $-2.00 \mathrm{E}+01$ & $5 E+01$ & $\mathrm{E}+03$ \\
\hline$-1.27 \mathrm{E}+02$ & $2.25 \mathrm{E}+02$ & $-1.71 \mathrm{E}+03$ & $-3.11 \mathrm{E}+01$ & $3.15 \mathrm{E}+01$ & $3 \mathrm{E}+03$ \\
\hline$-1.76 \mathrm{E}+01$ & $3.04 \mathrm{E}+01$ & $-1.74 \mathrm{E}+03$ & $-3.94 \mathrm{E}+01$ & $3.24 \mathrm{E}+01$ & $E+03$ \\
\hline$-2.59 \mathrm{E}+01$ & $3.09 \mathrm{E}+01$ & $-1.74 \mathrm{E}+03$ & $-4.68 \mathrm{E}+01$ & $3.30 \mathrm{E}+01$ & $-1.73 E+03$ \\
\hline$-3.44 \mathrm{E}+01$ & $3.17 \mathrm{E}+01$ & $-1.73 E+03$ & $-5.42 E+01$ & $3.38 \mathrm{E}+01$ & $-1.73 E+03$ \\
\hline$-4.21 E+01$ & $3.25 \mathrm{E}+01$ & $-1.73 E+03$ & $-6.19 E+01$ & $3.51 \mathrm{E}+01$ & $-1.72 \mathrm{E}+03$ \\
\hline$-5.30 \mathrm{E}+01$ & $39 \mathrm{E}+01$ & $-1.72 \mathrm{E}+03$ & $-6.95 E+01$ & $5 \mathrm{E}+01$ & \\
\hline$-6.23 E+01$ & $3.51 \mathrm{E}+01$ & $-1.72 E+03$ & $-8.13 E+01$ & $3.86 \mathrm{E}+01$ & \\
\hline$-7.14 \mathrm{E}+01$ & $3.63 \mathrm{E}+01$ & $-1.72 \mathrm{E}+03$ & $-8.67 \mathrm{E}+01$ & $5 \mathrm{E}+01$ & $2 \mathrm{E}+03$ \\
\hline$-8.06 \mathrm{E}+01$ & $3.81 \mathrm{E}+01$ & $-1.72 E+03$ & $8 \mathrm{E}+01$ & $E+01$ & -03 \\
\hline$-8.93 E+01$ & $3.99 \mathrm{E}+01$ & $-1.72 \mathrm{E}+03$ & $-1.02 \mathrm{E}+02$ & $5 \mathrm{E}+01$ & +03 \\
\hline$-9.77 \mathrm{E}+01$ & 4.11 & -1.7 & $E+02$ & 01 & +03 \\
\hline$-1.07 \mathrm{E}+02$ & $4.34 \mathrm{E}+01$ & $-1.71 \mathrm{E}+03$ & $-1.15 E+02$ & $6 \mathrm{E}+01$ & +03 \\
\hline$-1.17 \mathrm{E}+02$ & $4.60 \mathrm{E}+01$ & $-1.71 E+03$ & $-1.21 E+02$ & $4.71 \mathrm{E}+01$ & $-1.71 E+03$ \\
\hline$-1.23 E+02$ & $4.74 \mathrm{E}+01$ & $-1.71 E+03$ & $-1.25 E+02$ & $4.85 \mathrm{E}+01$ & $-1.71 E+03$ \\
\hline$-1.29 \mathrm{E}+02$ & $4.95 \mathrm{E}+01$ & $-1.71 \mathrm{E}+03$ & $-1.29 E+02$ & $4.94 \mathrm{E}+01$ & $-1.71 \mathrm{E}+\mathrm{C}$ \\
\hline$-5.07 E+00$ & $2.40 \mathrm{E}+02$ & $-1.75 E+03$ & $-7.71 \mathrm{E}+00$ & $2.42 \mathrm{E}+02$ & $-1.75 E+03$ \\
\hline$-1.84 \mathrm{E}+01$ & $2.39 \mathrm{E}+02$ & $-1.74 \mathrm{E}+03$ & $-1.54 \mathrm{E}+01$ & $2.43 E+02$ & $-1.74 \mathrm{E}+03$ \\
\hline$-3.84 \mathrm{E}+01$ & $2.39 \mathrm{E}+02$ & $-1.74 E+03$ & $-2.41 \mathrm{E}+01$ & $2.45 E+02$ & $-1.74 \mathrm{E}+03$ \\
\hline$-4.59 \mathrm{E}+01$ & $2.38 \mathrm{E}+02$ & $-1.73 E+03$ & $-3.14 \mathrm{E}+01$ & $2.46 \mathrm{E}+02$ & $-1.74 \mathrm{E}+03$ \\
\hline
\end{tabular}




\begin{tabular}{|c|c|c|c|c|c|}
\hline X-Cord. & Cord. & Cord. & X-Cord. & Y-Cord. & Z-Cord. \\
\hline+01 & $8 \mathrm{E}+02$ & $.73 E+03$ & $-1.69 E+02$ & $11 \mathrm{E}+01$ & $-1.69 E+03$ \\
\hline$-5.18 \mathrm{E}+01$ & $2.50 E+02$ & $-1.73 E+03$ & $-1.76 E+02$ & $8.62 \mathrm{E}+01$ & $-1.69 E+03$ \\
\hline$-6.28 \mathrm{E}+01$ & $52 E+02$ & $-1.73 E+03$ & $-1.81 \mathrm{E}+02$ & $8.98 \mathrm{E}+01$ & $-1.69 E+03$ \\
\hline+01 & $E+02$ & $1.73 E+03$ & $-1.87 \mathrm{E}+02$ & $40 \mathrm{E}+01$ & 03 \\
\hline+01 & $56 \mathrm{E}+02$ & $-1.72 E+03$ & $-1.92 \mathrm{E}+02$ & $9.82 \mathrm{E}+01$ & +03 \\
\hline$-9.66 \mathrm{E}+01$ & $2.59 \mathrm{E}+02$ & $-1.72 E+03$ & $-1.96 \mathrm{E}+02$ & $2 \mathrm{E}+02$ & $E+03$ \\
\hline$-1.04 E+02$ & $2.61 \mathrm{E}+02$ & $-1.72 E+03$ & $-1.99 E+02$ & $1.05 E+02$ & $=03$ \\
\hline$-1.10 E+02$ & +02 & +03 & $E+02$ & $E+02$ & $E+03$ \\
\hline$-1.19 E+02$ & $E+02$ & $E+03$ & $E+02$ & & +03 \\
\hline$=01$ & +02 & $E+03$ & +01 & & +03 \\
\hline 01 & 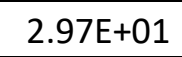 & 33 & 01 & & +03 \\
\hline & & & 01 & & +03 \\
\hline & & & & & \\
\hline & & & $-4.79 E+01$ & & \\
\hline & & & $-5.62 E+01$ & $\angle E+U \angle$ & $E+03$ \\
\hline$-2.14 \mathrm{E}+01$ & $3.11 \mathrm{E}+01$ & $-1.74 \mathrm{E}+03$ & $-6.57 E+01$ & $2.53 \mathrm{E}+02$ & $-1.72 E+03$ \\
\hline$-2.83 E+01$ & $3.19 E+01$ & $-1.74 E+03$ & $-7.38 \mathrm{E}+01$ & $.55 E+02$ & $E+03$ \\
\hline$-3.49 E+01$ & $3.26 \mathrm{E}+01$ & $-1.73 E+03$ & $-7.79 E+01$ & $6 \mathrm{E}+02$ & $2 \mathrm{E}+03$ \\
\hline$-4.07 E+01$ & $3.34 \mathrm{E}+01$ & $-1.73 E+03$ & $-8.56 \mathrm{E}+01$ & $2.57 \mathrm{E}+02$ & $2 \mathrm{E}+03$ \\
\hline$-4.84 E+01$ & $3.44 \mathrm{E}+01$ & $-1.73 E+03$ & $-9.07 E+01$ & $2.59 \mathrm{E}+02$ & $-1.72 E+03$ \\
\hline$-5.40 E+01$ & $3.54 \mathrm{E}+01$ & $-1.73 E+03$ & $-9.90 E+01$ & $2.60 E+02$ & $-1.72 E+03$ \\
\hline$-6.08 \mathrm{E}+01$ & $3.66 \mathrm{E}+01$ & $-1.73 E+03$ & $-1.05 E+02$ & $2.61 \mathrm{E}+02$ & $-1.72 E+03$ \\
\hline$-6.86 E+01$ & $3.84 \mathrm{E}+01$ & $-1.73 E+03$ & $-1.10 E+02$ & $2.62 \mathrm{E}+02$ & $-1.72 E+03$ \\
\hline$-8.76 E+01$ & $4.30 \mathrm{E}+01$ & $-1.72 E+03$ & $-1.16 \mathrm{E}+02$ & $2.63 E+02$ & $-1.72 E+03$ \\
\hline$-9.83 E+01$ & $4.60 \mathrm{E}+01$ & $-1.72 E+03$ & $-1.25 E+02$ & $2.65 \mathrm{E}+02$ & $-1.72 E+03$ \\
\hline$-1.05 E+02$ & $4.82 \mathrm{E}+01$ & $-1.72 \mathrm{E}+03$ & $5.66 \mathrm{E}+01$ & $4.76 \mathrm{E}+02$ & $-1.62 E+03$ \\
\hline$-1.12 \mathrm{E}+02$ & $5.09 \mathrm{E}+01$ & $-1.71 E+03$ & $-1.29 \mathrm{E}+01$ & $2.99 \mathrm{E}+01$ & $-1.74 \mathrm{E}+03$ \\
\hline$-1.20 E+02$ & $5.45 \mathrm{E}+01$ & $-1.71 E+03$ & $-4.18 \mathrm{E}+00$ & $2 \mathrm{E}+02$ & $4 \mathrm{E}+03$ \\
\hline$-1.27 E+02$ & $5.72 \mathrm{E}+01$ & $-1.71 E+03$ & $-2.07 E+02$ & $E+02$ & +03 \\
\hline$-1.34 \mathrm{E}+02$ & $6.08 \mathrm{E}+01$ & $-1.70 E+03$ & $-1.26 \mathrm{E}+02$ & $4 \mathrm{E}+02$ & $E+03$ \\
\hline$-1.39 E+02$ & $6.34 \mathrm{E}+01$ & $-1.70 E+03$ & $-1.51 E+01$ & $3.05 E+01$ & $-1.74 \mathrm{E}+03$ \\
\hline$-1.45 E+02$ & $6.66 \mathrm{E}+01$ & $-1.70 E+03$ & $-2.27 E+01$ & $3.14 \mathrm{E}+01$ & $-1.74 \mathrm{E}+03$ \\
\hline$-1.51 E+02$ & $6.96 \mathrm{E}+01$ & $-1.70 E+03$ & $-3.06 E+01$ & $3.22 \mathrm{E}+01$ & $-1.74 \mathrm{E}+03$ \\
\hline$-1.56 E+02$ & $7.29 \mathrm{E}+01$ & $-1.69 E+03$ & $-4.02 E+01$ & $3.35 E+01$ & $-1.73 E+03$ \\
\hline$-1.65 E+02$ & $7.87 \mathrm{E}+01$ & $-1.69 E+03$ & $-4.71 E+01$ & $3.45 \mathrm{E}+01$ & $-1.73 E+03$ \\
\hline
\end{tabular}




\begin{tabular}{|c|c|c|c|c|c|}
\hline X-Cord. & Cord. & Cord. & X-Cord. & Y-Cord. & Z-Cord. \\
\hline+01 & $8 \mathrm{E}+01$ & $.73 E+03$ & $-2.68 \mathrm{E}+00$ & $40 E+02$ & $-1.74 \mathrm{E}+03$ \\
\hline$-6.38 \mathrm{E}+01$ & $3.78 \mathrm{E}+01$ & $-1.73 E+03$ & $-1.40 \mathrm{E}+02$ & $5.46 \mathrm{E}+01$ & $-1.70 \mathrm{E}+03$ \\
\hline$-7.26 \mathrm{E}+01$ & $92 \mathrm{E}+01$ & $1.73 E+03$ & $-1.29 E+02$ & $.30 \mathrm{E}+02$ & $-1.71 \mathrm{E}+03$ \\
\hline$-8.29 E+01$ & $15 \mathrm{E}+01$ & $1.73 E+03$ & $-1.63 E+01$ & $04 \mathrm{E}+01$ & +03 \\
\hline+01 & $35 E+01$ & $-1.72 E+03$ & $-2.05 E+01$ & $3.09 \mathrm{E}+01$ & +03 \\
\hline$-9.94 E+01$ & $4.66 \mathrm{E}+01$ & $-1.72 E+03$ & $-2.59 E+01$ & $13 \mathrm{E}+01$ & $E+03$ \\
\hline$-1.06 E+02$ & $4.85 \mathrm{E}+01$ & $-1.72 E+03$ & $-3.32 E+01$ & $9 \mathrm{E}+01$ & $E+03$ \\
\hline$-1.13 E+02$ & $E+01$ & $=03$ & $E+01$ & $E+01$ & +03 \\
\hline$-1.21 E+02$ & $=01$ & $E+03$ & $E+01$ & & +03 \\
\hline$-1.29 E+02$ & 01 & $E+03$ & +01 & & +03 \\
\hline-1 . & 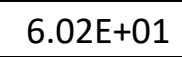 & & -6 & & +03 \\
\hline & & & & & +03 \\
\hline & & & & & \\
\hline & & & & & \\
\hline & & & & & $E+03$ \\
\hline$-1.83 E+02$ & $8.97 \mathrm{E}+01$ & $-1.70 E+03$ & $-9.91 E+01$ & $4.20 \mathrm{E}+01$ & $-1.72 E+03$ \\
\hline$-1.88 \mathrm{E}+02$ & $9.41 \mathrm{E}+01$ & $-1.69 E+03$ & $-1.05 E+02$ & $4.33 \mathrm{E}+01$ & $E+03$ \\
\hline$-1.95 \mathrm{E}+02$ & $1.01 \mathrm{E}+02$ & $-1.69 E+03$ & $-1.12 E+02$ & $4.48 \mathrm{E}+01$ & $2 \mathrm{E}+03$ \\
\hline$-2.02 E+02$ & $1.06 \mathrm{E}+02$ & $-1.69 E+03$ & $-1.19 E+02$ & $4.70 \mathrm{E}+01$ & $1 \mathrm{E}+03$ \\
\hline$-7.20 E+00$ & $2.40 \mathrm{E}+02$ & $-1.75 E+03$ & $-1.32 \mathrm{E}+02$ & $5.16 \mathrm{E}+01$ & $-1.70 E+03$ \\
\hline$-2.61 E+01$ & $2.40 \mathrm{E}+02$ & $-1.74 E+03$ & $-1.37 \mathrm{E}+02$ & $5.32 E+01$ & $-1.70 \mathrm{E}+03$ \\
\hline$-3.35 E+01$ & $2.40 \mathrm{E}+02$ & $-1.73 E+03$ & $-1.39 E+01$ & $2.40 E+02$ & $-1.74 \mathrm{E}+03$ \\
\hline$-4.15 E+01$ & $2.40 \mathrm{E}+02$ & $-1.73 E+03$ & $-2.57 E+01$ & $2.40 \mathrm{E}+02$ & $-1.73 E+03$ \\
\hline$-5.12 E+01$ & $2.40 E+02$ & $-1.73 E+03$ & $-4.20 E+01$ & $2.40 \mathrm{E}+02$ & $-1.72 E+03$ \\
\hline$-6.26 E+01$ & $2.39 \mathrm{E}+02$ & $-1.73 E+03$ & $-5.55 E+01$ & $2.39 \mathrm{E}+02$ & $-1.73 E+03$ \\
\hline$-7.44 E+01$ & $2.38 \mathrm{E}+02$ & $-1.72 E+03$ & $-6.38 \mathrm{E}+01$ & $2.39 E+02$ & $-1.73 E+03$ \\
\hline$-8.41 E+01$ & $2.37 \mathrm{E}+02$ & $-1.72 E+03$ & $-7.50 \mathrm{E}+01$ & $2.38 \mathrm{E}+02$ & $-1.72 \mathrm{E}+03$ \\
\hline$-9.13 E+01$ & $2.37 E+02$ & $-1.72 E+03$ & $-8.35 E+01$ & $7 E+02$ & $2 \mathrm{E}+03$ \\
\hline$-9.95 E+01$ & $2.35 E+02$ & $-1.72 E+03$ & $-7.25 E+01$ & $3 E+02$ & +03 \\
\hline$-1.05 E+02$ & $2.34 \mathrm{E}+02$ & $-1.72 E+03$ & $-8.23 E+01$ & $7 E+02$ & $E+03$ \\
\hline$-1.10 E+02$ & $2.34 \mathrm{E}+02$ & $-1.71 E+03$ & $-9.03 E+01$ & $2.36 \mathrm{E}+02$ & $-1.72 \mathrm{E}+03$ \\
\hline$-1.14 \mathrm{E}+02$ & $2.33 E+02$ & $-1.71 E+03$ & $-9.77 E+01$ & $2.36 \mathrm{E}+02$ & $-1.71 E+03$ \\
\hline$-1.22 \mathrm{E}+02$ & $2.31 \mathrm{E}+02$ & $-1.71 E+03$ & $-1.04 E+02$ & $2.34 \mathrm{E}+02$ & $-1.71 E+03$ \\
\hline $5.66 \mathrm{E}+01$ & $4.76 \mathrm{E}+02$ & $-1.62 \mathrm{E}+03$ & $-1.11 E+02$ & $2.33 \mathrm{E}+02$ & $-1.71 E+03$ \\
\hline$-1.23 E+01$ & $2.99 \mathrm{E}+01$ & $-1.74 \mathrm{E}+03$ & $-1.19 E+02$ & $2.32 \mathrm{E}+02$ & $-1.71 E+03$ \\
\hline
\end{tabular}




\begin{tabular}{|c|c|c|c|c|c|}
\hline rd. & Cord. & Cord. & X-Cord. & Y-Cord. & Z-Cord. \\
\hline+02 & $\mathrm{E}+02$ & $.71 E+03$ & $-1.18 \mathrm{E}+02$ & $2.68 \mathrm{E}+02$ & $-1.72 E+03$ \\
\hline $5.68 \mathrm{E}+01$ & $4.76 E+02$ & $-1.62 E+03$ & $-1.23 E+02$ & $2.69 \mathrm{E}+02$ & $-1.72 \mathrm{E}+03$ \\
\hline$-1.38 \mathrm{E}+01$ & $94 \mathrm{E}+01$ & $-1.74 E+03$ & $5.68 \mathrm{E}+01$ & $4.76 \mathrm{E}+02$ & $-1.62 \mathrm{E}+03$ \\
\hline 00 & $40 \mathrm{E}+02$ & $-1.74 \mathrm{E}+03$ & $-1.21 E+01$ & $.00 \mathrm{E}+01$ & 03 \\
\hline+02 & $5.52 \mathrm{E}+01$ & $-1.70 \mathrm{E}+03$ & $-7.13 E+00$ & $2.42 \mathrm{E}+02$ & +03 \\
\hline$-1.27 \mathrm{E}+02$ & $2.30 \mathrm{E}+02$ & $-1.71 E+03$ & $-2.15 E+02$ & $1 E+02$ & $9 \mathrm{E}+03$ \\
\hline$-1.35 \mathrm{E}+01$ & $3.01 \mathrm{E}+01$ & $-1.74 E+03$ & $-1.25 E+02$ & $\mathrm{DE}+02$ & $E+03$ \\
\hline$-2.04 E+01$ & +01 & $=03$ & $E+01$ & & +03 \\
\hline$-2.74 \mathrm{E}+01$ & 01 & $E+03$ & $E+01$ & & +03 \\
\hline+01 & 1 & $E+03$ & 01 & & \\
\hline-4 . & 3 & 33 & -3 & & +03 \\
\hline & & & 01 & & +03 \\
\hline & & & & & \\
\hline & & & $-7.09 E+01$ & & \\
\hline$-7.34 E+01$ & $3.64 \mathrm{E}+01$ & $-1.73 E+03$ & $-7.92 \mathrm{E}+01$ & 4. $\angle U E+U 1$ & $E+03$ \\
\hline$-8.31 E+01$ & $3.81 \mathrm{E}+01$ & $-1.72 E+03$ & $-9.56 E+01$ & $4.58 \mathrm{E}+01$ & $E+03$ \\
\hline$-9.29 E+01$ & $4.03 E+01$ & $-1.72 E+03$ & $-1.03 E+02$ & $4.79 E+01$ & $2 E+03$ \\
\hline$-1.01 E+02$ & 4.27E+01 & $-1.71 E+03$ & $-1.09 E+02$ & $5.00 \mathrm{E}+01$ & $1 E+03$ \\
\hline$-1.09 E+02$ & $4.46 \mathrm{E}+01$ & $-1.71 E+03$ & $-1.18 \mathrm{E}+02$ & $5.36 \mathrm{E}+01$ & $1 \mathrm{E}+03$ \\
\hline$-1.16 E+02$ & $4.65 E+01$ & $-1.71 E+03$ & $-1.25 E+02$ & $5.64 \mathrm{E}+01$ & $-1.71 E+03$ \\
\hline$-1.19 E+02$ & $4.78 \mathrm{E}+01$ & $-1.71 E+03$ & $-1.31 E+02$ & $5.89 E+01$ & $-1.71 E+03$ \\
\hline$-1.25 \mathrm{E}+02$ & $4.98 \mathrm{E}+01$ & $-1.70 E+03$ & $-1.37 E+02$ & $6.20 E+01$ & $-1.70 \mathrm{E}+03$ \\
\hline$-1.32 E+02$ & $5.17 \mathrm{E}+01$ & $-1.71 E+03$ & $-1.44 \mathrm{E}+02$ & $6.55 E+01$ & $-1.70 E+03$ \\
\hline$-1.37 E+02$ & $5.35 E+01$ & $-1.70 E+03$ & $-1.53 E+02$ & $7.06 \mathrm{E}+01$ & $-1.70 E+03$ \\
\hline$-1.04 E+01$ & $2.42 \mathrm{E}+02$ & $-1.75 E+03$ & $-1.58 \mathrm{E}+02$ & $7.36 \mathrm{E}+01$ & $-1.70 \mathrm{E}+03$ \\
\hline$-2.25 \mathrm{E}+01$ & $2.44 \mathrm{E}+02$ & $-1.75 E+03$ & $-1.64 E+02$ & $7.77 \mathrm{E}+01$ & $-1.70 \mathrm{E}+03$ \\
\hline$-3.60 E+01$ & $2.47 \mathrm{E}+02$ & $-1.74 \mathrm{E}+03$ & $-1.69 E+02$ & $8.17 E+01$ & $-1.69 \mathrm{E}+03$ \\
\hline$-5.02 E+01$ & $2.51 \mathrm{E}+02$ & $-1.73 E+03$ & $-1.75 E+02$ & $0 \mathrm{E}+01$ & $9 \mathrm{E}+03$ \\
\hline$-6.02 E+01$ & $2.53 \mathrm{E}+02$ & $-1.74 \mathrm{E}+03$ & $E+02$ & +01 & $E+03$ \\
\hline$-7.31 E+01$ & $2.56 \mathrm{E}+02$ & $-1.73 E+03$ & $6 \mathrm{E}+02$ & $E+01$ & $E+03$ \\
\hline$-8.38 \mathrm{E}+01$ & $2.58 \mathrm{E}+02$ & $-1.73 E+03$ & $-1.90 \mathrm{E}+02$ & $9.82 E+01$ & $-1.69 E+03$ \\
\hline$-9.39 E+01$ & $2.61 \mathrm{E}+02$ & & $-1.96 \mathrm{E}+02$ & $1.03 E+02$ & $-1.69 E+03$ \\
\hline$-1.00 E+02$ & $2.63 E+02$ & $-1.72 E+03$ & $-1.98 \mathrm{E}+02$ & $1.05 E+02$ & $-1.69 E+03$ \\
\hline$-1.08 \mathrm{E}+02$ & $2.65 \mathrm{E}+02$ & $-1.72 E+03$ & $-2.05 E+02$ & $1.12 \mathrm{E}+02$ & $-1.68 \mathrm{E}+03$ \\
\hline$-1.14 \mathrm{E}+02$ & $2.67 \mathrm{E}+02$ & $-1.72 \mathrm{E}+03$ & $-2.10 E+02$ & $1.17 \mathrm{E}+02$ & $-1.68 \mathrm{E}+03$ \\
\hline
\end{tabular}




\begin{tabular}{|c|c|c|c|c|c|}
\hline X-Cord. & Cord. & Cord. & X-Cord. & Y-Cord. & Z-Cord. \\
\hline+00 & $2 E+02$ & $.75 E+03$ & $-1.54 \mathrm{E}+02$ & $14 \mathrm{E}+01$ & $-1.70 E+03$ \\
\hline$-1.67 E+01$ & $44 \mathrm{E}+02$ & $-1.74 E+03$ & $-1.63 E+02$ & $7.72 E+01$ & $-1.70 \mathrm{E}+03$ \\
\hline$-2.63 E+01$ & $45 E+02$ & $1.74 \mathrm{E}+03$ & $-1.71 E+02$ & $3.26 \mathrm{E}+01$ & $-1.70 \mathrm{E}+03$ \\
\hline-5.04 & $0 \mathrm{E}+02$ & $-1.74 E+03$ & $-1.79 E+02$ & $.90 E+01$ & 03 \\
\hline-5.71 & $52 E+02$ & $-1.73 E+03$ & $-1.89 E+02$ & $9.70 \mathrm{E}+01$ & +03 \\
\hline$-6.37 E+01$ & $2.54 \mathrm{E}+02$ & $-1.73 E+03$ & $-1.97 \mathrm{E}+02$ & $4 E+02$ & $59 E+03$ \\
\hline$-7.26 E+01$ & $2.56 \mathrm{E}+02$ & $-1.73 E+03$ & $-2.01 E+02$ & $8 E+02$ & $E+03$ \\
\hline$-8.19 E+01$ & $2.58 \mathrm{E}+02$ & +03 & $3 E+02$ & $E+02$ & $E+03$ \\
\hline$-9.06 \mathrm{E}+01$ & $E+02$ & $E+03$ & $E+02$ & & +03 \\
\hline$-9.62 E+01$ & 02 & -1 & +01 & & \\
\hline-1. & 22 & 33 & -2 & & +03 \\
\hline & & & 01 & & \\
\hline & & & & & \\
\hline & & & & & \\
\hline & & & & & $E+03$ \\
\hline $5.67 \mathrm{E}+01$ & $4.76 \mathrm{E}+02$ & $-1.62 \mathrm{E}+03$ & $-7.56 \mathrm{E}+01$ & $2.58 \mathrm{E}+02$ & $-1.73 E+03$ \\
\hline$-1.20 \mathrm{E}+01$ & $2.99 \mathrm{E}+01$ & $-1.74 \mathrm{E}+03$ & $-8.21 E+01$ & $2.60 \mathrm{E}+02$ & $3 E+03$ \\
\hline$-5.14 \mathrm{E}+00$ & $2.42 \mathrm{E}+02$ & $-1.74 \mathrm{E}+03$ & $-9.01 E+01$ & $2.62 E+02$ & $2 \mathrm{E}+03$ \\
\hline$-2.14 \mathrm{E}+02$ & $1.21 \mathrm{E}+02$ & $-1.68 \mathrm{E}+03$ & $-9.83 E+01$ & $2.65 \mathrm{E}+02$ & $2 E+03$ \\
\hline$-1.27 E+02$ & $2.70 \mathrm{E}+02$ & $-1.71 E+03$ & $-1.11 E+02$ & $2.68 \mathrm{E}+02$ & $-1.72 E+03$ \\
\hline$-1.48 \mathrm{E}+01$ & $3.02 \mathrm{E}+01$ & $-1.74 E+03$ & $-1.16 E+02$ & $2.70 E+02$ & $-1.72 \mathrm{E}+03$ \\
\hline$-2.74 \mathrm{E}+01$ & $3.15 E+01$ & $-1.74 E+03$ & $-1.20 \mathrm{E}+02$ & $2.71 E+02$ & $-1.72 E+03$ \\
\hline$-3.69 E+01$ & $3.29 E+01$ & $-1.73 E+03$ & $5.65 E+01$ & $4.76 \mathrm{E}+02$ & $-1.62 E+03$ \\
\hline$-4.72 E+01$ & $3.45 E+01$ & $-1.73 E+03$ & $-1.18 \mathrm{E}+01$ & $3.01 \mathrm{E}+01$ & $-1.74 \mathrm{E}+03$ \\
\hline$-5.45 E+01$ & $3.60 \mathrm{E}+01$ & $-1.73 E+03$ & $-7.21 E+00$ & $2.42 \mathrm{E}+02$ & $-1.75 E+03$ \\
\hline$-6.58 \mathrm{E}+01$ & $3.81 \mathrm{E}+01$ & $-1.72 \mathrm{E}+03$ & $-2.22 \mathrm{E}+02$ & $1.31 \mathrm{E}+02$ & $-1.69 \mathrm{E}+03$ \\
\hline$-7.87 E+01$ & $4.11 \mathrm{E}+01$ & $-1.72 E+03$ & $-1.19 E+02$ & $2.72 \mathrm{E}+02$ & $-1.72 \mathrm{E}+03$ \\
\hline$-8.83 E+01$ & $4.37 \mathrm{E}+01$ & $-1.72 E+03$ & $-1.45 E+01$ & $6 \mathrm{E}+01$ & $4 E+03$ \\
\hline$-9.66 \mathrm{E}+01$ & $4.63 \mathrm{E}+01$ & $-1.71 E+03$ & $5 \mathrm{E}+01$ & $E+01$ & $E+03$ \\
\hline$-1.06 E+02$ & $4.94 \mathrm{E}+01$ & $-1.71 E+03$ & $-4.22 E+01$ & $3 E+01$ & $E+03$ \\
\hline$-1.14 \mathrm{E}+02$ & & $-1.71 E+03$ & $-5.98 \mathrm{E}+01$ & $3.75 E+01$ & $-1.72 \mathrm{E}+03$ \\
\hline$-1.24 \mathrm{E}+02$ & $5.56 \mathrm{E}+01$ & $-1.71 E+03$ & $-7.01 E+01$ & $3.98 E+01$ & $-1.72 E+03$ \\
\hline$-1.31 E+02$ & $5.94 \mathrm{E}+01$ & $-1.70 E+03$ & $-8.16 E+01$ & $4.26 \mathrm{E}+01$ & $-1.71 E+03$ \\
\hline$-1.40 \mathrm{E}+02$ & $6.37 \mathrm{E}+01$ & $-1.70 E+03$ & $-8.93 E+01$ & $4.49 \mathrm{E}+01$ & $-1.71 E+03$ \\
\hline$-1.48 \mathrm{E}+02$ & $6.80 \mathrm{E}+01$ & $-1.70 E+03$ & $-9.60 E+01$ & $4.64 \mathrm{E}+01$ & $-1.71 E+03$ \\
\hline
\end{tabular}




\begin{tabular}{|c|c|c|c|c|c|}
\hline X-Cord. & Cord. & Cord. & X-Cord. & Y-Cord. & Z-Cord. \\
\hline+02 & $6 \mathrm{E}+01$ & $.71 E+03$ & $-3.39 E+01$ & $3.27 \mathrm{E}+01$ & $-1.73 E+03$ \\
\hline$=02$ & $5.17 \mathrm{E}+01$ & $-1.71 E+03$ & $-4.08 \mathrm{E}+01$ & $3.35 E+01$ & $-1.73 E+03$ \\
\hline$-1.24 E+02$ & $64 E+01$ & $-1.71 E+03$ & $-4.71 E+01$ & $3.43 \mathrm{E}+01$ & $-1.73 E+03$ \\
\hline$E+02$ & $90 \mathrm{E}+01$ & $-1.71 E+03$ & $-5.33 E+01$ & $.52 E+01$ & +03 \\
\hline$E+02$ & $6.56 \mathrm{E}+01$ & $-1.70 \mathrm{E}+03$ & $-6.05 E+01$ & $3.65 \mathrm{E}+01$ & +03 \\
\hline$-1.51 E+02$ & $7.03 E+01$ & $-1.70 \mathrm{E}+03$ & $-6.76 E+01$ & $7 E+01$ & $E+03$ \\
\hline$-1.57 \mathrm{E}+02$ & $7.36 \mathrm{E}+01$ & $-1.70 E+03$ & $-7.66 \mathrm{E}+01$ & $E+01$ & $E+03$ \\
\hline$-1.62 E+02$ & $E+01$ & $E+03$ & $E+01$ & $E+01$ & +03 \\
\hline$-1.73 E+02$ & +01 & $E+03$ & $E+01$ & & +03 \\
\hline$-1.79 E+02$ & 1 & -1 & $=02$ & & +03 \\
\hline$-1 . \varepsilon$ & 0 & 33 & 02 & & +03 \\
\hline & & & & & \\
\hline & & & & & \\
\hline & & & & & \\
\hline & & & & & $E+03$ \\
\hline$-2.07 E+02$ & $1.14 \mathrm{E}+02$ & $-1.69 E+03$ & $-1.64 \mathrm{E}+02$ & $7.66 \mathrm{E}+01$ & $-1.70 \mathrm{E}+03$ \\
\hline$-2.10 \mathrm{E}+02$ & $1.18 \mathrm{E}+02$ & $-1.69 E+03$ & $-1.69 \mathrm{E}+02$ & $8.04 \mathrm{E}+01$ & $0 \mathrm{E}+03$ \\
\hline$-2.14 \mathrm{E}+02$ & $1.22 \mathrm{E}+02$ & $-1.68 \mathrm{E}+03$ & $-1.75 E+02$ & $8.49 \mathrm{E}+01$ & $0 E+03$ \\
\hline$-9.72 E+00$ & $2.43 E+02$ & $-1.74 \mathrm{E}+03$ & $-1.88 \mathrm{E}+02$ & $9.55 \mathrm{E}+01$ & $E+03$ \\
\hline$-1.77 E+01$ & $2.44 \mathrm{E}+02$ & $-1.74 E+03$ & $-1.92 E+02$ & $9.96 \mathrm{E}+01$ & $-1.69 E+03$ \\
\hline$-3.04 E+01$ & $2.47 E+02$ & $-1.74 E+03$ & $-2.03 E+02$ & $1.10 \mathrm{E}+02$ & $-1.69 \mathrm{E}+03$ \\
\hline$-4.20 E+01$ & $2.49 E+02$ & $-1.74 E+03$ & $-1.17 \mathrm{E}+01$ & $2.43 E+02$ & $-1.75 E+03$ \\
\hline$-5.14 E+01$ & $2.52 \mathrm{E}+02$ & $-1.73 E+03$ & $-2.09 E+01$ & $2.44 \mathrm{E}+02$ & $-1.75 E+03$ \\
\hline$-7.30 E+01$ & $2.58 \mathrm{E}+02$ & $-1.73 E+03$ & $-4.12 \mathrm{E}+01$ & $2.49 E+02$ & $-1.74 \mathrm{E}+03$ \\
\hline$-9.33 E+01$ & $2.63 \mathrm{E}+02$ & $-1.72 E+03$ & $-5.30 E+01$ & $2.53 \mathrm{E}+02$ & $-1.74 \mathrm{E}+03$ \\
\hline$-1.03 E+02$ & $2.66 \mathrm{E}+02$ & $-1.72 \mathrm{E}+03$ & $-6.18 E+01$ & $2.55 \mathrm{E}+02$ & $-1.74 \mathrm{E}+03$ \\
\hline$-1.10 E+02$ & $2.68 \mathrm{E}+02$ & $-1.72 E+03$ & $-9.09 E+01$ & $2.65 \mathrm{E}+02$ & $-1.72 E+03$ \\
\hline $5.65 \mathrm{E}+01$ & $4.76 \mathrm{E}+02$ & $-1.62 E+03$ & $-1.03 E+02$ & $\mathrm{OE}+02$ & $2 E+03$ \\
\hline$-1.26 \mathrm{E}+01$ & $2.99 \mathrm{E}+01$ & $-1.74 \mathrm{E}+03$ & $-1.12 E+02$ & $E+02$ & +03 \\
\hline$-1.17 E+01$ & $2.41 E+02$ & $-1.76 E+03$ & -1 & $5 E+02$ & $E+03$ \\
\hline$-2.22 \mathrm{E}+02$ & $1.31 \mathrm{E}+02$ & $-1.69 E+03$ & $-1.19 E+02$ & $2.75 E+02$ & $-1.71 E+03$ \\
\hline$-1.27 E+02$ & $2.74 \mathrm{E}+02$ & $-1.72 E+03$ & $5.66 \mathrm{E}+01$ & $4.76 \mathrm{E}+02$ & $-1.62 E+03$ \\
\hline$-1.42 E+01$ & $3.06 E+01$ & $-1.74 E+03$ & $-1.29 E+01$ & $2.98 \mathrm{E}+01$ & $-1.74 \mathrm{E}+03$ \\
\hline$-2.24 \mathrm{E}+01$ & $3.13 E+01$ & $-1.74 E+03$ & $-1.30 \mathrm{E}+01$ & $2.41 \mathrm{E}+02$ & $-1.77 E+03$ \\
\hline$-2.85 E+01$ & $3.19 \mathrm{E}+01$ & $-1.73 E+03$ & $-2.27 E+02$ & $1.38 \mathrm{E}+02$ & $-1.68 \mathrm{E}+03$ \\
\hline
\end{tabular}




\begin{tabular}{|c|c|c|c|c|c|}
\hline $\mathrm{X}-\mathrm{C}$ & Cord. & Cord. & X-Cord. & Y-Cord. & Z-Cord. \\
\hline 02 & $7 E+02$ & $.71 E+03$ & $-1.07 E+02$ & $2.69 E+02$ & $-1.72 E+03$ \\
\hline+01 & $3.07 E+01$ & $-1.74 E+03$ & $-1.12 \mathrm{E}+02$ & $2.71 \mathrm{E}+02$ & $-1.72 \mathrm{E}+03$ \\
\hline$-2.97 E+01$ & $20 \mathrm{E}+01$ & $-1.73 E+03$ & $5.67 \mathrm{E}+01$ & $.76 \mathrm{E}+02$ & $1625+02$ \\
\hline-4.6 & $44 \mathrm{E}+01$ & $1.73 E+03$ & $-1.13 E+01$ & $.03 E+01$ & 03 \\
\hline$E+01$ & $3.60 \mathrm{E}+01$ & $-1.73 E+03$ & $-1.37 E+01$ & $11 E+02$ & +03 \\
\hline$-7.35 E+01$ & $3.96 \mathrm{E}+01$ & $-1.72 E+03$ & $-2.27 \mathrm{E}+02$ & $39 \mathrm{E}+02$ & $-1.68 \mathrm{E}+03$ \\
\hline$-8.33 E+01$ & $4.18 \mathrm{E}+01$ & $-1.72 E+03$ & $-1.26 \mathrm{E}+02$ & $E+02$ & $2 E+03$ \\
\hline$-9.28 \mathrm{E}+01$ & $4.42 \mathrm{E}+01$ & $E+03$ & $E+01$ & & +03 \\
\hline$-1.01 E+02$ & +01 & $E+03$ & $E+01$ & & +03 \\
\hline$E+02$ & 01 & $E+03$ & +01 & & +03 \\
\hline-1 . & 5 & & 01 & & +03 \\
\hline & & & 01 & & +03 \\
\hline & & & & & \\
\hline & & & & & \\
\hline & & & & 4.85E+U1 & $E+03$ \\
\hline$-1.53 E+02$ & $7.11 \mathrm{E}+01$ & $-1.70 E+03$ & $-1.08 E+02$ & $5.03 E+01$ & $-1.71 E+03$ \\
\hline$-1.62 \mathrm{E}+02$ & $7.63 \mathrm{E}+01$ & $-1.70 \mathrm{E}+03$ & $-1.13 E+02$ & $5.16 \mathrm{E}+01$ & $1 E+03$ \\
\hline$-1.67 E+02$ & $7.97 \mathrm{E}+01$ & $-1.69 E+03$ & $-1.16 E+02$ & $5.27 E+01$ & $1 \mathrm{E}+03$ \\
\hline$-1.79 E+02$ & $8.90 \mathrm{E}+01$ & $-1.69 E+03$ & $-1.21 E+02$ & $5.48 \mathrm{E}+01$ & $1 \mathrm{E}+03$ \\
\hline$-1.86 \mathrm{E}+02$ & $9.41 E+01$ & $-1.69 E+03$ & $-1.26 \mathrm{E}+02$ & $5.69 \mathrm{E}+01$ & $-1.71 E+03$ \\
\hline$-1.90 E+02$ & $9.74 \mathrm{E}+01$ & $-1.69 E+03$ & $-1.32 E+02$ & $5.92 E+01$ & $-1.71 E+03$ \\
\hline$-1.97 \mathrm{E}+02$ & $1.03 E+02$ & $-1.69 E+03$ & $-1.38 \mathrm{E}+02$ & $6.23 E+01$ & $-1.70 \mathrm{E}+03$ \\
\hline$-2.06 E+02$ & $1.13 E+02$ & $-1.69 E+03$ & $-1.44 \mathrm{E}+02$ & $6.53 E+01$ & $-1.70 E+03$ \\
\hline$-2.11 E+02$ & $1.18 \mathrm{E}+02$ & $-1.69 E+03$ & $-1.50 E+02$ & $6.84 \mathrm{E}+01$ & $-1.70 E+03$ \\
\hline$-2.18 \mathrm{E}+02$ & $1.26 \mathrm{E}+02$ & $-1.68 \mathrm{E}+03$ & $-1.55 E+02$ & $7.15 E+01$ & $-1.70 \mathrm{E}+03$ \\
\hline$-9.30 \mathrm{E}+00$ & $2.43 E+02$ & $-1.75 E+03$ & $-1.61 \mathrm{E}+02$ & $7.51 \mathrm{E}+01$ & $-1.70 \mathrm{E}+03$ \\
\hline$-2.60 E+01$ & $2.46 \mathrm{E}+02$ & $-1.74 E+03$ & $-1.68 \mathrm{E}+02$ & $8.03 E+01$ & $-1.70 \mathrm{E}+03$ \\
\hline$-3.72 E+01$ & $2.49 \mathrm{E}+02$ & $-1.74 \mathrm{E}+03$ & $-1.71 E+02$ & $1 \mathrm{E}+01$ & $0 \mathrm{E}+03$ \\
\hline$-4.57 E+01$ & $2.51 \mathrm{E}+02$ & $-1.73 E+03$ & $5 \mathrm{E}+02$ & $E+01$ & $E+03$ \\
\hline$-5.55 E+01$ & $2.54 \mathrm{E}+02$ & $-1.73 E+03$ & $-1.81 E+02$ & $3 E+01$ & $E+03$ \\
\hline$-6.56 E+01$ & $2.56 \mathrm{E}+02$ & $-1.73 E+03$ & $-1.85 E+02$ & $9.30 \mathrm{E}+01$ & $-1.69 E+03$ \\
\hline $1 E+01$ & $2.59 \mathrm{E}+02$ & & $-1.89 E+02$ & $9.68 \mathrm{E}+01$ & $-1.69 E+03$ \\
\hline$-8.46 E+01$ & $2.62 \mathrm{E}+02$ & $-1.73 E+03$ & $-1.94 \mathrm{E}+02$ & $1.01 \mathrm{E}+02$ & $-1.69 E+03$ \\
\hline$-9.25 E+01$ & $2.64 \mathrm{E}+02$ & $-1.72 E+03$ & $-1.99 E+02$ & $1.06 \mathrm{E}+02$ & $-1.69 \mathrm{E}+03$ \\
\hline$-1.00 \mathrm{E}+02$ & $2.67 \mathrm{E}+02$ & $-1.72 \mathrm{E}+03$ & $-2.03 E+02$ & $1.11 \mathrm{E}+02$ & $-1.69 \mathrm{E}+03$ \\
\hline
\end{tabular}




\begin{tabular}{|c|c|c|c|c|c|}
\hline X-Cord. & Cord. & Cord. & X-Cord. & Y-Cord. & Z-Cord. \\
\hline+02 & $6 \mathrm{E}+02$ & $69 E+03$ & $-2.04 E+02$ & $1.12 \mathrm{E}+02$ & $-1.69 E+03$ \\
\hline$-2.12 E+02$ & $1.20 \mathrm{E}+02$ & $-1.69 E+03$ & $-2.10 E+02$ & $1.19 \mathrm{E}+02$ & $-1.69 \mathrm{E}+03$ \\
\hline$-2.14 E+02$ & $24 E+02$ & $-1.68 \mathrm{E}+03$ & $-2.21 \mathrm{E}+02$ & $.32 \mathrm{E}+02$ & $-1.68 \mathrm{E}+03$ \\
\hline-2 . & $9 E+02$ & $-1.68 \mathrm{E}+03$ & $-2.28 \mathrm{E}+02$ & $2 \mathrm{E}+02$ & $8 \mathrm{E}+03$ \\
\hline+01 & +02 & $-1.74 \mathrm{E}+03$ & $-8.76 \mathrm{E}+00$ & $+3 E+02$ & +03 \\
\hline$-2.51 E+01$ & $2.46 \mathrm{E}+02$ & $-1.74 E+03$ & $-1.80 \mathrm{E}+01$ & $5 \mathrm{E}+02$ & $E+03$ \\
\hline$-3.94 E+01$ & $2.50 \mathrm{E}+02$ & $-1.74 E+03$ & $-2.90 \mathrm{E}+01$ & $E+02$ & $E+03$ \\
\hline$-4.96 E+01$ & $E+02$ & $E+03$ & $5+01$ & $E+02$ & $E+03$ \\
\hline$-5.93 E+01$ & +02 & $\mathrm{E}+03$ & $E+01$ & & +03 \\
\hline+01 & 2 & +03 & 01 & & r03 \\
\hline-8 & 02 & 33 & -7 & & +03 \\
\hline & & & -8 & & \\
\hline & & & & & \\
\hline & & & & & \\
\hline & & & & & $E+03$ \\
\hline $5.67 \mathrm{E}+01$ & $4.76 \mathrm{E}+02$ & $-1.62 \mathrm{E}+03$ & $-1.22 \mathrm{E}+02$ & $2.79 \mathrm{E}+02$ & $-1.71 E+03$ \\
\hline$-1.31 E+01$ & $2.97 \mathrm{E}+01$ & $-1.74 \mathrm{E}+03$ & $5.66 \mathrm{E}+01$ & $4.76 \mathrm{E}+02$ & $-1.62 E+03$ \\
\hline$-1.36 \mathrm{E}+01$ & $2.41 \mathrm{E}+02$ & $-1.77 E+03$ & $-1.36 \mathrm{E}+01$ & $2.94 \mathrm{E}+01$ & $4 E+03$ \\
\hline$-2.32 E+02$ & $1.46 \mathrm{E}+02$ & $-1.68 \mathrm{E}+03$ & $-1.09 \mathrm{E}+01$ & $2.42 \mathrm{E}+02$ & $6 \mathrm{E}+03$ \\
\hline$-1.21 E+02$ & $2.79 \mathrm{E}+02$ & $-1.71 E+03$ & $-2.31 E+02$ & $1.48 \mathrm{E}+02$ & $-1.68 \mathrm{E}+03$ \\
\hline$-1.94 \mathrm{E}+01$ & $3.04 \mathrm{E}+01$ & $-1.74 E+03$ & $-1.23 E+02$ & $2.81 E+02$ & $-1.71 E+03$ \\
\hline$-3.60 E+01$ & $3.22 \mathrm{E}+01$ & $-1.74 E+03$ & $-1.53 E+01$ & $3.05 E+01$ & $-1.74 \mathrm{E}+03$ \\
\hline$-5.14 E+01$ & $3.50 \mathrm{E}+01$ & $-1.73 E+03$ & $-3.25 E+01$ & $3.29 E+01$ & $-1.73 E+03$ \\
\hline$-6.25 E+01$ & $3.70 E+01$ & $-1.72 E+03$ & $-4.81 E+01$ & $3.52 \mathrm{E}+01$ & $-1.72 E+03$ \\
\hline$-7.15 E+01$ & $3.91 \mathrm{E}+01$ & $-1.72 E+03$ & $-6.02 E+01$ & $3.74 \mathrm{E}+01$ & $-1.72 E+03$ \\
\hline$-8.33 E+01$ & $4.23 E+01$ & $-1.72 \mathrm{E}+03$ & $-7.56 \mathrm{E}+01$ & $4.11 \mathrm{E}+01$ & $-1.71 E+03$ \\
\hline$-9.72 E+01$ & $4.66 \mathrm{E}+01$ & $-1.71 E+03$ & $-8.76 E+01$ & $4.40 \mathrm{E}+01$ & $-1.71 E+03$ \\
\hline$-1.07 E+02$ & $4.97 \mathrm{E}+01$ & $-1.71 E+03$ & $-9.60 \mathrm{E}+01$ & $4.67 E+01$ & $1 E+03$ \\
\hline$-1.37 E+02$ & $6.26 \mathrm{E}+01$ & $-1.70 \mathrm{E}+03$ & $-1.07 E+02$ & $E+01$ & +03 \\
\hline$-1.45 E+02$ & $6.66 \mathrm{E}+01$ & $-1.70 E+03$ & $-1.18 \mathrm{E}+02$ & $E+01$ & $E+03$ \\
\hline$-1.52 E+02$ & $7.07 E+01$ & $-1.70 E+03$ & $-1.26 \mathrm{E}+02$ & $5.78 \mathrm{E}+01$ & $-1.70 \mathrm{E}+03$ \\
\hline$-1.62 E+02$ & $7.68 \mathrm{E}+01$ & $-1.70 E+03$ & $-1.31 E+02$ & $5.98 \mathrm{E}+01$ & $-1.70 E+03$ \\
\hline$-1.68 E+02$ & $8.11 \mathrm{E}+01$ & $-1.69 E+03$ & $-1.40 E+02$ & $6.39 E+01$ & $-1.70 E+03$ \\
\hline$-1.85 E+02$ & $9.44 \mathrm{E}+01$ & $-1.69 E+03$ & $-1.48 \mathrm{E}+02$ & $6.84 \mathrm{E}+01$ & $-1.70 \mathrm{E}+03$ \\
\hline$-1.92 \mathrm{E}+02$ & $1.01 \mathrm{E}+02$ & $-1.69 E+03$ & $-1.56 \mathrm{E}+02$ & $7.30 \mathrm{E}+01$ & $-1.70 \mathrm{E}+03$ \\
\hline
\end{tabular}




\begin{tabular}{|c|c|c|c|c|c|}
\hline rd. & Cord. & Cord. & X-Cord. & Y-Cord. & Z-Cord. \\
\hline 02 & $9 \mathrm{E}+01$ & $.70 E+03$ & $-7.38 \mathrm{E}+01$ & $3.72 E+01$ & $-1.72 E+03$ \\
\hline$-1.68 \mathrm{E}+02$ & $8.05 E+01$ & $-1.70 E+03$ & $-8.82 E+01$ & $3.92 \mathrm{E}+01$ & $-1.73 E+03$ \\
\hline$-1.74 E+02$ & $45 \mathrm{E}+01$ & $-1.70 E+03$ & $-9.71 E+01$ & 4.18E+01 & $-1.72 \mathrm{E}+03$ \\
\hline-1.81 & $9 \mathrm{E}+01$ & $1.69 E+03$ & $-1.07 E+02$ & $42 \mathrm{E}+01$ & +03 \\
\hline$-1.87 E+02$ & $9.50 \mathrm{E}+01$ & $-1.69 E+03$ & $-1.23 E+02$ & $4.96 \mathrm{E}+01$ & +03 \\
\hline$-1.93 E+02$ & $1.01 \mathrm{E}+02$ & $-1.69 E+03$ & $-1.26 \mathrm{E}+02$ & $5.06 \mathrm{E}+01$ & $1 E+03$ \\
\hline$-2.06 \mathrm{E}+02$ & $1.14 \mathrm{E}+02$ & $-1.69 E+03$ & $-1.35 E+02$ & $3 E+01$ & $E+03$ \\
\hline$-2.15 E+02$ & +02 & +03 & $\mathrm{E}+02$ & & +03 \\
\hline$-2.21 E+02$ & 02 & $E+03$ & $E+02$ & & +03 \\
\hline$E+02$ & 02 & +03 & +02 & & \\
\hline-2 & 02 & 33 & -7 & & +03 \\
\hline & & & 01 & & \\
\hline & & & & & \\
\hline & & & $-4.37 E+01$ & & \\
\hline & & & $-5.33 E+01$ & $.40 E+U \angle$ & $E+03$ \\
\hline$-5.11 E+01$ & $2.40 \mathrm{E}+02$ & $-1.73 E+03$ & $-6.17 E+01$ & $2.40 \mathrm{E}+02$ & $-1.73 E+03$ \\
\hline$-6.35 E+01$ & $2.40 \mathrm{E}+02$ & $-1.73 E+03$ & $-7.16 E+01$ & $2.39 E+02$ & $3 E+03$ \\
\hline$-7.44 \mathrm{E}+01$ & $2.39 \mathrm{E}+02$ & $-1.72 E+03$ & $-8.27 E+01$ & $2.38 \mathrm{E}+02$ & $2 \mathrm{E}+03$ \\
\hline$-8.51 E+01$ & $2.38 \mathrm{E}+02$ & $-1.72 E+03$ & $-9.27 E+01$ & $2.37 E+02$ & $2 E+03$ \\
\hline$-9.40 E+01$ & $2.37 \mathrm{E}+02$ & $-1.72 E+03$ & $-1.07 E+02$ & $2.36 \mathrm{E}+02$ & $-1.72 E+03$ \\
\hline$-1.01 E+02$ & $2.36 \mathrm{E}+02$ & $-1.72 E+03$ & $-1.15 E+02$ & $2.35 E+02$ & $-1.71 E+03$ \\
\hline$-1.11 E+02$ & $2.35 E+02$ & $-1.71 E+03$ & $-1.18 \mathrm{E}+02$ & $2.34 \mathrm{E}+02$ & $-1.71 E+03$ \\
\hline$-1.20 E+02$ & $2.33 E+02$ & $-1.71 E+03$ & $5.68 \mathrm{E}+01$ & $4.76 \mathrm{E}+02$ & $-1.62 E+03$ \\
\hline $5.67 \mathrm{E}+01$ & $4.76 E+02$ & $-1.62 E+03$ & $-1.32 E+01$ & $2.97 E+01$ & $-1.74 \mathrm{E}+03$ \\
\hline$-1.16 E+01$ & $3.01 \mathrm{E}+01$ & $-1.74 \mathrm{E}+03$ & $-4.83 E+00$ & $2.40 \mathrm{E}+02$ & $-1.74 \mathrm{E}+03$ \\
\hline$-5.26 \mathrm{E}+00$ & $2.40 \mathrm{E}+02$ & $-1.75 E+03$ & $-1.49 \mathrm{E}+02$ & $6.03 E+01$ & $-1.70 \mathrm{E}+03$ \\
\hline$-1.50 E+02$ & $6.06 \mathrm{E}+01$ & $-1.70 E+03$ & $-1.25 \mathrm{E}+02$ & $2.35 \mathrm{E}+02$ & $1 E+03$ \\
\hline$-1.25 \mathrm{E}+02$ & $2.35 \mathrm{E}+02$ & $-1.71 E+03$ & $-1.67 E+01$ & $2 E+01$ & $4 \mathrm{E}+03$ \\
\hline$-1.45 \mathrm{E}+01$ & $3.00 \mathrm{E}+01$ & $-1.74 \mathrm{E}+03$ & $-2.51 E+01$ & $E+01$ & $E+03$ \\
\hline$-2.37 \mathrm{E}+01$ & $3.08 \mathrm{E}+01$ & $-1.74 E+03$ & $-3.12 E+01$ & $E+01$ & $E+03$ \\
\hline$-3.19 E+01$ & $3.16 E+01$ & $-1.73 E+03$ & $-3.64 \mathrm{E}+01$ & & $-1.73 E+03$ \\
\hline$-3.96 E+01$ & $3.23 E+01$ & $-1.73 E+03$ & $-4.37 E+01$ & & $-1.73 E+03$ \\
\hline$-4.67 E+01$ & $3.32 \mathrm{E}+01$ & $-1.73 E+03$ & $-4.89 E+01$ & $3.34 \mathrm{E}+01$ & $-1.73 E+03$ \\
\hline$-6.01 E+01$ & $3.50 \mathrm{E}+01$ & $-1.73 E+03$ & $-5.41 E+01$ & $3.42 \mathrm{E}+01$ & $-1.73 E+03$ \\
\hline$-6.70 E+01$ & $3.58 \mathrm{E}+01$ & $-1.73 E+03$ & $-5.97 E+01$ & $3.51 \mathrm{E}+01$ & $-1.72 E+03$ \\
\hline
\end{tabular}




\begin{tabular}{|c|c|c|c|c|c|}
\hline rd. & Cord. & Cord. & X-Cord. & Y-Cord. & Z-Cord. \\
\hline+01 & $3 E+01$ & $.73 E+03$ & $-1.01 E+02$ & $45 E+01$ & $-1.71 E+03$ \\
\hline$-8.20 E+01$ & $3.85 E+01$ & $-1.72 E+03$ & $-1.09 E+02$ & $4.66 \mathrm{E}+01$ & $-1.71 E+03$ \\
\hline$-8.79 E+01$ & $3.98 \mathrm{E}+01$ & $-1.72 E+03$ & $-1.17 \mathrm{E}+02$ & $4.96 \mathrm{E}+01$ & $-1.71 E+03$ \\
\hline+01 & $E+01$ & $-1.72 E+03$ & $-1.24 \mathrm{E}+02$ & $.18 \mathrm{E}+01$ & +03 \\
\hline 02 & $4.35 \mathrm{E}+01$ & $-1.72 E+03$ & $-1.35 E+02$ & $5.57 \mathrm{E}+01$ & $E+03$ \\
\hline$-1.08 \mathrm{E}+02$ & $4.45 E+01$ & $-1.72 E+03$ & $-1.39 E+02$ & $5.71 \mathrm{E}+01$ & $\mathrm{OE}+03$ \\
\hline$-1.16 E+02$ & $4.71 \mathrm{E}+01$ & $-1.71 E+03$ & $-1.42 \mathrm{E}+02$ & $E+01$ & $E+03$ \\
\hline$-1.20 E+02$ & $E+01$ & $E+03$ & $\mathrm{E}+02$ & $E+01$ & +03 \\
\hline$-1.29 E+02$ & +01 & $E+03$ & $E+01$ & & +03 \\
\hline$E+02$ & 01 & $E+03$ & $E+01$ & & +03 \\
\hline 02 & $\ldots$ & -1 & -3 & & +03 \\
\hline & & & & & \\
\hline & & & & & \\
\hline & & & $-6.65 E+01$ & & \\
\hline & & $-1.73 E+03$ & $-7.56 \mathrm{E}+01$ & $2.4 \angle E+U \angle$ & $E+03$ \\
\hline$-5.45 E+01$ & $2.42 \mathrm{E}+02$ & $-1.73 E+03$ & $-8.63 E+01$ & $2.41 \mathrm{E}+02$ & $-1.72 E+03$ \\
\hline$-6.28 \mathrm{E}+01$ & $2.41 E+02$ & $-1.73 E+03$ & $-9.65 E+01$ & $2.40 E+02$ & $E+03$ \\
\hline$-7.16 \mathrm{E}+01$ & $2.41 \mathrm{E}+02$ & $-1.73 E+03$ & $-1.07 E+02$ & $2.40 \mathrm{E}+02$ & $1 \mathrm{E}+03$ \\
\hline$-8.31 E+01$ & $2.41 \mathrm{E}+02$ & $-1.72 E+03$ & $-1.15 E+02$ & $2.39 \mathrm{E}+02$ & $1 \mathrm{E}+03$ \\
\hline$-9.10 E+01$ & $2.41 \mathrm{E}+02$ & $-1.72 E+03$ & $-1.23 E+02$ & $2.38 \mathrm{E}+02$ & $-1.71 E+03$ \\
\hline$-1.19 E+02$ & $2.39 \mathrm{E}+02$ & $-1.71 E+03$ & $5.68 \mathrm{E}+01$ & $4.76 \mathrm{E}+02$ & $-1.62 \mathrm{E}+03$ \\
\hline$-1.24 \mathrm{E}+02$ & $2.38 \mathrm{E}+02$ & $-1.71 E+03$ & $-1.31 E+01$ & $2.97 E+01$ & $-1.74 \mathrm{E}+03$ \\
\hline $5.68 \mathrm{E}+01$ & $4.76 \mathrm{E}+02$ & $-1.62 E+03$ & $-4.70 \mathrm{E}-01$ & $2.41 E+02$ & $-1.73 E+03$ \\
\hline$-1.35 E+01$ & $2.95 E+01$ & $-1.74 \mathrm{E}+03$ & $-1.56 \mathrm{E}+02$ & $6.49 \mathrm{E}+01$ & $-1.70 E+03$ \\
\hline$-1.08 \mathrm{E}+00$ & $2.41 \mathrm{E}+02$ & $-1.73 E+03$ & $-1.27 E+02$ & $2.38 \mathrm{E}+02$ & $-1.71 E+03$ \\
\hline$-1.55 E+02$ & $6.48 \mathrm{E}+01$ & $-1.70 E+03$ & $-1.65 E+01$ & $3.03 E+01$ & $-1.74 \mathrm{E}+03$ \\
\hline$-1.27 \mathrm{E}+02$ & $2.38 \mathrm{E}+02$ & $-1.71 E+03$ & $-3.11 E+01$ & $3.14 \mathrm{E}+01$ & $-1.74 \mathrm{E}+03$ \\
\hline$-1.37 E+01$ & $3.02 E+01$ & $-1.74 \mathrm{E}+03$ & $-4.24 \mathrm{E}+01$ & $2 E+01$ & $4 \mathrm{E}+03$ \\
\hline$-3.17 E+01$ & $3.17 \mathrm{E}+01$ & $-1.73 E+03$ & $E+01$ & +01 & $E+03$ \\
\hline$-4.00 E+01$ & $3.26 \mathrm{E}+01$ & $-1.73 E+03$ & $-5.91 E+01$ & $E+01$ & $3 E+03$ \\
\hline$-4.94 E+01$ & $3.40 \mathrm{E}+01$ & $-1.73 E+03$ & $-6.74 E+01$ & $3.62 E+01$ & $-1.73 E+03$ \\
\hline$-6.62 E+01$ & $3.62 \mathrm{E}+01$ & $-1.73 E+03$ & $-7.53 E+01$ & $3.83 E+01$ & $-1.72 E+03$ \\
\hline$-7.29 E+01$ & $3.76 E+01$ & $-1.72 E+03$ & $-8.66 \mathrm{E}+01$ & $4.06 \mathrm{E}+01$ & $-1.72 E+03$ \\
\hline$-8.23 E+01$ & $3.96 \mathrm{E}+01$ & $-1.72 E+03$ & $-9.10 E+01$ & $4.17 E+01$ & $-1.72 E+03$ \\
\hline$-9.71 E+01$ & $4.33 E+01$ & $-1.72 \mathrm{E}+03$ & $-9.72 E+01$ & $4.32 \mathrm{E}+01$ & $-1.71 E+03$ \\
\hline
\end{tabular}




\begin{tabular}{|c|c|c|c|c|c|}
\hline rd. & Cord. & Cord. & X-Cord. & Y-Cord. & Z-Cord. \\
\hline+02 & $7 E+01$ & $.71 E+03$ & $-1.19 \mathrm{E}+02$ & $09 E+01$ & $-1.71 E+03$ \\
\hline$-1.23 E+02$ & $5.12 \mathrm{E}+01$ & $-1.71 E+03$ & $-1.26 \mathrm{E}+02$ & $5.37 \mathrm{E}+01$ & $-1.70 \mathrm{E}+03$ \\
\hline-1.28 & $5.32 \mathrm{E}+01$ & $-1.71 E+03$ & $-1.34 \mathrm{E}+02$ & $5.72 \mathrm{E}+01$ & $-1.70 E+03$ \\
\hline-1.37 & $67 E+01$ & $-1.70 E+03$ & $-1.41 E+02$ & $.97 \mathrm{E}+01$ & +03 \\
\hline+02 & $5.90 \mathrm{E}+01$ & $-1.70 \mathrm{E}+03$ & $-1.44 \mathrm{E}+02$ & $6.16 \mathrm{E}+01$ & +03 \\
\hline$-1.47 \mathrm{E}+02$ & $6.09 \mathrm{E}+01$ & $-1.70 \mathrm{E}+03$ & $-1.53 \mathrm{E}+02$ & $1 E+01$ & $\mathrm{OE}+03$ \\
\hline$-1.53 E+02$ & $6.35 \mathrm{E}+01$ & $-1.70 E+03$ & $-1.53 E+02$ & $E+01$ & $E+03$ \\
\hline$-1.79 E+01$ & $2.41 E+02$ & $=03$ & $\mathrm{E}+02$ & $E+01$ & +03 \\
\hline$-2.63 E+01$ & +02 & $E+03$ & $E+00$ & & +03 \\
\hline-3.69 & 2 & $E+03$ & +01 & & +03 \\
\hline 01 & 02 & 33 & 01 & & +03 \\
\hline & & & 01 & & +03 \\
\hline & & & & & \\
\hline & & & $-5.60 E+01$ & & \\
\hline & $2.43 E+02$ & $-1.72 E+03$ & $-6.53 E+01$ & $2.43 E+U 2$ & $E+03$ \\
\hline$-9.36 \mathrm{E}+01$ & $2.43 E+02$ & $-1.72 \mathrm{E}+03$ & $-7.54 \mathrm{E}+01$ & $2.44 \mathrm{E}+02$ & $-1.72 E+03$ \\
\hline$-1.04 E+02$ & $2.43 E+02$ & $-1.72 E+03$ & $-8.35 E+01$ & $.44 E+02$ & $E+03$ \\
\hline$-1.10 E+02$ & $2.43 E+02$ & $-1.71 E+03$ & $-9.15 E+01$ & $2.44 \mathrm{E}+02$ & $2 \mathrm{E}+03$ \\
\hline$-1.15 E+02$ & $2.43 E+02$ & $-1.71 E+03$ & $-1.01 E+02$ & $2.44 \mathrm{E}+02$ & $1 \mathrm{E}+03$ \\
\hline $5.69 E+01$ & $4.76 E+02$ & $-1.62 E+03$ & $-1.07 E+02$ & $2.43 \mathrm{E}+02$ & $-1.71 E+03$ \\
\hline$-1.20 E+01$ & $3.01 \mathrm{E}+01$ & $-1.74 E+03$ & $-1.12 \mathrm{E}+02$ & $2.43 E+02$ & $-1.71 E+03$ \\
\hline$-4.47 E+00$ & $2.41 E+02$ & $-1.74 E+03$ & $-1.21 E+02$ & $2.42 E+02$ & $-1.71 E+03$ \\
\hline$-1.64 E+02$ & $7.14 \mathrm{E}+01$ & $-1.69 E+03$ & $5.70 \mathrm{E}+01$ & $4.75 E+02$ & $-1.62 E+03$ \\
\hline$-1.24 \mathrm{E}+02$ & $2.43 E+02$ & $-1.71 E+03$ & $-1.22 \mathrm{E}+01$ & $3.00 E+01$ & $-1.74 \mathrm{E}+03$ \\
\hline$-1.87 E+01$ & $3.09 \mathrm{E}+01$ & $-1.73 E+03$ & $-2.48 \mathrm{E}+00$ & $2.41 \mathrm{E}+02$ & $-1.74 \mathrm{E}+03$ \\
\hline$-3.32 E+01$ & $3.23 E+01$ & $-1.73 E+03$ & $-1.64 \mathrm{E}+02$ & $7.09 E+01$ & $-1.69 \mathrm{E}+03$ \\
\hline$-4.34 \mathrm{E}+01$ & $3.38 \mathrm{E}+01$ & $-1.73 E+03$ & $-1.26 \mathrm{E}+02$ & $2.43 E+02$ & $-1.70 \mathrm{E}+03$ \\
\hline$-5.30 E+01$ & $3.52 \mathrm{E}+01$ & $-1.72 E+03$ & $-1.77 \mathrm{E}+01$ & $4 \mathrm{E}+01$ & $4 \mathrm{E}+03$ \\
\hline$-6.50 E+01$ & $3.72 E+01$ & $-1.72 E+03$ & $-2.35 E+01$ & $E+01$ & $E+03$ \\
\hline$-7.17 E+01$ & $3.87 E+01$ & $-1.71 E+03$ & $-3.39 E+01$ & $E+01$ & $E+03$ \\
\hline$-8.07 E+01$ & $4.03 E+01$ & $-1.71 E+03$ & $-4.14 \mathrm{E}+01$ & $3.27 E+01$ & $-1.73 E+03$ \\
\hline$-8.89 E+01$ & $4.20 \mathrm{E}+01$ & $-1.71 E+03$ & $-4.75 E+01$ & $3.36 \mathrm{E}+01$ & $-1.73 E+03$ \\
\hline$-9.55 E+01$ & $4.38 \mathrm{E}+01$ & $-1.71 E+03$ & $-5.43 E+01$ & $3.48 \mathrm{E}+01$ & $-1.73 E+03$ \\
\hline$-1.02 E+02$ & $4.58 \mathrm{E}+01$ & $-1.71 E+03$ & $-6.25 E+01$ & $3.60 E+01$ & $-1.73 E+03$ \\
\hline$-1.10 \mathrm{E}+02$ & $4.80 \mathrm{E}+01$ & $-1.71 E+03$ & $-7.22 \mathrm{E}+01$ & $3.78 \mathrm{E}+01$ & $-1.72 E+03$ \\
\hline
\end{tabular}




\begin{tabular}{|c|c|c|c|c|c|}
\hline X-Cord. & Cord. & Cord. & X-Cord. & Y-Cord. & Z-Cord. \\
\hline+01 & $4 \mathrm{E}+01$ & $.72 E+03$ & $-1.68 \mathrm{E}+01$ & $3.07 E+01$ & $-1.74 \mathrm{E}+03$ \\
\hline$-8.65 E+01$ & $4.10 E+01$ & $-1.72 E+03$ & $-2.41 E+01$ & $3.16 \mathrm{E}+01$ & $-1.73 E+03$ \\
\hline$-9.26 E+01$ & $24 \mathrm{E}+01$ & $1.72 E+03$ & $-3.41 E+01$ & $3.25 \mathrm{E}+01$ & $-1.73 E+03$ \\
\hline-9.9 & $5 \mathrm{E}+01$ & $1.71 \mathrm{E}+03$ & $-5.09 E+01$ & $5 \mathrm{E}+01$ & 03 \\
\hline$=02$ & $4.69 \mathrm{E}+01$ & $-1.71 E+03$ & $-5.80 E+01$ & $3.57 \mathrm{E}+01$ & +03 \\
\hline$-1.14 \mathrm{E}+02$ & $4.91 \mathrm{E}+01$ & $-1.71 E+03$ & $-6.59 E+01$ & $9 \mathrm{E}+01$ & $E+03$ \\
\hline$-1.23 E+02$ & $5.21 \mathrm{E}+01$ & $-1.71 E+03$ & $-7.60 \mathrm{E}+01$ & $E+01$ & $E+03$ \\
\hline$-1.30 E+02$ & +01 & +03 & $E+01$ & $E+01$ & +03 \\
\hline$-1.38 \mathrm{E}+02$ & +01 & $E+03$ & $E+01$ & & +03 \\
\hline$-1.44 \mathrm{E}+02$ & 1 & $E+03$ & $E+01$ & & +03 \\
\hline 02 & 6 & 33 & -1 & & +03 \\
\hline & & & & & \\
\hline & & & & & \\
\hline & & & $-1.18 \mathrm{E}+02$ & & \\
\hline & & $-1.74 E+03$ & $-1.24 \mathrm{E}+02$ & $3.35 E+U 1$ & $E+03$ \\
\hline$-3.02 E+01$ & $2.43 E+02$ & $-1.73 E+03$ & $-1.30 \mathrm{E}+02$ & $5.58 \mathrm{E}+01$ & $-1.71 E+03$ \\
\hline$-3.89 E+01$ & $2.43 E+02$ & $-1.73 E+03$ & $-1.36 E+02$ & $5.83 E+01$ & $E+03$ \\
\hline$-4.63 E+01$ & $2.44 \mathrm{E}+02$ & $-1.73 E+03$ & $-1.41 E+02$ & $6.04 \mathrm{E}+01$ & $E+03$ \\
\hline$-5.30 \mathrm{E}+01$ & $2.44 \mathrm{E}+02$ & $-1.73 E+03$ & $-1.44 \mathrm{E}+02$ & $6.23 E+01$ & $0 \mathrm{E}+03$ \\
\hline$-6.18 \mathrm{E}+01$ & $2.45 E+02$ & $-1.73 E+03$ & $-1.48 \mathrm{E}+02$ & $6.38 \mathrm{E}+01$ & $-1.70 E+03$ \\
\hline$-6.98 \mathrm{E}+01$ & $2.45 E+02$ & $-1.73 E+03$ & $-1.52 E+02$ & $6.57 E+01$ & $-1.70 \mathrm{E}+03$ \\
\hline$-7.82 E+01$ & $2.45 E+02$ & $-1.72 E+03$ & $-1.57 \mathrm{E}+02$ & $6.82 E+01$ & $-1.70 E+03$ \\
\hline$-8.56 E+01$ & $2.46 \mathrm{E}+02$ & $-1.72 E+03$ & $-1.62 E+02$ & $7.10 \mathrm{E}+01$ & $-1.70 E+03$ \\
\hline$-9.38 E+01$ & $2.46 \mathrm{E}+02$ & $-1.72 E+03$ & $-1.65 E+02$ & $7.31 \mathrm{E}+01$ & $-1.70 E+03$ \\
\hline$-1.01 E+02$ & $2.46 \mathrm{E}+02$ & $-1.72 E+03$ & $-1.70 \mathrm{E}+02$ & $7.59 \mathrm{E}+01$ & $-1.70 \mathrm{E}+03$ \\
\hline$-1.07 E+02$ & $2.46 \mathrm{E}+02$ & $-1.72 \mathrm{E}+03$ & $-4.88 \mathrm{E}+00$ & $2.41 \mathrm{E}+02$ & $-1.74 \mathrm{E}+03$ \\
\hline$-1.14 E+02$ & $2.46 \mathrm{E}+02$ & $-1.71 E+03$ & $-1.33 E+01$ & $2.42 \mathrm{E}+02$ & $4 \mathrm{E}+03$ \\
\hline$-1.18 \mathrm{E}+02$ & $2.46 \mathrm{E}+02$ & $-1.71 E+03$ & $-2.55 E+01$ & $3 E+02$ & $\mathrm{E}+03$ \\
\hline$-1.23 E+02$ & $2.46 \mathrm{E}+02$ & $-1.71 E+03$ & $-3.66 E+01$ & $\mathrm{E}+02$ & +03 \\
\hline$-1.25 E+02$ & $2.46 \mathrm{E}+02$ & $-1.71 E+03$ & $-4.40 E+01$ & $4 \mathrm{E}+02$ & $3 E+03$ \\
\hline $5.68 \mathrm{E}+01$ & $4.76 E+02$ & $-1.62 E+03$ & $-5.28 \mathrm{E}+01$ & $2.45 \mathrm{E}+02$ & $-1.72 E+03$ \\
\hline$-1.19 E+01$ & $3.02 \mathrm{E}+01$ & $-1.74 E+03$ & $-6.19 E+01$ & $2.45 E+02$ & $-1.72 E+03$ \\
\hline$-3.58 E+00$ & $2.41 E+02$ & $-1.74 E+03$ & $-7.02 E+01$ & $2.45 E+02$ & $-1.72 E+03$ \\
\hline$-1.73 E+02$ & $7.80 \mathrm{E}+01$ & $-1.69 E+03$ & $-7.73 E+01$ & $2.45 \mathrm{E}+02$ & $-1.72 E+03$ \\
\hline$-1.27 E+02$ & $2.47 \mathrm{E}+02$ & $-1.71 E+03$ & $-8.45 E+01$ & $2.46 \mathrm{E}+02$ & $-1.72 E+03$ \\
\hline
\end{tabular}




\begin{tabular}{|c|c|c|c|c|c|}
\hline rd. & Cord. & Cord. & X-Cord. & Y-Cord. & Z-Cord. \\
\hline+01 & $6 \mathrm{E}+02$ & $.72 E+03$ & $-1.67 E+02$ & $45 E+01$ & $-1.70 E+03$ \\
\hline$-9.94 E+01$ & $2.46 \mathrm{E}+02$ & $-1.72 E+03$ & $-1.71 E+02$ & $7.67 \mathrm{E}+01$ & $-1.69 \mathrm{E}+03$ \\
\hline$-1.09 E+02$ & $46 \mathrm{E}+02$ & $1.71 E+03$ & $-6.45 E+00$ & $2.41 \mathrm{E}+02$ & $-1.74 \mathrm{E}+03$ \\
\hline-1 & $46 \mathrm{E}+02$ & $-1.71 E+03$ & $-2.01 E+01$ & $43 \mathrm{E}+02$ & $-1.74 \mathrm{E}+03$ \\
\hline+02 & $46 \mathrm{E}+02$ & $-1.71 E+03$ & $-2.62 E+01$ & $2.43 E+02$ & +03 \\
\hline $5.68 \mathrm{E}+01$ & $4.76 \mathrm{E}+02$ & $-1.62 E+03$ & $-3.51 E+01$ & $44 \mathrm{E}+02$ & $4 \mathrm{E}+03$ \\
\hline$-1.24 \mathrm{E}+01$ & $3.00 E+01$ & $-1.74 E+03$ & $-4.62 E+01$ & $+5 E+02$ & $E+03$ \\
\hline$-4.59 E+00$ & +02 & $E+03$ & $E+01$ & $E+02$ & $E+03$ \\
\hline$E+02$ & $E+01$ & $E+03$ & $E+01$ & & +03 \\
\hline$E+02$ & -02 & -1 & +01 & & +03 \\
\hline 01 & 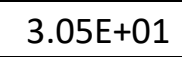 & -1 & -8 & & \\
\hline & & & & & \\
\hline & & & & & \\
\hline & & & & & \\
\hline & & & $-1.09 E+02$ & $2.49 E+U \angle$ & $E+03$ \\
\hline$-4.50 E+01$ & $3.40 \mathrm{E}+01$ & $-1.73 E+03$ & $-1.20 \mathrm{E}+02$ & $2.50 \mathrm{E}+02$ & $-1.71 E+03$ \\
\hline$-5.23 E+01$ & $3.51 \mathrm{E}+01$ & $-1.73 E+03$ & $5.68 \mathrm{E}+01$ & $4.75 E+02$ & $2 E+03$ \\
\hline$-5.89 E+01$ & $3.63 E+01$ & $-1.72 E+03$ & $-1.24 \mathrm{E}+01$ & $3.00 \mathrm{E}+01$ & $-1.74 \mathrm{E}+03$ \\
\hline$-6.63 E+01$ & $3.75 \mathrm{E}+01$ & $-1.72 E+03$ & $-6.86 E+00$ & $2.41 \mathrm{E}+02$ & $5 E+03$ \\
\hline$-7.50 E+01$ & $3.95 E+01$ & $-1.72 E+03$ & $-1.81 E+02$ & $8.46 \mathrm{E}+01$ & $-1.69 E+03$ \\
\hline$-8.30 E+01$ & $4.10 E+01$ & $-1.72 E+03$ & $-1.28 \mathrm{E}+02$ & $2.51 E+02$ & $-1.71 E+03$ \\
\hline$-9.13 E+01$ & $4.32 \mathrm{E}+01$ & $-1.72 E+03$ & $-1.26 \mathrm{E}+01$ & $3.03 E+01$ & $-1.74 \mathrm{E}+03$ \\
\hline$-1.00 E+02$ & $4.58 \mathrm{E}+01$ & $-1.72 E+03$ & $-1.82 \mathrm{E}+01$ & $3.07 E+01$ & $-1.74 E+03$ \\
\hline$-1.07 E+02$ & $4.78 \mathrm{E}+01$ & $-1.71 E+03$ & $-2.94 \mathrm{E}+01$ & $3.17 E+01$ & $-1.74 \mathrm{E}+03$ \\
\hline$-1.14 \mathrm{E}+02$ & $4.99 \mathrm{E}+01$ & $-1.71 E+03$ & $-4.09 E+01$ & $3.31 \mathrm{E}+01$ & $-1.73 E+03$ \\
\hline$-1.22 \mathrm{E}+02$ & $5.29 \mathrm{E}+01$ & $-1.71 E+03$ & $-5.09 E+01$ & $3.47 \mathrm{E}+01$ & $-1.73 E+03$ \\
\hline$-1.29 \mathrm{E}+02$ & $5.56 \mathrm{E}+01$ & $-1.71 E+03$ & $-6.13 E+01$ & $3.65 E+01$ & $3 E+03$ \\
\hline$-1.35 E+02$ & $5.81 \mathrm{E}+01$ & $-1.70 \mathrm{E}+03$ & $-7.17 E+01$ & $7 E+01$ & $2 \mathrm{E}+03$ \\
\hline$-1.40 E+02$ & $6.05 E+01$ & $-1.70 \mathrm{E}+03$ & $E+01$ & $E+01$ & $E+03$ \\
\hline$-1.44 E+02$ & $6.24 \mathrm{E}+01$ & $-1.70 E+03$ & $-8.68 \mathrm{E}+01$ & $0 E+01$ & $2 E+03$ \\
\hline$-1.47 \mathrm{E}+02$ & & $-1.70 E+03$ & $-9.60 E+01$ & $4.44 \mathrm{E}+01$ & $-1.72 \mathrm{E}+03$ \\
\hline$-1.51 E+02$ & $6.57 E+01$ & $-1.70 E+03$ & $-1.04 E+02$ & & $-1.72 E+03$ \\
\hline$-1.56 E+02$ & $6.82 \mathrm{E}+01$ & $-1.70 E+03$ & $-1.10 E+02$ & $4.91 \mathrm{E}+01$ & $-1.71 E+03$ \\
\hline$-1.60 E+02$ & $7.05 E+01$ & $-1.70 E+03$ & $-1.17 E+02$ & $5.16 \mathrm{E}+01$ & $-1.71 E+03$ \\
\hline$-1.64 \mathrm{E}+02$ & $7.25 E+01$ & $-1.70 E+03$ & $-1.28 \mathrm{E}+02$ & $5.58 \mathrm{E}+01$ & $-1.71 E+03$ \\
\hline
\end{tabular}




\begin{tabular}{|c|c|c|c|c|c|}
\hline rd. & Cord. & Cord. & X-Cord. & Y-Cord. & Z-Cord. \\
\hline+02 & $2 E+01$ & $.71 E+03$ & $-8.34 E+01$ & $4.09 E+01$ & $-1.72 E+03$ \\
\hline$-1.38 \mathrm{E}+02$ & $6.02 E+01$ & $-1.71 E+03$ & $-9.01 E+01$ & $4.26 \mathrm{E}+01$ & $-1.72 \mathrm{E}+03$ \\
\hline$-1.44 \mathrm{E}+02$ & $6.29 \mathrm{E}+01$ & $-1.71 E+03$ & $-1.01 E+02$ & $4.54 \mathrm{E}+01$ & $-1.72 E+03$ \\
\hline+02 & $61 E+01$ & $1.70 \mathrm{E}+03$ & $-1.07 E+02$ & $.76 \mathrm{E}+01$ & +03 \\
\hline$=02$ & $6.83 E+01$ & $-1.70 \mathrm{E}+03$ & $-1.14 \mathrm{E}+02$ & $4.96 \mathrm{E}+01$ & +03 \\
\hline$-1.59 E+02$ & $7.10 \mathrm{E}+01$ & $-1.70 \mathrm{E}+03$ & $-1.26 \mathrm{E}+02$ & $5.42 \mathrm{E}+01$ & $E+03$ \\
\hline$-1.64 E+02$ & $7.43 E+01$ & $-1.70 \mathrm{E}+03$ & $-1.32 \mathrm{E}+02$ & $5 E+01$ & $E+03$ \\
\hline$-1.68 \mathrm{E}+02$ & $7.66 \mathrm{E}+01$ & $-1.70 \mathrm{E}+03$ & $-1.38 \mathrm{E}+02$ & $E+01$ & +03 \\
\hline$-1.76 \mathrm{E}+02$ & $=01$ & $\mathrm{E}+03$ & $E+02$ & & +03 \\
\hline 00 & 02 & $=03$ & +02 & & \\
\hline 01 & 02 & 33 & -1 & & +03 \\
\hline & & & & & \\
\hline & & & & & \\
\hline & & & $-1.75 E+02$ & & \\
\hline & & & $-1.78 E+02$ & $8.30 E+U 1$ & $-1.69 E+03$ \\
\hline$-5.38 E+01$ & $2.45 E+02$ & $-1.73 E+03$ & $-1.03 E+01$ & $2.41 \mathrm{E}+02$ & $-1.75 E+03$ \\
\hline$-6.01 E+01$ & $2.46 \mathrm{E}+02$ & $-1.73 E+03$ & $-2.35 E+01$ & $2.43 E+02$ & $E+03$ \\
\hline$-6.73 E+01$ & $2.47 \mathrm{E}+02$ & $-1.72 \mathrm{E}+03$ & $-3.13 E+01$ & $2.44 \mathrm{E}+02$ & $E+03$ \\
\hline$-7.48 \mathrm{E}+01$ & $2.47 \mathrm{E}+02$ & $-1.72 E+03$ & $-4.12 E+01$ & $2.46 \mathrm{E}+02$ & $3 \mathrm{E}+03$ \\
\hline$-8.41 E+01$ & $2.48 \mathrm{E}+02$ & $-1.72 E+03$ & $-4.94 E+01$ & $2.47 E+02$ & $-1.73 E+03$ \\
\hline$-1.00 E+02$ & $2.49 \mathrm{E}+02$ & $-1.72 \mathrm{E}+03$ & $-5.70 E+01$ & $2.47 E+02$ & $-1.73 E+03$ \\
\hline$-1.07 E+02$ & $2.49 E+02$ & $-1.71 E+03$ & $-6.62 E+01$ & $2.48 \mathrm{E}+02$ & $-1.73 E+03$ \\
\hline$-1.16 E+02$ & $2.50 \mathrm{E}+02$ & $-1.71 E+03$ & $-7.48 \mathrm{E}+01$ & $2.49 E+02$ & $-1.72 E+03$ \\
\hline $5.69 E+01$ & $4.75 E+02$ & $-1.62 \mathrm{E}+03$ & $-8.47 E+01$ & $2.50 \mathrm{E}+02$ & $-1.72 E+03$ \\
\hline$-1.29 E+01$ & $3.00 \mathrm{E}+01$ & $-1.74 \mathrm{E}+03$ & $-9.54 E+01$ & $2.52 \mathrm{E}+02$ & $-1.72 E+03$ \\
\hline$-1.04 \mathrm{E}+00$ & $2.42 \mathrm{E}+02$ & $-1.73 E+03$ & $-1.03 E+02$ & $2.52 \mathrm{E}+02$ & $-1.72 E+03$ \\
\hline$-1.81 \mathrm{E}+02$ & $8.56 \mathrm{E}+01$ & $-1.69 \mathrm{E}+03$ & $-1.10 \mathrm{E}+02$ & $2.53 \mathrm{E}+02$ & $-1.72 \mathrm{E}+03$ \\
\hline$-1.27 E+02$ & $2.51 \mathrm{E}+02$ & $-1.71 E+03$ & $-1.22 \mathrm{E}+02$ & $4 \mathrm{E}+02$ & $1 E+03$ \\
\hline$-1.40 E+01$ & $3.05 E+01$ & $-1.74 \mathrm{E}+03$ & $8 \mathrm{E}+01$ & $E+02$ & $E+03$ \\
\hline$-2.46 \mathrm{E}+01$ & $3.14 \mathrm{E}+01$ & $-1.74 \mathrm{E}+03$ & $-1.17 \mathrm{E}+01$ & $2 \mathrm{E}+01$ & $E+03$ \\
\hline$-3.57 E+01$ & $3.25 E+01$ & $-1.74 \mathrm{E}+03$ & $-6.41 E+00$ & $2.41 E+02$ & $-1.75 E+03$ \\
\hline$-4.59 E+01$ & $3.39 E+01$ & $-1.73 E+03$ & $-1.88 \mathrm{E}+02$ & $9.18 \mathrm{E}+01$ & $-1.69 E+03$ \\
\hline$-5.44 E+01$ & $3.50 E+01$ & $-1.73 E+03$ & $-1.25 E+02$ & $2.55 E+02$ & $-1.71 E+03$ \\
\hline$-6.88 E+01$ & $3.78 \mathrm{E}+01$ & $-1.73 E+03$ & $-1.77 E+01$ & $3.11 \mathrm{E}+01$ & $-1.74 \mathrm{E}+03$ \\
\hline$-7.58 \mathrm{E}+01$ & $3.92 \mathrm{E}+01$ & $-1.73 E+03$ & $-2.82 E+01$ & $3.19 E+01$ & $-1.74 \mathrm{E}+03$ \\
\hline
\end{tabular}




\begin{tabular}{|c|c|c|c|c|c|}
\hline X-Cord. & Cord. & Cord. & X-Cord. & Y-Cord. & Z-Cord. \\
\hline 01 & $8 \mathrm{E}+01$ & $.74 E+03$ & $-9.66 E+01$ & $52 E+02$ & $-1.72 E+03$ \\
\hline$-4.45 E+01$ & $3.38 \mathrm{E}+01$ & $-1.73 E+03$ & $-1.03 E+02$ & $2.53 \mathrm{E}+02$ & $-1.72 \mathrm{E}+03$ \\
\hline$-5.07 E+01$ & $47 E+01$ & $-1.73 E+03$ & $-1.14 \mathrm{E}+02$ & $.54 \mathrm{E}+02$ & $-1.72 \mathrm{E}+03$ \\
\hline-5.7 & $9 E+01$ & $-1.73 E+03$ & $-1.18 \mathrm{E}+02$ & $.54 E+02$ & +03 \\
\hline+01 & $3.70 \mathrm{E}+01$ & $-1.73 E+03$ & $-1.24 \mathrm{E}+02$ & $2.54 \mathrm{E}+02$ & +03 \\
\hline$-6.97 E+01$ & $3.82 \mathrm{E}+01$ & $-1.73 E+03$ & $5.68 \mathrm{E}+01$ & $6 \mathrm{E}+02$ & $-1.62 E+03$ \\
\hline$-7.48 \mathrm{E}+01$ & $3.90 \mathrm{E}+01$ & $-1.73 E+03$ & $-1.17 \mathrm{E}+01$ & $3 E+01$ & $E+03$ \\
\hline$-8.19 E+01$ & $E+01$ & $=03$ & $E+00$ & $E+02$ & +03 \\
\hline$=01$ & 01 & $E+03$ & $E+02$ & & +03 \\
\hline$-9.44 E+01$ & 01 & $E+03$ & +02 & & r03 \\
\hline-1. & 4 & 33 & 01 & & +03 \\
\hline & & & & & \\
\hline & & & & & \\
\hline & & & & & \\
\hline & & & & & $E+03$ \\
\hline$-1.40 \mathrm{E}+02$ & $6.07 \mathrm{E}+01$ & $-1.71 E+03$ & $-6.90 E+01$ & $3.85 \mathrm{E}+01$ & $-1.73 E+03$ \\
\hline$-1.46 E+02$ & $6.39 \mathrm{E}+01$ & $-1.71 E+03$ & $-7.63 E+01$ & $4.04 \mathrm{E}+01$ & $E+03$ \\
\hline$-1.50 E+02$ & $6.61 \mathrm{E}+01$ & $-1.71 E+03$ & $-8.25 E+01$ & $4.18 \mathrm{E}+01$ & $2 \mathrm{E}+03$ \\
\hline$-1.56 \mathrm{E}+02$ & $6.93 \mathrm{E}+01$ & $-1.70 \mathrm{E}+03$ & $-9.45 E+01$ & $4.51 \mathrm{E}+01$ & $2 \mathrm{E}+03$ \\
\hline$-1.59 E+02$ & $7.14 \mathrm{E}+01$ & $-1.70 \mathrm{E}+03$ & $-9.92 E+01$ & $4.67 E+01$ & $-1.71 E+03$ \\
\hline$-1.64 E+02$ & $7.43 E+01$ & $-1.70 E+03$ & $-1.11 E+02$ & $5.01 \mathrm{E}+01$ & $-1.71 E+03$ \\
\hline$-1.67 E+02$ & $7.65 E+01$ & $-1.70 E+03$ & $-1.17 \mathrm{E}+02$ & $5.26 \mathrm{E}+01$ & $-1.71 E+03$ \\
\hline$-1.73 E+02$ & $8.05 E+01$ & $-1.70 E+03$ & $-1.22 \mathrm{E}+02$ & $5.42 \mathrm{E}+01$ & $-1.71 E+03$ \\
\hline$-1.77 E+02$ & $8.30 E+01$ & $-1.70 E+03$ & $-1.26 \mathrm{E}+02$ & $5.63 E+01$ & $-1.71 E+03$ \\
\hline$-1.82 \mathrm{E}+02$ & $8.73 E+01$ & $-1.69 E+03$ & $-1.31 E+02$ & $5.82 \mathrm{E}+01$ & $-1.71 E+03$ \\
\hline$-1.85 E+02$ & $8.93 E+01$ & $-1.69 \mathrm{E}+03$ & $-1.36 \mathrm{E}+02$ & $6.06 \mathrm{E}+01$ & $-1.70 \mathrm{E}+03$ \\
\hline$-7.69 E+00$ & $2.41 \mathrm{E}+02$ & $-1.74 E+03$ & $-1.42 E+02$ & $6.33 \mathrm{E}+01$ & $-1.70 \mathrm{E}+03$ \\
\hline$-1.35 \mathrm{E}+01$ & $2.42 \mathrm{E}+02$ & $-1.74 \mathrm{E}+03$ & $-1.47 E+02$ & $6.58 \mathrm{E}+01$ & $\mathrm{E}+03$ \\
\hline$-2.33 E+01$ & $2.43 E+02$ & $-1.74 \mathrm{E}+03$ & $3 E+02$ & $E+01$ & $E+03$ \\
\hline$-3.19 E+01$ & $2.44 \mathrm{E}+02$ & $-1.74 E+03$ & -1 & $2 E+01$ & $E+03$ \\
\hline & $2.45 E+02$ & $-1.73 E+03$ & $-1.63 E+02$ & $7.54 \mathrm{E}+01$ & $-1.70 \mathrm{E}+03$ \\
\hline$-4.77 E+01$ & $2.46 \mathrm{E}+02$ & $-1.73 E+03$ & $-1.68 E+02$ & $7.84 \mathrm{E}+01$ & $-1.70 E+03$ \\
\hline$-5.92 E+01$ & $2.48 \mathrm{E}+02$ & $-1.73 E+03$ & $-1.77 E+02$ & $8.44 E+01$ & $-1.69 E+03$ \\
\hline$-6.94 E+01$ & $2.49 \mathrm{E}+02$ & $-1.73 E+03$ & $-1.81 E+02$ & $8.73 E+01$ & $-1.69 \mathrm{E}+03$ \\
\hline$-8.74 E+01$ & $2.51 \mathrm{E}+02$ & $-1.72 \mathrm{E}+03$ & $-1.85 E+02$ & $9.01 \mathrm{E}+01$ & $-1.69 \mathrm{E}+03$ \\
\hline
\end{tabular}




\begin{tabular}{|c|c|c|c|c|c|}
\hline X-Cord. & Cord. & Cord. & X-Cord. & Y-Cord. & Z-Cord. \\
\hline 00 & $2 E+02$ & $.74 E+03$ & $-1.12 \mathrm{E}+02$ & $04 \mathrm{E}+01$ & $-1.72 E+03$ \\
\hline+01 & $2.42 \mathrm{E}+02$ & $-1.74 E+03$ & $-1.18 \mathrm{E}+02$ & $5.25 E+01$ & $-1.72 \mathrm{E}+03$ \\
\hline$-2.55 E+01$ & $44 \mathrm{E}+02$ & $-1.74 E+03$ & $-1.24 \mathrm{E}+02$ & $.46 \mathrm{E}+01$ & $-1.72 \mathrm{E}+03$ \\
\hline+01 & $E+02$ & $-1.74 E+03$ & $-1.35 E+02$ & $02 \mathrm{E}+01$ & +03 \\
\hline+01 & $47 E+02$ & $-1.74 \mathrm{E}+03$ & $-1.40 \mathrm{E}+02$ & $6.27 \mathrm{E}+01$ & +03 \\
\hline$-5.19 E+01$ & $2.48 \mathrm{E}+02$ & $-1.73 E+03$ & $-1.45 E+02$ & $9 E+01$ & $0 \mathrm{E}+03$ \\
\hline$-5.97 E+01$ & $2.49 \mathrm{E}+02$ & $-1.73 E+03$ & $-1.51 \mathrm{E}+02$ & $E+01$ & $E+03$ \\
\hline$-6.98 \mathrm{E}+01$ & $E+02$ & +03 & $7 E+02$ & & +03 \\
\hline$-7.79 E+01$ & +02 & $E+03$ & $E+02$ & & +03 \\
\hline$=01$ & 02 & $E+03$ & +02 & & +03 \\
\hline-9 . & 2 & 33 & 02 & & +03 \\
\hline & & & 02 & & \\
\hline & & & & & \\
\hline & & & & & \\
\hline & & & $-1.92 E+02$ & & $E+03$ \\
\hline $5.67 \mathrm{E}+01$ & $4.76 \mathrm{E}+02$ & $-1.62 \mathrm{E}+03$ & $-1.93 E+02$ & $9.77 \mathrm{E}+01$ & $-1.69 \mathrm{E}+03$ \\
\hline$-1.17 E+01$ & $3.03 E+01$ & $-1.74 \mathrm{E}+03$ & $-1.05 E+01$ & $2.42 \mathrm{E}+02$ & $-1.74 \mathrm{E}+03$ \\
\hline$-7.00 E+00$ & $2.41 \mathrm{E}+02$ & $-1.75 E+03$ & $-1.83 E+01$ & $2.43 E+02$ & $4 E+03$ \\
\hline$-1.95 \mathrm{E}+02$ & $9.94 \mathrm{E}+01$ & $-1.69 E+03$ & $-2.97 E+01$ & $2.45 \mathrm{E}+02$ & $E+03$ \\
\hline$-1.25 \mathrm{E}+02$ & $2.58 \mathrm{E}+02$ & $-1.71 E+03$ & $-3.87 E+01$ & $2.46 \mathrm{E}+02$ & $-1.73 E+03$ \\
\hline$-1.47 \mathrm{E}+01$ & $3.04 \mathrm{E}+01$ & $-1.74 E+03$ & $-4.80 E+01$ & $2.47 E+02$ & $-1.73 E+03$ \\
\hline$-2.26 \mathrm{E}+01$ & $3.09 E+01$ & $-1.74 E+03$ & $-5.96 E+01$ & $2.49 E+02$ & $-1.73 E+03$ \\
\hline$-3.17 E+01$ & $3.20 \mathrm{E}+01$ & $-1.74 \mathrm{E}+03$ & $-7.05 E+01$ & $2.51 E+02$ & $-1.72 E+03$ \\
\hline$-4.05 E+01$ & $3.31 \mathrm{E}+01$ & $-1.74 \mathrm{E}+03$ & $-8.03 E+01$ & $2.52 \mathrm{E}+02$ & $-1.72 E+03$ \\
\hline$-4.73 E+01$ & $3.40 \mathrm{E}+01$ & $-1.74 \mathrm{E}+03$ & $-9.09 E+01$ & $2.54 \mathrm{E}+02$ & $-1.72 E+03$ \\
\hline$-5.31 E+01$ & $3.49 \mathrm{E}+01$ & $-1.74 \mathrm{E}+03$ & $-9.98 E+01$ & $2.55 \mathrm{E}+02$ & $-1.72 E+03$ \\
\hline$-5.93 E+01$ & $3.61 \mathrm{E}+01$ & $-1.73 E+03$ & $-1.07 E+02$ & $2.56 \mathrm{E}+02$ & $-1.71 E+03$ \\
\hline$-6.56 E+01$ & $3.72 \mathrm{E}+01$ & $-1.73 E+03$ & $-1.13 E+02$ & $7 E+02$ & $1 E+03$ \\
\hline$-7.12 E+01$ & $3.85 E+01$ & $-1.73 E+03$ & $8 \mathrm{E}+02$ & $E+02$ & +03 \\
\hline$-7.81 E+01$ & $4.01 \mathrm{E}+01$ & $-1.73 E+03$ & $-1.23 E+02$ & $8 E+02$ & $E+03$ \\
\hline$-8.25 E+01$ & $4.14 \mathrm{E}+01$ & $-1.73 E+03$ & $5.67 E+01$ & $4.76 \mathrm{E}+02$ & $-1.62 \mathrm{E}+03$ \\
\hline$-8.88 E+01$ & $4.30 \mathrm{E}+01$ & & $-1.15 E+01$ & $3.03 E+01$ & $-1.74 E+03$ \\
\hline$-9.52 E+01$ & $4.47 E+01$ & $-1.72 E+03$ & $-3.12 E+00$ & $2.42 \mathrm{E}+02$ & $-1.74 \mathrm{E}+03$ \\
\hline$-1.01 E+02$ & $4.67 \mathrm{E}+01$ & $-1.72 E+03$ & $-1.97 E+02$ & $1.00 \mathrm{E}+02$ & $-1.69 \mathrm{E}+03$ \\
\hline$-1.06 E+02$ & $4.83 E+01$ & $-1.72 \mathrm{E}+03$ & $-1.26 \mathrm{E}+02$ & $2.58 \mathrm{E}+02$ & $-1.71 E+03$ \\
\hline
\end{tabular}




\begin{tabular}{|c|c|c|c|c|c|}
\hline X-Cord. & Cord. & Cord. & X-Cord. & Y-Cord. & Z-Cord. \\
\hline 01 & $4 E+01$ & $.74 E+03$ & $-9.39 E+01$ & $56 \mathrm{E}+02$ & $-1.73 E+03$ \\
\hline$-2.41 E+01$ & $3.17 E+01$ & $-1.73 E+03$ & $-1.02 E+02$ & $2.58 \mathrm{E}+02$ & $-1.72 \mathrm{E}+03$ \\
\hline$-4.00 E+01$ & $3.38 \mathrm{E}+01$ & $-1.73 E+03$ & $-1.08 \mathrm{E}+02$ & $2.59 \mathrm{E}+02$ & $-1.72 E+03$ \\
\hline-4.69 & $48 \mathrm{E}+01$ & $1.73 E+03$ & $-1.13 E+02$ & $60 \mathrm{E}+02$ & 03 \\
\hline+01 & $3.72 \mathrm{E}+01$ & $-1.72 E+03$ & $-1.19 E+02$ & $1 \mathrm{E}+02$ & +03 \\
\hline$-6.38 \mathrm{E}+01$ & $3.82 \mathrm{E}+01$ & $-1.72 E+03$ & $-1.25 E+02$ & $1 \mathrm{E}+02$ & $72 E+03$ \\
\hline$-6.91 E+01$ & $3.93 \mathrm{E}+01$ & $-1.72 E+03$ & $65 E+01$ & $E+02$ & $E+03$ \\
\hline$-7.60 E+01$ & $4.09 \mathrm{E}+01$ & $E+03$ & $E+01$ & & +03 \\
\hline$-8.38 \mathrm{E}+01$ & $E+01$ & $E+03$ & $E+00$ & & +03 \\
\hline$-9.27 E+01$ & 01 & $E+03$ & $E+02$ & & +03 \\
\hline-1 . & 4 & 33 & -1 & & +03 \\
\hline & & & 01 & & \\
\hline & & & & & \\
\hline & & & & & \\
\hline & & & & & $E+03$ \\
\hline$-1.40 \mathrm{E}+02$ & $6.30 \mathrm{E}+01$ & $-1.71 E+03$ & $-5.79 E+01$ & $3.66 \mathrm{E}+01$ & $-1.73 E+03$ \\
\hline$-1.45 E+02$ & $6.57 \mathrm{E}+01$ & $-1.70 \mathrm{E}+03$ & $-6.99 E+01$ & $3.88 \mathrm{E}+01$ & $3 E+03$ \\
\hline$-1.50 E+02$ & $6.86 \mathrm{E}+01$ & $-1.70 \mathrm{E}+03$ & $-8.56 E+01$ & $4.24 \mathrm{E}+01$ & $2 \mathrm{E}+03$ \\
\hline$-1.56 \mathrm{E}+02$ & $7.23 \mathrm{E}+01$ & $-1.70 \mathrm{E}+03$ & $-9.11 E+01$ & $3 E+01$ & $2 \mathrm{E}+03$ \\
\hline$-1.62 E+02$ & $7.50 \mathrm{E}+01$ & $-1.70 \mathrm{E}+03$ & $-9.71 E+01$ & $4.62 E+01$ & $-1.72 E+03$ \\
\hline$-1.68 \mathrm{E}+02$ & $7.90 \mathrm{E}+01$ & $-1.70 E+03$ & $-1.07 E+02$ & $4.90 \mathrm{E}+01$ & $-1.72 \mathrm{E}+03$ \\
\hline$-1.75 E+02$ & $8.36 E+01$ & $-1.70 E+03$ & $-1.16 E+02$ & $5.17 E+01$ & $-1.72 E+03$ \\
\hline$-1.81 E+02$ & $8.86 \mathrm{E}+01$ & $-1.69 E+03$ & $-1.23 E+02$ & $5.49 E+01$ & $-1.71 E+03$ \\
\hline$-1.87 E+02$ & $9.23 E+01$ & $-1.69 E+03$ & $-1.31 E+02$ & $5.83 E+01$ & $-1.71 E+03$ \\
\hline$-1.91 E+02$ & $9.56 \mathrm{E}+01$ & $-1.69 E+03$ & $-1.39 E+02$ & $6.25 \mathrm{E}+01$ & $-1.71 E+03$ \\
\hline$-8.61 E+00$ & $2.41 \mathrm{E}+02$ & $-1.75 E+03$ & $-1.47 E+02$ & $6.71 \mathrm{E}+01$ & $-1.70 \mathrm{E}+03$ \\
\hline$-2.03 E+01$ & $2.42 \mathrm{E}+02$ & $-1.75 E+03$ & $-1.55 E+02$ & $7.16 \mathrm{E}+01$ & $-1.70 \mathrm{E}+03$ \\
\hline$-2.51 E+01$ & $2.43 E+02$ & $-1.75 E+03$ & $-1.60 \mathrm{E}+02$ & $5 \mathrm{E}+01$ & $0 \mathrm{E}+03$ \\
\hline$-2.74 \mathrm{E}+01$ & $2.45 E+02$ & $-1.74 \mathrm{E}+03$ & $-1.66 \mathrm{E}+02$ & $E+01$ & $E+03$ \\
\hline$-3.75 E+01$ & $2.46 \mathrm{E}+02$ & $-1.74 E+03$ & $-1.76 E+02$ & $E+01$ & $E+03$ \\
\hline$-4.74 E+01$ & $2.48 \mathrm{E}+02$ & $-1.74 E+03$ & $-1.84 \mathrm{E}+02$ & $8.97 E+01$ & $-1.70 \mathrm{E}+03$ \\
\hline$-5.58 E+01$ & $2.49 E+02$ & $-1.73 E+03$ & $-1.90 E+02$ & & $-1.69 E+03$ \\
\hline$-6.47 E+01$ & $2.51 \mathrm{E}+02$ & $-1.73 E+03$ & $-1.95 E+02$ & $9.92 \mathrm{E}+01$ & $-1.69 E+03$ \\
\hline$-7.62 E+01$ & $2.53 \mathrm{E}+02$ & $-1.73 E+03$ & $-1.97 E+02$ & $1.01 \mathrm{E}+02$ & $-1.69 \mathrm{E}+03$ \\
\hline$-8.47 E+01$ & $2.55 \mathrm{E}+02$ & $-1.73 E+03$ & $-1.09 E+01$ & $2.42 \mathrm{E}+02$ & $-1.74 \mathrm{E}+03$ \\
\hline
\end{tabular}




\begin{tabular}{|c|c|c|c|c|c|}
\hline X-Cord. & Y-Cord. & Z-Cord. & X-Cord. & Y-Cord. & Z-Cord. \\
\hline$-1.85 E+01$ & $2.43 E+02$ & $-1.74 E+03$ & $-1.81 E+02$ & $8.86 \mathrm{E}+01$ & $-1.69 E+03$ \\
\hline$-2.69 E+01$ & $2.45 E+02$ & $-1.74 E+03$ & $-1.85 E+02$ & $9.16 \mathrm{E}+01$ & $-1.69 \mathrm{E}+03$ \\
\hline$-3.54 \mathrm{E}+01$ & $2.46 \mathrm{E}+02$ & $-1.74 \mathrm{E}+03$ & $-1.92 \mathrm{E}+02$ & $9.77 \mathrm{E}+01$ & $-1.69 \mathrm{E}+03$ \\
\hline$-4.57 \mathrm{E}+01$ & $2.48 \mathrm{E}+02$ & $-1.74 E+03$ & $-1.96 \mathrm{E}+02$ & $1.00 \mathrm{E}+02$ & $-1.69 \mathrm{E}+03$ \\
\hline$-5.37 \mathrm{E}+01$ & $2.49 \mathrm{E}+02$ & $-1.74 E+03$ & $-1.98 \mathrm{E}+02$ & $1.02 \mathrm{E}+02$ & $-1.69 \mathrm{E}+03$ \\
\hline$-6.17 E+01$ & $2.51 \mathrm{E}+02$ & $-1.73 E+03$ & & & \\
\hline$-7.10 E+01$ & $2.52 \mathrm{E}+02$ & $-1.73 E+03$ & & & \\
\hline$-7.89 E+01$ & $2.54 \mathrm{E}+02$ & $-1.73 E+03$ & & & \\
\hline$-8.70 E+01$ & $2.55 \mathrm{E}+02$ & $-1.72 E+03$ & & & \\
\hline$-9.61 E+01$ & $2.57 \mathrm{E}+02$ & $-1.72 E+03$ & & & \\
\hline$-1.03 E+02$ & $2.58 \mathrm{E}+02$ & $-1.72 E+03$ & & & \\
\hline$-1.11 E+02$ & $2.60 \mathrm{E}+02$ & $-1.72 E+03$ & & & \\
\hline$-1.16 E+02$ & $2.60 \mathrm{E}+02$ & $-1.72 E+03$ & & & \\
\hline $5.65 E+01$ & $4.76 \mathrm{E}+02$ & $-1.62 E+03$ & & & \\
\hline$-1.14 \mathrm{E}+01$ & $3.03 E+01$ & $-1.74 E+03$ & & & \\
\hline$-2.68 E+00$ & $2.42 \mathrm{E}+02$ & $-1.73 E+03$ & & & \\
\hline$-2.01 E+02$ & $1.05 \mathrm{E}+02$ & $-1.69 E+03$ & & & \\
\hline$-1.26 \mathrm{E}+02$ & $2.63 E+02$ & $-1.71 E+03$ & & & \\
\hline$-4.30 \mathrm{E}+01$ & $3.33 E+01$ & $-1.74 E+03$ & & & \\
\hline$-2.42 E+01$ & $3.17 \mathrm{E}+01$ & $-1.74 E+03$ & & & \\
\hline$-3.58 E+01$ & $3.32 \mathrm{E}+01$ & $-1.73 E+03$ & & & \\
\hline$-5.17 E+01$ & $3.57 E+01$ & $-1.73 E+03$ & & & \\
\hline$-6.39 E+01$ & $3.81 \mathrm{E}+01$ & $-1.72 E+03$ & & & \\
\hline$-7.84 E+01$ & $4.17 \mathrm{E}+01$ & $-1.72 E+03$ & & & \\
\hline$-8.76 E+01$ & $4.42 \mathrm{E}+01$ & $-1.72 \mathrm{E}+03$ & & & \\
\hline$-9.57 E+01$ & $4.63 E+01$ & $-1.71 E+03$ & & & \\
\hline$-1.07 E+02$ & $5.02 E+01$ & $-1.71 E+03$ & & & \\
\hline$-1.19 E+02$ & $5.41 \mathrm{E}+01$ & $-1.71 E+03$ & & & \\
\hline$-1.26 \mathrm{E}+02$ & $5.68 \mathrm{E}+01$ & $-1.71 E+03$ & & & \\
\hline$-1.37 E+02$ & $6.18 \mathrm{E}+01$ & $-1.70 E+03$ & & & \\
\hline$-1.47 E+02$ & $6.72 \mathrm{E}+01$ & $-1.70 E+03$ & & & \\
\hline$-1.57 E+02$ & $7.28 \mathrm{E}+01$ & $-1.70 E+03$ & & & \\
\hline$-1.64 E+02$ & $7.67 \mathrm{E}+01$ & $-1.70 E+03$ & & & \\
\hline$-1.67 E+02$ & $7.89 \mathrm{E}+01$ & $-1.70 E+03$ & & & \\
\hline$-1.74 \mathrm{E}+02$ & $8.40 E+01$ & $-1.69 E+03$ & & & \\
\hline
\end{tabular}


Experiment 3

Table C-0-3:Data for Experiment 3.

\begin{tabular}{|c|c|c|c|c|c|}
\hline X-Cord. & Y-Cord. & Z-Cord. & X-Cord. & Y-Cord. & Z-Cord. \\
\hline $1.87 E+02$ & $3.89 \mathrm{E}+02$ & $-1.53 E+03$ & $1.29 E+02$ & $3.86 \mathrm{E}+02$ & $-1.52 E+03$ \\
\hline $1.70 \mathrm{E}+02$ & $3.88 \mathrm{E}+02$ & $-1.52 E+03$ & $1.14 \mathrm{E}+02$ & $3.85 E+02$ & $-1.52 E+03$ \\
\hline $1.53 E+02$ & $3.87 \mathrm{E}+02$ & $-1.52 E+03$ & $9.89 E+01$ & $3.83 E+02$ & $-1.52 \mathrm{E}+03$ \\
\hline $1.34 E+02$ & $3.86 \mathrm{E}+02$ & $-1.52 E+03$ & $8.69 E+01$ & $3.82 E+02$ & $-1.52 E+03$ \\
\hline $1.14 \mathrm{E}+02$ & $3.85 E+02$ & $-1.52 \mathrm{E}+03$ & $7.57 \mathrm{E}+01$ & $3.80 E+02$ & $-1.52 \mathrm{E}+03$ \\
\hline $9.67 \mathrm{E}+01$ & $3.83 E+02$ & $-1.52 \mathrm{E}+03$ & $6.52 E+01$ & $3.77 E+02$ & $-1.51 E+03$ \\
\hline $7.74 \mathrm{E}+01$ & $3.80 \mathrm{E}+02$ & $-1.51 E+03$ & $5.64 \mathrm{E}+01$ & $3.75 E+02$ & $-1.51 \mathrm{E}+03$ \\
\hline $6.61 E+01$ & $3.78 \mathrm{E}+02$ & $-1.52 E+03$ & $4.82 E+01$ & $3.73 E+02$ & $-1.51 E+03$ \\
\hline $5.18 \mathrm{E}+01$ & $3.75 E+02$ & $-1.52 \mathrm{E}+03$ & $4.12 \mathrm{E}+01$ & $3.71 E+02$ & $-1.51 \mathrm{E}+03$ \\
\hline $4.03 E+01$ & $3.71 E+02$ & $-1.51 E+03$ & $2.33 E+02$ & $6.14 E+02$ & $-1.38 \mathrm{E}+03$ \\
\hline $2.33 E+02$ & $6.14 \mathrm{E}+02$ & $-1.38 \mathrm{E}+03$ & $1.98 \mathrm{E}+02$ & $1.78 \mathrm{E}+02$ & $-1.54 \mathrm{E}+03$ \\
\hline $1.98 \mathrm{E}+02$ & $1.78 \mathrm{E}+02$ & $-1.54 \mathrm{E}+03$ & $1.97 E+02$ & $3.89 E+02$ & $-1.55 E+03$ \\
\hline $1.98 \mathrm{E}+02$ & $3.89 \mathrm{E}+02$ & $-1.55 E+03$ & $3.23 E+01$ & $1.92 \mathrm{E}+02$ & $-1.52 \mathrm{E}+03$ \\
\hline $3.23 E+01$ & $1.92 \mathrm{E}+02$ & $-1.52 E+03$ & $2.75 \mathrm{E}+01$ & $3.67 E+02$ & $-1.51 E+03$ \\
\hline $3.12 \mathrm{E}+01$ & $3.68 \mathrm{E}+02$ & $-1.51 E+03$ & $1.93 \mathrm{E}+02$ & $1.78 \mathrm{E}+02$ & $-1.54 \mathrm{E}+03$ \\
\hline $1.94 \mathrm{E}+02$ & $1.78 \mathrm{E}+02$ & $4 E+03$ & $3 \mathrm{E}+02$ & +02 & +03 \\
\hline $1.85 \mathrm{E}+02$ & $1.78 \mathrm{E}+02$ & $-1.55 E+03$ & $1.69 E+02$ & $1.78 \mathrm{E}+02$ & $-1.54 \mathrm{E}+03$ \\
\hline $1.72 \mathrm{E}+02$ & $1.78 \mathrm{E}+02$ & $-1.55 E+03$ & $1.56 \mathrm{E}+02$ & $1.78 \mathrm{E}+02$ & $-1.54 \mathrm{E}+03$ \\
\hline $1.56 \mathrm{E}+02$ & $1.78 \mathrm{E}+02$ & $-1.55 E+03$ & $1.34 \mathrm{E}+02$ & $1.79 \mathrm{E}+02$ & $-1.54 \mathrm{E}+03$ \\
\hline $1.40 \mathrm{E}+02$ & $1.79 \mathrm{E}+02$ & $-1.55 E+03$ & $1.23 E+02$ & $1.79 E+02$ & $-1.54 \mathrm{E}+03$ \\
\hline $1.28 \mathrm{E}+02$ & $1.79 \mathrm{E}+02$ & $-1.54 \mathrm{E}+03$ & $1.13 E+02$ & $1.80 \mathrm{E}+02$ & $-1.54 \mathrm{E}+03$ \\
\hline $1.17 \mathrm{E}+02$ & $1.80 \mathrm{E}+02$ & $-1.54 \mathrm{E}+03$ & $1.02 E+02$ & $1.81 \mathrm{E}+02$ & $-1.54 \mathrm{E}+03$ \\
\hline $1.06 \mathrm{E}+02$ & $1.81 \mathrm{E}+02$ & $-1.54 \mathrm{E}+03$ & $9.05 \mathrm{E}+01$ & $1.82 \mathrm{E}+02$ & $-1.53 E+03$ \\
\hline $9.74 \mathrm{E}+01$ & $1.82 \mathrm{E}+02$ & $-1.54 \mathrm{E}+03$ & $7.89 E+01$ & $1.84 \mathrm{E}+02$ & $-1.53 E+03$ \\
\hline $8.63 E+01$ & $1.83 \mathrm{E}+02$ & $-1.54 \mathrm{E}+03$ & $6.67 \mathrm{E}+01$ & $1.86 \mathrm{E}+02$ & $-1.53 E+03$ \\
\hline $7.82 \mathrm{E}+01$ & $1.84 \mathrm{E}+02$ & $-1.54 \mathrm{E}+03$ & $5.54 \mathrm{E}+01$ & $1.88 \mathrm{E}+02$ & $-1.53 E+03$ \\
\hline $6.90 \mathrm{E}+01$ & $1.85 \mathrm{E}+02$ & $-1.54 \mathrm{E}+03$ & $4.51 E+01$ & $1.90 \mathrm{E}+02$ & $-1.53 E+03$ \\
\hline $5.83 \mathrm{E}+01$ & $1.87 \mathrm{E}+02$ & $-1.53 E+03$ & $3.76 \mathrm{E}+01$ & $1.91 \mathrm{E}+02$ & $-1.52 E+03$ \\
\hline $4.86 \mathrm{E}+01$ & $1.89 \mathrm{E}+02$ & $-1.54 \mathrm{E}+03$ & $1.95 \mathrm{E}+02$ & $3.89 E+02$ & $-1.54 \mathrm{E}+03$ \\
\hline $4.10 \mathrm{E}+01$ & $1.91 \mathrm{E}+02$ & $-1.53 E+03$ & $1.71 E+02$ & $3.89 E+02$ & $-1.53 E+03$ \\
\hline $3.37 \mathrm{E}+01$ & $1.92 \mathrm{E}+02$ & $-1.53 E+03$ & $1.61 E+02$ & $3.89 E+02$ & $-1.53 E+03$ \\
\hline $1.84 \mathrm{E}+02$ & $3.89 \mathrm{E}+02$ & $-1.53 E+03$ & $1.45 \mathrm{E}+02$ & $3.89 E+02$ & $-1.53 E+03$ \\
\hline $1.76 \mathrm{E}+02$ & $3.88 \mathrm{E}+02$ & $-1.53 E+03$ & $1.32 \mathrm{E}+02$ & $3.89 E+02$ & $-1.53 E+03$ \\
\hline $1.64 \mathrm{E}+02$ & $3.88 \mathrm{E}+02$ & $-1.52 \mathrm{E}+03$ & $1.20 E+02$ & $3.88 \mathrm{E}+02$ & $-1.52 E+03$ \\
\hline $1.45 \mathrm{E}+02$ & $3.87 \mathrm{E}+02$ & $-1.52 E+03$ & $1.07 \mathrm{E}+02$ & $3.88 \mathrm{E}+02$ & $-1.52 E+03$ \\
\hline
\end{tabular}




\begin{tabular}{|c|c|c|c|c|c|}
\hline X-Cord. & Y-Cord. & Z-Cord. & X-Cord. & Y-Cord. & Z-Cord. \\
\hline $9.56 \mathrm{E}+01$ & $3.88 \mathrm{E}+02$ & $-1.52 E+03$ & $2.33 \mathrm{E}+02$ & $6.14 \mathrm{E}+02$ & $-1.38 \mathrm{E}+03$ \\
\hline $8.34 \mathrm{E}+01$ & $3.87 E+02$ & $-1.52 E+03$ & $1.98 \mathrm{E}+02$ & $1.78 \mathrm{E}+02$ & $-1.55 E+03$ \\
\hline $6.91 \mathrm{E}+01$ & $3.85 \mathrm{E}+02$ & $-1.51 E+03$ & $.00 \mathrm{E}+02$ & $3.89 \mathrm{E}+02$ & $-1.53 E+03$ \\
\hline $4.64 \mathrm{E}+01$ & $3.81 \mathrm{E}+02$ & $-1.51 E+03$ & $1.30 \mathrm{E}+01$ & $2.03 \mathrm{E}+02$ & $-1.52 \mathrm{E}+03$ \\
\hline $2.33 \mathrm{E}+02$ & $6.14 \mathrm{E}+02$ & $-1.38 \mathrm{E}+03$ & $2.62 \mathrm{E}+01$ & $3.78 \mathrm{E}+02$ & $-1.51 \mathrm{E}+03$ \\
\hline $1.98 \mathrm{E}+02$ & $1.78 \mathrm{E}+02$ & $-1.54 \mathrm{E}+03$ & $1.94 \mathrm{E}+02$ & $1.79 \mathrm{E}+02$ & $-1.54 \mathrm{E}+03$ \\
\hline $1.99 \mathrm{E}+02$ & $3.89 \mathrm{E}+02$ & $-1.53 E+03$ & $1.79 \mathrm{E}+02$ & $79 E+02$ & $5 \mathrm{E}+03$ \\
\hline $1.24 \mathrm{E}+01$ & $2.04 \mathrm{E}+02$ & $-1.52 E+03$ & $62 \mathrm{E}+02$ & $79 E+02$ & $E+03$ \\
\hline $2.77 \mathrm{E}+01$ & $3.78 \mathrm{E}+02$ & $-1.51 E+03$ & $E+02$ & $1.80 \mathrm{E}+02$ & $E+03$ \\
\hline $1.93 \mathrm{E}+02$ & $1.79 \mathrm{E}+02$ & $-1.54 \mathrm{E}+03$ & $1.31 \mathrm{E}+02$ & $1.80 \mathrm{E}+02$ & $-1.54 \mathrm{E}+03$ \\
\hline $1.73 \mathrm{E}+02$ & $1.79 \mathrm{E}+02$ & $-1.54 \mathrm{E}+03$ & $19 \mathrm{E}+02$ & $81 E+02$ & $-1.54 \mathrm{E}+03$ \\
\hline $1.55 \mathrm{E}+02$ & $1.79 \mathrm{E}+02$ & $-1.54 \mathrm{E}+03$ & $1.06 \mathrm{E}+02$ & $1.83 \mathrm{E}+02$ & $-1.54 \mathrm{E}+03$ \\
\hline $1.41 \mathrm{E}+02$ & $1.80 \mathrm{E}+02$ & $-1.54 \mathrm{E}+03$ & $9.53 \mathrm{E}+01$ & $1.84 \mathrm{E}+02$ & 03 \\
\hline $1.28 \mathrm{E}+02$ & $1.80 \mathrm{E}+02$ & $-1.54 \mathrm{E}+03$ & $8.16 \mathrm{E}+01$ & $1.86 \mathrm{E}+02$ & $-1.53 E+03$ \\
\hline $1.16 \mathrm{E}+02$ & $1.81 \mathrm{E}+02$ & $-1.54 \mathrm{E}+03$ & $6.73 \mathrm{E}+01$ & $1.89 \mathrm{E}+02$ & $-1.53 E+03$ \\
\hline $1.03 E+02$ & $1.82 \mathrm{E}+02$ & $-1.53 E+03$ & $5.41 E+01$ & $1.92 \mathrm{E}+02$ & $-1.53 E+03$ \\
\hline $8.99 E+01$ & $1.84 \mathrm{E}+02$ & $-1.53 E+03$ & & $1.94 \mathrm{E}+02$ & $-1.53 E+03$ \\
\hline $7.43 E+01$ & $1.87 \mathrm{E}+02$ & $-1.53 E+03$ & $3.67 E+01$ & $1.97 E+02$ & $-1.53 E+03$ \\
\hline $6.25 E+01$ & $1.90 \mathrm{E}+02$ & $-1.53 E+03$ & $2.36 \mathrm{E}+01$ & $2.00 \mathrm{E}+02$ & $-1.53 E+03$ \\
\hline $4.85 E+01$ & $1.93 \mathrm{E}+02$ & $-1.53 E+03$ & $1.79 \mathrm{E}+01$ & $2.02 \mathrm{E}+02$ & $-1.52 E+03$ \\
\hline $3.54 \mathrm{E}+01$ & $1.96 \mathrm{E}+02$ & $-1.53 E+03$ & $1.96 \mathrm{E}+02$ & $3.89 \mathrm{E}+02$ & $-1.54 \mathrm{E}+03$ \\
\hline $2.05 E+01$ & $2.01 \mathrm{E}+02$ & $-1.52 E+03$ & $1.82 \mathrm{E}+02$ & $3.90 \mathrm{E}+02$ & $-1.53 E+03$ \\
\hline $1.95 \mathrm{E}+02$ & $3.89 \mathrm{E}+02$ & $-1.53 E+03$ & $1.70 \mathrm{E}+02$ & $3.90 \mathrm{E}+02$ & $-1.53 E+03$ \\
\hline $1.81 \mathrm{E}+02$ & $3.89 \mathrm{E}+02$ & $-1.53 E+03$ & $1.55 \mathrm{E}+02$ & $3.91 \mathrm{E}+02$ & $-1.53 E+03$ \\
\hline $1.65 \mathrm{E}+02$ & $3.89 \mathrm{E}+02$ & $-1.53 E+03$ & $1.40 \mathrm{E}+02$ & $3.92 \mathrm{E}+02$ & $-1.53 E+03$ \\
\hline $1.51 \mathrm{E}+02$ & $3.89 \mathrm{E}+02$ & $-1.53 E+03$ & $1.25 E+02$ & $3.92 \mathrm{E}+02$ & $-1.52 E+03$ \\
\hline $1.38 \mathrm{E}+02$ & $3.89 \mathrm{E}+02$ & $-1.52 E+03$ & $1.12 \mathrm{E}+02$ & $3.92 \mathrm{E}+02$ & $-1.52 E+03$ \\
\hline $1.26 \mathrm{E}+02$ & $3.89 \mathrm{E}+02$ & $-1.52 E+03$ & $9.89 \mathrm{E}+01$ & $3.92 \mathrm{E}+02$ & $-1.52 E+03$ \\
\hline $1.11 \mathrm{E}+02$ & $3.88 \mathrm{E}+02$ & $-1.52 E+03$ & $8.62 E+01$ & $3.92 \mathrm{E}+02$ & $-1.52 E+03$ \\
\hline $9.83 \mathrm{E}+01$ & $3.88 \mathrm{E}+02$ & $-1.52 E+03$ & $7.34 \mathrm{E}+01$ & $3.91 \mathrm{E}+02$ & $-1.52 E+03$ \\
\hline $8.40 \mathrm{E}+01$ & $3.86 \mathrm{E}+02$ & $-1.52 \mathrm{E}+03$ & $6.12 \mathrm{E}+01$ & $3.91 \mathrm{E}+02$ & $-1.51 E+03$ \\
\hline $6.97 \mathrm{E}+01$ & $3.85 E+02$ & $-1.52 E+03$ & $4.92 \mathrm{E}+01$ & $3.90 E+02$ & $-1.51 \mathrm{E}+03$ \\
\hline $5.45 \mathrm{E}+01$ & $3.82 \mathrm{E}+02$ & $-1.51 E+03$ & $2.33 \mathrm{E}+02$ & $6.14 \mathrm{E}+02$ & $-1.38 \mathrm{E}+03$ \\
\hline $4.79 E+01$ & $3.82 \mathrm{E}+02$ & $-1.51 E+03$ & $1.98 \mathrm{E}+02$ & $1.79 \mathrm{E}+02$ & $-1.54 \mathrm{E}+03$ \\
\hline $4.01 E+01$ & $3.80 \mathrm{E}+02$ & $-1.51 E+03$ & $1.99 \mathrm{E}+02$ & $3.89 \mathrm{E}+02$ & $-1.53 E+03$ \\
\hline
\end{tabular}




\begin{tabular}{|c|c|c|c|c|c|}
\hline X-Cord. & Y-Cord. & Z-Cord. & X-Cord. & Y-Cord. & Z-Cord. \\
\hline$-5.77 E+00$ & $2.16 \mathrm{E}+02$ & $-1.52 E+03$ & $1.91 E+02$ & $1.79 E+02$ & $-1.54 \mathrm{E}+03$ \\
\hline $2.92 \mathrm{E}+01$ & $3.88 \mathrm{E}+02$ & $-1.51 \mathrm{E}+03$ & $1.75 \mathrm{E}+02$ & $1.79 \mathrm{E}+02$ & $-1.54 \mathrm{E}+03$ \\
\hline $1.94 \mathrm{E}+02$ & $1.79 E+02$ & $-1.54 \mathrm{E}+03$ & $1.52 \mathrm{E}+02$ & $1.80 \mathrm{E}+02$ & $-1.54 \mathrm{E}+03$ \\
\hline $1.80 \mathrm{E}+02$ & $1.79 \mathrm{E}+02$ & $-1.54 \mathrm{E}+03$ & $1.41 \mathrm{E}+02$ & $1.80 \mathrm{E}+02$ & $-1.54 \mathrm{E}+03$ \\
\hline $1.65 \mathrm{E}+02$ & $1.79 E+02$ & $-1.54 \mathrm{E}+03$ & $1.27 \mathrm{E}+02$ & $1.82 \mathrm{E}+02$ & $-1.53 E+03$ \\
\hline $1.53 E+02$ & $1.80 E+02$ & $-1.54 \mathrm{E}+03$ & $1.14 \mathrm{E}+02$ & $1.83 E+02$ & $-1.53 E+03$ \\
\hline $1.37 \mathrm{E}+02$ & $1.81 \mathrm{E}+02$ & $-1.54 \mathrm{E}+03$ & $1.03 E+02$ & $1.85 \mathrm{E}+02$ & $-1.53 E+03$ \\
\hline $1.23 \mathrm{E}+02$ & $1.82 \mathrm{E}+02$ & $-1.54 \mathrm{E}+03$ & $9.18 \mathrm{E}+01$ & $1.86 \mathrm{E}+02$ & $\mathrm{E}+03$ \\
\hline $1.12 \mathrm{E}+02$ & $1.83 E+02$ & $-1.54 \mathrm{E}+03$ & $8.31 E+01$ & $1.88 \mathrm{E}+02$ & $-1.53 E+03$ \\
\hline $9.88 \mathrm{E}+01$ & $1.85 \mathrm{E}+02$ & $-1.53 E+03$ & $6.84 \mathrm{E}+01$ & $1.91 \mathrm{E}+02$ & $-1.53 E+03$ \\
\hline $8.61 \mathrm{E}+01$ & $1.87 \mathrm{E}+02$ & $-1.53 E+03$ & $5.13 E+01$ & $1.96 \mathrm{E}+02$ & $-1.53 E+03$ \\
\hline $7.48 \mathrm{E}+01$ & $1.89 \mathrm{E}+02$ & $-1.53 E+03$ & $4.01 E+01$ & $1.99 \mathrm{E}+02$ & $-1.52 E+03$ \\
\hline $6.57 \mathrm{E}+01$ & $1.91 \mathrm{E}+02$ & $\mathrm{E}+03$ & $3.01 E+01$ & $E+02$ & $=03$ \\
\hline $5.43 E+01$ & $1.94 \mathrm{E}+02$ & $-1.53 E+03$ & $2.19 E+01$ & $2.05 E+02$ & $-1.52 E+03$ \\
\hline $4.41 \mathrm{E}+01$ & $1.97 \mathrm{E}+02$ & $-1.52 \mathrm{E}+03$ & $1.46 \mathrm{E}+01$ & $2.08 \mathrm{E}+02$ & $-1.52 E+03$ \\
\hline $3.39 \mathrm{E}+01$ & $2.01 E+02$ & $-1.53 E+03$ & $7.41 E+00$ & $2.11 E+02$ & $-1.52 E+03$ \\
\hline $2.33 \mathrm{E}+01$ & $2.05 E+02$ & $-1.52 E+03$ & $-1.89 E+00$ & $15 E+02$ & \\
\hline $1.36 \mathrm{E}+01$ & $2.09 E+02$ & $-1.52 E+03$ & $1.83 E+02$ & $3.91 E+02$ & $-1.53 E+03$ \\
\hline $1.04 \mathrm{E}+00$ & $2.14 E+02$ & $-1.52 E+03$ & $1.61 E+02$ & $3.92 E+02$ & $-1.52 \mathrm{E}+03$ \\
\hline $1.78 \mathrm{E}+02$ & $3.90 E+02$ & $-1.53 E+03$ & $1.47 E+02$ & $3.93 E+02$ & $-1.52 E+03$ \\
\hline $1.68 \mathrm{E}+02$ & $3.90 E+02$ & $-1.53 \mathrm{E}+03$ & $1.33 E+02$ & $3.94 \mathrm{E}+02$ & $-1.52 E+03$ \\
\hline $1.56 \mathrm{E}+02$ & $3.91 E+02$ & $-1.53 E+03$ & $1.10 E+02$ & $3.96 E+02$ & $-1.52 E+03$ \\
\hline $1.43 \mathrm{E}+02$ & $3.91 E+02$ & $-1.52 E+03$ & $1.03 E+02$ & $3.96 \mathrm{E}+02$ & $-1.52 E+03$ \\
\hline $1.29 \mathrm{E}+02$ & $3.92 E+02$ & $-1.52 \mathrm{E}+03$ & $9.18 \mathrm{E}+01$ & $3.97 \mathrm{E}+02$ & $-1.52 E+03$ \\
\hline $1.11 \mathrm{E}+02$ & $3.92 E+02$ & $-1.52 \mathrm{E}+03$ & $8.08 \mathrm{E}+01$ & $3.98 \mathrm{E}+02$ & $-1.52 E+03$ \\
\hline $9.44 \mathrm{E}+01$ & $3.92 E+02$ & $-1.52 \mathrm{E}+03$ & $7.06 E+01$ & $3.98 E+02$ & $-1.51 E+03$ \\
\hline $8.10 \mathrm{E}+01$ & $3.92 E+02$ & $-1.52 \mathrm{E}+03$ & $6.00 \mathrm{E}+01$ & $3.98 \mathrm{E}+02$ & $-1.51 \mathrm{E}+03$ \\
\hline $6.57 \mathrm{E}+01$ & $3.91 E+02$ & $-1.51 E+03$ & $5.06 \mathrm{E}+01$ & $3.98 \mathrm{E}+02$ & $-1.51 E+03$ \\
\hline $5.25 \mathrm{E}+01$ & $3.91 E+02$ & $-1.51 E+03$ & $2.33 \mathrm{E}+02$ & $6.14 E+02$ & $-1.38 \mathrm{E}+03$ \\
\hline $3.84 \mathrm{E}+01$ & $3.89 E+02$ & $-1.51 E+03$ & $1.98 \mathrm{E}+02$ & $1.79 E+02$ & $-1.54 \mathrm{E}+03$ \\
\hline $2.33 \mathrm{E}+02$ & $6.14 \mathrm{E}+02$ & $-1.38 \mathrm{E}+03$ & $2.00 \mathrm{E}+02$ & $3.89 \mathrm{E}+02$ & $-1.52 E+03$ \\
\hline $1.98 \mathrm{E}+02$ & $1.79 E+02$ & $-1.54 \mathrm{E}+03$ & $-2.19 \mathrm{E}+01$ & $2.31 E+02$ & $-1.51 E+03$ \\
\hline $2.00 \mathrm{E}+02$ & $3.89 E+02$ & $-1.52 \mathrm{E}+03$ & $2.96 \mathrm{E}+01$ & $3.99 E+02$ & $-1.51 E+03$ \\
\hline$-5.19 E+00$ & $2.17 E+02$ & $-1.52 \mathrm{E}+03$ & $1.92 \mathrm{E}+02$ & $1.79 \mathrm{E}+02$ & $-1.54 \mathrm{E}+03$ \\
\hline $2.82 \mathrm{E}+01$ & $3.89 E+02$ & $-1.51 E+03$ & $1.79 \mathrm{E}+02$ & $1.79 E+02$ & $-1.54 \mathrm{E}+03$ \\
\hline
\end{tabular}




\begin{tabular}{|c|c|c|c|c|c|}
\hline X-Cord. & Y-Cord. & Z-Cord. & X-Cord. & Y-Cord. & Z-Cord. \\
\hline $1.63 E+02$ & $1.80 \mathrm{E}+02$ & $-1.54 \mathrm{E}+03$ & $1.92 \mathrm{E}+02$ & $1.79 \mathrm{E}+02$ & $-1.54 \mathrm{E}+03$ \\
\hline $1.49 E+02$ & $1.81 \mathrm{E}+02$ & $-1.54 \mathrm{E}+03$ & $.55 E+02$ & $1.80 \mathrm{E}+02$ & $-1.54 E+03$ \\
\hline $1.34 \mathrm{E}+02$ & $1.82 \mathrm{E}+02$ & $-1.54 \mathrm{E}+03$ & $1.42 \mathrm{E}+02$ & $1.81 \mathrm{E}+02$ & $-1.54 \mathrm{E}+03$ \\
\hline $1.20 \mathrm{E}+02$ & $1.84 \mathrm{E}+02$ & $-1.54 \mathrm{E}+03$ & $1.26 \mathrm{E}+02$ & $1.83 \mathrm{E}+02$ & $-1.54 \mathrm{E}+03$ \\
\hline $1.08 \mathrm{E}+02$ & $1.85 \mathrm{E}+02$ & $-1.54 \mathrm{E}+03$ & $1.16 \mathrm{E}+02$ & $1.84 \mathrm{E}+02$ & $-1.54 \mathrm{E}+03$ \\
\hline $9.57 \mathrm{E}+01$ & $1.87 \mathrm{E}+02$ & $-1.54 E+03$ & $1.06 \mathrm{E}+02$ & $1.86 \mathrm{E}+02$ & $-1.54 \mathrm{E}+03$ \\
\hline$E+01$ & $1.90 \mathrm{E}+02$ & $-1.54 \mathrm{E}+03$ & $9.21 \mathrm{E}+01$ & $.88 \mathrm{E}+02$ & $3 \mathrm{E}+03$ \\
\hline+01 & $1.92 \mathrm{E}+02$ & $-1.53 E+03$ & $\mathrm{E}+01$ & $90 \mathrm{E}+02$ & $E+03$ \\
\hline $5.92 E+01$ & $1.96 \mathrm{E}+02$ & $-1.53 E+03$ & $6.04 \mathrm{E}+01$ & $5 \mathrm{E}+02$ & $=03$ \\
\hline $4.96 \mathrm{E}+01$ & $1.99 \mathrm{E}+02$ & $-1.53 E+03$ & $4.88 \mathrm{E}+01$ & $1.98 \mathrm{E}+02$ & $-1.53 E+03$ \\
\hline $3.80 \mathrm{E}+01$ & $2.03 \mathrm{E}+02$ & $-1.53 E+03$ & $3.80 \mathrm{E}+01$ & $\mathrm{O} 2 \mathrm{E}+02$ & $3 E+03$ \\
\hline $2.62 \mathrm{E}+01$ & $2.07 E+02$ & $-1.52 E+03$ & $2.72 \mathrm{E}+01$ & $2.06 \mathrm{E}+02$ & $3 \mathrm{E}+03$ \\
\hline $1.84 \mathrm{E}+01$ & $2.10 \mathrm{E}+02$ & $-1.52 E+03$ & $1.66 \mathrm{E}+01$ & $\mathrm{OE}+02$ & +03 \\
\hline $1.12 \mathrm{E}+01$ & $2.14 \mathrm{E}+02$ & $-1.52 E+03$ & $8.86 \mathrm{E}+00$ & $2.14 \mathrm{E}+02$ & $-1.52 E+03$ \\
\hline $4.96 \mathrm{E}+00$ & $2.17 E+02$ & $-1.52 \mathrm{E}+03$ & $-2.97 E+00$ & $2.20 \mathrm{E}+02$ & $-1.52 E+03$ \\
\hline$-2.36 \mathrm{E}+00$ & $2.20 \mathrm{E}+02$ & $-1.52 E+03$ & $1.96 \mathrm{E}+02$ & $3.90 \mathrm{E}+02$ & $-1.53 E+03$ \\
\hline$-1.03 E+01$ & $2.25 \mathrm{E}+02$ & $-1.52 E+03$ & & $3.93 E+02$ & \\
\hline $1.94 \mathrm{E}+02$ & $3.90 \mathrm{E}+02$ & $-1.53 E+03$ & $1.53 \mathrm{E}+02$ & $3.94 \mathrm{E}+02$ & $-1.53 E+03$ \\
\hline $1.82 \mathrm{E}+02$ & $3.91 \mathrm{E}+02$ & $-1.53 E+03$ & $1.37 E+02$ & $3.96 \mathrm{E}+02$ & $-1.53 E+03$ \\
\hline $1.66 \mathrm{E}+02$ & $3.92 \mathrm{E}+02$ & $-1.53 E+03$ & $1.23 E+02$ & $3.98 \mathrm{E}+02$ & $-1.53 E+03$ \\
\hline $1.53 E+02$ & $3.93 E+02$ & $-1.53 E+03$ & $1.07 E+02$ & $4.00 \mathrm{E}+02$ & $-1.52 E+03$ \\
\hline $1.37 \mathrm{E}+02$ & $3.94 \mathrm{E}+02$ & $-1.53 E+03$ & $9.25 E+01$ & $4.01 E+02$ & $-1.52 E+03$ \\
\hline $1.24 \mathrm{E}+02$ & $3.95 E+02$ & $-1.53 E+03$ & $6.30 E+01$ & $4.04 \mathrm{E}+02$ & $-1.52 E+03$ \\
\hline $1.10 \mathrm{E}+02$ & $3.96 \mathrm{E}+02$ & $-1.52 E+03$ & $5.24 \mathrm{E}+01$ & $4.06 \mathrm{E}+02$ & $-1.52 E+03$ \\
\hline $9.57 \mathrm{E}+01$ & $3.97 \mathrm{E}+02$ & $-1.52 E+03$ & $4.35 \mathrm{E}+01$ & $4.06 \mathrm{E}+02$ & $-1.51 \mathrm{E}+03$ \\
\hline $8.06 E+01$ & $3.98 \mathrm{E}+02$ & $-1.52 E+03$ & $2.33 E+02$ & $6.14 \mathrm{E}+02$ & $-1.38 \mathrm{E}+03$ \\
\hline $7.18 \mathrm{E}+01$ & $3.98 \mathrm{E}+02$ & $-1.52 E+03$ & $1.98 \mathrm{E}+02$ & $1.79 \mathrm{E}+02$ & $-1.54 \mathrm{E}+03$ \\
\hline $6.45 \mathrm{E}+01$ & $3.98 \mathrm{E}+02$ & $-1.51 E+03$ & $2.00 \mathrm{E}+02$ & $3.90 \mathrm{E}+02$ & $-1.52 E+03$ \\
\hline $5.58 \mathrm{E}+01$ & $3.98 \mathrm{E}+02$ & $-1.51 E+03$ & $-3.62 E+01$ & $2.45 \mathrm{E}+02$ & $-1.51 \mathrm{E}+03$ \\
\hline $4.63 E+01$ & $3.99 \mathrm{E}+02$ & $-1.51 E+03$ & $2.70 \mathrm{E}+01$ & $4.08 \mathrm{E}+02$ & $-1.51 E+03$ \\
\hline $2.33 \mathrm{E}+02$ & $6.14 \mathrm{E}+02$ & $-1.38 \mathrm{E}+03$ & $1.96 \mathrm{E}+02$ & $1.79 \mathrm{E}+02$ & $-1.54 \mathrm{E}+03$ \\
\hline $1.98 \mathrm{E}+02$ & $1.79 \mathrm{E}+02$ & $-1.54 \mathrm{E}+03$ & $1.80 \mathrm{E}+02$ & $1.79 \mathrm{E}+02$ & $-1.54 \mathrm{E}+03$ \\
\hline $1.97 \mathrm{E}+02$ & $3.90 \mathrm{E}+02$ & $-1.55 E+03$ & $1.62 \mathrm{E}+02$ & $1.80 \mathrm{E}+02$ & $-1.54 \mathrm{E}+03$ \\
\hline$-2.18 \mathrm{E}+01$ & $2.30 \mathrm{E}+02$ & $-1.51 E+03$ & $1.49 \mathrm{E}+02$ & $1.81 \mathrm{E}+02$ & $-1.54 \mathrm{E}+03$ \\
\hline $2.88 \mathrm{E}+01$ & $3.99 \mathrm{E}+02$ & $-1.51 E+03$ & $1.35 E+02$ & $1.82 \mathrm{E}+02$ & $-1.54 \mathrm{E}+03$ \\
\hline
\end{tabular}




\begin{tabular}{|c|l|l|l|l|l|}
\hline X-Cord. & Y-Cord. & Z-Cord. & X-Cord. & Y-Cord. & Z-Cord. \\
\hline $1.21 E+02$ & $1.84 E+02$ & $-1.54 E+03$ & $1.45 E+02$ & $1.81 E+02$ & $-1.54 E+03$ \\
\hline $1.09 E+02$ & $1.86 E+02$ & $-1.54 E+03$ & $1.16 E+02$ & $1.85 E+02$ & $-1.53 E+03$ \\
\hline $9.63 E+01$ & $1.88 E+02$ & $-1.54 E+03$ & $1.02 E+02$ & $1.88 E+02$ & $-1.53 E+03$ \\
\hline $8.42 E+01$ & $1.91 E+02$ & $-1.53 E+03$ & $8.99 E+01$ & $1.90 E+02$ & $-1.53 E+03$ \\
\hline $7.08 E+01$ & $1.95 E+02$ & $-1.53 E+03$ & $6.64 E+01$ & $1.96 E+02$ & $-1.53 E+03$ \\
\hline $5.83 E+01$ & $1.98 E+02$ & $-1.53 E+03$ & $5.47 E+01$ & $1.99 E+02$ & $-1.53 E+03$ \\
\hline $4.65 E+01$ & $2.02 E+02$ & $-1.52 E+03$ & $4.48 E+01$ & $2.03 E+02$ & $-1.53 E+03$ \\
\hline $3.78 E+01$ & $2.05 E+02$ & $-1.52 E+03$ & $3.02 E+01$ & $2.09 E+02$ & $-1.53 E+03$ \\
\hline $2.57 E+01$ & $2.10 E+02$ & $-1.52 E+03$ & $4.21 E+00$ & $2.21 E+02$ & $-1.52 E+03$ \\
\hline $1.36 E+01$ & $2.16 E+02$ & $-1.52 E+03$ & $-6.17 E+00$ & $2.27 E+02$ & $-1.52 E+03$ \\
\hline $3.29 E+00$ & $2.21 E+02$ & $-1.52 E+03$ & $-1.75 E+01$ & $2.34 E+02$ & $-1.52 E+03$ \\
\hline$-4.83 E+00$ & $2.26 E+02$ & $-1.52 E+03$ & $-2.88 E+01$ & $2.42 E+02$ & $-1.51 E+03$ \\
\hline$-1.27 E+01$ & $2.30 E+02$ & $-1.52 E+03$ & & & \\
\hline$-2.05 E+01$ & $2.35 E+02$ & $-1.52 E+03$ & & & \\
\hline$-2.80 E+01$ & $2.40 E+02$ & $-1.51 E+03$ & & & \\
\hline $1.91 E+02$ & $3.90 E+02$ & $-1.53 E+03$ & & & \\
\hline $1.77 E+02$ & $3.92 E+02$ & $-1.53 E+03$ & & & \\
\hline $1.60 E+02$ & $3.93 E+02$ & $-1.53 E+03$ & & & \\
\hline $1.44 E+02$ & $3.95 E+02$ & $-1.52 E+03$ & & & \\
\hline $1.31 E+02$ & $3.97 E+02$ & $-1.52 E+03$ & & & \\
\hline $1.22 E+02$ & $3.98 E+02$ & $-1.52 E+03$ & & & \\
\hline $1.10 E+02$ & $4.00 E+02$ & $-1.52 E+03$ & & & \\
\hline $9.64 E+01$ & $4.01 E+02$ & $-1.52 E+03$ & & & \\
\hline $8.11 E+01$ & $4.03 E+02$ & $-1.52 E+03$ & & & \\
\hline $7.08 E+01$ & $4.05 E+02$ & $-1.52 E+03$ & & & \\
\hline $5.75 E+01$ & $4.06 E+02$ & $-1.52 E+03$ & & & \\
\hline $4.73 E+01$ & $4.07 E+02$ & $-1.52 E+03$ & & & \\
\hline $3.91 E+01$ & $4.08 E+02$ & $-1.52 E+03$ & & & \\
\hline $2.33 E+02$ & $6.14 E+02$ & $-1.38 E+03$ & & & \\
\hline $1.98 E+02$ & $1.78 E+02$ & $-1.54 E+03$ & & & \\
\hline $1.99 E+02$ & $3.90 E+02$ & $-1.52 E+03$ & & & \\
\hline$-3.61 E+01$ & $2.45 E+02$ & $-1.51 E+03$ & & & \\
\hline $2.86 E+01$ & $4.07 E+02$ & $-1.51 E+03$ & & & \\
\hline $1.93 E+02$ & $1.79 E+02$ & $-1.54 E+03$ & & & \\
\hline $1.58 E+02$ & $1.80 E+02$ & $-1.54 E+03$ & & & \\
\hline
\end{tabular}


Experiment 4

Table C-0-4:Data for Experiment 4.

\begin{tabular}{|c|c|c|c|c|c|}
\hline X-Cord. & Y-Cord. & Z-Cord. & X-Cord. & Y-Cord. & Z-Cord. \\
\hline $2.18 \mathrm{E}+02$ & $2.92 \mathrm{E}+02$ & $-1.55 E+03$ & $3.45 \mathrm{E}+01$ & $9.20 \mathrm{E}+01$ & $-1.54 \mathrm{E}+03$ \\
\hline $2.05 E+02$ & $2.92 \mathrm{E}+02$ & $-1.54 \mathrm{E}+03$ & $2.82 \mathrm{E}+01$ & $9.33 \mathrm{E}+01$ & $-1.54 \mathrm{E}+03$ \\
\hline $1.89 \mathrm{E}+02$ & $2.92 \mathrm{E}+02$ & $-1.54 \mathrm{E}+03$ & $2.30 \mathrm{E}+01$ & $9.48 \mathrm{E}+01$ & $-1.53 E+03$ \\
\hline $1.80 \mathrm{E}+02$ & $2.92 \mathrm{E}+02$ & $-1.53 E+03$ & $2.20 \mathrm{E}+02$ & $2.92 \mathrm{E}+02$ & $-1.55 E+03$ \\
\hline $1.60 \mathrm{E}+02$ & $2.92 \mathrm{E}+02$ & $-1.53 E+03$ & $2.06 \mathrm{E}+02$ & $2.92 \mathrm{E}+02$ & $-1.55 E+03$ \\
\hline $1.52 \mathrm{E}+02$ & $2.91 \mathrm{E}+02$ & $-1.53 E+03$ & $1.93 \mathrm{E}+02$ & $2.92 \mathrm{E}+02$ & $-1.54 \mathrm{E}+03$ \\
\hline $1.41 \mathrm{E}+02$ & $2.91 \mathrm{E}+02$ & $-1.53 E+03$ & $1.78 \mathrm{E}+02$ & $2.92 \mathrm{E}+02$ & $-1.55 \mathrm{E}+03$ \\
\hline $1.29 E+02$ & $2.90 \mathrm{E}+02$ & $-1.54 \mathrm{E}+03$ & $1.62 \mathrm{E}+02$ & $2.92 \mathrm{E}+02$ & $-1.54 \mathrm{E}+03$ \\
\hline 1.19E+02 & $2.89 \mathrm{E}+02$ & $-1.54 \mathrm{E}+03$ & $1.49 \mathrm{E}+02$ & $2.91 E+02$ & $-1.54 \mathrm{E}+03$ \\
\hline $1.12 \mathrm{E}+02$ & $2.88 \mathrm{E}+02$ & $-1.54 \mathrm{E}+03$ & $1.30 \mathrm{E}+02$ & $2.90 E+02$ & $-1.54 \mathrm{E}+03$ \\
\hline $1.02 \mathrm{E}+02$ & $2.87 \mathrm{E}+02$ & $-1.54 \mathrm{E}+03$ & $1.14 \mathrm{E}+02$ & $2.88 \mathrm{E}+02$ & $-1.54 \mathrm{E}+03$ \\
\hline $8.29 E+01$ & $2.85 \mathrm{E}+02$ & $-1.54 \mathrm{E}+03$ & $8.79 \mathrm{E}+01$ & $2.86 \mathrm{E}+02$ & $-1.54 \mathrm{E}+03$ \\
\hline $7.23 \mathrm{E}+01$ & $2.83 \mathrm{E}+02$ & $-1.53 E+03$ & $8.96 \mathrm{E}+01$ & $2.86 \mathrm{E}+02$ & $3 E+03$ \\
\hline $6.22 \mathrm{E}+01$ & $2.81 \mathrm{E}+02$ & $-1.53 E+03$ & $7.94 \mathrm{E}+01$ & $2.84 \mathrm{E}+02$ & $-1.53 \mathrm{E}+03$ \\
\hline $5.39 \mathrm{E}+01$ & $2.80 \mathrm{E}+02$ & $-1.53 \mathrm{E}+03$ & $4.61 \mathrm{E}+01$ & $2.78 \mathrm{E}+02$ & $-1.54 \mathrm{E}+03$ \\
\hline $4.68 \mathrm{E}+01$ & $2.78 \mathrm{E}+02$ & $-1.53 E+03$ & $3.89 \mathrm{E}+01$ & $2.77 \mathrm{E}+02$ & $-1.53 \mathrm{E}+03$ \\
\hline$=01$ & & 03 & +01 & & 03 \\
\hline $2.60 \mathrm{E}+02$ & $5.27 \mathrm{E}+02$ & $-1.42 E+03$ & $2.24 \mathrm{E}+01$ & $2.71 E+02$ & $-1.53 E+03$ \\
\hline $2.28 \mathrm{E}+02$ & $8.04 \mathrm{E}+01$ & $-1.56 \mathrm{E}+03$ & $2.60 \mathrm{E}+02$ & $5.27 \mathrm{E}+02$ & $-1.42 \mathrm{E}+03$ \\
\hline $2.29 E+02$ & $2.92 \mathrm{E}+02$ & $-1.55 \mathrm{E}+03$ & $2.28 \mathrm{E}+02$ & $8.08 \mathrm{E}+01$ & $-1.56 \mathrm{E}+03$ \\
\hline $2.22 \mathrm{E}+01$ & $9.56 \mathrm{E}+01$ & $-1.53 E+03$ & $2.30 \mathrm{E}+02$ & $2.93 \mathrm{E}+02$ & $-1.55 \mathrm{E}+03$ \\
\hline $1.86 \mathrm{E}+01$ & $2.71 \mathrm{E}+02$ & $-1.53 E+03$ & $1.88 \mathrm{E}+01$ & $9.74 \mathrm{E}+01$ & $-1.53 \mathrm{E}+03$ \\
\hline $2.19 \mathrm{E}+02$ & $8.03 \mathrm{E}+01$ & $-1.56 \mathrm{E}+03$ & $1.51 \mathrm{E}+01$ & $2.70 \mathrm{E}+02$ & $-1.53 \mathrm{E}+03$ \\
\hline $2.07 E+02$ & $8.02 \mathrm{E}+01$ & $-1.56 \mathrm{E}+03$ & $2.18 \mathrm{E}+02$ & $8.05 E+01$ & $-1.56 \mathrm{E}+03$ \\
\hline $1.95 \mathrm{E}+02$ & $7.96 \mathrm{E}+01$ & $-1.56 \mathrm{E}+03$ & $2.09 \mathrm{E}+02$ & $8.04 \mathrm{E}+01$ & $-1.56 \mathrm{E}+03$ \\
\hline $1.74 \mathrm{E}+02$ & $7.98 \mathrm{E}+01$ & $-1.55 \mathrm{E}+03$ & $1.94 \mathrm{E}+02$ & $8.00 \mathrm{E}+01$ & $-1.55 \mathrm{E}+03$ \\
\hline $1.66 \mathrm{E}+02$ & $7.93 \mathrm{E}+01$ & $-1.56 \mathrm{E}+03$ & $1.81 \mathrm{E}+02$ & $7.97 \mathrm{E}+01$ & $-1.55 \mathrm{E}+03$ \\
\hline $1.50 \mathrm{E}+02$ & $7.96 \mathrm{E}+01$ & $-1.55 E+03$ & $1.63 \mathrm{E}+02$ & $7.92 \mathrm{E}+01$ & $-1.56 \mathrm{E}+03$ \\
\hline $1.37 \mathrm{E}+02$ & 7.97E+01 & $-1.55 \mathrm{E}+03$ & $1.47 \mathrm{E}+02$ & $7.94 \mathrm{E}+01$ & $-1.55 \mathrm{E}+03$ \\
\hline $1.25 \mathrm{E}+02$ & $8.01 \mathrm{E}+01$ & $-1.55 \mathrm{E}+03$ & $1.36 \mathrm{E}+02$ & $7.98 \mathrm{E}+01$ & $-1.55 E+03$ \\
\hline $1.11 \mathrm{E}+02$ & $8.11 \mathrm{E}+01$ & $-1.55 E+03$ & $1.22 \mathrm{E}+02$ & $8.06 \mathrm{E}+01$ & $-1.55 E+03$ \\
\hline $9.39 E+01$ & $8.29 E+01$ & $-1.54 \mathrm{E}+03$ & $1.08 \mathrm{E}+02$ & $8.12 \mathrm{E}+01$ & $-1.55 E+03$ \\
\hline $8.25 \mathrm{E}+01$ & $8.38 \mathrm{E}+01$ & $-1.54 \mathrm{E}+03$ & $1.03 \mathrm{E}+02$ & $8.18 \mathrm{E}+01$ & $-1.55 E+03$ \\
\hline $6.99 E+01$ & $8.58 \mathrm{E}+01$ & $-1.54 \mathrm{E}+03$ & $6.98 \mathrm{E}+01$ & $8.44 \mathrm{E}+01$ & $-1.54 \mathrm{E}+03$ \\
\hline $5.41 E+01$ & $8.82 E+01$ & $-1.54 \mathrm{E}+03$ & $6.09 \mathrm{E}+01$ & $8.56 \mathrm{E}+01$ & $-1.54 \mathrm{E}+03$ \\
\hline
\end{tabular}




\begin{tabular}{|c|c|c|c|c|c|}
\hline X-Cord. & Y-Cord. & Z-Cord. & X-Cord. & Y-Cord. & Z-Cord. \\
\hline $4.26 \mathrm{E}+01$ & $8.93 E+01$ & $-1.53 E+03$ & $8.91 \mathrm{E}+01$ & $8.51 \mathrm{E}+01$ & $-1.55 E+03$ \\
\hline $3.73 \mathrm{E}+01$ & $9.02 \mathrm{E}+01$ & $-1.53 \mathrm{E}+03$ & $8.34 \mathrm{E}+01$ & $8.59 \mathrm{E}+01$ & $-1.55 \mathrm{E}+03$ \\
\hline $3.06 \mathrm{E}+01$ & $9.21 \mathrm{E}+01$ & $-1.53 E+03$ & $5.82 E+01$ & $8.87 \mathrm{E}+01$ & $-1.54 \mathrm{E}+03$ \\
\hline $2.73 \mathrm{E}+01$ & $9.26 \mathrm{E}+01$ & $-1.53 \mathrm{E}+03$ & $5.32 \mathrm{E}+01$ & $8.95 \mathrm{E}+01$ & $-1.54 \mathrm{E}+03$ \\
\hline $2.21 E+02$ & $2.92 \mathrm{E}+02$ & $-1.56 \mathrm{E}+03$ & $4.49 E+01$ & $9.24 \mathrm{E}+01$ & $-1.54 \mathrm{E}+03$ \\
\hline $2.11 \mathrm{E}+02$ & $2.93 \mathrm{E}+02$ & $-1.55 E+03$ & $2.79 \mathrm{E}+01$ & $9.72 \mathrm{E}+01$ & $-1.53 \mathrm{E}+03$ \\
\hline $1.96 \mathrm{E}+02$ & $2.93 \mathrm{E}+02$ & $-1.56 \mathrm{E}+03$ & $2.22 \mathrm{E}+01$ & $9.85 \mathrm{E}+01$ & $-1.53 E+03$ \\
\hline $1.79 E+02$ & $2.93 E+02$ & $-1.55 E+03$ & $1.64 \mathrm{E}+01$ & $1.00 \mathrm{E}+02$ & $-1.53 E+03$ \\
\hline $1.60 \mathrm{E}+02$ & $2.93 \mathrm{E}+02$ & $-1.55 E+03$ & $2.17 E+02$ & $2.93 \mathrm{E}+02$ & $-1.56 \mathrm{E}+03$ \\
\hline $1.44 \mathrm{E}+02$ & $2.93 \mathrm{E}+02$ & $-1.55 E+03$ & $2.11 E+02$ & $2.93 \mathrm{E}+02$ & $-1.56 \mathrm{E}+03$ \\
\hline $1.30 \mathrm{E}+02$ & $2.93 E+02$ & $-1.55 E+03$ & $1.99 E+02$ & $2.93 \mathrm{E}+02$ & $-1.55 E+03$ \\
\hline $1.10 \mathrm{E}+02$ & $2.93 E+02$ & $-1.54 \mathrm{E}+03$ & $1.72 \mathrm{E}+02$ & $2.93 E+02$ & $-1.55 E+03$ \\
\hline $8.35 E+01$ & $2.91 \mathrm{E}+02$ & $-1.54 \mathrm{E}+03$ & $1.59 E+02$ & $2.93 \mathrm{E}+02$ & $-1.55 E+03$ \\
\hline $6.65 E+01$ & $2.91 E+02$ & $-1.54 \mathrm{E}+03$ & $1.47 \mathrm{E}+02$ & $2.94 \mathrm{E}+02$ & $-1.55 E+03$ \\
\hline $5.41 E+01$ & $2.89 E+02$ & $-1.54 \mathrm{E}+03$ & $1.31 \mathrm{E}+02$ & $2.94 \mathrm{E}+02$ & $-1.55 E+03$ \\
\hline $4.47 \mathrm{E}+01$ & $2.88 \mathrm{E}+02$ & $-1.54 \mathrm{E}+03$ & $1.10 \mathrm{E}+02$ & $2.93 \mathrm{E}+02$ & $-1.55 E+03$ \\
\hline $3.67 E+01$ & $2.87 E+02$ & $-1.54 \mathrm{E}+03$ & $8.44 \mathrm{E}+01$ & $2.92 \mathrm{E}+02$ & $-1.54 \mathrm{E}+03$ \\
\hline $2.87 E+01$ & $2.85 \mathrm{E}+02$ & $-1.54 \mathrm{E}+03$ & $8.00 E+01$ & $2.92 \mathrm{E}+02$ & $-1.54 \mathrm{E}+03$ \\
\hline $1.97 \mathrm{E}+01$ & $2.83 E+02$ & $-1.54 \mathrm{E}+03$ & $6.72 \mathrm{E}+01$ & $2.91 \mathrm{E}+02$ & $-1.54 \mathrm{E}+03$ \\
\hline $2.60 E+02$ & $5.27 \mathrm{E}+02$ & $-1.42 \mathrm{E}+03$ & $4.75 E+01$ & $2.88 \mathrm{E}+02$ & $-1.53 E+03$ \\
\hline $2.28 \mathrm{E}+02$ & $8.08 \mathrm{E}+01$ & $-1.56 \mathrm{E}+03$ & $3.88 \mathrm{E}+01$ & $2.87 \mathrm{E}+02$ & $-1.53 E+03$ \\
\hline $2.26 \mathrm{E}+02$ & $2.91 E+02$ & $-1.58 \mathrm{E}+03$ & $2.74 \mathrm{E}+01$ & $2.84 \mathrm{E}+02$ & $-1.53 E+03$ \\
\hline$-1.81 \mathrm{E}+00$ & $1.09 \mathrm{E}+02$ & $-1.53 \mathrm{E}+03$ & $2.60 \mathrm{E}+02$ & $5.27 \mathrm{E}+02$ & $-1.42 \mathrm{E}+03$ \\
\hline $1.21 \mathrm{E}+01$ & $2.82 \mathrm{E}+02$ & $-1.53 E+03$ & $2.28 \mathrm{E}+02$ & $8.08 \mathrm{E}+01$ & $-1.56 \mathrm{E}+03$ \\
\hline $2.23 E+02$ & $8.11 E+01$ & $-1.56 \mathrm{E}+03$ & $2.26 \mathrm{E}+02$ & $2.91 \mathrm{E}+02$ & $-1.58 \mathrm{E}+03$ \\
\hline $2.14 \mathrm{E}+02$ & $8.10 E+01$ & $-1.56 \mathrm{E}+03$ & $-1.28 \mathrm{E}+00$ & $1.08 \mathrm{E}+02$ & $-1.53 E+03$ \\
\hline $2.03 E+02$ & $8.09 E+01$ & $-1.56 \mathrm{E}+03$ & $1.58 \mathrm{E}+01$ & $2.83 \mathrm{E}+02$ & $-1.53 E+03$ \\
\hline $1.93 \mathrm{E}+02$ & $8.08 \mathrm{E}+01$ & $-1.56 \mathrm{E}+03$ & $2.24 \mathrm{E}+02$ & $8.11 E+01$ & $-1.56 E+03$ \\
\hline $1.82 \mathrm{E}+02$ & $8.09 E+01$ & $-1.56 \mathrm{E}+03$ & $2.04 \mathrm{E}+02$ & $8.06 \mathrm{E}+01$ & $-1.55 \mathrm{E}+03$ \\
\hline $1.69 \mathrm{E}+02$ & $8.11 E+01$ & $-1.56 \mathrm{E}+03$ & $1.93 \mathrm{E}+02$ & $8.05 \mathrm{E}+01$ & $-1.55 E+03$ \\
\hline $1.57 \mathrm{E}+02$ & $8.13 E+01$ & $-1.55 E+03$ & $1.76 \mathrm{E}+02$ & $8.03 \mathrm{E}+01$ & $-1.55 \mathrm{E}+03$ \\
\hline $1.34 \mathrm{E}+02$ & $8.25 E+01$ & $-1.55 \mathrm{E}+03$ & $1.65 \mathrm{E}+02$ & $8.03 E+01$ & $-1.55 E+03$ \\
\hline $1.23 \mathrm{E}+02$ & $8.29 E+01$ & $-1.55 E+03$ & $1.57 \mathrm{E}+02$ & $7.99 \mathrm{E}+01$ & $-1.55 \mathrm{E}+03$ \\
\hline $1.12 \mathrm{E}+02$ & $8.37 \mathrm{E}+01$ & $-1.55 E+03$ & $1.42 \mathrm{E}+02$ & $8.01 \mathrm{E}+01$ & $-1.55 E+03$ \\
\hline $9.60 \mathrm{E}+01$ & $8.50 E+01$ & $-1.55 E+03$ & $1.31 E+02$ & $8.04 \mathrm{E}+01$ & $-1.55 E+03$ \\
\hline
\end{tabular}




\begin{tabular}{|c|c|c|c|c|c|}
\hline X-Cord. & Y-Cord. & Z-Cord. & X-Cord. & Y-Cord. & Z-Cord. \\
\hline $1.21 \mathrm{E}+02$ & $8.09 \mathrm{E}+01$ & $-1.55 E+03$ & $1.99 \mathrm{E}+02$ & $8.10 E+01$ & $-1.55 E+03$ \\
\hline $1.11 \mathrm{E}+02$ & $8.15 \mathrm{E}+01$ & $-1.55 \mathrm{E}+03$ & $1.87 \mathrm{E}+02$ & $8.12 \mathrm{E}+01$ & $-1.55 \mathrm{E}+03$ \\
\hline $9.81 \mathrm{E}+01$ & $8.25 E+01$ & $-1.55 E+03$ & $1.64 \mathrm{E}+02$ & $8.18 \mathrm{E}+01$ & $-1.55 \mathrm{E}+03$ \\
\hline $8.38 \mathrm{E}+01$ & $8.42 \mathrm{E}+01$ & $-1.55 \mathrm{E}+03$ & $1.56 \mathrm{E}+02$ & $8.16 \mathrm{E}+01$ & $-1.56 \mathrm{E}+03$ \\
\hline $7.48 \mathrm{E}+01$ & $8.53 \mathrm{E}+01$ & $-1.55 E+03$ & $1.43 \mathrm{E}+02$ & $8.27 \mathrm{E}+01$ & $-1.55 \mathrm{E}+03$ \\
\hline $6.27 \mathrm{E}+01$ & $8.74 \mathrm{E}+01$ & $-1.55 \mathrm{E}+03$ & $1.29 \mathrm{E}+02$ & $8.37 \mathrm{E}+01$ & $-1.55 \mathrm{E}+03$ \\
\hline $5.21 \mathrm{E}+01$ & $8.95 \mathrm{E}+01$ & $-1.54 \mathrm{E}+03$ & $1.15 \mathrm{E}+02$ & $8.52 \mathrm{E}+01$ & $-1.55 E+03$ \\
\hline $3.50 \mathrm{E}+01$ & $9.27 \mathrm{E}+01$ & $-1.55 E+03$ & $1.02 \mathrm{E}+02$ & $8.70 \mathrm{E}+01$ & $-1.55 \mathrm{E}+03$ \\
\hline $2.81 \mathrm{E}+01$ & $9.40 \mathrm{E}+01$ & $-1.54 \mathrm{E}+03$ & $8.02 E+01$ & $9.09 \mathrm{E}+01$ & $-1.54 \mathrm{E}+03$ \\
\hline $1.99 \mathrm{E}+01$ & $9.55 \mathrm{E}+01$ & $-1.54 \mathrm{E}+03$ & $7.37 \mathrm{E}+01$ & $9.19 \mathrm{E}+01$ & $-1.54 \mathrm{E}+03$ \\
\hline $5.59 E+00$ & $1.00 \mathrm{E}+02$ & $-1.54 \mathrm{E}+03$ & $6.10 \mathrm{E}+01$ & $9.47 \mathrm{E}+01$ & $-1.54 \mathrm{E}+03$ \\
\hline $2.19 \mathrm{E}+00$ & $1.02 \mathrm{E}+02$ & $-1.54 \mathrm{E}+03$ & $5.12 \mathrm{E}+01$ & $9.74 \mathrm{E}+01$ & $-1.54 \mathrm{E}+03$ \\
\hline $2.16 \mathrm{E}+02$ & $2.93 \mathrm{E}+02$ & $-1.56 \mathrm{E}+03$ & $3.09 E+01$ & $1.03 E+02$ & $-1.54 \mathrm{E}+03$ \\
\hline $2.05 \mathrm{E}+02$ & $2.93 \mathrm{E}+02$ & $-1.56 E+03$ & $2.16 \mathrm{E}+01$ & $1.06 \mathrm{E}+02$ & $-1.54 \mathrm{E}+03$ \\
\hline $1.92 \mathrm{E}+02$ & $2.94 \mathrm{E}+02$ & $-1.56 \mathrm{E}+03$ & $1.34 \mathrm{E}+01$ & $1.09 \mathrm{E}+02$ & $-1.54 \mathrm{E}+03$ \\
\hline $1.75 \mathrm{E}+02$ & $2.94 \mathrm{E}+02$ & $-1.56 \mathrm{E}+03$ & $6.52 \mathrm{E}+00$ & $1.12 \mathrm{E}+02$ & $-1.54 \mathrm{E}+03$ \\
\hline $1.61 \mathrm{E}+02$ & $2.95 \mathrm{E}+02$ & $-1.56 \mathrm{E}+03$ & $3.21 \mathrm{E}-01$ & $1.15 \mathrm{E}+02$ & $-1.54 \mathrm{E}+03$ \\
\hline $1.45 \mathrm{E}+02$ & $2.96 \mathrm{E}+02$ & $-1.56 \mathrm{E}+03$ & $-3.39 E+00$ & $1.16 \mathrm{E}+02$ & $-1.54 \mathrm{E}+03$ \\
\hline $1.29 E+02$ & $2.96 \mathrm{E}+02$ & $-1.55 E+03$ & $-7.53 E+00$ & $1.18 \mathrm{E}+02$ & $-1.54 \mathrm{E}+03$ \\
\hline $1.14 \mathrm{E}+02$ & $2.97 \mathrm{E}+02$ & $-1.54 \mathrm{E}+03$ & $-1.29 \mathrm{E}+01$ & $1.21 \mathrm{E}+02$ & $-1.54 \mathrm{E}+03$ \\
\hline $1.00 \mathrm{E}+02$ & $2.97 \mathrm{E}+02$ & $-1.54 \mathrm{E}+03$ & $2.12 \mathrm{E}+02$ & $2.93 E+02$ & $-1.56 \mathrm{E}+03$ \\
\hline $7.98 \mathrm{E}+01$ & $2.97 \mathrm{E}+02$ & $-1.54 \mathrm{E}+03$ & $1.98 \mathrm{E}+02$ & $2.93 \mathrm{E}+02$ & $-1.56 \mathrm{E}+03$ \\
\hline $6.92 \mathrm{E}+01$ & $2.97 \mathrm{E}+02$ & $-1.54 \mathrm{E}+03$ & $1.87 \mathrm{E}+02$ & $2.94 \mathrm{E}+02$ & $-1.56 \mathrm{E}+03$ \\
\hline $6.12 \mathrm{E}+01$ & $2.96 \mathrm{E}+02$ & $-1.54 \mathrm{E}+03$ & $1.77 \mathrm{E}+02$ & $2.95 \mathrm{E}+02$ & $-1.55 E+03$ \\
\hline $5.25 \mathrm{E}+01$ & $2.96 \mathrm{E}+02$ & $-1.54 \mathrm{E}+03$ & $1.62 \mathrm{E}+02$ & $2.95 \mathrm{E}+02$ & $-1.55 \mathrm{E}+03$ \\
\hline $3.95 E+01$ & $2.96 \mathrm{E}+02$ & $-1.54 \mathrm{E}+03$ & $1.46 \mathrm{E}+02$ & $2.95 \mathrm{E}+02$ & $-1.55 \mathrm{E}+03$ \\
\hline $3.01 \mathrm{E}+01$ & $2.95 \mathrm{E}+02$ & $-1.53 \mathrm{E}+03$ & $1.35 \mathrm{E}+02$ & $2.96 \mathrm{E}+02$ & $-1.55 \mathrm{E}+03$ \\
\hline $2.34 \mathrm{E}+01$ & $2.94 \mathrm{E}+02$ & $-1.53 E+03$ & $1.19 E+02$ & $2.96 \mathrm{E}+02$ & $-1.55 E+03$ \\
\hline $2.60 \mathrm{E}+02$ & $5.27 \mathrm{E}+02$ & $-1.42 \mathrm{E}+03$ & $1.04 \mathrm{E}+02$ & $2.97 \mathrm{E}+02$ & $-1.54 \mathrm{E}+03$ \\
\hline $2.28 \mathrm{E}+02$ & $8.09 \mathrm{E}+01$ & $-1.56 \mathrm{E}+03$ & $8.86 \mathrm{E}+01$ & $2.97 \mathrm{E}+02$ & $-1.54 \mathrm{E}+03$ \\
\hline $2.25 \mathrm{E}+02$ & $2.91 \mathrm{E}+02$ & $-1.58 \mathrm{E}+03$ & $7.32 \mathrm{E}+01$ & $2.97 \mathrm{E}+02$ & $-1.54 \mathrm{E}+03$ \\
\hline$-1.57 \mathrm{E}+01$ & $1.21 \mathrm{E}+02$ & $-1.53 E+03$ & $5.60 \mathrm{E}+01$ & $2.96 \mathrm{E}+02$ & $-1.54 \mathrm{E}+03$ \\
\hline $1.42 \mathrm{E}+01$ & $2.93 \mathrm{E}+02$ & $-1.53 \mathrm{E}+03$ & $3.16 \mathrm{E}+01$ & $2.94 \mathrm{E}+02$ & $-1.53 \mathrm{E}+03$ \\
\hline $2.27 \mathrm{E}+02$ & $8.14 \mathrm{E}+01$ & $-1.55 \mathrm{E}+03$ & $2.60 \mathrm{E}+02$ & $5.27 \mathrm{E}+02$ & $-1.42 \mathrm{E}+03$ \\
\hline $2.13 E+02$ & $8.12 \mathrm{E}+01$ & $-1.55 E+03$ & $2.29 \mathrm{E}+02$ & $8.13 E+01$ & $-1.55 E+03$ \\
\hline
\end{tabular}




\begin{tabular}{|c|c|c|c|c|c|}
\hline X-Cord. & Y-Cord. & Z-Cord. & X-Cord. & Y-Cord. & Z-Cord. \\
\hline $2.25 E+02$ & $2.91 \mathrm{E}+02$ & $-1.58 \mathrm{E}+03$ & $2.60 E+02$ & $5.26 \mathrm{E}+02$ & $-1.42 \mathrm{E}+03$ \\
\hline$-1.86 \mathrm{E}+01$ & $1.23 E+02$ & $-1.53 E+03$ & $2.29 E+02$ & $8.14 E+01$ & $-1.55 E+03$ \\
\hline $1.51 \mathrm{E}+01$ & $2.94 \mathrm{E}+02$ & $-1.53 \mathrm{E}+03$ & $2.29 \mathrm{E}+02$ & $2.93 E+02$ & $-1.55 \mathrm{E}+03$ \\
\hline $2.24 \mathrm{E}+02$ & $8.09 \mathrm{E}+01$ & $-1.56 \mathrm{E}+03$ & $-3.52 E+01$ & $1.38 \mathrm{E}+02$ & $-1.52 E+03$ \\
\hline $2.12 \mathrm{E}+02$ & $8.09 \mathrm{E}+01$ & $-1.56 \mathrm{E}+03$ & $1.31 \mathrm{E}+01$ & $3.06 \mathrm{E}+02$ & $-1.53 E+03$ \\
\hline $1.99 E+02$ & $8.08 \mathrm{E}+01$ & $-1.56 \mathrm{E}+03$ & $2.27 E+02$ & $8.11 E+01$ & $-1.56 \mathrm{E}+03$ \\
\hline $1.87 \mathrm{E}+02$ & $8.11 \mathrm{E}+01$ & $-1.55 \mathrm{E}+03$ & $2.14 \mathrm{E}+02$ & $8.08 \mathrm{E}+01$ & $-1.55 \mathrm{E}+03$ \\
\hline $1.72 \mathrm{E}+02$ & $8.13 E+01$ & $-1.55 E+03$ & $1.98 \mathrm{E}+02$ & $8.08 \mathrm{E}+01$ & $-1.55 \mathrm{E}+03$ \\
\hline $1.57 \mathrm{E}+02$ & $8.19 \mathrm{E}+01$ & $-1.56 \mathrm{E}+03$ & $1.84 \mathrm{E}+02$ & $8.11 E+01$ & $-1.55 \mathrm{E}+03$ \\
\hline $1.42 \mathrm{E}+02$ & $8.28 \mathrm{E}+01$ & $-1.55 E+03$ & $1.69 E+02$ & $8.15 E+01$ & $-1.55 \mathrm{E}+03$ \\
\hline $1.27 \mathrm{E}+02$ & $8.40 \mathrm{E}+01$ & $-1.55 \mathrm{E}+03$ & $1.52 \mathrm{E}+02$ & $8.25 \mathrm{E}+01$ & $-1.55 \mathrm{E}+03$ \\
\hline $1.16 \mathrm{E}+02$ & $8.51 \mathrm{E}+01$ & $-1.55 E+03$ & $1.36 \mathrm{E}+02$ & $8.40 E+01$ & $-1.55 \mathrm{E}+03$ \\
\hline $9.19 \mathrm{E}+01$ & $8.86 \mathrm{E}+01$ & $-1.55 \mathrm{E}+03$ & $1.16 \mathrm{E}+02$ & $8.61 \mathrm{E}+01$ & $-1.55 \mathrm{E}+03$ \\
\hline $8.18 \mathrm{E}+01$ & $9.03 E+01$ & $-1.55 E+03$ & $9.38 \mathrm{E}+01$ & $9.03 E+01$ & $-1.54 \mathrm{E}+03$ \\
\hline $7.27 \mathrm{E}+01$ & $9.22 \mathrm{E}+01$ & $-1.55 \mathrm{E}+03$ & $7.70 \mathrm{E}+01$ & $9.42 \mathrm{E}+01$ & $-1.54 \mathrm{E}+03$ \\
\hline $6.22 \mathrm{E}+01$ & $9.42 \mathrm{E}+01$ & $-1.55 E+03$ & $6.80 \mathrm{E}+01$ & $9.59 E+01$ & $-1.54 \mathrm{E}+03$ \\
\hline $5.17 \mathrm{E}+01$ & $9.72 \mathrm{E}+01$ & $-1.55 \mathrm{E}+03$ & $5.07 \mathrm{E}+01$ & $.00 \mathrm{E}+02$ & $-1.54 \mathrm{E}+03$ \\
\hline $3.96 \mathrm{E}+01$ & $1.01 \mathrm{E}+02$ & $-1.54 \mathrm{E}+03$ & $3.07 E+01$ & $1.06 \mathrm{E}+02$ & $-1.54 \mathrm{E}+03$ \\
\hline $2.72 \mathrm{E}+01$ & $1.05 \mathrm{E}+02$ & $-1.54 \mathrm{E}+03$ & $2.44 \mathrm{E}+00$ & $1.19 \mathrm{E}+02$ & $-1.53 \mathrm{E}+03$ \\
\hline $1.72 \mathrm{E}+01$ & $1.08 \mathrm{E}+02$ & $-1.54 \mathrm{E}+03$ & $-4.58 \mathrm{E}+00$ & $1.22 \mathrm{E}+02$ & $-1.53 E+03$ \\
\hline $8.70 \mathrm{E}+00$ & $1.12 \mathrm{E}+02$ & $-1.54 \mathrm{E}+03$ & $-1.22 \mathrm{E}+01$ & $1.26 \mathrm{E}+02$ & $-1.53 E+03$ \\
\hline 2.39E-01 & $1.16 \mathrm{E}+02$ & $-1.54 \mathrm{E}+03$ & $-2.06 E+01$ & $1.31 \mathrm{E}+02$ & $-1.53 E+03$ \\
\hline$-9.31 E+00$ & $1.20 \mathrm{E}+02$ & $-1.53 \mathrm{E}+03$ & $-2.80 \mathrm{E}+01$ & $1.35 \mathrm{E}+02$ & $-1.53 E+03$ \\
\hline $2.22 \mathrm{E}+02$ & $2.93 \mathrm{E}+02$ & $-1.56 \mathrm{E}+03$ & $2.14 \mathrm{E}+02$ & $2.93 E+02$ & $-1.56 \mathrm{E}+03$ \\
\hline $2.12 \mathrm{E}+02$ & $2.93 \mathrm{E}+02$ & $-1.56 \mathrm{E}+03$ & $2.00 \mathrm{E}+02$ & $2.94 \mathrm{E}+02$ & $-1.56 \mathrm{E}+03$ \\
\hline $1.93 E+02$ & $2.95 \mathrm{E}+02$ & $-1.55 E+03$ & $1.86 \mathrm{E}+02$ & $2.95 \mathrm{E}+02$ & $-1.56 \mathrm{E}+03$ \\
\hline $1.75 \mathrm{E}+02$ & $2.96 \mathrm{E}+02$ & $-1.55 \mathrm{E}+03$ & $1.72 \mathrm{E}+02$ & $2.96 \mathrm{E}+02$ & $-1.56 \mathrm{E}+03$ \\
\hline $1.60 \mathrm{E}+02$ & $2.97 \mathrm{E}+02$ & $-1.55 \mathrm{E}+03$ & $1.56 \mathrm{E}+02$ & $2.97 \mathrm{E}+02$ & $-1.55 \mathrm{E}+03$ \\
\hline $1.43 E+02$ & $2.99 \mathrm{E}+02$ & $-1.55 \mathrm{E}+03$ & $1.27 E+02$ & $2.99 \mathrm{E}+02$ & $-1.55 E+03$ \\
\hline $1.26 \mathrm{E}+02$ & $3.00 \mathrm{E}+02$ & $-1.55 \mathrm{E}+03$ & $1.15 \mathrm{E}+02$ & $3.00 E+02$ & $-1.55 \mathrm{E}+03$ \\
\hline $1.10 \mathrm{E}+02$ & $3.02 \mathrm{E}+02$ & $-1.54 \mathrm{E}+03$ & $9.43 E+01$ & $3.02 E+02$ & $-1.55 E+03$ \\
\hline $9.39 E+01$ & $3.03 E+02$ & $-1.54 \mathrm{E}+03$ & $8.18 \mathrm{E}+01$ & $3.03 E+02$ & $-1.54 \mathrm{E}+03$ \\
\hline $7.55 \mathrm{E}+01$ & $3.03 E+02$ & $-1.54 \mathrm{E}+03$ & $7.10 \mathrm{E}+01$ & $3.04 \mathrm{E}+02$ & $-1.54 \mathrm{E}+03$ \\
\hline $5.81 \mathrm{E}+01$ & $3.04 \mathrm{E}+02$ & $-1.53 \mathrm{E}+03$ & $5.49 \mathrm{E}+01$ & $3.04 \mathrm{E}+02$ & $-1.54 \mathrm{E}+03$ \\
\hline $2.58 \mathrm{E}+01$ & $3.05 E+02$ & $-1.53 E+03$ & $4.15 E+01$ & $3.04 E+02$ & $-1.54 \mathrm{E}+03$ \\
\hline
\end{tabular}




\begin{tabular}{|c|c|c|c|c|c|}
\hline X-Cord. & Y-Cord. & Z-Cord. & X-Cord. & Y-Cord. & Z-Cord. \\
\hline $2.80 \mathrm{E}+01$ & $3.05 E+02$ & $-1.53 E+03$ & $4.10 \mathrm{E}+01$ & $3.11 E+02$ & $-1.54 \mathrm{E}+03$ \\
\hline $1.84 \mathrm{E}+01$ & $3.05 E+02$ & $-1.53 E+03$ & $2.96 \mathrm{E}+01$ & $3.12 E+02$ & $-1.53 E+03$ \\
\hline $2.60 \mathrm{E}+02$ & $5.27 \mathrm{E}+02$ & $-1.42 \mathrm{E}+03$ & $2.27 \mathrm{E}+01$ & $3.12 E+02$ & $-1.53 E+03$ \\
\hline $2.28 \mathrm{E}+02$ & $8.09 E+01$ & $-1.56 \mathrm{E}+03$ & $2.60 E+02$ & $5.26 \mathrm{E}+02$ & $-1.42 \mathrm{E}+03$ \\
\hline $2.27 \mathrm{E}+02$ & $2.92 \mathrm{E}+02$ & $-1.57 E+03$ & $2.28 \mathrm{E}+02$ & $8.07 E+01$ & $-1.56 \mathrm{E}+03$ \\
\hline$-3.53 E+01$ & $1.39 E+02$ & $-1.53 \mathrm{E}+03$ & $2.25 \mathrm{E}+02$ & $2.91 E+02$ & $-1.58 \mathrm{E}+03$ \\
\hline $1.36 \mathrm{E}+01$ & $3.06 \mathrm{E}+02$ & $-1.53 \mathrm{E}+03$ & $-4.95 \mathrm{E}+01$ & $1.54 \mathrm{E}+02$ & $-1.52 \mathrm{E}+03$ \\
\hline $2.25 \mathrm{E}+02$ & $8.09 E+01$ & $-1.56 \mathrm{E}+03$ & $1.37 \mathrm{E}+01$ & $3.16 \mathrm{E}+02$ & $-1.53 E+03$ \\
\hline $2.11 E+02$ & $8.07 E+01$ & $-1.56 \mathrm{E}+03$ & $2.25 \mathrm{E}+02$ & $8.08 \mathrm{E}+01$ & $-1.56 \mathrm{E}+03$ \\
\hline $1.94 \mathrm{E}+02$ & $8.09 E+01$ & $-1.55 E+03$ & $2.15 E+02$ & $8.06 E+01$ & $-1.55 \mathrm{E}+03$ \\
\hline $1.79 \mathrm{E}+02$ & $8.15 E+01$ & $-1.55 \mathrm{E}+03$ & $2.02 \mathrm{E}+02$ & $8.07 \mathrm{E}+01$ & $-1.55 \mathrm{E}+03$ \\
\hline $1.62 E+02$ & $8.22 E+01$ & $-1.55 E+03$ & $1.89 \mathrm{E}+02$ & $8.09 E+01$ & $-1.55 \mathrm{E}+03$ \\
\hline $1.45 \mathrm{E}+02$ & $8.36 \mathrm{E}+01$ & $-1.55 \mathrm{E}+03$ & $1.78 \mathrm{E}+02$ & $8.13 E+01$ & $-1.55 \mathrm{E}+03$ \\
\hline $1.26 \mathrm{E}+02$ & $8.54 \mathrm{E}+01$ & $-1.54 \mathrm{E}+03$ & $1.67 E+02$ & $8.18 \mathrm{E}+01$ & $-1.55 \mathrm{E}+03$ \\
\hline $1.09 \mathrm{E}+02$ & $8.73 \mathrm{E}+01$ & $-1.54 \mathrm{E}+03$ & $1.54 \mathrm{E}+02$ & $8.26 \mathrm{E}+01$ & $-1.55 \mathrm{E}+03$ \\
\hline $7.55 \mathrm{E}+01$ & $9.36 \mathrm{E}+01$ & $-1.54 \mathrm{E}+03$ & $1.42 \mathrm{E}+02$ & $8.36 \mathrm{E}+01$ & $-1.55 \mathrm{E}+03$ \\
\hline $6.16 \mathrm{E}+01$ & $9.72 \mathrm{E}+01$ & $-1.54 \mathrm{E}+03$ & $1.28 \mathrm{E}+02$ & $.52 \mathrm{E}+01$ & $-1.55 \mathrm{E}+03$ \\
\hline $5.01 \mathrm{E}+01$ & $1.01 E+02$ & $-1.54 \mathrm{E}+03$ & $1.14 \mathrm{E}+02$ & $8.74 \mathrm{E}+01$ & $-1.55 \mathrm{E}+03$ \\
\hline $4.02 \mathrm{E}+01$ & $1.03 E+02$ & $-1.54 \mathrm{E}+03$ & $1.02 \mathrm{E}+02$ & $8.98 \mathrm{E}+01$ & $-1.55 \mathrm{E}+03$ \\
\hline $3.21 E+01$ & $1.06 \mathrm{E}+02$ & $-1.54 \mathrm{E}+03$ & $9.06 \mathrm{E}+01$ & $9.19 E+01$ & $-1.55 \mathrm{E}+03$ \\
\hline $3.31 \mathrm{E}+00$ & $1.17 \mathrm{E}+02$ & $-1.54 \mathrm{E}+03$ & $7.68 \mathrm{E}+01$ & $9.53 \mathrm{E}+01$ & $-1.55 E+03$ \\
\hline$-1.37 E+01$ & $1.26 \mathrm{E}+02$ & $-1.53 E+03$ & $6.19 E+01$ & $9.94 \mathrm{E}+01$ & $-1.54 \mathrm{E}+03$ \\
\hline$-2.35 E+01$ & $1.32 \mathrm{E}+02$ & $-1.53 \mathrm{E}+03$ & $4.97 \mathrm{E}+01$ & $1.03 E+02$ & $-1.54 \mathrm{E}+03$ \\
\hline $2.13 E+02$ & $2.94 \mathrm{E}+02$ & $-1.56 \mathrm{E}+03$ & $4.23 E+01$ & $1.06 \mathrm{E}+02$ & $-1.54 \mathrm{E}+03$ \\
\hline $2.03 E+02$ & $2.94 \mathrm{E}+02$ & $-1.56 \mathrm{E}+03$ & $3.50 \mathrm{E}+01$ & $1.09 \mathrm{E}+02$ & $-1.54 \mathrm{E}+03$ \\
\hline $1.91 \mathrm{E}+02$ & $2.95 \mathrm{E}+02$ & $-1.56 \mathrm{E}+03$ & $2.72 \mathrm{E}+01$ & $1.12 \mathrm{E}+02$ & $-1.54 \mathrm{E}+03$ \\
\hline $1.74 \mathrm{E}+02$ & $2.97 E+02$ & $-1.56 \mathrm{E}+03$ & $1.81 \mathrm{E}+01$ & $1.16 \mathrm{E}+02$ & $-1.54 \mathrm{E}+03$ \\
\hline $1.42 \mathrm{E}+02$ & $3.00 E+02$ & $-1.55 \mathrm{E}+03$ & $9.74 \mathrm{E}+00$ & $1.19 \mathrm{E}+02$ & $-1.54 \mathrm{E}+03$ \\
\hline $1.31 \mathrm{E}+02$ & $3.01 E+02$ & $-1.55 \mathrm{E}+03$ & $3.16 \mathrm{E}+00$ & $1.23 \mathrm{E}+02$ & $-1.54 \mathrm{E}+03$ \\
\hline $1.18 \mathrm{E}+02$ & $3.03 E+02$ & $-1.55 \mathrm{E}+03$ & $-1.07 E+01$ & $1.30 \mathrm{E}+02$ & $-1.54 \mathrm{E}+03$ \\
\hline $1.00 \mathrm{E}+02$ & $3.05 E+02$ & $-1.55 \mathrm{E}+03$ & $-1.63 \mathrm{E}+01$ & $1.34 \mathrm{E}+02$ & $-1.54 \mathrm{E}+03$ \\
\hline $8.43 E+01$ & $3.07 E+02$ & $-1.54 \mathrm{E}+03$ & $-1.90 \mathrm{E}+01$ & $1.35 \mathrm{E}+02$ & $-1.54 \mathrm{E}+03$ \\
\hline $7.26 \mathrm{E}+01$ & $3.08 \mathrm{E}+02$ & $-1.54 \mathrm{E}+03$ & $-2.35 \mathrm{E}+01$ & $1.38 \mathrm{E}+02$ & $-1.54 \mathrm{E}+03$ \\
\hline $5.80 \mathrm{E}+01$ & $3.10 E+02$ & $-1.54 \mathrm{E}+03$ & $-3.03 E+01$ & $1.42 \mathrm{E}+02$ & $-1.53 E+03$ \\
\hline $4.95 E+01$ & $3.11 E+02$ & $-1.54 \mathrm{E}+03$ & $-3.79 E+01$ & $1.47 \mathrm{E}+02$ & $-1.53 E+03$ \\
\hline
\end{tabular}




\begin{tabular}{|c|c|c|c|c|c|}
\hline X-Cord. & Y-Cord. & Z-Cord. & X-Cord. & Y-Cord. & Z-Cord. \\
\hline $2.17 \mathrm{E}+02$ & $2.93 \mathrm{E}+02$ & $-1.56 \mathrm{E}+03$ & $-2.28 \mathrm{E}+00$ & $1.25 \mathrm{E}+02$ & $-1.53 E+03$ \\
\hline $2.04 \mathrm{E}+02$ & $2.94 \mathrm{E}+02$ & $-1.56 \mathrm{E}+03$ & $-1.74 \mathrm{E}+01$ & $1.33 \mathrm{E}+02$ & $-1.53 \mathrm{E}+03$ \\
\hline $1.87 \mathrm{E}+02$ & $2.96 \mathrm{E}+02$ & $-1.56 E+03$ & $-2.64 \mathrm{E}+01$ & $1.38 \mathrm{E}+02$ & $-1.53 E+03$ \\
\hline $1.77 \mathrm{E}+02$ & $2.97 \mathrm{E}+02$ & $-1.56 \mathrm{E}+03$ & $-3.42 \mathrm{E}+01$ & $1.43 \mathrm{E}+02$ & $-1.53 \mathrm{E}+03$ \\
\hline $1.68 \mathrm{E}+02$ & $2.98 \mathrm{E}+02$ & $-1.56 \mathrm{E}+03$ & $-4.21 E+01$ & $1.46 \mathrm{E}+02$ & $-1.53 E+03$ \\
\hline $1.59 \mathrm{E}+02$ & $2.99 \mathrm{E}+02$ & $-1.56 \mathrm{E}+03$ & & & \\
\hline $1.47 \mathrm{E}+02$ & $3.01 \mathrm{E}+02$ & $-1.55 E+03$ & & & \\
\hline $1.32 \mathrm{E}+02$ & $3.02 \mathrm{E}+02$ & $-1.55 E+03$ & & & \\
\hline $1.06 \mathrm{E}+02$ & $3.05 E+02$ & $-1.55 E+03$ & & & \\
\hline $6.66 \mathrm{E}+01$ & $3.11 \mathrm{E}+02$ & $-1.54 \mathrm{E}+03$ & & & \\
\hline $5.55 \mathrm{E}+01$ & $3.12 \mathrm{E}+02$ & $-1.54 \mathrm{E}+03$ & & & \\
\hline $4.72 \mathrm{E}+01$ & $3.14 \mathrm{E}+02$ & $-1.53 E+03$ & & & \\
\hline $4.40 \mathrm{E}+01$ & $3.14 \mathrm{E}+02$ & $-1.53 E+03$ & & & \\
\hline $3.64 \mathrm{E}+01$ & $3.14 \mathrm{E}+02$ & $-1.54 \mathrm{E}+03$ & & & \\
\hline $2.60 \mathrm{E}+02$ & $5.27 \mathrm{E}+02$ & $-1.42 \mathrm{E}+03$ & & & \\
\hline $2.28 \mathrm{E}+02$ & $8.08 \mathrm{E}+01$ & $-1.56 \mathrm{E}+03$ & & & \\
\hline $2.29 E+02$ & $2.93 E+02$ & $-1.55 E+03$ & & & \\
\hline$-4.87 E+01$ & $1.54 \mathrm{E}+02$ & $-1.52 E+03$ & & & \\
\hline $1.43 \mathrm{E}+01$ & $3.15 \mathrm{E}+02$ & $-1.53 E+03$ & & & \\
\hline $2.23 E+02$ & $8.12 \mathrm{E}+01$ & $-1.55 E+03$ & & & \\
\hline $1.94 \mathrm{E}+02$ & $8.10 \mathrm{E}+01$ & $-1.55 E+03$ & & & \\
\hline $1.80 \mathrm{E}+02$ & $8.13 E+01$ & $-1.55 E+03$ & & & \\
\hline $1.43 E+02$ & $8.37 \mathrm{E}+01$ & $-1.55 E+03$ & & & \\
\hline $1.33 \mathrm{E}+02$ & $8.50 \mathrm{E}+01$ & $-1.54 \mathrm{E}+03$ & & & \\
\hline $1.17 \mathrm{E}+02$ & $8.70 \mathrm{E}+01$ & $-1.54 \mathrm{E}+03$ & & & \\
\hline $1.03 \mathrm{E}+02$ & $9.01 \mathrm{E}+01$ & $-1.54 \mathrm{E}+03$ & & & \\
\hline $8.03 E+01$ & $9.52 \mathrm{E}+01$ & $-1.53 E+03$ & & & \\
\hline 7.19E+01 & $9.70 \mathrm{E}+01$ & $-1.53 E+03$ & & & \\
\hline $5.45 \mathrm{E}+01$ & $1.02 \mathrm{E}+02$ & $-1.53 E+03$ & & & \\
\hline $4.57 \mathrm{E}+01$ & $1.05 \mathrm{E}+02$ & $-1.53 E+03$ & & & \\
\hline $3.81 \mathrm{E}+01$ & $1.08 \mathrm{E}+02$ & $-1.53 E+03$ & & & \\
\hline $2.55 \mathrm{E}+01$ & $1.12 \mathrm{E}+02$ & $-1.53 E+03$ & & & \\
\hline $1.77 \mathrm{E}+01$ & $1.16 \mathrm{E}+02$ & $-1.53 E+03$ & & & \\
\hline $1.03 \mathrm{E}+01$ & $1.19 \mathrm{E}+02$ & $-1.53 E+03$ & & & \\
\hline $4.09 \mathrm{E}+00$ & $1.22 \mathrm{E}+02$ & $-1.53 E+03$ & & & \\
\hline
\end{tabular}


Experiment 5

Table C-0-5:Data for Experiment 5.

\begin{tabular}{|c|c|c|c|c|c|}
\hline X-Cord. & Y-Cord. & Z-Cord. & X-Cord. & Y-Cord. & Z-Cord. \\
\hline $2.22 \mathrm{E}+02$ & $2.92 \mathrm{E}+02$ & $-1.56 \mathrm{E}+03$ & $-5.73 E+00$ & $9.09 \mathrm{E}+01$ & $-1.53 E+03$ \\
\hline $2.08 \mathrm{E}+02$ & $2.92 \mathrm{E}+02$ & $-1.56 \mathrm{E}+03$ & $2.23 \mathrm{E}+02$ & $2.92 \mathrm{E}+02$ & $-1.56 \mathrm{E}+03$ \\
\hline $1.93 \mathrm{E}+02$ & $2.92 \mathrm{E}+02$ & $-1.56 \mathrm{E}+03$ & $1.99 \mathrm{E}+02$ & $2.92 \mathrm{E}+02$ & $-1.55 E+03$ \\
\hline $1.76 \mathrm{E}+02$ & $2.92 \mathrm{E}+02$ & $-1.55 E+03$ & $1.88 \mathrm{E}+02$ & $2.92 \mathrm{E}+02$ & $-1.55 E+03$ \\
\hline $1.58 \mathrm{E}+02$ & $2.92 \mathrm{E}+02$ & $-1.55 \mathrm{E}+03$ & $1.72 \mathrm{E}+02$ & $2.92 \mathrm{E}+02$ & $-1.55 E+03$ \\
\hline $1.41 \mathrm{E}+02$ & $2.91 \mathrm{E}+02$ & $-1.55 \mathrm{E}+03$ & $1.61 \mathrm{E}+02$ & $2.92 \mathrm{E}+02$ & $-1.55 E+03$ \\
\hline $9.40 \mathrm{E}+01$ & $2.89 \mathrm{E}+02$ & $-1.54 \mathrm{E}+03$ & $1.30 \mathrm{E}+02$ & $2.91 \mathrm{E}+02$ & $-1.55 E+03$ \\
\hline $5.73 \mathrm{E}+01$ & $2.86 \mathrm{E}+02$ & $-1.53 \mathrm{E}+03$ & $1.12 \mathrm{E}+02$ & $2.90 \mathrm{E}+02$ & $-1.54 \mathrm{E}+03$ \\
\hline $4.07 E+01$ & $2.83 E+02$ & $-1.53 \mathrm{E}+03$ & $7.99 \mathrm{E}+01$ & $2.87 \mathrm{E}+02$ & $-1.54 \mathrm{E}+03$ \\
\hline $2.47 \mathrm{E}+01$ & $2.80 \mathrm{E}+02$ & $-1.53 E+03$ & $6.70 \mathrm{E}+01$ & $2.85 \mathrm{E}+02$ & $-1.54 \mathrm{E}+03$ \\
\hline $1.28 \mathrm{E}+01$ & $2.77 \mathrm{E}+02$ & $-1.53 E+03$ & $5.22 \mathrm{E}+01$ & $2.84 \mathrm{E}+02$ & $-1.54 \mathrm{E}+03$ \\
\hline 8.46E-01 & $2.74 \mathrm{E}+02$ & $-1.52 \mathrm{E}+03$ & $3.85 E+01$ & $2.81 \mathrm{E}+02$ & $-1.54 \mathrm{E}+03$ \\
\hline$-1.13 E+01$ & $2.71 \mathrm{E}+02$ & $-1.53 E+03$ & $2.72 \mathrm{E}+01$ & $2.79 \mathrm{E}+02$ & $-1.54 \mathrm{E}+03$ \\
\hline $2.60 \mathrm{E}+02$ & $5.27 \mathrm{E}+02$ & $-1.42 \mathrm{E}+03$ & $1.32 \mathrm{E}+01$ & $2.75 \mathrm{E}+02$ & $-1.53 E+03$ \\
\hline $2.28 \mathrm{E}+02$ & $8.09 \mathrm{E}+01$ & $-1.55 \mathrm{E}+03$ & $-4.75 \mathrm{E}+00$ & $2.69 \mathrm{E}+02$ & $-1.53 \mathrm{E}+03$ \\
\hline $2.27 \mathrm{E}+02$ & $2.91 \mathrm{E}+02$ & $-1.57 \mathrm{E}+03$ & $2.60 \mathrm{E}+02$ & $5.27 \mathrm{E}+02$ & $-1.42 \mathrm{E}+03$ \\
\hline$-1.81 \mathrm{E}+01$ & 01 & & +02 & & +03 \\
\hline$-2.03 E+01$ & $2.69 \mathrm{E}+02$ & $-1.53 \mathrm{E}+03$ & $2.27 \mathrm{E}+02$ & $2.91 \mathrm{E}+02$ & $-1.58 \mathrm{E}+03$ \\
\hline $2.23 \mathrm{E}+02$ & 8.07E+01 & $-1.56 \mathrm{E}+03$ & $-1.77 \mathrm{E}+01$ & $9.33 \mathrm{E}+01$ & $-1.53 \mathrm{E}+03$ \\
\hline $2.15 \mathrm{E}+02$ & $8.03 E+01$ & $-1.56 \mathrm{E}+03$ & $-1.83 \mathrm{E}+01$ & $2.69 \mathrm{E}+02$ & $-1.52 \mathrm{E}+03$ \\
\hline $2.06 \mathrm{E}+02$ & $7.97 \mathrm{E}+01$ & $-1.56 \mathrm{E}+03$ & $2.27 \mathrm{E}+02$ & $8 \mathrm{E}+01$ & $-1.55 \mathrm{E}+03$ \\
\hline $1.96 \mathrm{E}+02$ & $7.92 \mathrm{E}+01$ & $-1.56 \mathrm{E}+03$ & $2.08 \mathrm{E}+02$ & $7.99 \mathrm{E}+01$ & $E+03$ \\
\hline $1.85 \mathrm{E}+02$ & $7.88 \mathrm{E}+01$ & $-1.56 \mathrm{E}+03$ & $2.00 \mathrm{E}+02$ & $7.96 \mathrm{E}+01$ & $-1.55 \mathrm{E}+03$ \\
\hline $1.75 \mathrm{E}+02$ & $7.87 \mathrm{E}+01$ & $-1.55 \mathrm{E}+03$ & $1.91 \mathrm{E}+02$ & $7.94 \mathrm{E}+01$ & $-1.55 E+03$ \\
\hline $1.67 \mathrm{E}+02$ & $7.86 \mathrm{E}+01$ & $-1.55 \mathrm{E}+03$ & $1.82 \mathrm{E}+02$ & $7.91 \mathrm{E}+01$ & $-1.55 \mathrm{E}+03$ \\
\hline $1.56 \mathrm{E}+02$ & $7.84 \mathrm{E}+01$ & $-1.55 \mathrm{E}+03$ & $1.69 \mathrm{E}+02$ & $7.88 \mathrm{E}+01$ & $-1.55 \mathrm{E}+03$ \\
\hline $1.44 \mathrm{E}+02$ & $7.84 \mathrm{E}+01$ & $-1.55 \mathrm{E}+03$ & $1.54 \mathrm{E}+02$ & $7.85 \mathrm{E}+01$ & $-1.55 \mathrm{E}+03$ \\
\hline $1.18 \mathrm{E}+02$ & $7.84 \mathrm{E}+01$ & $-1.55 \mathrm{E}+03$ & $1.40 \mathrm{E}+02$ & $7.86 \mathrm{E}+01$ & $-1.55 E+03$ \\
\hline $1.08 \mathrm{E}+02$ & $7.89 \mathrm{E}+01$ & $-1.54 \mathrm{E}+03$ & $1.20 \mathrm{E}+02$ & $7.88 \mathrm{E}+01$ & $-1.55 \mathrm{E}+03$ \\
\hline $1.00 \mathrm{E}+02$ & $7.87 \mathrm{E}+01$ & $-1.54 \mathrm{E}+03$ & $1.04 \mathrm{E}+02$ & $7.93 E+01$ & $-1.54 \mathrm{E}+03$ \\
\hline $9.33 \mathrm{E}+01$ & $7.90 \mathrm{E}+01$ & $-1.54 \mathrm{E}+03$ & $9.27 \mathrm{E}+01$ & $8.00 \mathrm{E}+01$ & $-1.54 \mathrm{E}+03$ \\
\hline $8.44 \mathrm{E}+01$ & $7.89 \mathrm{E}+01$ & $-1.54 \mathrm{E}+03$ & $7.69 \mathrm{E}+01$ & $8.15 E+01$ & $-1.54 \mathrm{E}+03$ \\
\hline $7.35 \mathrm{E}+01$ & 7.97E+01 & $-1.54 \mathrm{E}+03$ & $6.10 \mathrm{E}+01$ & $8.31 \mathrm{E}+01$ & $-1.53 E+03$ \\
\hline $6.16 \mathrm{E}+01$ & $8.08 \mathrm{E}+01$ & $-1.54 \mathrm{E}+03$ & $4.24 \mathrm{E}+01$ & $8.56 \mathrm{E}+01$ & $-1.53 E+03$ \\
\hline $4.94 \mathrm{E}+01$ & $8.24 \mathrm{E}+01$ & $-1.54 \mathrm{E}+03$ & $2.90 \mathrm{E}+01$ & $8.78 \mathrm{E}+01$ & $-1.53 E+03$ \\
\hline $3.90 \mathrm{E}+01$ & $8.31 \mathrm{E}+01$ & $-1.54 \mathrm{E}+03$ & $1.79 \mathrm{E}+01$ & $8.99 \mathrm{E}+01$ & $-1.53 E+03$ \\
\hline $2.47 \mathrm{E}+01$ & $8.51 \mathrm{E}+01$ & $-1.53 \mathrm{E}+03$ & $4.86 \mathrm{E}+00$ & $9.23 \mathrm{E}+01$ & $-1.53 E+03$ \\
\hline $1.34 \mathrm{E}+01$ & $8.72 \mathrm{E}+01$ & $-1.53 \mathrm{E}+03$ & $-4.16 \mathrm{E}+00$ & $9.40 \mathrm{E}+01$ & $-1.53 E+03$ \\
\hline $2.04 \mathrm{E}+00$ & $8.95 E+01$ & $-1.53 \mathrm{E}+03$ & $2.19 E+02$ & $2.92 \mathrm{E}+02$ & $-1.55 \mathrm{E}+03$ \\
\hline
\end{tabular}




\begin{tabular}{|c|c|c|c|c|c|}
\hline ord. & Y-Cord. & Z-Cord. & X-Cord. & Y-Cord. & d. \\
\hline $2.10 \mathrm{E}+02$ & $92 \mathrm{E}+02$ & $-1.56 \mathrm{E}+03$ & $-1.01 E+01$ & $1.01 \mathrm{E}+02$ & $-1.53 E+03$ \\
\hline $1.97 \mathrm{E}+02$ & $92 \mathrm{E}+02$ & $-1.55 E+03$ & $-2.11 E+01$ & $1.05 E+02$ & $-1.53 E+03$ \\
\hline $1.83 E+02$ & $2.92 \mathrm{E}+02$ & $-1.55 E+03$ & $2.21 \mathrm{E}+02$ & $2.92 \mathrm{E}+02$ & $-1.56 \mathrm{E}+03$ \\
\hline $1.67 \mathrm{E}+02$ & $2.93 E+02$ & $-1.55 E+03$ & $2.06 \mathrm{E}+02$ & $2.92 \mathrm{E}+02$ & $-1.55 E+03$ \\
\hline $1.50 \mathrm{E}+02$ & $2.93 \mathrm{E}+02$ & $-1.55 E+03$ & $1.88 \mathrm{E}+02$ & $2.93 \mathrm{E}+02$ & $-1.55 \mathrm{E}+03$ \\
\hline $1.37 E+02$ & $2.93 E+02$ & $-1.55 E+03$ & $1.73 \mathrm{E}+02$ & $2.93 E+02$ & $-1.55 E+03$ \\
\hline $1.22 \mathrm{E}+02$ & $2.93 \mathrm{E}+02$ & $-1.55 E+03$ & $1.41 \mathrm{E}+02$ & $2.93 \mathrm{E}+02$ & $-1.55 \mathrm{E}+03$ \\
\hline $1.10 \mathrm{E}+02$ & $2.92 E+02$ & $-1.55 E+03$ & $1.26 \mathrm{E}+02$ & $2.93 E+02$ & $-1.55 E+03$ \\
\hline $9.79 \mathrm{E}+01$ & $2.92 \mathrm{E}+02$ & $-1.55 E+03$ & $1.06 \mathrm{E}+02$ & $94 \mathrm{E}+02$ & $-1.54 \mathrm{E}+03$ \\
\hline $8.29 E+01$ & $2.91 E+02$ & $-1.55 E+03$ & $8.94 \mathrm{E}+01$ & $2.93 E+02$ & $-1.54 \mathrm{E}+03$ \\
\hline $6.61 \mathrm{E}+01$ & $2.90 \mathrm{E}+02$ & $-1.54 \mathrm{E}+03$ & $7.39 \mathrm{E}+01$ & $2.93 E+02$ & $-1.54 \mathrm{E}+03$ \\
\hline $4.17 \mathrm{E}+01$ & $2.87 \mathrm{E}+02$ & $-1.54 \mathrm{E}+03$ & $6.11 E+01$ & $2.92 \mathrm{E}+02$ & $-1.54 \mathrm{E}+03$ \\
\hline $3.10 \mathrm{E}+01$ & $2.86 \mathrm{E}+02$ & $-1.54 \mathrm{E}+03$ & $1.95 \mathrm{E}+01$ & $87 \mathrm{E}+02$ & $-1.53 E+03$ \\
\hline $1.54 \mathrm{E}+01$ & $2.83 E+02$ & $-1.53 E+03$ & $4.29 E+00$ & $2.84 \mathrm{E}+02$ & $-1.53 E+03$ \\
\hline $2.60 \mathrm{E}+02$ & $5.27 \mathrm{E}+02$ & $-1.42 E+03$ & $2.60 \mathrm{E}+02$ & $5.27 \mathrm{E}+02$ & $-1.42 \mathrm{E}+03$ \\
\hline $2.28 \mathrm{E}+02$ & $8.05 E+01$ & $-1.56 \mathrm{E}+03$ & $2.28 \mathrm{E}+02$ & $8.04 E+01$ & $-1.56 \mathrm{E}+03$ \\
\hline $2.29 E+02$ & $33 E+02$ & $-1.55 E+03$ & $2.30 \mathrm{E}+02$ & $3 \mathrm{E}+02$ & +03 \\
\hline & & & & & -03 \\
\hline$-1.89 \mathrm{E}+01$ & $2.82 E+02$ & $-1.53 E+03$ & $-2.17 E+01$ & $2.82 \mathrm{E}+02$ & $E+03$ \\
\hline $2.21 \mathrm{E}+02$ & $8.07 E+01$ & $-1.55 E+03$ & $2.24 \mathrm{E}+02$ & $8.05 E+01$ & $-1.56 \mathrm{E}+03$ \\
\hline $2.11 E+02$ & $8.00 E+01$ & $-1.56 \mathrm{E}+03$ & $2.12 \mathrm{E}+02$ & $8.00 E+01$ & $-1.56 \mathrm{E}+03$ \\
\hline $2.00 E+02$ & $7.97 \mathrm{E}+01$ & $-1.56 \mathrm{E}+03$ & $1.98 \mathrm{E}+02$ & $6 \mathrm{E}+01$ & +03 \\
\hline $1.89 \mathrm{E}+02$ & $7.94 \mathrm{E}+01$ & $-1.56 \mathrm{E}+03$ & $1.87 E+02$ & $7.94 \mathrm{E}+01$ & $56 \mathrm{E}+03$ \\
\hline $1.74 \mathrm{E}+02$ & $7.92 \mathrm{E}+01$ & $-1.56 \mathrm{E}+03$ & $1.77 \mathrm{E}+02$ & $7.93 \mathrm{E}+01$ & $-1.56 \mathrm{E}+03$ \\
\hline $1.62 \mathrm{E}+02$ & $7.91 \mathrm{E}+01$ & $-1.56 \mathrm{E}+03$ & $1.59 \mathrm{E}+02$ & $7.91 E+01$ & $-1.56 \mathrm{E}+03$ \\
\hline $1.35 \mathrm{E}+02$ & $7.91 \mathrm{E}+01$ & $-1.56 \mathrm{E}+03$ & $1.50 \mathrm{E}+02$ & $7.95 \mathrm{E}+01$ & $-1.56 \mathrm{E}+03$ \\
\hline $1.25 \mathrm{E}+02$ & $7.93 E+01$ & $-1.56 \mathrm{E}+03$ & $1.36 \mathrm{E}+02$ & $7.96 \mathrm{E}+01$ & $-1.55 \mathrm{E}+03$ \\
\hline $1.14 \mathrm{E}+02$ & $7.99 \mathrm{E}+01$ & $-1.56 \mathrm{E}+03$ & $1.19 \mathrm{E}+02$ & $8.03 E+01$ & $-1.55 E+03$ \\
\hline $1.02 \mathrm{E}+02$ & $8.05 E+01$ & $-1.56 \mathrm{E}+03$ & $1.05 E+02$ & $8.11 E+01$ & $-1.55 E+03$ \\
\hline $9.17 \mathrm{E}+01$ & $8.14 \mathrm{E}+01$ & $-1.56 \mathrm{E}+03$ & $9.35 \mathrm{E}+01$ & $8.19 E+01$ & $-1.55 \mathrm{E}+03$ \\
\hline $8.21 \mathrm{E}+01$ & $8.15 E+01$ & $-1.56 \mathrm{E}+03$ & $7.87 \mathrm{E}+01$ & $8.35 E+01$ & $-1.55 E+03$ \\
\hline $7.34 \mathrm{E}+01$ & $8.26 \mathrm{E}+01$ & $-1.56 \mathrm{E}+03$ & $6.61 \mathrm{E}+01$ & $8.51 \mathrm{E}+01$ & $-1.55 \mathrm{E}+03$ \\
\hline $6.29 E+01$ & $8.33 E+01$ & $-1.56 \mathrm{E}+03$ & $5.47 \mathrm{E}+01$ & $8.67 \mathrm{E}+01$ & $-1.54 \mathrm{E}+03$ \\
\hline $5.54 \mathrm{E}+01$ & $8.50 \mathrm{E}+01$ & $-1.56 \mathrm{E}+03$ & $4.43 \mathrm{E}+01$ & $8.86 \mathrm{E}+01$ & $-1.54 \mathrm{E}+03$ \\
\hline $4.76 \mathrm{E}+01$ & $8.59 E+01$ & $-1.56 \mathrm{E}+03$ & $3.80 \mathrm{E}+01$ & $9.01 E+01$ & $-1.54 \mathrm{E}+03$ \\
\hline $4.07 E+01$ & $8.77 \mathrm{E}+01$ & $-1.55 E+03$ & $3.02 \mathrm{E}+01$ & $9.21 \mathrm{E}+01$ & $-1.54 \mathrm{E}+03$ \\
\hline $2.94 \mathrm{E}+01$ & $8.99 E+01$ & $-1.55 E+03$ & $1.93 \mathrm{E}+01$ & $9.45 \mathrm{E}+01$ & $-1.54 \mathrm{E}+03$ \\
\hline $1.80 \mathrm{E}+01$ & $9.27 \mathrm{E}+01$ & $-1.54 \mathrm{E}+03$ & $5.90 \mathrm{E}+00$ & $9.80 \mathrm{E}+01$ & $-1.53 \mathrm{E}+03$ \\
\hline$-1.20 E+00$ & $9.87 \mathrm{E}+01$ & $-1.53 E+03$ & $-4.95 E+00$ & $1.01 E+02$ & $-1.53 E+03$ \\
\hline
\end{tabular}




\begin{tabular}{|c|c|c|c|c|c|}
\hline X-Cord. & Y-Cord. & Z-Cord. & X-Cord. & Y-Cord. & Z-Cord. \\
\hline$-1.45 \mathrm{E}+01$ & $.04 \mathrm{E}+02$ & $-1.53 E+03$ & $-4.15 E+01$ & $1.20 \mathrm{E}+02$ & $-1.53 E+03$ \\
\hline$-2.62 \mathrm{E}+01$ & $07 \mathrm{E}+02$ & $-1.53 E+03$ & $11 \mathrm{E}+02$ & $33 \mathrm{E}+02$ & $.56 \mathrm{E}+03$ \\
\hline $2.23 \mathrm{E}+02$ & $2.92 \mathrm{E}+02$ & $-1.56 \mathrm{E}+03$ & $2.00 \mathrm{E}+02$ & $2.93 \mathrm{E}+02$ & $-1.55 E+03$ \\
\hline $2.08 \mathrm{E}+02$ & $93 \mathrm{E}+02$ & $-1.56 \mathrm{E}+03$ & $86 \mathrm{E}+02$ & $.94 \mathrm{E}+02$ & $-1.55 \mathrm{E}+03$ \\
\hline $1.90 \mathrm{E}+02$ & $3 \mathrm{E}+02$ & $-1.56 \mathrm{E}+03$ & $59 \mathrm{E}+02$ & $94 \mathrm{E}+02$ & +03 \\
\hline$E+02$ & $4 \mathrm{E}+02$ & $-1.56 \mathrm{E}+03$ & $56 \mathrm{E}+02$ & $5 \mathrm{E}+02$ & +03 \\
\hline $1.59 \mathrm{E}+02$ & $2.95 \mathrm{E}+02$ & $-1.56 \mathrm{E}+03$ & $1.41 \mathrm{E}+02$ & $2.95 \mathrm{E}+02$ & $-1.55 \mathrm{E}+03$ \\
\hline $1.38 \mathrm{E}+02$ & $96 \mathrm{E}+02$ & $-1.56 \mathrm{E}+03$ & $5 \mathrm{E}+02$ & $.96 \mathrm{E}+02$ & +03 \\
\hline $1.05 \mathrm{E}+02$ & $2.97 \mathrm{E}+02$ & $-1.55 E+03$ & $E+02$ & +02 & +03 \\
\hline $8.87 \mathrm{E}+01$ & $2.98 \mathrm{E}+02$ & $-1.55 E+03$ & $\mathrm{E}+01$ & $7 \mathrm{E}+02$ & +03 \\
\hline $7.27 \mathrm{E}+01$ & $2.98 \mathrm{E}+02$ & $-1.55 E+03$ & $7.47 \mathrm{E}+01$ & $2.97 \mathrm{E}+02$ & $-1.54 \mathrm{E}+03$ \\
\hline $5.36 \mathrm{E}+01$ & $2.98 \mathrm{E}+02$ & $-1.54 \mathrm{E}+03$ & $96 \mathrm{E}+01$ & $96 \mathrm{E}+02$ & $-1.54 \mathrm{E}+03$ \\
\hline $3.75 E+01$ & $2.97 \mathrm{E}+02$ & $-1.54 \mathrm{E}+03$ & $2.72 \mathrm{E}+01$ & $2.96 \mathrm{E}+02$ & $=03$ \\
\hline 01 & 02 & -1 & & & \\
\hline $7.52 E+00$ & $2.95 \mathrm{E}+02$ & $-1.53 E+03$ & 4.13E-01 & $2.93 E+02$ & $-1.53 E+03$ \\
\hline $2.60 \mathrm{E}+02$ & $5.27 \mathrm{E}+02$ & $-1.42 \mathrm{E}+03$ & $2.60 \mathrm{E}+02$ & $5.27 \mathrm{E}+02$ & $-1.42 \mathrm{E}+03$ \\
\hline $2.28 \mathrm{E}+02$ & 8.07E+01 & $-1.56 \mathrm{E}+03$ & $2.28 \mathrm{E}+02$ & $8.05 E+01$ & $-1.56 \mathrm{E}+03$ \\
\hline $2.27 \mathrm{E}+02$ & $2.91 \mathrm{E}+02$ & & & & \\
\hline$-5.35 E+01$ & $1.24 \mathrm{E}+02$ & $-1.52 E+03$ & $-5.17 E+01$ & $1.24 \mathrm{E}+02$ & $-1.52 E+03$ \\
\hline$-2.11 \mathrm{E}+01$ & $2.95 \mathrm{E}+02$ & $-1.53 E+03$ & $-2.05 E+01$ & $2.95 \mathrm{E}+02$ & $-1.53 E+03$ \\
\hline $2.28 \mathrm{E}+02$ & $8.09 E+01$ & $-1.56 \mathrm{E}+03$ & $2.09 \mathrm{E}+02$ & -01 & +03 \\
\hline & $8.05 \mathrm{E}+01$ & & & & \\
\hline $2.11 \mathrm{E}+02$ & $8.00 \mathrm{E}+01$ & $-1.56 \mathrm{E}+03$ & $E+02$ & $E+01$ & +03 \\
\hline $1.97 \mathrm{E}+02$ & $7.97 \mathrm{E}+01$ & $-1.56 \mathrm{E}+03$ & $1.71 \mathrm{E}+02$ & $7.97 \mathrm{E}+01$ & +03 \\
\hline $1.83 \mathrm{E}+02$ & $7.96 \mathrm{E}+01$ & $-1.55 E+03$ & $1.59 \mathrm{E}+02$ & $7.99 \mathrm{E}+01$ & $-1.55 \mathrm{E}+03$ \\
\hline $1.70 \mathrm{E}+02$ & $7.95 \mathrm{E}+01$ & $-1.56 \mathrm{E}+03$ & $1.48 \mathrm{E}+02$ & $8.01 \mathrm{E}+01$ & $-1.55 \mathrm{E}+03$ \\
\hline $1.44 \mathrm{E}+02$ & $8.02 \mathrm{E}+01$ & $-1.55 E+03$ & $1.19 \mathrm{E}+02$ & $8.19 \mathrm{E}+01$ & +03 \\
\hline $1.39 \mathrm{E}+02$ & $8.04 \mathrm{E}+01$ & $-1.55 E+03$ & $1.10 \mathrm{E}+02$ & $8.18 \mathrm{E}+01$ & $-1.55 \mathrm{E}+03$ \\
\hline $1.31 \mathrm{E}+02$ & $8.10 \mathrm{E}+01$ & $-1.55 E+03$ & $9.60 \mathrm{E}+01$ & $8.30 \mathrm{E}+01$ & $-1.55 \mathrm{E}+03$ \\
\hline $1.18 \mathrm{E}+02$ & $8.21 \mathrm{E}+01$ & $-1.55 E+03$ & $8.57 \mathrm{E}+01$ & $8.47 \mathrm{E}+01$ & $-1.55 E+03$ \\
\hline $9.86 \mathrm{E}+01$ & $8.34 \mathrm{E}+01$ & $-1.56 \mathrm{E}+03$ & $7.54 \mathrm{E}+01$ & $8.59 \mathrm{E}+01$ & $-1.55 E+03$ \\
\hline $8.26 \mathrm{E}+01$ & $8.53 \mathrm{E}+01$ & $-1.55 E+03$ & $6.68 \mathrm{E}+01$ & $8.74 \mathrm{E}+01$ & $-1.55 E+03$ \\
\hline $6.80 \mathrm{E}+01$ & $8.76 \mathrm{E}+01$ & $-1.55 E+03$ & $5.82 \mathrm{E}+01$ & $8.82 \mathrm{E}+01$ & $-1.55 \mathrm{E}+03$ \\
\hline $5.44 \mathrm{E}+01$ & $9.00 \mathrm{E}+01$ & $-1.54 \mathrm{E}+03$ & $4.98 \mathrm{E}+01$ & $8.97 \mathrm{E}+01$ & $-1.55 \mathrm{E}+03$ \\
\hline $4.15 \mathrm{E}+01$ & $9.30 \mathrm{E}+01$ & $-1.54 \mathrm{E}+03$ & $3.90 \mathrm{E}+01$ & $9.23 \mathrm{E}+01$ & $-1.55 E+03$ \\
\hline $2.81 \mathrm{E}+01$ & $9.60 \mathrm{E}+01$ & $-1.54 \mathrm{E}+03$ & $2.73 \mathrm{E}+01$ & $9.51 \mathrm{E}+01$ & $-1.55 E+03$ \\
\hline $1.24 \mathrm{E}+01$ & $1.00 \mathrm{E}+02$ & $-1.54 \mathrm{E}+03$ & $1.75 \mathrm{E}+01$ & $9.82 \mathrm{E}+01$ & $-1.54 \mathrm{E}+03$ \\
\hline$-3.17 \mathrm{E}+00$ & $1.06 \mathrm{E}+02$ & $-1.54 \mathrm{E}+03$ & $-1.72 \mathrm{E}+00$ & $1.04 \mathrm{E}+02$ & $-1.54 \mathrm{E}+03$ \\
\hline$-1.52 \mathrm{E}+01$ & $1.09 \mathrm{E}+02$ & $-1.54 \mathrm{E}+03$ & $-1.35 E+01$ & $1.08 \mathrm{E}+02$ & $-1.53 E+03$ \\
\hline
\end{tabular}




\begin{tabular}{|c|c|c|c|c|c|}
\hline X-Cord. & -Cord. & Z-Cord. & X-Cord. & Y-Cord. & Z-Cord. \\
\hline$-2.45 \mathrm{E}+01$ & $1.13 \mathrm{E}+02$ & $-1.53 E+03$ & $-3.60 E+01$ & $1.22 \mathrm{E}+02$ & $-1.53 E+03$ \\
\hline$-4.53 \mathrm{E}+01$ & $1.21 \mathrm{E}+02$ & $-1.53 E+03$ & $-4.31 E+01$ & $26 \mathrm{E}+02$ & $-1.53 E+03$ \\
\hline $2.18 \mathrm{E}+02$ & $2.93 E+02$ & $-1.56 \mathrm{E}+03$ & $-5.13 E+01$ & $.31 \mathrm{E}+02$ & $-1.53 E+03$ \\
\hline $2.06 \mathrm{E}+02$ & $2.93 \mathrm{E}+02$ & $-1.56 \mathrm{E}+03$ & $-5.87 E+01$ & $34 \mathrm{E}+02$ & $3 \mathrm{E}+03$ \\
\hline $1.89 \mathrm{E}+02$ & $4 \mathrm{E}+02$ & $-1.55 E+03$ & $-6.39 E+01$ & $1.37 \mathrm{E}+02$ & $E+03$ \\
\hline $1.74 \mathrm{E}+02$ & $2.95 \mathrm{E}+02$ & $\mathrm{E}+03$ & $.21 \mathrm{E}+02$ & $33 \mathrm{E}+02$ & $56 \mathrm{E}+03$ \\
\hline $1.39 \mathrm{E}+02$ & $2.98 \mathrm{E}+02$ & $-1.56 \mathrm{E}+03$ & $2.08 \mathrm{E}+02$ & $2.93 \mathrm{E}+02$ & $56 \mathrm{E}+03$ \\
\hline $1.21 \mathrm{E}+02$ & $3.00 \mathrm{E}+02$ & $-1.55 E+03$ & $92 \mathrm{E}+02$ & $.94 E+02$ & $\mathrm{E}+03$ \\
\hline $1.04 \mathrm{E}+02$ & $3.01 \mathrm{E}+02$ & $-1.54 \mathrm{E}+03$ & $1.70 \mathrm{E}+02$ & $2.95 \mathrm{E}+02$ & $E+03$ \\
\hline $8.41 \mathrm{E}+01$ & $3.03 E+02$ & $-1.54 \mathrm{E}+03$ & $1.53 \mathrm{E}+02$ & $7 E+02$ & $E+03$ \\
\hline $6.95 \mathrm{E}+01$ & $3.04 \mathrm{E}+02$ & $-1.54 \mathrm{E}+03$ & $1.37 \mathrm{E}+02$ & $2.98 \mathrm{E}+02$ & $-1.56 \mathrm{E}+03$ \\
\hline $2.99 \mathrm{E}+01$ & $3.07 E+02$ & $-1.53 E+03$ & $14 \mathrm{E}+02$ & $3.00 \mathrm{E}+02$ & $-1.55 E+03$ \\
\hline $2.26 \mathrm{E}+01$ & $3.07 E+02$ & $-1.53 E+03$ & $9.68 \mathrm{E}+01$ & $3.01 E+02$ & +03 \\
\hline $6.60 \mathrm{E}+00$ & $E+02$ & $E+03$ & $E+01$ & +02 & +03 \\
\hline $2.60 \mathrm{E}+02$ & $5.26 \mathrm{E}+02$ & $-1.42 E+03$ & $6.66 \mathrm{E}+01$ & $3.04 \mathrm{E}+02$ & $-1.54 \mathrm{E}+03$ \\
\hline $2.27 \mathrm{E}+02$ & $8.03 E+01$ & $-1.56 \mathrm{E}+03$ & $3.97 E+01$ & $3.05 E+02$ & $-1.54 \mathrm{E}+03$ \\
\hline $2.30 \mathrm{E}+02$ & $2.94 \mathrm{E}+02$ & $-1.54 \mathrm{E}+03$ & $2.53 \mathrm{E}+01$ & $3.05 E+02$ & $-1.53 E+03$ \\
\hline$-6.84 E+01$ & & $-1.52 E+03$ & & $3.06 \mathrm{E}+02$ & \\
\hline$-2.02 E+01$ & $3.06 \mathrm{E}+02$ & $-1.53 E+03$ & $-1.32 E+01$ & $3.05 E+02$ & $-1.53 E+03$ \\
\hline $2.25 \mathrm{E}+02$ & $8.06 \mathrm{E}+01$ & $-1.56 E+03$ & $2.60 \mathrm{E}+02$ & $5.26 \mathrm{E}+02$ & $-1.42 \mathrm{E}+03$ \\
\hline $2.12 \mathrm{E}+02$ & $8.02 \mathrm{E}+01$ & $-1.55 E+03$ & $2.28 \mathrm{E}+02$ & $8.05 E+01$ & $-1.56 \mathrm{E}+03$ \\
\hline $1.96 \mathrm{E}+02$ & $7.96 \mathrm{E}+01$ & $-1.56 \mathrm{E}+03$ & $2.29 \mathrm{E}+02$ & $3 \mathrm{E}+02$ & $E+03$ \\
\hline $1.78 \mathrm{E}+02$ & $7.94 \mathrm{E}+01$ & $-1.56 \mathrm{E}+03$ & $-6.89 \mathrm{E}+01$ & $1.40 \mathrm{E}+02$ & -1.5 \\
\hline $1.63 E+02$ & $7.97 E+01$ & $-1.56 \mathrm{E}+03$ & $-2.05 E+01$ & $3.07 E+02$ & $-1.53 E+03$ \\
\hline $1.48 \mathrm{E}+02$ & $8.02 \mathrm{E}+01$ & $-1.56 \mathrm{E}+03$ & $2.23 \mathrm{E}+02$ & $8.04 \mathrm{E}+01$ & $-1.56 \mathrm{E}+03$ \\
\hline $1.33 \mathrm{E}+02$ & $8.13 E+01$ & $-1.55 E+03$ & $2.05 \mathrm{E}+02$ & $8.02 \mathrm{E}+01$ & $-1.55 \mathrm{E}+03$ \\
\hline $1.20 \mathrm{E}+02$ & $8.25 \mathrm{E}+01$ & $-1.55 E+03$ & $1.89 \mathrm{E}+02$ & $8.01 \mathrm{E}+01$ & $-1.55 E+03$ \\
\hline $1.03 E+02$ & $8.41 E+01$ & $-1.55 E+03$ & $1.72 \mathrm{E}+02$ & $8.04 \mathrm{E}+01$ & $-1.54 \mathrm{E}+03$ \\
\hline $8.88 \mathrm{E}+01$ & $8.58 \mathrm{E}+01$ & $-1.55 E+03$ & $1.57 \mathrm{E}+02$ & $8.11 \mathrm{E}+01$ & $-1.54 \mathrm{E}+03$ \\
\hline $7.47 \mathrm{E}+01$ & $8.78 \mathrm{E}+01$ & $-1.55 E+03$ & $1.43 \mathrm{E}+02$ & $8.15 \mathrm{E}+01$ & $-1.54 \mathrm{E}+03$ \\
\hline $6.27 \mathrm{E}+01$ & $9.02 \mathrm{E}+01$ & $-1.55 E+03$ & $1.27 \mathrm{E}+02$ & $8.23 \mathrm{E}+01$ & $-1.54 \mathrm{E}+03$ \\
\hline $4.89 \mathrm{E}+01$ & $9.33 E+01$ & $-1.54 \mathrm{E}+03$ & $1.11 \mathrm{E}+02$ & $8.40 E+01$ & $-1.54 \mathrm{E}+03$ \\
\hline $3.84 \mathrm{E}+01$ & $9.62 \mathrm{E}+01$ & $-1.54 \mathrm{E}+03$ & $9.72 \mathrm{E}+01$ & $8.55 \mathrm{E}+01$ & $-1.54 \mathrm{E}+03$ \\
\hline $2.73 \mathrm{E}+01$ & $9.88 \mathrm{E}+01$ & $-1.54 \mathrm{E}+03$ & $8.45 \mathrm{E}+01$ & $8.72 \mathrm{E}+01$ & $-1.54 \mathrm{E}+03$ \\
\hline $1.54 \mathrm{E}+01$ & $1.02 \mathrm{E}+02$ & $-1.54 \mathrm{E}+03$ & $7.18 \mathrm{E}+01$ & $8.88 \mathrm{E}+01$ & $-1.54 \mathrm{E}+03$ \\
\hline $4.45 \mathrm{E}+00$ & $1.06 \mathrm{E}+02$ & $-1.54 \mathrm{E}+03$ & $5.69 \mathrm{E}+01$ & $9.13 \mathrm{E}+01$ & $-1.54 \mathrm{E}+03$ \\
\hline$-7.59 E+00$ & $1.10 \mathrm{E}+02$ & $-1.54 \mathrm{E}+03$ & $4.39 \mathrm{E}+01$ & $9.41 \mathrm{E}+01$ & $-1.54 \mathrm{E}+03$ \\
\hline$-1.89 \mathrm{E}+01$ & $1.15 \mathrm{E}+02$ & $-1.53 E+03$ & $2.96 \mathrm{E}+01$ & $9.78 \mathrm{E}+01$ & $-1.54 \mathrm{E}+03$ \\
\hline$-2.94 \mathrm{E}+01$ & $1.19 \mathrm{E}+02$ & $-1.53 E+03$ & $1.38 \mathrm{E}+01$ & $1.03 E+02$ & $-1.54 \mathrm{E}+03$ \\
\hline
\end{tabular}




\begin{tabular}{|c|c|c|c|c|c|}
\hline X-Cord. & Y-Cord. & Z-Cord. & X-Cord. & Y-Cord. & Z-Cord. \\
\hline 4.99E-01 & $1.08 \mathrm{E}+02$ & $-1.54 \mathrm{E}+03$ & $1.64 \mathrm{E}+01$ & $1.06 \mathrm{E}+02$ & $-1.54 \mathrm{E}+03$ \\
\hline$-1.69 \mathrm{E}+01$ & $.15 \mathrm{E}+02$ & $-1.53 E+03$ & $.54 \mathrm{E}+00$ & $1.09 \mathrm{E}+02$ & $-1.54 \mathrm{E}+03$ \\
\hline$-3.49 E+01$ & $23 \mathrm{E}+02$ & $-1.53 E+03$ & $6 \mathrm{E}-01$ & $3 \mathrm{E}+02$ & $-1.53 E+03$ \\
\hline$-4.70 \mathrm{E}+01$ & $1.30 \mathrm{E}+02$ & $-1.53 E+03$ & $-1.05 E+01$ & $17 \mathrm{E}+02$ & $-1.53 E+03$ \\
\hline$-5.73 E+01$ & $1.35 \mathrm{E}+02$ & $-1.52 E+03$ & $-1.91 E+01$ & $1.21 \mathrm{E}+02$ & $-1.53 E+03$ \\
\hline$-6.52 \mathrm{E}+01$ & $1.39 \mathrm{E}+02$ & $-1.52 \mathrm{E}+03$ & $-2.79 \mathrm{E}+01$ & $1.26 \mathrm{E}+02$ & $-1.53 E+03$ \\
\hline $2.10 \mathrm{E}+02$ & $2.94 \mathrm{E}+02$ & $-1.55 E+03$ & $-3.67 E+01$ & $1.31 \mathrm{E}+02$ & $-1.53 E+03$ \\
\hline $1.97 \mathrm{E}+02$ & $2.94 \mathrm{E}+02$ & $-1.55 E+03$ & $-4.75 E+01$ & $36 \mathrm{E}+02$ & $-1.52 \mathrm{E}+03$ \\
\hline $1.83 \mathrm{E}+02$ & $2.96 \mathrm{E}+02$ & $-1.55 E+03$ & $-5.59 E+01$ & $41 \mathrm{E}+02$ & $E+03$ \\
\hline $1.69 \mathrm{E}+02$ & $2.97 \mathrm{E}+02$ & $-1.54 \mathrm{E}+03$ & $-6.31 E+01$ & $1.45 \mathrm{E}+02$ & $-1.52 \mathrm{E}+03$ \\
\hline $1.57 \mathrm{E}+02$ & $2.98 \mathrm{E}+02$ & $-1.55 E+03$ & $-6.77 E+01$ & $1.48 \mathrm{E}+02$ & $-1.52 E+03$ \\
\hline $1.46 \mathrm{E}+02$ & $99 \mathrm{E}+02$ & $-1.55 E+03$ & $-7.44 \mathrm{E}+01$ & $\mathrm{BE}+02$ & +03 \\
\hline $1.33 \mathrm{E}+02$ & $: 02$ & $-1.55 E+03$ & $2.20 \mathrm{E}+02$ & & \\
\hline $3 \mathrm{E}+01$ & $E+02$ & $-1.55 E+03$ & $5 \mathrm{E}+02$ & $4 \mathrm{E}+02$ & +03 \\
\hline $4.75 E+01$ & $3.09 E+02$ & $-1.54 \mathrm{E}+03$ & $1.86 \mathrm{E}+02$ & $2.95 \mathrm{E}+02$ & $-1.56 \mathrm{E}+03$ \\
\hline $3.42 \mathrm{E}+01$ & $3.10 \mathrm{E}+02$ & $-1.54 \mathrm{E}+03$ & $1.64 \mathrm{E}+02$ & $2.97 \mathrm{E}+02$ & $-1.55 \mathrm{E}+03$ \\
\hline $1.83 \mathrm{E}+01$ & $3.11 \mathrm{E}+02$ & $-1.54 \mathrm{E}+03$ & $1.44 \mathrm{E}+02$ & $2.99 \mathrm{E}+02$ & -03 \\
\hline $8.49 \mathrm{E}+00$ & $3.12 \mathrm{E}+02$ & $-1.54 \mathrm{E}+03$ & $1.01 \mathrm{E}+02$ & & \\
\hline$-5.19 E+00$ & $3.12 \mathrm{E}+02$ & $-1.53 E+03$ & $9.04 \mathrm{E}+01$ & $3.06 \mathrm{E}+02$ & $-1.55 E+03$ \\
\hline $2.60 \mathrm{E}+02$ & $5.26 \mathrm{E}+02$ & $-1.42 \mathrm{E}+03$ & $7.55 \mathrm{E}+01$ & +02 & +03 \\
\hline $2.28 \mathrm{E}+02$ & $8.04 \mathrm{E}+01$ & -1. & 01 & +02 & +03 \\
\hline $2.29 \mathrm{E}+02$ & $2.93 \mathrm{E}+02$ & & $\mathrm{E}+01$ & & $=03$ \\
\hline$-8.24 \mathrm{E}+01$ & $1.57 \mathrm{E}+02$ & -1.52 & +01 & +02 & +03 \\
\hline$-2.33 E+01$ & $3.19 \mathrm{E}+02$ & $-1.53 E+03$ & $5.69 \mathrm{E}-02$ & $3.15 E+02$ & $-1.53 E+03$ \\
\hline $2.18 \mathrm{E}+02$ & $8.01 \mathrm{E}+01$ & $-1.56 \mathrm{E}+03$ & $2.60 \mathrm{E}+02$ & $5.27 \mathrm{E}+02$ & $-1.42 E+03$ \\
\hline $2.05 E+02$ & $7.97 \mathrm{E}+01$ & $-1.55 E+03$ & $2.28 \mathrm{E}+02$ & $8.03 E+01$ & $-1.56 \mathrm{E}+03$ \\
\hline $1.90 \mathrm{E}+02$ & $7.94 \mathrm{E}+01$ & $-1.55 E+03$ & $2.30 \mathrm{E}+02$ & $2.94 \mathrm{E}+02$ & $E+03$ \\
\hline $1.75 E+02$ & $7.95 E+01$ & $-1.55 E+03$ & $-8.29 E+01$ & $1.57 \mathrm{E}+02$ & $-1.52 E+03$ \\
\hline $1.57 \mathrm{E}+02$ & $8.03 E+01$ & $-1.54 \mathrm{E}+03$ & $-2.07 E+01$ & $3.18 \mathrm{E}+02$ & $-1.53 E+03$ \\
\hline $1.41 \mathrm{E}+02$ & $8.13 E+01$ & $-1.54 \mathrm{E}+03$ & $2.18 \mathrm{E}+02$ & $7.98 \mathrm{E}+01$ & $-1.56 \mathrm{E}+03$ \\
\hline $1.29 \mathrm{E}+02$ & $8.22 \mathrm{E}+01$ & $-1.54 \mathrm{E}+03$ & $2.00 \mathrm{E}+02$ & $7.92 \mathrm{E}+01$ & $-1.55 \mathrm{E}+03$ \\
\hline $1.07 \mathrm{E}+02$ & $8.47 \mathrm{E}+01$ & $-1.54 \mathrm{E}+03$ & $1.79 \mathrm{E}+02$ & $7.89 E+01$ & $-1.55 \mathrm{E}+03$ \\
\hline $9.70 \mathrm{E}+01$ & $8.64 \mathrm{E}+01$ & $-1.53 E+03$ & $1.57 \mathrm{E}+02$ & $7.92 \mathrm{E}+01$ & $-1.55 \mathrm{E}+03$ \\
\hline $8.50 \mathrm{E}+01$ & $8.81 \mathrm{E}+01$ & $-1.54 \mathrm{E}+03$ & $1.39 \mathrm{E}+02$ & $8.02 \mathrm{E}+01$ & $-1.55 \mathrm{E}+03$ \\
\hline $7.09 \mathrm{E}+01$ & $9.03 \mathrm{E}+01$ & $-1.54 \mathrm{E}+03$ & $1.22 \mathrm{E}+02$ & $8.18 \mathrm{E}+01$ & $-1.55 \mathrm{E}+03$ \\
\hline $5.34 \mathrm{E}+01$ & $9.45 E+01$ & $-1.54 \mathrm{E}+03$ & $1.04 \mathrm{E}+02$ & $8.36 \mathrm{E}+01$ & $-1.55 E+03$ \\
\hline $4.31 \mathrm{E}+01$ & $9.79 \mathrm{E}+01$ & $-1.54 \mathrm{E}+03$ & $8.69 \mathrm{E}+01$ & $8.60 \mathrm{E}+01$ & $-1.55 E+03$ \\
\hline $3.53 \mathrm{E}+01$ & $1.00 \mathrm{E}+02$ & $-1.54 \mathrm{E}+03$ & $7.28 \mathrm{E}+01$ & $8.90 \mathrm{E}+01$ & $-1.55 \mathrm{E}+03$ \\
\hline $2.51 \mathrm{E}+01$ & $1.03 \mathrm{E}+02$ & $-1.54 \mathrm{E}+03$ & $5.79 \mathrm{E}+01$ & $9.27 \mathrm{E}+01$ & $-1.54 \mathrm{E}+03$ \\
\hline
\end{tabular}


Deflection Validation and Correction

Table C-0-6:Deflection Validation.

\begin{tabular}{|c|c|c|c|c|c|}
\hline X-Cord. & Y-Cord. & Z-Cord. & X-Cord. & Y-Cord. & Z-Cord. \\
\hline $1.84 \mathrm{E}+02$ & $5.35 \mathrm{E}+02$ & $-1.35 E+03$ & $-2.13 E+01$ & $1.55 \mathrm{E}+02$ & $-1.44 E+03$ \\
\hline $1.47 \mathrm{E}+02$ & $9.03 E+01$ & $-1.49 E+03$ & $3.62 E+01$ & $3.08 \mathrm{E}+02$ & $-1.45 E+03$ \\
\hline $1.46 \mathrm{E}+02$ & $2.98 \mathrm{E}+02$ & $-1.50 \mathrm{E}+03$ & $-2.86 E+01$ & $1.63 E+02$ & $-1.44 E+03$ \\
\hline $6.25 E+01$ & $1.09 E+02$ & $-1.45 E+03$ & $3.70 E+01$ & $3.12 E+02$ & $-1.45 E+03$ \\
\hline $5.84 \mathrm{E}+01$ & $2.75 \mathrm{E}+02$ & $-1.46 \mathrm{E}+03$ & $-3.63 E+01$ & $1.72 \mathrm{E}+02$ & $-1.44 \mathrm{E}+03$ \\
\hline $5.20 \mathrm{E}+01$ & $1.15 E+02$ & $-1.45 E+03$ & $3.76 \mathrm{E}+01$ & $3.16 E+02$ & $-1.45 E+03$ \\
\hline $5.73 E+01$ & $2.79 \mathrm{E}+02$ & $-1.46 \mathrm{E}+03$ & $-4.33 E+01$ & $1.80 \mathrm{E}+02$ & $-1.44 \mathrm{E}+03$ \\
\hline $4.16 \mathrm{E}+01$ & $1.20 E+02$ & $-1.45 E+03$ & $3.80 E+01$ & $3.20 E+02$ & $-1.45 E+03$ \\
\hline $5.67 \mathrm{E}+01$ & $2.84 \mathrm{E}+02$ & $-1.46 \mathrm{E}+03$ & $2.26 \mathrm{E}+01$ & $1.09 \mathrm{E}+02$ & $-1.45 E+03$ \\
\hline $3.16 \mathrm{E}+01$ & $1.27 \mathrm{E}+02$ & $-1.45 E+03$ & $1.90 \mathrm{E}+01$ & $2.73 E+02$ & $-1.45 E+03$ \\
\hline $5.60 \mathrm{E}+01$ & $2.90 \mathrm{E}+02$ & $-1.46 E+03$ & $1.33 \mathrm{E}+01$ & $1.14 \mathrm{E}+02$ & $-1.44 E+03$ \\
\hline $2.19 E+01$ & $1.33 \mathrm{E}+02$ & $-1.45 E+03$ & $1.78 \mathrm{E}+01$ & $2.78 \mathrm{E}+02$ & $-1.45 E+03$ \\
\hline $5.58 \mathrm{E}+01$ & $2.94 \mathrm{E}+02$ & $-1.46 E+03$ & $4.37 \mathrm{E}+00$ & $1.20 \mathrm{E}+02$ & $-1.44 E+03$ \\
\hline $1.25 \mathrm{E}+01$ & $1.41 E+02$ & $-1.45 E+03$ & $1.74 \mathrm{E}+01$ & $2.83 E+02$ & $-1.45 E+03$ \\
\hline $5.54 \mathrm{E}+01$ & $2.99 \mathrm{E}+02$ & $-1.46 \mathrm{E}+03$ & $-4.61 \mathrm{E}+00$ & $1.26 \mathrm{E}+02$ & $-1.44 \mathrm{E}+03$ \\
\hline $3.50 E+00$ & $1.48 \mathrm{E}+02$ & $-1.44 \mathrm{E}+03$ & $1.66 \mathrm{E}+01$ & $2.88 \mathrm{E}+02$ & $-1.45 E+03$ \\
\hline $5.47 \mathrm{E}+01$ & $3.03 E+02$ & $-1.46 \mathrm{E}+03$ & $-1.33 \mathrm{E}-$ & $.33 \mathrm{E}+02$ & \\
\hline$-5.10 E+00$ & $1.56 \mathrm{E}+02$ & $-1.44 \mathrm{E}+03$ & $1.65 \mathrm{E}+01$ & $2.93 E+02$ & $-1.45 E+03$ \\
\hline $5.60 \mathrm{E}+01$ & $3.08 \mathrm{E}+02$ & $-1.46 \mathrm{E}+03$ & $-2.15 \mathrm{E}+01$ & $1.39 \mathrm{E}+02$ & $-1.44 \mathrm{E}+03$ \\
\hline$-1.34 \mathrm{E}+01$ & $1.65 \mathrm{E}+02$ & $-1.44 \mathrm{E}+03$ & $1.61 \mathrm{E}+01$ & $2.98 \mathrm{E}+02$ & $-1.45 E+03$ \\
\hline $5.65 \mathrm{E}+01$ & $3.12 \mathrm{E}+02$ & $-1.46 \mathrm{E}+03$ & $-2.93 \mathrm{E}+01$ & $.46 \mathrm{E}+02$ & $-1.44 \mathrm{E}+03$ \\
\hline$-2.13 \mathrm{E}+01$ & $1.73 E+02$ & $-1.44 \mathrm{E}+03$ & $1.64 \mathrm{E}+01$ & $3.03 E+02$ & $-1.45 E+03$ \\
\hline $5.65 \mathrm{E}+01$ & $3.15 E+02$ & $-1.46 \mathrm{E}+03$ & $-3.70 \mathrm{E}+01$ & $1.54 \mathrm{E}+02$ & $-1.44 \mathrm{E}+03$ \\
\hline$-2.87 \mathrm{E}+01$ & $1.82 \mathrm{E}+02$ & $-1.44 \mathrm{E}+03$ & $1.64 \mathrm{E}+01$ & $3.07 E+02$ & $-1.45 E+03$ \\
\hline $5.80 \mathrm{E}+01$ & $3.19 E+02$ & $-1.46 \mathrm{E}+03$ & $-4.43 \mathrm{E}+01$ & $1.62 \mathrm{E}+02$ & $-1.44 \mathrm{E}+03$ \\
\hline $4.24 \mathrm{E}+01$ & $1.09 E+02$ & $-1.45 E+03$ & $1.68 \mathrm{E}+01$ & $3.12 E+02$ & $-1.45 E+03$ \\
\hline $3.84 \mathrm{E}+01$ & $2.74 \mathrm{E}+02$ & $-1.45 \mathrm{E}+03$ & $-5.13 E+01$ & $1.69 \mathrm{E}+02$ & $-1.44 \mathrm{E}+03$ \\
\hline $3.26 \mathrm{E}+01$ & $1.15 \mathrm{E}+02$ & $-1.45 E+03$ & $1.74 \mathrm{E}+01$ & $3.16 \mathrm{E}+02$ & $-1.45 E+03$ \\
\hline $3.75 \mathrm{E}+01$ & $2.79 \mathrm{E}+02$ & $-1.45 \mathrm{E}+03$ & $-5.76 \mathrm{E}+01$ & $1.79 \mathrm{E}+02$ & $-1.43 E+03$ \\
\hline $2.30 \mathrm{E}+01$ & $1.20 \mathrm{E}+02$ & $-1.45 E+03$ & $1.81 \mathrm{E}+01$ & $3.19 E+02$ & $-1.45 E+03$ \\
\hline $3.67 \mathrm{E}+01$ & $2.84 \mathrm{E}+02$ & $-1.45 E+03$ & $2.88 \mathrm{E}+00$ & $1.09 E+02$ & $-1.44 \mathrm{E}+03$ \\
\hline $1.35 \mathrm{E}+01$ & $1.27 \mathrm{E}+02$ & $-1.44 \mathrm{E}+03$ & $-6.46 \mathrm{E}-01$ & $2.72 E+02$ & $-1.44 \mathrm{E}+03$ \\
\hline $3.62 \mathrm{E}+01$ & $2.89 \mathrm{E}+02$ & $-1.45 \mathrm{E}+03$ & $-6.28 \mathrm{E}+00$ & $1.14 \mathrm{E}+02$ & $-1.44 \mathrm{E}+03$ \\
\hline $4.48 \mathrm{E}+00$ & $1.34 \mathrm{E}+02$ & $-1.44 \mathrm{E}+03$ & $-1.78 \mathrm{E}+00$ & $2.77 E+02$ & $-1.44 E+03$ \\
\hline $3.59 \mathrm{E}+01$ & $2.93 E+02$ & $-1.45 \mathrm{E}+03$ & $-1.44 \mathrm{E}+01$ & $1.20 \mathrm{E}+02$ & $-1.44 \mathrm{E}+03$ \\
\hline$-4.21 E+00$ & $1.41 E+02$ & $-1.44 \mathrm{E}+03$ & $-2.55 E+00$ & $2.83 E+02$ & $-1.44 E+03$ \\
\hline $3.58 \mathrm{E}+01$ & $2.98 \mathrm{E}+02$ & $-1.45 \mathrm{E}+03$ & $-2.27 \mathrm{E}+01$ & $1.25 \mathrm{E}+02$ & $-1.44 \mathrm{E}+03$ \\
\hline$-1.28 \mathrm{E}+01$ & $1.48 \mathrm{E}+02$ & $-1.44 \mathrm{E}+03$ & $-2.74 \mathrm{E}+00$ & $2.87 E+02$ & $-1.44 \mathrm{E}+03$ \\
\hline $3.53 \mathrm{E}+01$ & $3.03 E+02$ & $-1.45 E+03$ & $-3.07 E+01$ & $1.33 E+02$ & $-1.44 \mathrm{E}+03$ \\
\hline
\end{tabular}




\begin{tabular}{|c|c|c|c|c|c|}
\hline ord. & Y-Cord. & Z-Cord. & X-Cord. & Y-Cord. & rd. \\
\hline$-3.45 E+00$ & $.92 \mathrm{E}+02$ & $-1.45 E+03$ & $-5.16 \mathrm{E}+01$ & $1.22 \mathrm{E}+02$ & $-1.43 E+03$ \\
\hline$-3.85 E+01$ & $1.39 E+02$ & $-1.44 \mathrm{E}+03$ & $-4.15 E+01$ & $2.81 E+02$ & $-1.44 \mathrm{E}+03$ \\
\hline$-3.24 \mathrm{E}+00$ & $2.97 \mathrm{E}+02$ & $-1.45 E+03$ & $-5.95 E+01$ & $1.26 \mathrm{E}+02$ & $-1.43 E+03$ \\
\hline$-4.61 E+01$ & $1.46 \mathrm{E}+02$ & $-1.43 E+03$ & $-4.23 E+01$ & $2.86 \mathrm{E}+02$ & $-1.44 \mathrm{E}+03$ \\
\hline$-3.48 \mathrm{E}+00$ & $3.01 E+02$ & $-1.45 E+03$ & $-6.63 E+01$ & $32 \mathrm{E}+02$ & $-1.43 E+03$ \\
\hline$-5.31 E+01$ & $1.53 E+02$ & $-1.43 E+03$ & $-4.26 \mathrm{E}+01$ & $2.90 E+02$ & $-1.44 \mathrm{E}+03$ \\
\hline$-3.26 \mathrm{E}+00$ & $3.06 \mathrm{E}+02$ & $-1.45 E+03$ & $-7.34 \mathrm{E}+01$ & $1.39 \mathrm{E}+02$ & $-1.43 E+03$ \\
\hline$-6.01 E+01$ & $1.61 E+02$ & $-1.43 E+03$ & $-4.28 \mathrm{E}+01$ & $95 \mathrm{E}+02$ & $-1.44 \mathrm{E}+03$ \\
\hline$-2.69 E+00$ & $E+02$ & $-1.45 E+03$ & $-8.01 E+01$ & $46 \mathrm{E}+02$ & +03 \\
\hline$-6.66 \mathrm{E}+01$ & $1.69 \mathrm{E}+02$ & $-1.43 E+03$ & -4.2 & $2 E+02$ & \pm+03 \\
\hline$-2.70 \mathrm{E}+00$ & $3.15 E+02$ & $-1.45 E+03$ & $-8.65 E+01$ & $1.53 \mathrm{E}+02$ & $-1.43 E+03$ \\
\hline$-7.27 E+01$ & $1.77 \mathrm{E}+02$ & $-1.43 E+03$ & $-4.28 \mathrm{E}+01$ & $.06 \mathrm{E}+02$ & $-1.44 \mathrm{E}+03$ \\
\hline$-2.85 E+00$ & $9 \mathrm{E}+02$ & $-1.45 E+03$ & $-9.26 E+01$ & $1 E+02$ & $43 E+03$ \\
\hline+01 & 02 & 03 & -4 & +02 & +03 \\
\hline$-2.05 E+01$ & $2.72 \mathrm{E}+02$ & $-1.44 \mathrm{E}+03$ & $-9.86 E+01$ & $1.68 \mathrm{E}+02$ & $-1.43 E+03$ \\
\hline$-2.48 \mathrm{E}+01$ & $1.14 \mathrm{E}+02$ & $-1.44 \mathrm{E}+03$ & $-4.21 E+01$ & $3.17 \mathrm{E}+02$ & $-1.44 \mathrm{E}+03$ \\
\hline$-2.12 \mathrm{E}+01$ & $7 E+02$ & $-1.44 \mathrm{E}+03$ & $-1.04 \mathrm{E}+02$ & $\mathrm{E}+02$ & $3 E+03$ \\
\hline & & & & & \\
\hline$-2.20 \mathrm{E}+01$ & $2.82 \mathrm{E}+02$ & $-1.44 \mathrm{E}+03$ & $-5.60 E+01$ & $1.08 \mathrm{E}+02$ & $-1.43 E+03$ \\
\hline$-4.08 \mathrm{E}+01$ & $1.26 \mathrm{E}+02$ & $-1.43 E+03$ & $-6.00 \mathrm{E}+01$ & $2.71 \mathrm{E}+02$ & $-1.43 E+03$ \\
\hline$-2.25 \mathrm{E}+01$ & $2.87 \mathrm{E}+02$ & $-1.44 \mathrm{E}+03$ & $-6.32 E+01$ & $1.15 \mathrm{E}+02$ & $-1.43 E+03$ \\
\hline$-4.84 \mathrm{E}+01$ & $1.32 \mathrm{E}+02$ & $-1.43 E+03$ & $-6.07 E+01$ & $6 \mathrm{E}+02$ & $-1.43 E+03$ \\
\hline$-2.28 \mathrm{E}+01$ & $2.92 \mathrm{E}+02$ & $-1.44 \mathrm{E}+03$ & $-7.03 E+01$ & $1.19 \mathrm{E}+02$ & $-1.43 E+03$ \\
\hline$-5.58 \mathrm{E}+01$ & $1.39 \mathrm{E}+02$ & $-1.43 E+03$ & $-6.11 E+01$ & $2.81 E+02$ & $-1.43 E+03$ \\
\hline$-2.30 E+01$ & $2.98 \mathrm{E}+02$ & $-1.44 E+03$ & $-7.76 \mathrm{E}+01$ & $1.26 \mathrm{E}+02$ & $-1.43 E+03$ \\
\hline$-6.29 \mathrm{E}+01$ & $1.45 \mathrm{E}+02$ & $-1.43 E+03$ & $-6.22 \mathrm{E}+01$ & $2.87 \mathrm{E}+02$ & $-1.43 E+03$ \\
\hline$-2.30 E+01$ & $3.02 E+02$ & $-1.44 E+03$ & $-8.42 E+01$ & $1.31 \mathrm{E}+02$ & $-1.43 E+03$ \\
\hline$-6.97 \mathrm{E}+01$ & $1.53 \mathrm{E}+02$ & $-1.43 E+03$ & $-6.23 E+01$ & $2.91 \mathrm{E}+02$ & $-1.43 E+03$ \\
\hline$-2.27 \mathrm{E}+01$ & $3.08 \mathrm{E}+02$ & $-1.44 \mathrm{E}+03$ & $-9.08 E+01$ & $1.40 \mathrm{E}+02$ & $-1.43 E+03$ \\
\hline$-7.61 \mathrm{E}+01$ & $1.60 \mathrm{E}+02$ & $-1.43 E+03$ & $-6.24 \mathrm{E}+01$ & $2.96 \mathrm{E}+02$ & $-1.43 E+03$ \\
\hline$-2.28 \mathrm{E}+01$ & $3.11 E+02$ & $-1.44 \mathrm{E}+03$ & $-9.76 E+01$ & $1.45 \mathrm{E}+02$ & $-1.42 \mathrm{E}+03$ \\
\hline$-8.25 E+01$ & $1.68 \mathrm{E}+02$ & $-1.43 E+03$ & $-6.26 \mathrm{E}+01$ & $3.02 \mathrm{E}+02$ & $-1.43 E+03$ \\
\hline$-2.22 \mathrm{E}+01$ & $3.17 E+02$ & $-1.44 \mathrm{E}+03$ & $-1.04 \mathrm{E}+02$ & $1.54 \mathrm{E}+02$ & $-1.42 \mathrm{E}+03$ \\
\hline$-8.83 E+01$ & $1.77 \mathrm{E}+02$ & $-1.43 E+03$ & $-6.22 \mathrm{E}+01$ & $3.07 E+02$ & $-1.44 \mathrm{E}+03$ \\
\hline$-2.15 \mathrm{E}+01$ & $3.22 E+02$ & $-1.44 \mathrm{E}+03$ & $-1.09 E+02$ & $1.60 \mathrm{E}+02$ & $-1.42 \mathrm{E}+03$ \\
\hline$-3.63 E+01$ & $1.10 \mathrm{E}+02$ & $-1.43 E+03$ & $-6.21 E+01$ & $3.12 \mathrm{E}+02$ & $-1.44 \mathrm{E}+03$ \\
\hline$-4.02 E+01$ & $2.71 E+02$ & $-1.44 \mathrm{E}+03$ & $-1.15 E+02$ & $1.67 E+02$ & $-1.42 \mathrm{E}+03$ \\
\hline$-4.41 E+01$ & $1.15 \mathrm{E}+02$ & $-1.43 E+03$ & $-6.16 \mathrm{E}+01$ & $3.18 \mathrm{E}+02$ & $-1.44 \mathrm{E}+03$ \\
\hline$-4.08 \mathrm{E}+01$ & $2.76 \mathrm{E}+02$ & $-1.44 \mathrm{E}+03$ & $-1.21 E+02$ & $1.75 \mathrm{E}+02$ & $-1.42 \mathrm{E}+03$ \\
\hline
\end{tabular}




\begin{tabular}{|c|c|c|c|c|c|}
\hline X-Cord. & Y-Cord. & Z-Cord. & X-Cord. & Y-Cord. & Z-Cord. \\
\hline$-6.11 E+01$ & $3.23 E+02$ & $-1.44 \mathrm{E}+03$ & $-1.43 E+02$ & $1.60 \mathrm{E}+02$ & $-1.42 E+03$ \\
\hline$-7.56 \mathrm{E}+01$ & $1.09 \mathrm{E}+02$ & $-1.43 E+03$ & $-1.01 \mathrm{E}+02$ & $3.10 \mathrm{E}+02$ & $-1.43 E+03$ \\
\hline$-7.97 E+01$ & $2.71 \mathrm{E}+02$ & $-1.43 E+03$ & $-1.49 E+02$ & $1.65 \mathrm{E}+02$ & $-1.42 \mathrm{E}+03$ \\
\hline$-8.25 \mathrm{E}+01$ & $1.15 \mathrm{E}+02$ & $-1.43 E+03$ & $-1.01 \mathrm{E}+02$ & $3.16 \mathrm{E}+02$ & $-1.43 E+03$ \\
\hline$-8.02 E+01$ & $2.74 \mathrm{E}+02$ & $-1.43 E+03$ & $-1.53 E+02$ & $1.75 \mathrm{E}+02$ & $-1.42 \mathrm{E}+03$ \\
\hline$-8.88 \mathrm{E}+01$ & $1.20 \mathrm{E}+02$ & $-1.42 \mathrm{E}+03$ & $-1.01 E+02$ & $3.22 \mathrm{E}+02$ & $-1.43 E+03$ \\
\hline$-8.07 E+01$ & $2.78 \mathrm{E}+02$ & $-1.43 E+03$ & $-1.15 E+02$ & $1.06 \mathrm{E}+02$ & $-1.42 \mathrm{E}+03$ \\
\hline$-9.62 \mathrm{E}+01$ & $1.23 \mathrm{E}+02$ & $-1.42 \mathrm{E}+03$ & $-1.18 \mathrm{E}+02$ & $2.70 \mathrm{E}+02$ & $-1.42 \mathrm{E}+03$ \\
\hline$-8.13 E+01$ & $2.87 \mathrm{E}+02$ & $-1.43 E+03$ & $-1.21 E+02$ & $1.13 \mathrm{E}+02$ & $-1.42 \mathrm{E}+03$ \\
\hline$-1.03 E+02$ & $1.33 \mathrm{E}+02$ & $-1.42 \mathrm{E}+03$ & $-1.19 \mathrm{E}+02$ & $2.75 \mathrm{E}+02$ & $-1.42 \mathrm{E}+03$ \\
\hline$-8.19 E+01$ & $2.92 \mathrm{E}+02$ & $-1.43 E+03$ & $-1.27 E+02$ & $1.18 \mathrm{E}+02$ & $-1.42 \mathrm{E}+03$ \\
\hline$-1.09 E+02$ & $1.38 \mathrm{E}+02$ & $-1.42 \mathrm{E}+03$ & $-1.20 \mathrm{E}+02$ & $2.80 \mathrm{E}+02$ & $-1.42 \mathrm{E}+03$ \\
\hline$-8.19 E+01$ & $2.96 \mathrm{E}+02$ & $-1.43 E+03$ & $-1.34 \mathrm{E}+02$ & $1.24 \mathrm{E}+02$ & $-1.42 \mathrm{E}+03$ \\
\hline$-1.16 \mathrm{E}+02$ & $1.45 \mathrm{E}+02$ & $-1.42 \mathrm{E}+03$ & $-1.21 \mathrm{E}+02$ & $2.85 \mathrm{E}+02$ & $-1.42 \mathrm{E}+03$ \\
\hline$-8.19 E+01$ & $3.01 \mathrm{E}+02$ & $-1.43 E+03$ & $-1.39 E+02$ & $1.32 \mathrm{E}+02$ & $-1.42 \mathrm{E}+03$ \\
\hline$-1.21 \mathrm{E}+02$ & $1.52 \mathrm{E}+02$ & $-1.42 \mathrm{E}+03$ & $-1.21 \mathrm{E}+02$ & $2.88 \mathrm{E}+02$ & $-1.42 \mathrm{E}+03$ \\
\hline$-8.23 E+01$ & $3.08 \mathrm{E}+02$ & $-1.43 E+03$ & $-1.45 E+02$ & $1.36 \mathrm{E}+02$ & $-1.42 E+03$ \\
\hline$-1.27 \mathrm{E}+02$ & $1.59 \mathrm{E}+02$ & $-1.42 \mathrm{E}+03$ & $-1.21 E+02$ & $2.96 \mathrm{E}+02$ & $-1.42 \mathrm{E}+03$ \\
\hline$-8.18 \mathrm{E}+01$ & $3.11 \mathrm{E}+02$ & $-1.43 E+03$ & $-1.51 E+02$ & $1.44 \mathrm{E}+02$ & $-1.41 E+03$ \\
\hline$-1.32 \mathrm{E}+02$ & $1.67 \mathrm{E}+02$ & $-1.42 \mathrm{E}+03$ & $-1.21 E+02$ & $3.02 E+02$ & $-1.42 \mathrm{E}+03$ \\
\hline$-8.14 \mathrm{E}+01$ & $3.18 \mathrm{E}+02$ & $-1.43 E+03$ & $-1.56 \mathrm{E}+02$ & $1.50 \mathrm{E}+02$ & $-1.41 E+03$ \\
\hline$-1.37 \mathrm{E}+02$ & $1.74 \mathrm{E}+02$ & $-1.42 \mathrm{E}+03$ & $-1.21 E+02$ & $3.06 \mathrm{E}+02$ & $-1.42 \mathrm{E}+03$ \\
\hline$-8.21 E+01$ & $3.21 \mathrm{E}+02$ & $-1.43 E+03$ & $-1.62 E+02$ & $1.55 \mathrm{E}+02$ & $-1.41 E+03$ \\
\hline$-9.52 E+01$ & $1.08 \mathrm{E}+02$ & $-1.42 \mathrm{E}+03$ & $-1.21 E+02$ & $3.11 E+02$ & $-1.42 \mathrm{E}+03$ \\
\hline$-9.90 \mathrm{E}+01$ & $2.68 \mathrm{E}+02$ & $-1.43 E+03$ & $-1.66 \mathrm{E}+02$ & $1.61 \mathrm{E}+02$ & $-1.41 E+03$ \\
\hline$-1.02 E+02$ & $1.14 \mathrm{E}+02$ & $-1.42 \mathrm{E}+03$ & $-1.21 E+02$ & $3.16 \mathrm{E}+02$ & $-1.42 \mathrm{E}+03$ \\
\hline$-9.96 \mathrm{E}+01$ & $2.72 \mathrm{E}+02$ & $-1.43 E+03$ & $-1.71 E+02$ & $1.68 \mathrm{E}+02$ & $-1.41 E+03$ \\
\hline$-1.08 \mathrm{E}+02$ & $1.18 \mathrm{E}+02$ & $-1.42 E+03$ & $-1.20 E+02$ & $3.21 E+02$ & $-1.42 \mathrm{E}+03$ \\
\hline$-1.01 E+02$ & $2.80 \mathrm{E}+02$ & $-1.43 E+03$ & & & \\
\hline$-1.15 \mathrm{E}+02$ & $1.26 \mathrm{E}+02$ & $-1.42 \mathrm{E}+03$ & & & \\
\hline$-1.01 \mathrm{E}+02$ & $2.86 \mathrm{E}+02$ & $-1.43 E+03$ & & & \\
\hline$-1.21 E+02$ & $1.31 \mathrm{E}+02$ & $-1.42 E+03$ & & & \\
\hline$-1.01 \mathrm{E}+02$ & $2.91 \mathrm{E}+02$ & $-1.43 E+03$ & & & \\
\hline$-1.27 \mathrm{E}+02$ & $1.38 \mathrm{E}+02$ & $-1.42 \mathrm{E}+03$ & & & \\
\hline$-1.02 \mathrm{E}+02$ & $2.96 \mathrm{E}+02$ & $-1.43 E+03$ & & & \\
\hline$-1.33 E+02$ & $1.44 \mathrm{E}+02$ & $-1.42 \mathrm{E}+03$ & & & \\
\hline$-1.02 \mathrm{E}+02$ & $3.00 \mathrm{E}+02$ & $-1.43 E+03$ & & & \\
\hline$-1.38 \mathrm{E}+02$ & $1.51 \mathrm{E}+02$ & $-1.42 \mathrm{E}+03$ & & & \\
\hline$-1.02 \mathrm{E}+02$ & $3.06 \mathrm{E}+02$ & $-1.43 E+03$ & & & \\
\hline
\end{tabular}


Table C-0-7:Deflection Correction.

\begin{tabular}{|c|c|c|c|c|c|}
\hline X-Cord. & -Cord. & X-Cord. & Y-Cord. & X-Cord. & Y-Cord. \\
\hline $1.87 \mathrm{E}+02$ & $4.20 \mathrm{E}+02$ & $-2.14 \mathrm{E}+01$ & $3.32 \mathrm{E}+01$ & $5.41 \mathrm{E}+00$ & $1.89 \mathrm{E}+02$ \\
\hline $6.31 \mathrm{E}+01$ & $-1.49 \mathrm{E}+01$ & $4.48 \mathrm{E}+01$ & $98 \mathrm{E}+02$ & $-3.93 \mathrm{E}+01$ & $2.14 \mathrm{E}+01$ \\
\hline $6.48 \mathrm{E}+01$ & $1.65 \mathrm{E}+02$ & $-2.84 \mathrm{E}+01$ & $.04 \mathrm{E}+01$ & $5.58 \mathrm{E}+00$ & $1.92 \mathrm{E}+02$ \\
\hline $5.36 \mathrm{E}+01$ & $-9.87 E+00$ & $4.53 E+01$ & $01 \mathrm{E}+02$ & $-4.61 E+01$ & $2.66 \mathrm{E}+01$ \\
\hline $6.40 \mathrm{E}+01$ & $1.70 \mathrm{E}+02$ & $-3.52 E+01$ & 4.77E+01 & $5.82 \mathrm{E}+00$ & $1.96 \mathrm{E}+02$ \\
\hline $4.47 \mathrm{E}+01$ & $-4.43 E+00$ & $4.59 \mathrm{E}+01$ & $2.05 E+02$ & $-5.26 \mathrm{E}+01$ & $3.32 \mathrm{E}+01$ \\
\hline $6.35 \mathrm{E}+01$ & $1.74 \mathrm{E}+02$ & $2.40 \mathrm{E}+01$ & $-1.34 \mathrm{E}+01$ & $6.04 \mathrm{E}+00$ & $2.00 \mathrm{E}+02$ \\
\hline $3.55 \mathrm{E}+01$ & $1.14 \mathrm{E}+00$ & $2.56 \mathrm{E}+01$ & $1.66 \mathrm{E}+02$ & $-5.88 \mathrm{E}+01$ & $8 \mathrm{E}+01$ \\
\hline+01 & $8 \mathrm{E}+02$ & $E+01$ & $-8.28 \mathrm{E}+00$ & $E+00$ & $E+02$ \\
\hline $2.69 \mathrm{E}+01$ & $7.41 \mathrm{E}+00$ & $2.46 \mathrm{E}+01$ & $\mathrm{IE}+02$ & $2 \mathrm{E}+01$ & $7 \mathrm{E}+01$ \\
\hline $6.31 \mathrm{E}+01$ & $1.82 \mathrm{E}+02$ & $7.90 \mathrm{E}+00$ & $-2.61 E+00$ & $7.16 \mathrm{E}+00$ & $2.07 \mathrm{E}+02$ \\
\hline $1.84 \mathrm{E}+01$ & $4 \mathrm{E}+01$ & $2.50 \mathrm{E}+01$ & $75 \mathrm{E}+02$ & $-1.46 \mathrm{E}+01$ & $-1.26 \mathrm{E}+01$ \\
\hline $6.31 \mathrm{E}+01$ & $1.86 \mathrm{E}+02$ & $7.68 \mathrm{E}-02$ & $2.77 \mathrm{E}+00$ & $-1.32 \mathrm{E}+01$ & $1.66 \mathrm{E}+02$ \\
\hline $1.01 \mathrm{E}+01$ & $1.99 \mathrm{E}+01$ & $2.47 \mathrm{E}+01$ & $E+02$ & $\mathrm{E}+01$ & $\mathrm{E}+00$ \\
\hline $6.31 \mathrm{E}+01$ & $1.90 \mathrm{E}+02$ & $-7.61 \mathrm{E}+00$ & $8.87 \mathrm{E}+00$ & $-1.36 \mathrm{E}+01$ & $1.71 \mathrm{E}+02$ \\
\hline $1.92 \mathrm{E}+00$ & $2.66 \mathrm{E}+01$ & $2.48 \mathrm{E}+01$ & $1.84 \mathrm{E}+02$ & $-2.90 \mathrm{E}+01$ & $-1.77 \mathrm{E}+00$ \\
\hline $6.36 \mathrm{E}+01$ & $1.93 \mathrm{E}+02$ & $-1.52 \mathrm{E}+01$ & $1.54 \mathrm{E}+01$ & $-1.38 \mathrm{E}+01$ & $1.75 \mathrm{E}+02$ \\
\hline$-6.14 \mathrm{E}+00$ & $3.33 \mathrm{E}+01$ & & & $-3.61 E+01$ & \\
\hline $6.41 \mathrm{E}+01$ & $1.96 \mathrm{E}+02$ & $-2.25 \mathrm{E}+01$ & $2.03 \mathrm{E}+01$ & $-1.39 \mathrm{E}+01$ & $1.80 \mathrm{E}+02$ \\
\hline$-1.37 \mathrm{E}+01$ & $4.04 \mathrm{E}+01$ & $2.48 \mathrm{E}+01$ & $1.92 \mathrm{E}+02$ & $-4.32 \mathrm{E}+01$ & $8.50 \mathrm{E}+00$ \\
\hline $6.46 \mathrm{E}+01$ & $1.99 \mathrm{E}+02$ & $-2.98 \mathrm{E}+01$ & $2.76 \mathrm{E}+01$ & $-1.41 E+01$ & $1.85 \mathrm{E}+02$ \\
\hline$-2.12 \mathrm{E}+01$ & 4.74E+01 & $2.51 \mathrm{E}+01$ & $1.96 \mathrm{E}+02$ & $-4.97 \mathrm{E}+01$ & $1.47 \mathrm{E}+01$ \\
\hline $6.52 \mathrm{E}+01$ & $2.01 \mathrm{E}+02$ & $-3.67 \mathrm{E}+01$ & $3.28 \mathrm{E}+01$ & $-1.40 \mathrm{E}+01$ & $1.88 \mathrm{E}+02$ \\
\hline $4.35 \mathrm{E}+01$ & $-1.41 E+01$ & $2.55 \mathrm{E}+01$ & $1.99 \mathrm{E}+02$ & $-5.60 \mathrm{E}+01$ & $2.09 E+01$ \\
\hline $4.51 \mathrm{E}+01$ & $1.65 \mathrm{E}+02$ & $-4.35 \mathrm{E}+01$ & $3.97 \mathrm{E}+01$ & $-1.39 \mathrm{E}+01$ & $1.93 E+02$ \\
\hline $3.48 \mathrm{E}+01$ & $-8.86 E+00$ & $2.59 \mathrm{E}+01$ & $2.02 \mathrm{E}+02$ & $-6.27 \mathrm{E}+01$ & $2.74 \mathrm{E}+01$ \\
\hline $4.47 \mathrm{E}+01$ & $1.70 \mathrm{E}+02$ & $-4.99 \mathrm{E}+01$ & $4.76 \mathrm{E}+01$ & $-1.40 \mathrm{E}+01$ & $1.97 \mathrm{E}+02$ \\
\hline $2.63 \mathrm{E}+01$ & $-3.30 E+00$ & $2.65 \mathrm{E}+01$ & $2.07 \mathrm{E}+02$ & $-6.88 \mathrm{E}+01$ & $3.33 \mathrm{E}+01$ \\
\hline $4.43 E+01$ & $1.75 \mathrm{E}+02$ & $4.73 E+00$ & $-1.25 \mathrm{E}+01$ & $-1.33 \mathrm{E}+01$ & $2.01 E+02$ \\
\hline $1.78 \mathrm{E}+01$ & $2.25 \mathrm{E}+00$ & $6.30 \mathrm{E}+00$ & $1.65 E+02$ & $-7.48 \mathrm{E}+01$ & $3.94 \mathrm{E}+01$ \\
\hline $4.41 \mathrm{E}+01$ & $1.79 \mathrm{E}+02$ & $-2.97 \mathrm{E}+00$ & $-7.87 E+00$ & $-1.28 \mathrm{E}+01$ & $2.04 \mathrm{E}+02$ \\
\hline $9.72 \mathrm{E}+00$ & $8.22 \mathrm{E}+00$ & $6.02 \mathrm{E}+00$ & $1.71 \mathrm{E}+02$ & $-8.06 \mathrm{E}+01$ & $4.57 \mathrm{E}+01$ \\
\hline $4.40 \mathrm{E}+01$ & $1.83 \mathrm{E}+02$ & $-1.06 \mathrm{E}+01$ & $-2.18 \mathrm{E}+00$ & $-1.24 \mathrm{E}+01$ & $2.08 \mathrm{E}+02$ \\
\hline $1.73 \mathrm{E}+00$ & $1.40 \mathrm{E}+01$ & $5.77 \mathrm{E}+00$ & $1.75 \mathrm{E}+02$ & $-3.39 \mathrm{E}+01$ & $-1.20 \mathrm{E}+01$ \\
\hline $4.40 \mathrm{E}+01$ & $1.87 \mathrm{E}+02$ & $-1.80 \mathrm{E}+01$ & $3.44 \mathrm{E}+00$ & $-3.24 \mathrm{E}+01$ & $1.66 \mathrm{E}+02$ \\
\hline$-6.23 E+00$ & $2.02 \mathrm{E}+01$ & $5.47 \mathrm{E}+00$ & $1.80 \mathrm{E}+02$ & $-4.09 \mathrm{E}+01$ & $-6.42 \mathrm{E}+00$ \\
\hline $4.40 \mathrm{E}+01$ & $1.91 \mathrm{E}+02$ & $-2.53 \mathrm{E}+01$ & $8.69 \mathrm{E}+00$ & $-3.27 E+01$ & $1.71 \mathrm{E}+02$ \\
\hline$-1.39 E+01$ & $2.65 \mathrm{E}+01$ & $5.34 \mathrm{E}+00$ & $1.83 \mathrm{E}+02$ & $-4.74 \mathrm{E}+01$ & $-1.31 \mathrm{E}+00$ \\
\hline $4.44 \mathrm{E}+01$ & $1.95 \mathrm{E}+02$ & $-3.25 \mathrm{E}+01$ & $1.57 \mathrm{E}+01$ & $-3.30 \mathrm{E}+01$ & $1.75 E+02$ \\
\hline
\end{tabular}




\begin{tabular}{|c|c|c|c|c|c|}
\hline X-Cord. & Y-Cord. & X-Cord. & Y-Cord. & X-Cord. & Y-Cord. \\
\hline$-5.42 \mathrm{E}+01$ & $4.39 E+00$ & $-7.07 E+01$ & $1.64 \mathrm{E}+02$ & $-1.41 E+02$ & $4.03 E+01$ \\
\hline$-3.31 E+01$ & $1.80 \mathrm{E}+02$ & $-7.85 E+01$ & $-6.24 E+00$ & $-9.06 E+01$ & $2.08 \mathrm{E}+02$ \\
\hline$-6.06 \mathrm{E}+01$ & $1.01 \mathrm{E}+01$ & $-7.13 E+01$ & $1.70 \mathrm{E}+02$ & $-1.46 \mathrm{E}+02$ & $4.77 \mathrm{E}+01$ \\
\hline$-3.32 \mathrm{E}+01$ & $1.84 \mathrm{E}+02$ & $-8.45 E+01$ & $1.48 \mathrm{E}-01$ & $-9.05 E+01$ & $2.12 \mathrm{E}+02$ \\
\hline$-6.70 \mathrm{E}+01$ & $1.58 \mathrm{E}+01$ & $-7.15 E+01$ & $1.74 \mathrm{E}+02$ & $-1.11 \mathrm{E}+02$ & $-9.23 E+00$ \\
\hline$-3.33 E+01$ & $1.88 \mathrm{E}+02$ & $-9.04 E+01$ & $5.17 \mathrm{E}+00$ & $-1.10 \mathrm{E}+02$ & $1.66 \mathrm{E}+02$ \\
\hline$-7.33 \mathrm{E}+01$ & $2.14 \mathrm{E}+01$ & $-7.19 E+01$ & $1.79 E+02$ & $-1.17 \mathrm{E}+02$ & $-5.87 E+00$ \\
\hline$-3.32 E+01$ & $1.93 \mathrm{E}+02$ & $-9.64 E+01$ & $1.06 \mathrm{E}+01$ & $-1.10 E+02$ & $1.73 E+02$ \\
\hline$-7.91 E+01$ & $2.80 \mathrm{E}+01$ & $-7.21 E+01$ & $1.83 E+02$ & $-1.22 \mathrm{E}+02$ & 8.27E-01 \\
\hline$-3.29 E+01$ & $1.96 \mathrm{E}+02$ & $-1.02 E+02$ & $1.53 E+01$ & $-1.10 \mathrm{E}+02$ & $1.77 \mathrm{E}+02$ \\
\hline$-8.50 E+01$ & $3.40 E+01$ & $-7.20 \mathrm{E}+01$ & $1.88 \mathrm{E}+02$ & $-1.27 \mathrm{E}+02$ & $5.93 \mathrm{E}+00$ \\
\hline$-3.27 E+01$ & $2.00 E+02$ & $-1.08 \mathrm{E}+02$ & $2.13 E+01$ & $-1.10 \mathrm{E}+02$ & $1.81 \mathrm{E}+02$ \\
\hline$-9.11 E+01$ & $3.84 \mathrm{E}+01$ & $-7.19 E+01$ & $1.92 \mathrm{E}+02$ & $-1.33 E+02$ & $1.13 \mathrm{E}+01$ \\
\hline$-3.22 \mathrm{E}+01$ & $2.06 \mathrm{E}+02$ & $-1.13 E+02$ & $2.90 \mathrm{E}+01$ & $-1.11 \mathrm{E}+02$ & $1.86 \mathrm{E}+02$ \\
\hline$-9.65 E+01$ & $4.61 E+01$ & $-7.16 \mathrm{E}+01$ & $1.96 \mathrm{E}+02$ & $-1.38 \mathrm{E}+02$ & $1.89 \mathrm{E}+01$ \\
\hline$-3.17 E+01$ & $2.10 E+02$ & $-1.18 \mathrm{E}+02$ & $3.36 \mathrm{E}+01$ & $-1.10 E+02$ & $1.88 \mathrm{E}+02$ \\
\hline$-5.33 E+01$ & $-1.05 E+01$ & $-7.15 E+01$ & $2.01 E+02$ & $-1.43 E+02$ & $2.29 \mathrm{E}+01$ \\
\hline$-5.17 \mathrm{E}+01$ & $1.67 E+02$ & $-1.23 E+02$ & $3.74 \mathrm{E}+01$ & $-1.10 \mathrm{E}+02$ & $1.94 \mathrm{E}+02$ \\
\hline$-5.97 E+01$ & $-5.91 E+00$ & $-7.10 \mathrm{E}+01$ & $2.05 E+02$ & $-1.48 \mathrm{E}+02$ & $2.96 \mathrm{E}+01$ \\
\hline$-5.22 \mathrm{E}+01$ & $1.72 \mathrm{E}+02$ & $-1.29 E+02$ & $4.36 \mathrm{E}+01$ & $-1.10 \mathrm{E}+02$ & $1.98 \mathrm{E}+02$ \\
\hline$-6.61 E+01$ & $4.98 \mathrm{E}-01$ & $-7.05 E+01$ & $2.09 E+02$ & $-1.53 E+02$ & $3.38 \mathrm{E}+01$ \\
\hline$-5.23 E+01$ & $1.76 \mathrm{E}+02$ & $-9.17 \mathrm{E}+01$ & $-9.03 E+00$ & $-1.10 \mathrm{E}+02$ & $2.03 E+02$ \\
\hline$-7.24 \mathrm{E}+01$ & $5.37 \mathrm{E}+00$ & $-9.03 E+01$ & $1.67 \mathrm{E}+02$ & $-1.58 \mathrm{E}+02$ & $3.83 E+01$ \\
\hline$-5.26 \mathrm{E}+01$ & $1.81 \mathrm{E}+02$ & $-9.76 \mathrm{E}+01$ & $-4.46 \mathrm{E}+00$ & $-1.10 \mathrm{E}+02$ & $2.09 E+02$ \\
\hline$-7.85 \mathrm{E}+01$ & $1.12 \mathrm{E}+01$ & $-9.07 E+01$ & $1.73 \mathrm{E}+02$ & $-1.63 E+02$ & $4.61 \mathrm{E}+01$ \\
\hline$-5.27 \mathrm{E}+01$ & $1.85 \mathrm{E}+02$ & $-1.03 E+02$ & $1.15 \mathrm{E}+00$ & $-1.10 \mathrm{E}+02$ & $2.12 \mathrm{E}+02$ \\
\hline$-8.45 E+01$ & $1.71 \mathrm{E}+01$ & $-9.10 \mathrm{E}+01$ & $1.77 \mathrm{E}+02$ & & \\
\hline$-5.27 \mathrm{E}+01$ & $1.89 E+02$ & $-1.09 E+02$ & $8.13 E+00$ & & \\
\hline$-9.05 E+01$ & $2.23 \mathrm{E}+01$ & $-9.11 E+01$ & $1.81 \mathrm{E}+02$ & & \\
\hline$-5.25 \mathrm{E}+01$ & $1.94 \mathrm{E}+02$ & $-1.15 \mathrm{E}+02$ & $1.21 \mathrm{E}+01$ & & \\
\hline$-9.61 E+01$ & $2.81 \mathrm{E}+01$ & $-9.14 \mathrm{E}+01$ & $1.87 \mathrm{E}+02$ & & \\
\hline$-5.22 \mathrm{E}+01$ & $1.99 E+02$ & $-1.20 \mathrm{E}+02$ & $1.69 E+01$ & & \\
\hline$-1.02 \mathrm{E}+02$ & $3.35 \mathrm{E}+01$ & $-9.13 E+01$ & $1.91 \mathrm{E}+02$ & & \\
\hline$-5.20 \mathrm{E}+01$ & $2.03 E+02$ & $-1.26 \mathrm{E}+02$ & $2.28 \mathrm{E}+01$ & & \\
\hline$-1.07 \mathrm{E}+02$ & $4.10 \mathrm{E}+01$ & $-9.12 E+01$ & $1.95 \mathrm{E}+02$ & & \\
\hline$-5.19 \mathrm{E}+01$ & $2.06 \mathrm{E}+02$ & $-1.31 \mathrm{E}+02$ & $2.92 \mathrm{E}+01$ & & \\
\hline$-1.12 \mathrm{E}+02$ & $4.70 \mathrm{E}+01$ & $-9.09 E+01$ & $2.00 \mathrm{E}+02$ & & \\
\hline$-5.12 \mathrm{E}+01$ & $2.11 E+02$ & $-1.36 \mathrm{E}+02$ & $3.33 E+01$ & & \\
\hline$-7.23 \mathrm{E}+01$ & $-1.02 \mathrm{E}+01$ & $-9.07 E+01$ & $2.05 E+02$ & & \\
\hline
\end{tabular}


Deflection Angle Data

Table 0-8:Deflection Angle Data.

\begin{tabular}{|c|c|c|c|c|c|}
\hline X-Cord. & Y-Cord. & X-Cord. & Y-Cord. & X-Cord. & Y-Cord. \\
\hline 186.5336 & 419.868 & $-5.05 E+01$ & $4.22 \mathrm{E}+01$ & $-3.30 E+01$ & $1.94 \mathrm{E}+02$ \\
\hline $6.30 \mathrm{E}+01$ & $-1.51 E+01$ & $2.64 \mathrm{E}+01$ & $2.01 E+02$ & $-9.40 \mathrm{E}+01$ & $3.82 E+01$ \\
\hline $6.43 \mathrm{E}+01$ & $1.65 E+02$ & $-6.27 E+01$ & $5.63 E+01$ & $-3.24 E+01$ & $2.01 \mathrm{E}+02$ \\
\hline $4.66 \mathrm{E}+01$ & $-7.52 \mathrm{E}+00$ & $2.77 \mathrm{E}+01$ & $2.07 \mathrm{E}+02$ & $-1.07 \mathrm{E}+02$ & $5.29 E+01$ \\
\hline $6.36 \mathrm{E}+01$ & $1.71 E+02$ & $4.40 E+00$ & $-1.30 \mathrm{E}+01$ & $-3.10 E+01$ & $2.11 \mathrm{E}+02$ \\
\hline $3.11 \mathrm{E}+01$ & $1.46 \mathrm{E}+00$ & $6.12 \mathrm{E}+00$ & $1.66 \mathrm{E}+02$ & $-1.18 \mathrm{E}+02$ & $6.75 \mathrm{E}+01$ \\
\hline $6.31 \mathrm{E}+01$ & $1.78 \mathrm{E}+02$ & $-1.17 \mathrm{E}+01$ & $-3.03 E+00$ & $-2.96 \mathrm{E}+01$ & $2.17 \mathrm{E}+02$ \\
\hline $1.60 \mathrm{E}+01$ & $1.17 \mathrm{E}+01$ & $5.37 \mathrm{E}+00$ & $1.74 \mathrm{E}+02$ & $-5.36 \mathrm{E}+01$ & $-1.16 \mathrm{E}+01$ \\
\hline $6.30 \mathrm{E}+01$ & $1.84 \mathrm{E}+02$ & $-2.74 \mathrm{E}+01$ & $7.08 \mathrm{E}+00$ & $-5.21 E+01$ & $1.67 \mathrm{E}+02$ \\
\hline $1.46 \mathrm{E}+00$ & $2.27 \mathrm{E}+01$ & $5.15 \mathrm{E}+00$ & $1.83 \mathrm{E}+02$ & $-6.97 \mathrm{E}+01$ & $-2.11 \mathrm{E}-01$ \\
\hline $6.35 \mathrm{E}+01$ & $1.89 E+02$ & $-4.22 E+01$ & $1.98 \mathrm{E}+01$ & $-5.27 E+01$ & 1.77E+02 \\
\hline$-1.24 \mathrm{E}+01$ & $3.45 \mathrm{E}+01$ & $5.43 E+00$ & $1.90 \mathrm{E}+02$ & $-8.49 \mathrm{E}+01$ & $1.34 \mathrm{E}+01$ \\
\hline $6.43 \mathrm{E}+01$ & $1.94 \mathrm{E}+02$ & $-5.61 E+01$ & $3.21 E+01$ & $-5.29 E+01$ & $1.88 \mathrm{E}+02$ \\
\hline$-2.52 \mathrm{E}+01$ & $4.72 \mathrm{E}+01$ & $6.07 \mathrm{E}+00$ & $1.98 \mathrm{E}+02$ & $-9.95 E+01$ & $69 \mathrm{E}+01$ \\
\hline $6.54 \mathrm{E}+01$ & $1.99 E+02$ & $-6.93 E+01$ & $4.59 E+01$ & $-5.24 \mathrm{E}+01$ & $1.98 \mathrm{E}+02$ \\
\hline $4.32 \mathrm{E}+01$ & $-1.46 \mathrm{E}+01$ & $7.26 \mathrm{E}+00$ & $2.05 \mathrm{E}+02$ & $-1.13 E+02$ & $4.09 E+01$ \\
\hline $4.50 \mathrm{E}+01$ & $1.65 \mathrm{E}+02$ & $-8.13 E+01$ & $6.03 E+01$ & $-5.16 \mathrm{E}+01$ & $2.06 \mathrm{E}+02$ \\
\hline $2.70 \mathrm{E}+01$ & $-6.33 E+00$ & & & & \\
\hline $4.41 \mathrm{E}+01$ & $1.72 \mathrm{E}+02$ & $-1.50 \mathrm{E}+01$ & $-1.27 \mathrm{E}+01$ & $-5.02 \mathrm{E}+01$ & $2.14 \mathrm{E}+02$ \\
\hline $1.15 \mathrm{E}+01$ & $3.22 \mathrm{E}+00$ & $-1.32 \mathrm{E}+01$ & $1.66 \mathrm{E}+02$ & $-1.36 \mathrm{E}+02$ & $7.26 \mathrm{E}+01$ \\
\hline $4.37 \mathrm{E}+01$ & $1.79 E+02$ & $-3.12 E+01$ & $-2.35 E+00$ & $-4.88 \mathrm{E}+01$ & $2.21 E+02$ \\
\hline$-3.64 \mathrm{E}+00$ & $1.41 \mathrm{E}+01$ & $-1.39 \mathrm{E}+01$ & $1.75 \mathrm{E}+02$ & $-7.27 \mathrm{E}+01$ & $-9.65 E+00$ \\
\hline $4.38 \mathrm{E}+01$ & $1.86 \mathrm{E}+02$ & $-4.67 E+01$ & $9.04 \mathrm{E}+00$ & $-7.11 E+01$ & $1.66 \mathrm{E}+02$ \\
\hline$-1.80 \mathrm{E}+01$ & $2.58 \mathrm{E}+01$ & $-1.41 \mathrm{E}+01$ & $1.83 E+02$ & $-8.89 \mathrm{E}+01$ & $1.12 \mathrm{E}+00$ \\
\hline $4.43 \mathrm{E}+01$ & $1.92 \mathrm{E}+02$ & $-6.15 E+01$ & $2.17 \mathrm{E}+01$ & $-7.20 E+01$ & $1.79 \mathrm{E}+02$ \\
\hline$-3.15 E+01$ & $3.85 \mathrm{E}+01$ & $-1.38 \mathrm{E}+01$ & $1.92 \mathrm{E}+02$ & $-1.04 \mathrm{E}+02$ & $1.54 \mathrm{E}+01$ \\
\hline $4.53 \mathrm{E}+01$ & $1.98 \mathrm{E}+02$ & $-7.51 \mathrm{E}+01$ & $3.55 E+01$ & $-7.21 \mathrm{E}+01$ & $1.89 \mathrm{E}+02$ \\
\hline$-4.40 \mathrm{E}+01$ & $5.19 \mathrm{E}+01$ & $-1.31 \mathrm{E}+01$ & $2.00 E+02$ & $-1.18 \mathrm{E}+02$ & $2.82 \mathrm{E}+01$ \\
\hline $4.65 \mathrm{E}+01$ & $2.03 E+02$ & $-8.80 \mathrm{E}+01$ & $4.99 \mathrm{E}+01$ & $-7.17 \mathrm{E}+01$ & $1.98 \mathrm{E}+02$ \\
\hline $2.38 \mathrm{E}+01$ & $-1.38 \mathrm{E}+01$ & $-1.20 \mathrm{E}+01$ & $2.07 E+02$ & $-1.31 \mathrm{E}+02$ & $4.40 \mathrm{E}+01$ \\
\hline $2.54 \mathrm{E}+01$ & $1.66 \mathrm{E}+02$ & $-9.97 \mathrm{E}+01$ & $6.46 \mathrm{E}+01$ & $-7.07 \mathrm{E}+01$ & $2.09 \mathrm{E}+02$ \\
\hline $7.61 \mathrm{E}+00$ & $-4.73 E+00$ & $-1.04 \mathrm{E}+01$ & $2.15 E+02$ & $-1.44 \mathrm{E}+02$ & $5.94 \mathrm{E}+01$ \\
\hline $2.47 \mathrm{E}+01$ & $1.73 E+02$ & $-3.44 E+01$ & $-1.20 \mathrm{E}+01$ & $-6.95 E+01$ & $2.15 E+02$ \\
\hline$-8.26 E+00$ & $5.91 \mathrm{E}+00$ & $-3.26 \mathrm{E}+01$ & $1.66 \mathrm{E}+02$ & $-1.55 E+02$ & $7.46 \mathrm{E}+01$ \\
\hline $2.44 \mathrm{E}+01$ & $1.81 \mathrm{E}+02$ & $-5.04 \mathrm{E}+01$ & $-6.92 \mathrm{E}-01$ & $-6.80 \mathrm{E}+01$ & $2.24 \mathrm{E}+02$ \\
\hline$-2.30 \mathrm{E}+01$ & $1.64 \mathrm{E}+01$ & $-3.34 \mathrm{E}+01$ & $1.78 \mathrm{E}+02$ & $-9.20 \mathrm{E}+01$ & $-1.04 E+01$ \\
\hline $2.47 \mathrm{E}+01$ & $1.88 \mathrm{E}+02$ & $-6.59 \mathrm{E}+01$ & $1.09 \mathrm{E}+01$ & $-9.05 E+01$ & $1.66 \mathrm{E}+02$ \\
\hline$-3.74 \mathrm{E}+01$ & $2.91 \mathrm{E}+01$ & $-3.34 \mathrm{E}+01$ & $1.86 \mathrm{E}+02$ & $-1.08 \mathrm{E}+02$ & $2.59 \mathrm{E}+00$ \\
\hline $2.53 \mathrm{E}+01$ & $1.95 \mathrm{E}+02$ & $-8.02 E+01$ & $2.47 \mathrm{E}+01$ & $-9.12 \mathrm{E}+01$ & $1.78 \mathrm{E}+02$ \\
\hline
\end{tabular}




\begin{tabular}{|l|c|}
\hline$X$-Cord. & Y-Cord. \\
\hline$-1.23 \mathrm{E}+02$ & $1.57 \mathrm{E}+01$ \\
\hline$-9.15 \mathrm{E}+01$ & $1.89 \mathrm{E}+02$ \\
\hline$-1.37 \mathrm{E}+02$ & $3.06 \mathrm{E}+01$ \\
\hline$-9.08 \mathrm{E}+01$ & $2.00 \mathrm{E}+02$ \\
\hline$-1.50 \mathrm{E}+02$ & $4.66 \mathrm{E}+01$ \\
\hline$-8.99 \mathrm{E}+01$ & $2.08 \mathrm{E}+02$ \\
\hline$-1.62 \mathrm{E}+02$ & $6.17 \mathrm{E}+01$ \\
\hline$-8.91 \mathrm{E}+01$ & $2.16 \mathrm{E}+02$ \\
\hline$-1.68 \mathrm{E}+02$ & $7.11 \mathrm{E}+01$ \\
\hline$-8.84 \mathrm{E}+01$ & $2.19 \mathrm{E}+02$ \\
\hline$-1.11 \mathrm{E}+02$ & $-9.94 \mathrm{E}+00$ \\
\hline$-1.09 \mathrm{E}+02$ & $1.64 \mathrm{E}+02$ \\
\hline$-1.27 \mathrm{E}+02$ & $2.76 \mathrm{E}+00$ \\
\hline$-1.10 \mathrm{E}+02$ & $1.78 \mathrm{E}+02$ \\
\hline$-1.42 \mathrm{E}+02$ & $1.58 \mathrm{E}+01$ \\
\hline$-1.11 \mathrm{E}+02$ & $1.89 \mathrm{E}+02$ \\
\hline$-1.56 \mathrm{E}+02$ & $3.20 \mathrm{E}+01$ \\
\hline$-1.10 \mathrm{E}+02$ & $2.01 \mathrm{E}+02$ \\
\hline$-1.69 \mathrm{E}+02$ & $4.82 \mathrm{E}+01$ \\
\hline$-1.09 \mathrm{E}+02$ & $2.11 \mathrm{E}+02$ \\
\hline
\end{tabular}




\section{BIBLIOGRAPHY}

[1] "The Wright Brothers - First Flight, 1903," Eye Witness History, 2003. [Online]. Available: http://www.eyewitnesstohistory.com/wright.htm.

[2] R. Song, "Lecture Notes 2 - Bird Flight I," People EKU, [Online]. Available: http://people.eku.edu/ritchisong/554notes2.html.

[3] S. Barbarino, O. Bilgen, R. M. Ajaj, M. I. Friswell and D. J. Inman, "A Review of Morphing Aircraft," Journal of Intelligent Material Systems and Structures, vol. 22, pp. 823-877, June 2011.

[4] A. Sofla, S. Meguid, K. Tan and W. Yeo, "Shape morphing of aircraft wing: Status and challenges," Material and Design, pp. 1284-1292, 2010.

[5] H. P. Monner, D. Sachau and E. Breitbach, "Design Aspects of the Elastic Trailing Edge for an Adaptive Wing," in Structural Aspects of Flexible Aircraft Control, Ottawa, 1999.

[6] J. Szodruch, "The Influence of Camber Variation on the Aerodynamics of Civili Transport Aircraft," in AIAA 23rd Aerospace Sciences Meeting, Reno, 1985.

[7] J. D. Bartley-Cho, D. P. Wang, C. A. Martin, J. N. Kudva and M. N. West, "Development of High-rate, Adaptive Trailing Edge Control Surface for the Smart Wing Phase 2 Wind Tunnel Model," Journal of Intelligent Material Systems and Structures, vol. 15, pp. 279291, 2004.

[8] P. M. Hetrick and D. B. Paul, "Flight Testing of Mission Adaptive Compliant Wing," in 48th AIAA/ASME/ASCE/AHS/ASC Structures, Structural Dynamics, and Materials Conference, Honolulu, 2007.

[9] D. J. Inman and H. H. Cudney, "Structural and machine design using piezoceramic materials: a guide for structural design engineers," 2000.

[10] W. K. Wilkie, R. G. Bryant, J. W. High, R. L. Fox, R. F. Hellbaum, A. Jalink Jr, B. D. Little and P. H. Mirick, "Low-cost piezocomposite actuator for structural control applications," in SPIE's 7th Annual International Symposium on Smart Structures and Materials, 2000.

[11] "Macro Fiber Composite," [Online]. Available: http://www.smart-material.com/MFCproduct-main.html.

[12] O. Bilgen, "Aerodynamic and electromechanical design, modeling and implementation of piezocomposite airfoils," 2010.

[13] R. J. Prazenica, D. Kim, H. Moncayo, B. Azizi and M. Chan, "Design, characterization, and testing of macro-fiber composite actuators for integration on a fixed-wing UAV," in SPIE 
Smart Structures and Materials + Nondestructive Evaluation and Health Monitoring, 2014.

[14] O. Bilgen, K. B. Kochersberger, D. J. Inman and O. J. Ohanian, "Novel, bidirectional, variable-camber airfoil via macro-fiber composite actuators," Journal of Aircraft, vol. 47, no. 1, pp. 303-314, 2010.

[15] O. Bilgen, M. I. Friswell, K. B. Kochersberger and D. J. Inman, "Surface actuated variablecamber and variable-twist morphing wings using piezocomposites," Proceedings of 52nd AIAA/ASME/ASCE/AHS/ASC Structures, Structural Dynamics, and Materials, vol. 4, no. 7, pp. 2011-2072, 2011.

[16] O. Bilgen, D. Landman and M. I. Friswell, "Low reynolds number behavior of a solid-state piezocomposite variable-camber wing," AIAA Oaoer, vol. 1515, pp. 8-11, 2013.

[17] A. Pankonien and D. J. Inman, "Experimental testing of spanwise morphing trailing edge concept," in SPIE Smart Structures and Materials+ Nondestructive Evaluation and Health Monitoring, 2013.

[18] A. M. Panjonien, C. T. Faria and D. J. Inman, "Synergistic smart morphing aileron: Experimental quasi-static performance characterization," Journal of Intelligent Material Systems and Structures, vol. 26, no. 10, pp. 1179-1190, 2015.

[19] O. J. Ohanian III, E. D. Karni, C. C. Olien, E. A. Gustafson, K. B. Kochersberger, P. A. Gelhausen and B. L. Brown, "Piezoelectric composite morphing control surfaces for unmanned aerial vehicles," in SPIE Smart Structures and Materials + Nondestructive Evaluation and Health Monitoring, 2011.

[20] O. Ohanian III, C. Hickling, B. Stiltner, E. D. Karni, K. B. Kochersberger, T. Probst, P. A. Gelhausen and A. P. Blain, "Piezoelectric morphing versus servo-actuated MAV control surfaces," AIAA Paper, vol. 1512, pp. 23-26, 2012.

[21] V. K. Wickramasinghe, Y. Chen, M. Martinez, R. Kernaghan and F. Wong, "Design and verification of a smart wing for an extremely-agile micro-air-vehicle," California: American Institute of Aeronautics and Astronautics, USA, 2009.

[22] T. D. Usher, K. R. Ulibarri and G. S. Camargo, "Piezoelectric microfiber composite actuators for morphing wings," ISRN Materials Science, 2013.

[23] F. Mattioni, P. Weaver, K. Potter and M. Friswell, "Analysis of thermally induced multistable composites," International Journal of Solids and Structures, vol. 45, no. 2, pp. 657-675, 2008.

[24] S. A. Tawfik, S. D. Dancila and E. Armanios, "Unsymmetric composite laminates morphing via piezoelectric actuators," Composites Part A: Applied Science and Manufacturing, vol. 42, no. 7, pp. 748-756, 2011. 
[25] M. R. Schultz and M. W. Hyer, "A morphing concept based on unsymmetric composite laminates and piezoceramic MFC actuators," AIAA Paper, vol. 1806, pp. 19-22, 2004.

[26] C. R. Bowen, P. F. Giddings, A. I. Salo and H. A. Kim, "Modeling and characterization of piezoelectrically actuated bistable composites," IEEE transactions on ultrasonics, ferroelectrics, and frequency control, vol. 58, no. 9, pp. 1737-1750, 2011.

[27] M.-L. Dano, M. Jean-St-Laurent and A. Fecteau, "Morphing of bistable composite laminates using distributed piezoelectric actuators," Smart Materials Research, vol. 2012, 2012.

[28] N. M. Ursache, T. Melin, A. T. Isikveren and M. I. Friswell, "Morphing winglets for aircraft multi-phase improvement," in 7th AIAA ATIO Conf, 2nd CEIAT Int'l Conf on Innov $\backslash \&$ Integr in Aero Sciences, 17th LTA Systems Tech Conf, 2007.

[29] S.-W. Kim, J.-Y. Lee and K.-J. Cho, "Towards a bistable morphing winglet for unmanned aerial vehicle (UAV)," in In Robotics (ISR), 2013 44th International Symposium, 2013.

[30] P. Bourdin, A. Gatto and M. I. Friswell, "The application of variable cant angle winglets for morphing aircraft control," in 24th Applied Aerodynamics Conference, 2006.

[31] T. Yokozeki, S.-i. Takeda, T. Ogasawara and T. Ishikawa, "Mechanical properties of corrugated composites for candidate materials of flexible wing structures," Composites Part A: applied science and manufacturing, vol. 37, no. 10, pp. 1578-1586, 2006.

[32] G. Murray, F. Gandhi and C. Bakis, "Flexible matrix composite skins for one-dimensional wing morphing," Journal of Intelligent Material Systems and Structures, vol. 21, no. 17, pp. 1771-1781, 2010.

[33] C. Wang, "Post-buckling of a clamped-simply supported elastica," International Journal of Non-Linear Mechanics, pp. 1115-1122, 1997.

[34] K. Xu and N. Simaan, "Analytic Formulation for Kinematics, Statics, and Shape Restoration of Multibackbone Continuum Robots Via Elliptic Integrals," Journal of Mechanisms and Robotics, vol. 2, 2010.

[35] Y. Tian, M. Luan, X. Gao, W. Wang and L. Li, "Kinematic Analysis of Continuum Robot Consisted of Driven Flexible Rods".

[36] A. Pankonien, "Smart Material Wing Morphing for Unmanned Aerial Vehicles," 2015.

[37] "Misumi-SIngle Axis Actuator," [Online]. Available: https://us.misumiec.com/vona2/detail/110300075450/?Inch=0.

[38] "Crouzet DC Motor," Digikey, [Online]. Available: https://www.digikey.ca/productdetail/en/crouzet/89810908/966-1758-ND/6138849. 
[39] "Misumi- Coupling," [Online]. Available: https://us.misumiec.com/vona2/detail/110300119730/?catalogType=00000027416\&PNSearch=MCGL\&sear chFlow=suggest 2 products \&Keyword=MCGL.

[40] "Bourns Rotary Optical Encoder," Digikey, [Online]. Available: https://www.digikey.ca/product-detail/en/bourns-inc/ENC1J-D16-L00128L/ENC1J-D16L00128L-ND/2538012.

[41] "MDC2230," RoboteQ, [Online]. Available: https://www.roboteq.com/index.php/roboteqproducts-and-services/brushed-dc-motor-controllers/270/mdc2230-detail.

[42] "Misumi- Urethane Roller," [Online]. Available: https://us.misumiec.com/vona2/detail/110302002820/?PNSearch=UMJ35\&SYCD=UMJ35\&searchFlow=sug gest2products\&Keyword=UMJ35.

[43] "Misumi- Rotary Shaft," [Online]. Available: https://us.misumiec.com/vona2/detail/110300086920/?HissuCode=PSFHR10-\%5B15600\%2F0.1\%5D\&PNSearch=PSFHR10-\%5B15$600 \% 2 F 0.1 \% 5$ D\&searchFlow=suggest 2 products \&Keyword=PSFHR10-.

[44] S. M. Corp, "MFC," [Online]. Available: https://www.smart-material.com/MFC-productmain.html.

[45] "Unidirectional Carbon," FibreGlast, [Online]. Available: http://cdn.fibreglast.com/downloads/00296-B.pdf.

[46] "MVS Epoxy," Composites Canada, [Online]. Available: https://www.compositescanada.com/product-catalog/resins/product/147-mvs-epoxy-410hardener-462-464-5-1.

[47] S. P. Timoshenko and J. M. Gere, Theory of elastic stability, Courier Corporation, 2009.

[48] "How Does 3D Creator Work?," Boulder Innovators Group, [Online]. Available: https://boulderinnovators.com/products/how-does-t3d-creator-work/.

[49] Mathworks, "Least-Squares Fitting," [Online]. Available: https://www.mathworks.com/help/curvefit/least-squares-fitting.html.

[50] "Polynomial Curve Fitting," Mathworks, [Online]. Available: https://www.mathworks.com/help/matlab/ref/polyfit.html.

[51] "Advanced Brushed and Brushless Digital Motor Controller," RoboteQ, [Online]. Available: https://www.roboteq.com/index.php/docman/motor-controllers-documents-andfiles/documentation/user-manual/272-roboteq-controllers-user-manual-v17/file.

[52] "MATLAB GUI," Mathworks, [Online]. Available: 
https://www.mathworks.com/discovery/matlab-gui.html.

[53] A. Fontanazza, R. Talling, M. Jackson, R. Dashwood, S. Dye and L. Iannucci, "Morphing Wing Technologies Research," in In Seas DTC first conference, Edinburg, 2006. 